Check for updates

Cite this: Chem. Soc. Rev., 2021, 50,12189

Received 23rd December 2019

DOI: $10.1039 / \mathrm{c} 9 \mathrm{cs} 00828 \mathrm{~d}$

rsc.li/chem-soc-rev

\title{
Lanthanide-tetrapyrrole complexes: synthesis, redox chemistry, photophysical properties, and photonic applications
}

\author{
Wai-Lun Chan, (D) ab Chen Xie, (DD ${ }^{a}$ Wai-Sum Lo, (DD b Jean-Claude G. Bünzli, (D) *ac \\ Wai-Kwok Wong (iD *a and Ka-Leung Wong (iD *a
}

\begin{abstract}
Tetrapyrrole derivatives such as porphyrins, phthalocyanines, naphthalocyanines, and porpholactones, are highly stable macrocyclic compounds that play important roles in many phenomena linked to the development of life. Their complexes with lanthanides are known for more than 60 years and present breath-taking properties such as a range of easily accessible redox states leading to photo- and electrochromism, paramagnetism, large non-linear optical parameters, and remarkable light emission in the visible and near-infrared (NIR) ranges. They are at the centre of many applications with an increasing focus on their ability to generate singlet oxygen for photodynamic therapy coupled with bioimaging and biosensing properties. This review first describes the synthetic paths leading to lanthanide-tetrapyrrole complexes together with their structures. The initial synthetic protocols were plagued by low yields and long reaction times; they have now been replaced with much more efficient and faster routes, thanks to the stunning advances in synthetic organic chemistry, so that quite complex multinuclear edifices are presently routinely obtained. Aspects such as redox properties, sensitization of NIR-emitting lanthanide ions, and non-linear optical properties are then presented. The spectacular improvements in the quantum yield and brightness of $\mathrm{Yb}^{\mathrm{III}}$-containing tetrapyrrole complexes achieved in the past five years are representative of the vitality of the field and open welcome opportunities for the bio-applications described in the last section. Perspectives for the field are vast and exciting as new derivatizations of the macrocycles may lead to sensitization of other $\mathrm{Ln}^{\mathrm{III}} \mathrm{NIR}$-emitting ions with luminescence in the NIR-II and NIR-III biological windows, while conjugation with peptides and aptamers opens the way for lanthanide-tetrapyrrole theranostics.
\end{abstract}

\section{Introduction}

Tetrapyrrole derivatives such as porphyrins or phthalocyanines are highly chemically stable macrocycles and considered as essential constituents in the emergence of life. Porphyrins are known since the seminal work of Hoppe-Seyler in the $1870 \mathrm{~s}$, the founder of physiological chemistry ${ }^{1}$ who studied various body fluids, including blood, and measured the electronic spectra of haemoglobin and chlorophyll, among others. The simplest compound is porphine $\left(\mathrm{H}_{2}\right.$ Por, Scheme 1$)$ that does not occur in nature, but some substituted porphines do, such as protoporphyrin IX $\left(\mathrm{H}_{2} \mathrm{ProP} 9\right.$, Scheme 1$)$, a precursor to haem and

\footnotetext{
${ }^{a}$ Department of Chemistry, Hong Kong Baptist University, Kowloon Tong, Hong KongSAR, China.E-mail:wkwong@hkbu.edu.hk,klwong@hkbu.edu.hk

${ }^{b}$ Department of Applied Biology and Chemical Technology, The Hong Kong Polytechnic University, Hung Hom, Kowloon, Hong Kong SAR, China

${ }^{c}$ Institute of Chemical Sciences \& Engineering, Swiss Federal Institute of Technology, Lausanne (EPFL), Switzerland.E-mail: jean-claude.bunzli@epfl.ch
}

haemoglobin. ${ }^{2}$ Common synthetic mimics of protoporphyrin IX used in coordination chemistry of transition metal ions and lanthanides are octaethylporphyrin $\left(\mathrm{H}_{2} \mathrm{OEP}\right)$, tetrabenzoporphyrin $\left(\mathrm{H}_{2} \mathrm{TBP}\right)$, and tetraphenylporphyrin $\left(\mathrm{H}_{2} \mathrm{TPP}\right)$ (Scheme 1). The highly delocalized $\pi$-system of porphyrins (highlighted in red in Scheme 1) confers them vivid colours and a wide variety of genuine optical, electric, and magnetic properties with applications ranging from catalysis to electronic materials, photonics, biomedical analysis, imaging, and therapy. ${ }^{3-5}$ Partial hydrogenation of $\mathrm{H}_{2}$ Por results in highly photosensitive macrocycles termed chlorins $\left(\mathrm{H}_{2} \mathrm{cl}\right.$; bacteriochlorin $\mathrm{H}_{2} \mathrm{Bcl}$; isobacteriochlorin $\mathrm{H}_{2} \mathrm{iBcl}$, see Scheme 1) that are commonly used as singlet oxygen generators in photodynamic therapy (PDT) of cancer. ${ }^{6,7}$ When the methine bridges between the pyrrole moieties of porphyrins are replaced with methylene bridges, the corresponding hydrogenated macrocycles are named porphyrinogens $\left(\mathrm{H}_{4} \mathrm{Pg}\right)$. These compounds occur in living organisms, substituted with various side chains, and are reaction intermediates in the biosynthesis of several 
strategic life-indispensable molecules such as haemoglobins, cytochromes, or chlorophylls; a typical example is protoporphyrinogen IX $\left(\mathrm{H}_{4} \mathrm{ProPg} 9\right.$, Scheme 1$)$, the precursor to protoporphyrin IX. The meso-octasubstituted porphyrinogens constitute a class of macrocycles known since the 19th century, called calix[4]pyrroles $\left(\mathrm{H}_{4} \mathrm{Cx}[4] \mathrm{Py}\right)$, and were put in front of the chemical scene in the 1990s by Floriani et al. ${ }^{8}$ and Sessler et al. ${ }^{9}$ mainly in view of their host-guest properties and smallmolecule activation capability.

Contrary to porphyrinogens that are usually colourless due to the lack of a delocalized $\pi$-electron system, phthalocyanines $\left(\mathrm{H}_{2} \mathrm{Pc}\right)$ are intensively coloured derivatives of tetraazaporphyrin
$\left(\mathrm{H}_{2} \mathrm{~N}_{4}\right.$ Por, Scheme 1), in which the methine bridges are replaced with imine nitrogens, with the pyrrole units being additionally fused with benzene rings. Such intensively bluegreen-coloured synthetic macrocycles were apparently isolated in 1907 from a mixture resulting from the reaction of acetic anhydride with phthalamide ${ }^{11}$ and found to be identical to a product discovered by Posner in 1897 upon heating $o$ cyanobenzamide at an elevated temperature. ${ }^{12}$ These compounds can also be thought of as having an aza-annulene core. The metal derivatives of tetraazaporphyrin are not natural products, but due to their extended $\pi$-electron system, they have many applications as pigments-in particular the

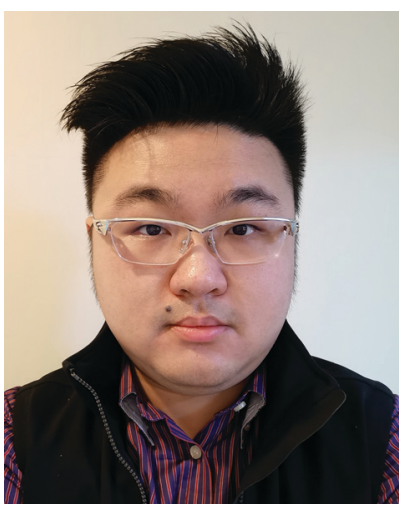

Wai-Lun Chan
Wai-Lun Chan received a BSc (Hons.) in Chemistry (2014) under the supervision of Prof. Ka-Leung (Gary) Wong and a $M A$ in Communication (2015) from Hong Kong Baptist University, followed by a PhD in Chemistry (2019) from the National University of Singapore under the supervision of Prof. Yixin Lu. After a postdoctoral visit (2020) with Prof. Markus Zweckstetter at Max Planck Institute for Biophysical Chemistry and German Center for Neurodegenerative Diseases, he was appointed as a research assistant professor (2021) at the Department of Applied Biology and Chemical Technology, Hong Kong Polytechnic University. His research interests include lanthanide spectroscopy, asymmetric organocatalysis, natural product/peptide synthesis, bioimaging, and targeted protein degradation.

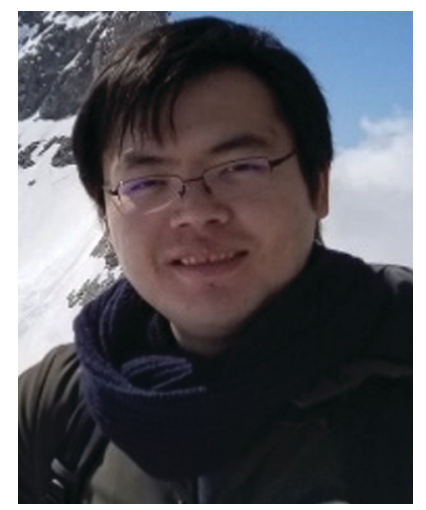

Chen Xie received a MSc from Hong Kong Baptist University in 2017 and is now a PhD candidate in the research group of Prof. $\mathrm{Ka}$ Leung (Gary) Wong. His current research focuses on the design and preparation of lanthanidebased complexes and the investigation of their photophysical properties and biological applications.

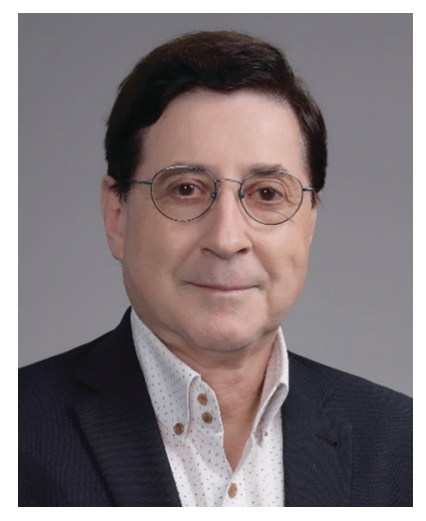

Jean-Claude G. Bünzli

Prof. Bünzli received his PhD degree from the Swiss Federal Institute of Technology, Lausanne (EPFL) in 1971. After post-doctoral stays at UBC, Vancouver, and ETHZ, Zürich, he returned to Lausanne in 1974 as an assistant professor at the University; he was promoted to Chair Professor in 1980; he served as Dean of the Faculty of Sciences (1990-1991) and Vice-President of the University (1991-1995) before transferring to EPFL in 2001. His research interests are focused on coordination, macrocyclic, and supramolecular chemistry of rare earths with main emphasis on the development of lanthanide-based luminescent materials and bioprobes. 
important phthalocyanine blue, [Cu(Pc)], electrochromic materials, redox catalysts, agents for photodynamic treatment of cancer or flow-injection analysis. ${ }^{13}$ Fusion of $\mathrm{H}_{2} \mathrm{~N}_{4}$ Por with anthracene rings results in naphthalocyanine $\left(\mathrm{H}_{2} \mathrm{Nc}\right.$, Scheme 1) which made the highlights in 2012 when scientists used it to visualize charge distribution in a single molecule by a combination of advanced microscopy techniques. ${ }^{14}$

From a historical perspective, lanthanide complexes with porphyrins were first reported by Horrocks et al., [Ln(TPP)L] (L is a $\beta$-diketonate, often acetylacetonate, $\mathrm{acac}^{-}$), in the search for efficient magnetic resonance dipolar probes, ${ }^{15}$ while in the same year Tsvirko et al. demonstrated energy transfer from TPP to $\mathrm{Yb}^{\mathrm{III}}$ and reported a quantum yield in solution of $0.5 \%$ for the metal-centred NIR luminescence. ${ }^{16}$ These $1: 1$ complexes are usually prepared by reacting $\left[\operatorname{Ln}(\mathrm{acac})_{3}\left(\mathrm{H}_{2} \mathrm{O}\right)_{n}\right]$ with the ligand in trichlorobenzene. By starting with $\left[\mathrm{Ce}(\operatorname{acac})_{3}\left(\mathrm{H}_{2} \mathrm{O}\right)_{3}\right]$ and prolonging the refluxing time, Buchler et al. surprisingly isolated in 1983 the first neutral and diamagnetic bis(porphyrinato) complex $\left[\mathrm{Ce}^{\mathrm{IV}}(\mathrm{TPP})_{2}\right]$, followed by $\left[\mathrm{Pr}^{\mathrm{III}} \mathrm{H}(\mathrm{TPP})_{2}\right]{ }^{17}$ Then, the triple-decker complex $\left[\mathrm{Ce}^{\mathrm{III}}{ }_{2}(\mathrm{OEP})_{3}\right]$ was obtained simultaneously with $\left[\mathrm{Ce}^{\mathrm{IV}}(\mathrm{OEP})_{2}\right]$ by a competitive condensation/autoxidation reaction. ${ }^{18}$ Regarding phthalocyanines, they were introduced as pigments on the market in the $1930 \mathrm{~s}$, consisting of either un-metalated $\mathrm{H}_{2} \mathrm{Pc}$ (blue-green) or $[\mathrm{Cu}(\mathrm{Pc})]$ (blue). When the benzene rings are fully chlorinated the corresponding $\mathrm{Cu}^{\mathrm{II}}$ pigment is green; many colour variations can be obtained by modifying the ring substituents. When it comes to lanthanides, the first tetrapyrrole "sandwich" complexes were isolated by Kirin et al. in the 1960s, $\left[\mathrm{LnH}(\mathrm{Pc})_{2}\right]$ $(\mathrm{Ln}=\mathrm{Pr}, \mathrm{Nd}, \mathrm{Er}, \mathrm{Lu}){ }^{19}$ who subsequently demonstrated their

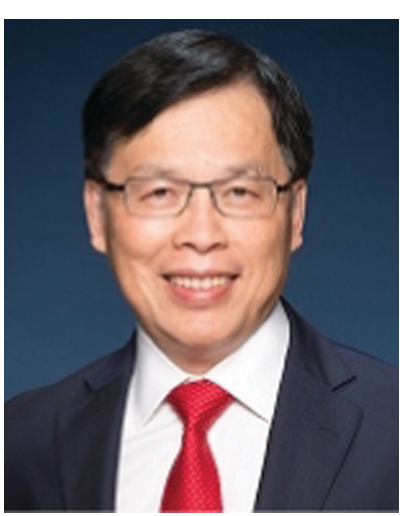

Wai-Kwok Wong
Prof. Wai-Kwok Wong, a native of Hong Kong, received his $P h D$ degree in Chemistry from the University of Wisconsin, Madison in 1978. He then spent a year at UCLA as a post-doctoral researcher with Prof. John Gladysz before moving on to work with the late Prof. Sir Geoffrey Wilkinson at Imperial College, London in 1979. He returned to Hong Kong in 1984 and took up a lecturer position at the Hong Kong Polytechnic University (then Hong Kong Polytechnic). In 1989, he joined the Chemistry Department of Hong Kong Baptist University (then Hong Kong Baptist College) where he stayed ever since. He was promoted to Chair Professor of Chemistry in 2005. He was Dean of Science (2002-2010) and the Vice-President (Research and Development) (2011-2019). He has published more than 260 papers. His main research interests include organometallic synthesis, bioactivity of inorganic/organometallic compounds, luminescent materials and homogeneous catalysis. electrochromism. In fact the green $\mathrm{Ln}^{\mathrm{III}}$-phthalocyanine sandwich complexes have a radical nature, which was established by EPR spectroscopy for the $\mathrm{Lu}^{\mathrm{III}}$ compound: one macrocycle is a di-anion but the other is a radical mono-anion so that the correct chemical formula is $\left[\mathrm{Ln}\left(\mathrm{Pc}^{2-}\right)\left(\mathrm{HPc}^{-\bullet}\right)\right],{ }^{20}$ the structure responsible for their particular properties. ${ }^{21}$

The diameters of lanthanide ions are larger than the cavity diameter of Por and Pc ligands so that the metal centres in the complexes lie above the planar macrocycles. The main stoichiometries and structures encountered in the coordination of lanthanides with tetrapyrrole ligands are illustrated in Fig. 1. The $1: 1$ and $1: 2(\mathrm{Ln}: \mathrm{L})$ geometries are the commonest, followed by triple deckers ideally suited for the study of magnetic interactions since the Ln-Ln distance is rather short ( $\sim 0.35 \mathrm{~nm}$ ); although less observed, the $2: 2$ stoichiometry also yields interesting $\mathrm{f}-\mathrm{f}$ assemblies. ${ }^{22-24}$ More elaborate structures such as quadruple-decker $2: 4$ complexes $^{25}$ in which two double-decker units are linked by a diethoxybenzyl unit ${ }^{26}$ have also been explored, as well as $4: 5$ bimetallic $4 \mathrm{~d}-4 \mathrm{f}$ quintuple deckers. $^{27}$

Although lanthanide tetrapyrrole complexes are regularly mentioned in review articles dealing with one or another aspect of 4 f-element coordination chemistry, ${ }^{28}$ supramolecular chemistry, ${ }^{29,30}$ photo- and spectro-chemistry, ${ }^{31-34}$ liquid crystals, ${ }^{35}$ analytical ${ }^{10,36}$ or bio-applications, ${ }^{4,37}$ non-linear optical properties, ${ }^{38}$ and magnetism, ${ }^{39}$ the field itself has seen a few comprehensive reviews during the past 20 years, since the publication of the Porphyrin Handbook. ${ }^{40}$ In addition, most of these reviews are focused onto a particular class of compounds, mononuclear complexes, ${ }^{41,42}$ sandwich complexes, ${ }^{43}$ porphyrin complexes, ${ }^{41}$ or phthalocyanine complexes. ${ }^{21}$

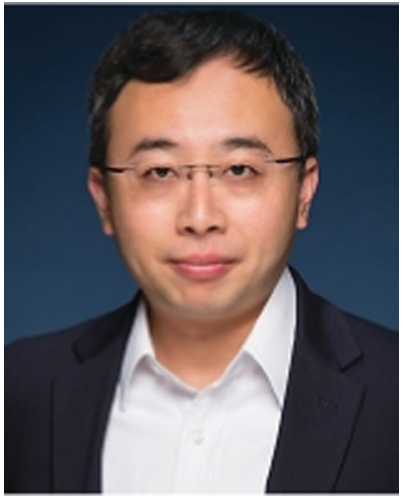

Ka-Leung Wong
Ka-Leung (Gary) Wong is the Dr Mok Man Hung Endowed Professor of Chemistry and Head of the Department at Hong Kong Baptist University. His undergraduate and graduate training was undertaken at Hong Kong University where he worked with Prof. Wing-Tak Wong, followed by post-doctoral periods at City University Hong Kong and Durham University (Royal Society post-doctoral fellowship with Prof. David Parker). His research interests span bioinorganic chemistry, the study of responsive luminescent materials as well as numerous applications of lanthanide science and optical spectroscopy. Recent work embraces the development of new probes and drugs for cancer diagnostics and photodynamic therapy. 
(A)
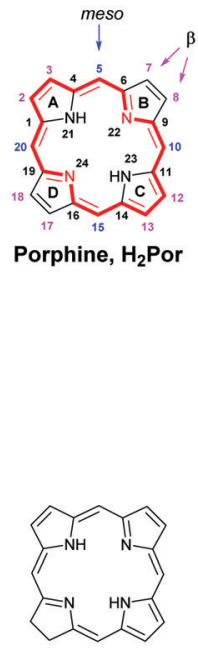

$\mathrm{H}_{2} \mathrm{Cl}$

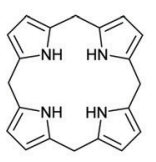

$\mathrm{H}_{4} \mathrm{Pg}$

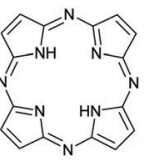

$\mathrm{H}_{2} \mathrm{~N}_{4}$ Por

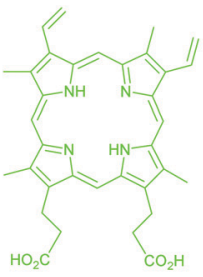

$\mathrm{H}_{2}$ ProP9

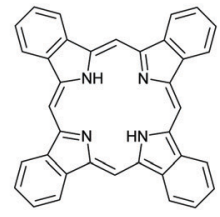

$\mathrm{H}_{2}$ TBP

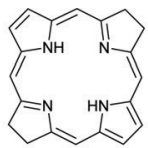

$\mathrm{H}_{2} \mathrm{Bcl}$
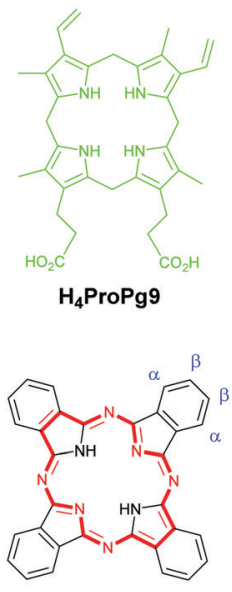

$\mathrm{H}_{2} \mathrm{Pc}$

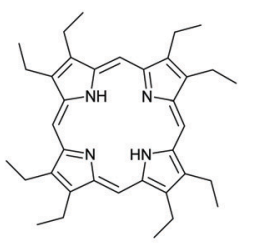

$\mathrm{H}_{2} \mathrm{OEP}$
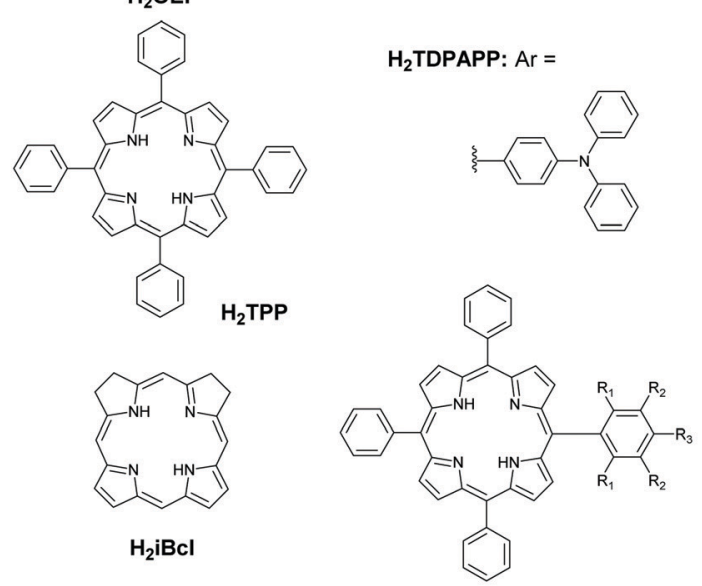

$\mathrm{H}_{2} \mathrm{iBcl}$

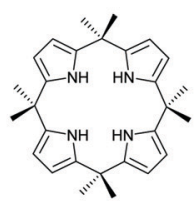

$\mathrm{H}_{4} \mathrm{Cx}[4] \mathrm{py}$

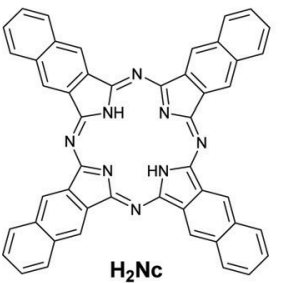

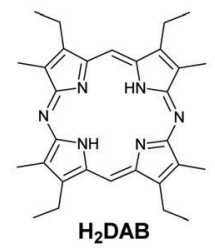

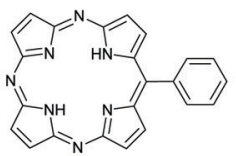

$\mathrm{H}_{2}{ }^{\mathrm{Ph}}$ TBTAP
H2TDPAPP: $\mathrm{Ar}=$
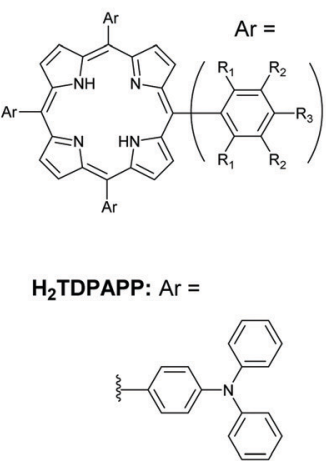

$\mathrm{H}_{2}$ TTP $\quad \mathrm{R}_{1}=\mathrm{R}_{2}=\mathrm{H} ; \mathrm{R}_{3}=\mathrm{Me}$

$\mathrm{H}_{2}$ TMOPP $\quad \mathrm{R}_{1}=\mathrm{R}_{2}=\mathrm{H} ; \mathrm{R}_{3}=\mathrm{OMe}$

$\mathrm{H}_{2} \mathrm{TMO}^{2,4,6} \mathrm{PP}_{\mathrm{R}}=\mathrm{R}_{3}=\mathrm{OMe} ; \mathrm{R}_{2}=\mathrm{H}$

$\mathrm{H}_{2} \mathrm{TMO}^{3,4,5} \mathrm{PP} \quad \mathrm{R}_{1}=\mathrm{H} ; \mathrm{R}_{2}=\mathrm{R}_{3}=\mathrm{OMe}$

$m$ - $\mathrm{H}_{2}$ APTPP $\quad \mathrm{R}_{1}=\mathrm{R}_{3}=\mathrm{H} ; \mathrm{R}_{2}=\mathrm{NH}_{2}$

TDMAPP $\quad \mathrm{R}_{1}=\mathrm{R}_{2}=\mathrm{H} ; \mathrm{R}_{3}=\mathrm{N}(\mathrm{Me})_{2}$

$\mathrm{H}_{2}$ TCPP $\quad \mathrm{R}_{1}=\mathrm{R}_{2}=\mathrm{H} ; \mathrm{R}_{3}=\mathrm{Cl}$

$\mathrm{H}_{2}$ TBPP $\quad \mathrm{R}_{1}=\mathrm{R}_{2}=\mathrm{H} ; \mathrm{R}_{3}=\mathrm{Br}$

$\mathrm{H}_{2}$ TFPP $\quad \mathrm{R}_{1}=\mathrm{R}_{2}=\mathrm{H} ; \mathrm{R}_{3}=\mathrm{F}$

TBPor $\quad \mathrm{R}_{1}=\mathrm{R}_{2}=\mathrm{H} ; \mathrm{R}_{3}=t-B u$

TCBP

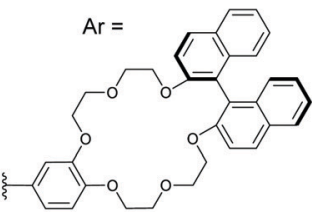

$\mathrm{H}_{2}$ HPTPP: $\mathrm{R}_{1}=\mathrm{R}_{2}=\mathrm{H} ; \mathrm{R}_{3}=\mathrm{OH}$

$\mathrm{H}_{2}$ NOTPP: $\mathrm{R}_{1}=\mathrm{R}_{2}=\mathrm{H} ; \mathrm{R}_{3}=\mathrm{NO}_{2}$

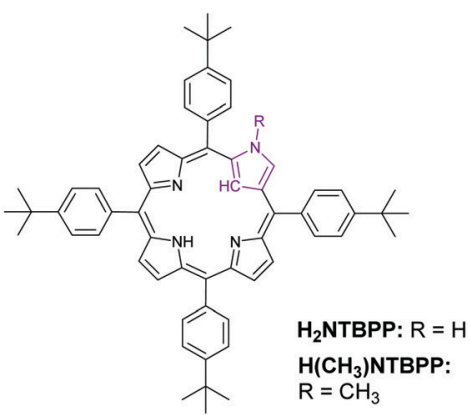

(B)<smiles>O=C1C(Cl)=C(Cl)C(=O)C(Cl)=C1Cl</smiles>

Chloranil

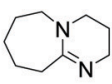

DBU<smiles>C1CC2=NCCN2C1</smiles>

DBN

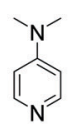

DMAP

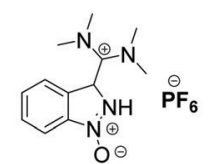

HBTU

Scheme 1 (A) Chemical structures and formulae of porphine (with the IUPAC numbering scheme ${ }^{10}$ ), porphyrins, chlorins, porphyrinogens, and phthalocyanines discussed in this review. In green: naturally occurring macrocycles; in red: $18 \pi$-electron system of $\mathrm{H}_{2} \mathrm{Por}$ and $\mathrm{H}_{2} \mathrm{Pc}$. (B) $\mathrm{Chemical}$ structures and formulae of common reagents involved in the syntheses of tetrapyrroles.

In this review, we therefore aim at giving an updated compendium of lanthanide-tetrapyrrole complexes, from their synthesis and structure to spectroscopy and reactivity, including the fast-developing fields of photophysical properties, non-linear optics and theranostics. Excluded herein are tetrapyrrole-attached/conjugated lanthanide nanomaterials/complexes, and single-molecule magnetism. Applications will be presented, including optical limiting materials, NIR-emitting sensors, bioprobes, and singlet oxygen generators. The literature is covered up to October 2020, with a particular emphasis on the period spanning the past 20 years. 


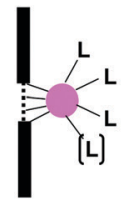

1:1

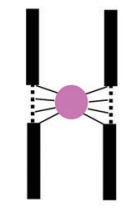

1:2

double decker

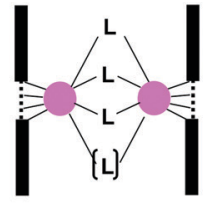

$2: 2$

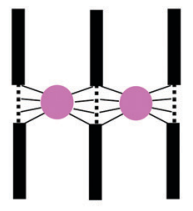

2:3

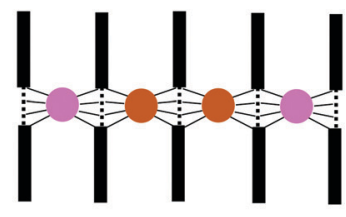

2:2:5

triple decker

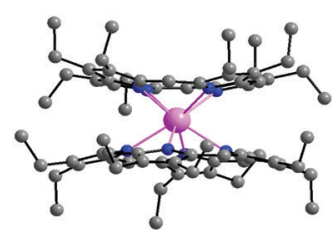

$\left[\mathrm{Ce}^{\mathrm{IV}}(\mathrm{OEP})_{2}\right]$

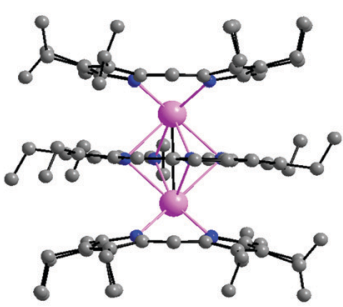

$\left[\mathrm{Ce}_{2}{ }_{2}{ }_{2}(\mathrm{OEP})_{2}\right]$

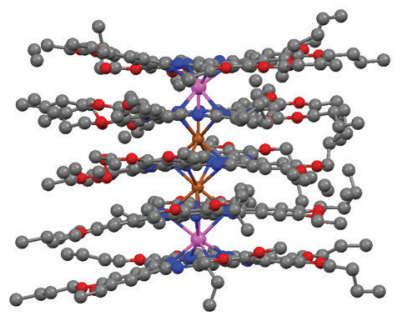

$\left[\mathrm{Tb}_{2}{ }_{2} \mathrm{Cd}_{2}{ }_{2}(\mathrm{OBPC})_{5}\right]$

Fig. 1 Top: Schematic representation of some of the various structures encountered in lanthanide-tetrapyrrole $L n: L$ complexes; $1: 1$ and $2: 2$ complexes may be 7- or 8-coordinated. Bottom: Crystal structures of (left) double-decker [Ce $\left.{ }^{I V}(\mathrm{OEP})_{2}\right]$, (middle) triple-decker [Ce $\left.{ }_{2}{ }_{2}(\mathrm{OEP})_{3}\right]$. Redrawn from data in ref. 18; and (right) $\left[\mathrm{Tb}_{2}{ }_{2} \mathrm{Cd}_{2}{ }_{2}(\mathrm{OBPC})_{5}\right], \mathrm{OBPC}=$ octabutoxy-phthalocyanate, redrawn from data in ref. 27.

\section{Structure and synthesis}

\subsection{Lanthanide mono-tetrapyrrole complexes}

\subsubsection{Landmark synthetic methods for tetrapyrroles}

(a) Porphyrins. One cannot discuss porphyrin synthesis without mentioning Rothemund's synthesis, first reported in 1936, ${ }^{44}$ which was achieved by reacting formaldehyde and pyrrole in an acid medium at high temperatures for $24 \mathrm{~h}$. In 1967, a "simplified version" of Rothemund's synthetic procedures was published for the preparation of meso-substituted porphyrins, which is now commonly known as the Adler-Longo methodology (Scheme 2). ${ }^{45}$ Adler and Longo claimed that while their procedure does not necessarily lead to the highest synthetic yield $(\sim 20 \%)$, it represents a convenient (in open air), fast ( $\sim 30 \mathrm{~min})$, and reproducible synthesis of highly pure porphyrins. In general, equimolar amounts of freshly distilled pyrrole and aldehyde are added into propionic acid and refluxed for $30 \mathrm{~min}$. The reaction mixture is then cooled and filtered; the filter cake is washed with methanol and hot water, followed by the removal of residual acid in vacuo. The substituted porphyrin is obtained as coloured crystals. Lindsey et $a .^{46}$ further modified the procedure, putting emphasis on improving the synthetic yields and using milder reaction conditions, for instance, lowering the "unnecessarily high" reaction temperature, while broadening the choice of accessible benzaldehydes. The generic synthesis starts with adding equimolar amounts of pyrrole, aldehyde and triethyl orthoacetate into dry $\mathrm{CH}_{2} \mathrm{Cl}_{2}$ under $\mathrm{N}_{2}$. An aliquot of boron trifluoride etherate (Lewis acid) is also added and the reactants are mixed at room temperature for $1 \mathrm{~h}$. Then, 2,3,5,6-tetrachlorobenzoquinone (chloranil, Scheme 1) is added as the oxidant and the reaction mixture is refluxed for $1 \mathrm{~h}$. Removing the solvent in vacuo and further purification by column chromatography give the product in $\sim 45-50 \%$ isolated yield. The authors noted that, after systematic studies, the synthetic yields were found to be dependent on various conditions such as the nature of the acid catalyst, the choice of oxidant, the reaction time, the concentrations of the reactants, as well as on the solvent dryness.

In 1998, Wong et al. investigated the synthesis of cationic lanthanide porphyrin complexes, where the free base porphyrins in use, 5,10,15,20-tetrakis( $p$-tolyl)porphyrin $\left(\mathrm{H}_{2} \mathrm{TTP}\right.$, Scheme 1) and 5,10,15,20-tetrakis-( $p$-methoxyphenyl)porphyrin

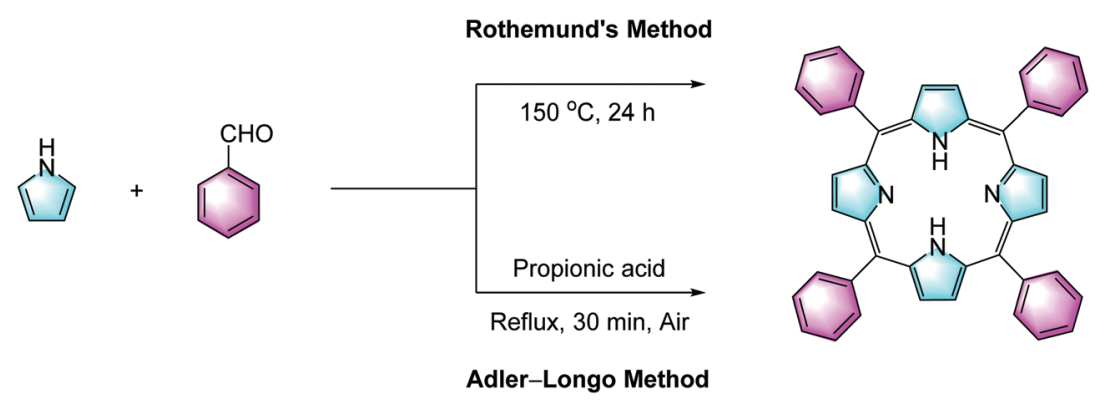

Scheme 2 Classical Rothemund's and Adler-Longo synthetic approaches to porphyrins. ${ }^{44,45}$ 
( $\mathrm{H}_{2}$ TMOPP, Scheme 1), were conveniently synthesized according to the Adler-Longo method. ${ }^{47}$ Yu's group also obtained $\mathrm{H}_{2}$ TPP with the same methodology for the solid state synthesis of [LnTPP(acac)] complexes. ${ }^{48}$ Both the Adler-Longo and Lindsey syntheses remained popular in the early 2000s with AsanoSomeda's group, ${ }^{49}$ Tsukube's group, ${ }^{50}$ Wong's group, ${ }^{51,52} \mathrm{He}$ 's group $^{53-56}$ and Zhang's group, ${ }^{57}$ all employing similar procedures for the synthesis of lanthanide-monoporphyrinates with different functional groups (Fig. 2), including $\mathrm{H}_{2} \mathrm{OEP}$, crown ether-containing 5 -(3-aminophenyl)-10,15,20-triphenylporphyrin ( $m-\mathrm{H}_{2} \mathrm{APTPP}$, Scheme 1) (see Section 2.1.8 for a specific discussion on crown-porphyrins), 5,10,15,20-tetrakis[3,4,5-tri(methoxy) phenyl]porphyrinate $\left(\mathrm{H}_{2} \mathrm{TMO}^{3,4,5} \mathrm{PP}\right), \mathrm{H}_{2} \mathrm{TMOPP}$ and $\mathrm{H}_{2} \mathrm{TTP}$, 5,10,15,20-tetrakis ( $p$-chlorophenyl)porphyrin $\quad\left(\mathrm{H}_{2} \mathrm{TCPP}\right), \quad 5,10$, 15,20-tetrakis(p-bromophenyl)porphyrin $\quad\left(\mathrm{H}_{2} \mathrm{TBPP}\right), \quad 5,10,15,20$ tetrakis( $p$-fluorophenyl)porphyrin $\left(\mathrm{H}_{2} \mathrm{TFPP}\right)$ and 5,10,15,20tetrakis(2,4,6-trimethoxyphenyl)porphyrin $\left(\mathrm{H}_{2} \mathrm{TMO}^{2,4,6} \mathrm{PP}\right)$, see Scheme 1. As such, the Adler-Longo and Lindsey protocols have regularly underpinned the synthesis of porphyrins in recent decades.

Lindsey later became interested in improving the synthesis of ortho-substituted tetraphenylporphyrins, especially those that are sterically hindered and are difficult to synthesize under the established mild conditions. He and Wagner discovered that, by adding a boron trifluoride-ethanol co-catalyst, the reaction yields of 2-alkyl-, 2-alkoxy- and 2,6-dialkoxybenzaldehydes increased, whereas the catalytic system did not improve the reaction involving six ortho-halogen-substituted benzaldehydes. ${ }^{58}$ In Wong's report of the first series of monoporphyrinato lanthanide complexes with large optical-limiting capabilities, ${ }^{59}$ the porphyrin free base 5,10,15,20-tetrakis( $p$-diphenylaminophenyl)-21 $\mathrm{H}, 23 \mathrm{H}$ porphine $\left(\mathrm{H}_{2}\right.$ TDPAPP) was prepared by the condensation of pyrrole and 4-diphenylaminobenzaldehyde referencing to Cheng's synthesis, ${ }^{60}$ itself inspired by Lindsey's method.

When it comes to novel porphyrin-based electronic pushpull, bioconjugated framework systems for supramolecular photonic and biomedical applications, unsymmetrically substituted porphyrinoids have been foregrounded, in which the tetraphenylporphyrins comprise different meso-phenyl functionalities (A, B, C, and D), giving rise to $\mathrm{A}_{3} \mathrm{~B}$-Por, cis/trans$\mathrm{A}_{2} \mathrm{BC}-$ Por, cis/trans- $\mathrm{A}_{2} \mathrm{~B}_{2}-$ Por and $\mathrm{ABCD}-\mathrm{Por}$ combinations. To access them, three general approaches are employed: (i) statistical mixed condensation of pyrrole/dipyrromethene with different aldehydes, ${ }^{61}$ (ii) late-stage core/peripheral functionalization with organometallics, ${ }^{62}$ and (iii) cross-coupling of preformed pyrrolic precursors via the " $2+2$ " (for the $\mathrm{A}_{2} \mathrm{~B}_{2}$-type) and " $3+1$ " (for the $\mathrm{A}_{3} \mathrm{~B}$-type) additions. ${ }^{63}$ All their synthetic details are well documented in the literature.

(b) Phthalocyanines. Phthalocyanines have structural similarity with porphyrins, with four isoindole units linked by nitrogen atoms in an azo position instead of pyrrole units linked by carbon bridges. They can be synthesized by various cyclotetramerization methods starting from a catalogue of

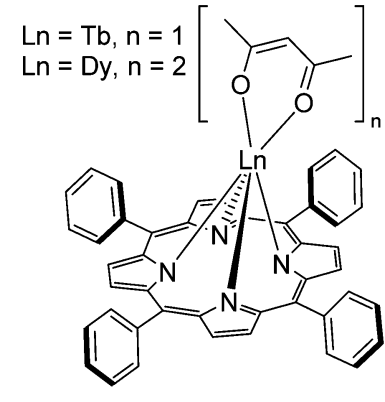

Yu's Work

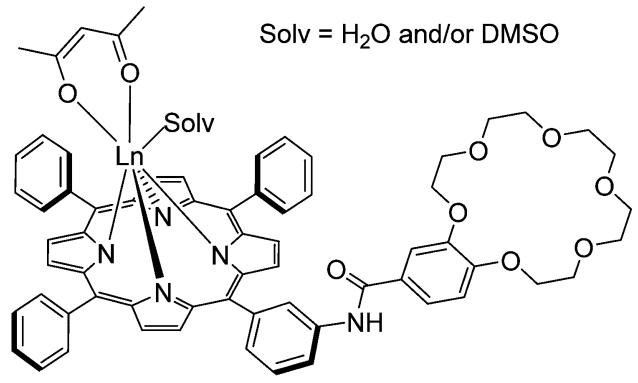

Tsukube's Work

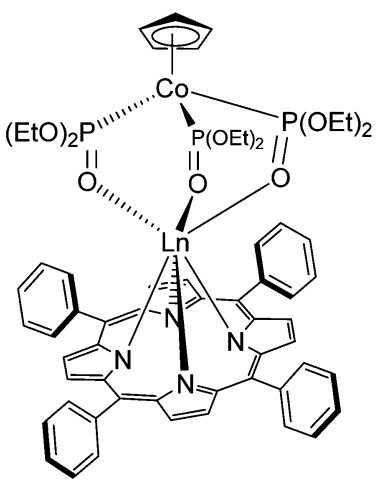

Wong's Work
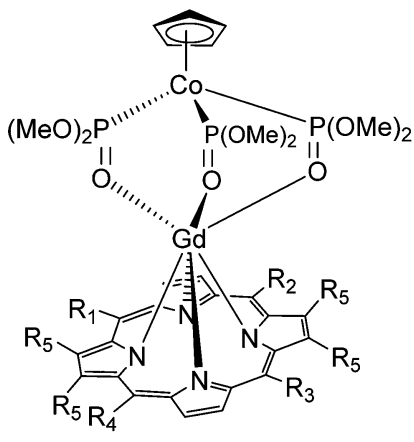

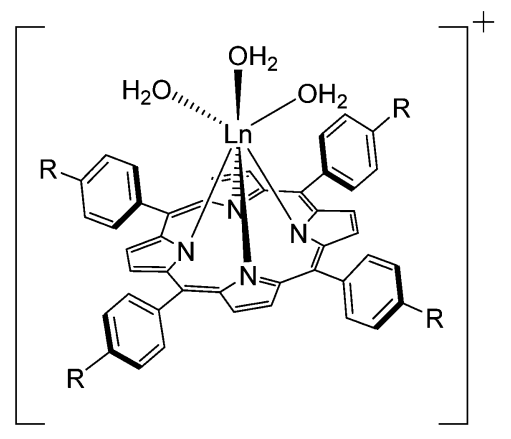

$\mathrm{Ln}=\mathrm{Yb}, \mathrm{Er}$

$\mathrm{R}=\mathrm{H}, \mathrm{OCH}_{3}, \mathrm{Cl}, \mathrm{Br}, \mathrm{F}$

Fig. 2 Examples of lanthanide monoporphyrinates synthesized using Alder and Longo's method. ${ }^{48,50-53,57}$ 


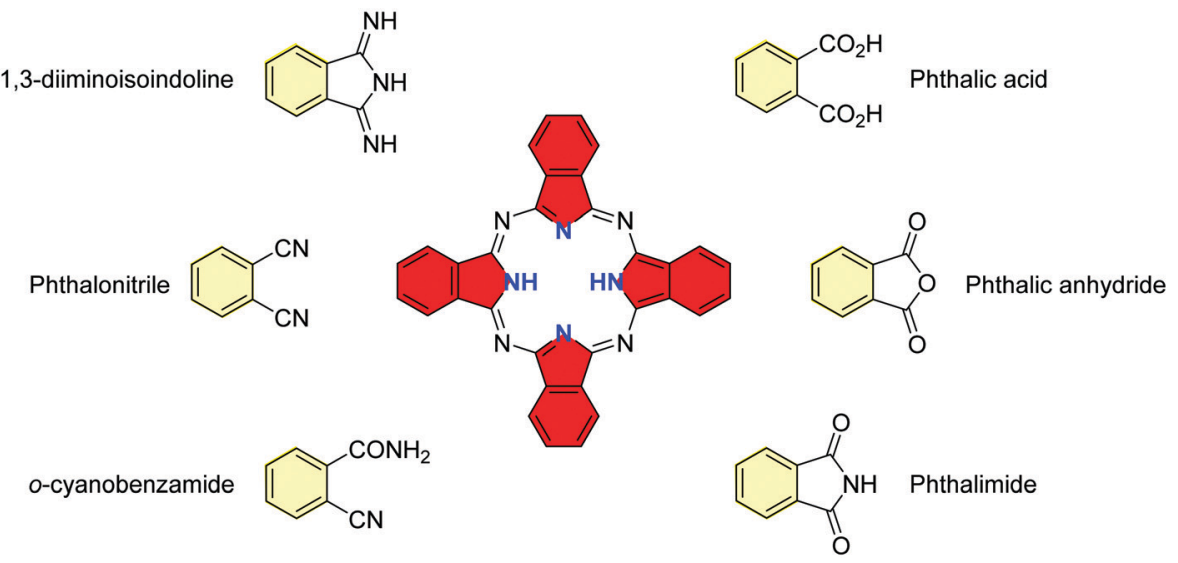

Fig. 3 Common synthetic precursors for phthalocyanines.

phthalic acid derivatives, e.g. phthalonitrile, phthalic anhydride, phthalimide, and diiminoisoindoline (Fig. 3), using the seminal Linstead procedure. ${ }^{64}$ Two well-established routes are (i) metal-templated synthesis, by refluxing phthalonitrile and lithium metal in pentanol to form di-lithium phthalocyanines, followed by the removal of the lithium content under acidic conditions; (ii) metal-free synthesis, upon heating phthalonitrile either in a melt with hydroquinone as a reductant, or in the presence of 1,8-diazabicyclo[5.4.0]undec-7-ene (DBU), or 1,5diazabicyclo[4.3.0]non-5-ene (DBN) (Scheme 1), in high-boiling pentanol. Subsequently, the insoluble crude product can be purified by sublimation and/or washing with various solvents under Soxhlet extraction or centrifugation. Microwave irradiation in an optimized solvent is an alternative for preparing both metal-free and metallo-phthalocyanines in high yields and in a very short period of time, e.g., in a few minutes.

As far as less symmetrically substituted phthalocyanines are concerned, several synthetic methods have been developed. The first one is statistical mixed condensation in which equimolar quantities of dinitriles $\mathrm{A} \& \mathrm{~B}$ produce a statistical mixture of $\mathrm{A}_{4}(8.33 \%), \mathrm{A}_{3} \mathrm{~B}(25 \%)$, cis- $\mathrm{A}_{2} \mathrm{~B}_{2}(25 \%)$, trans $-\mathrm{A}_{2} \mathrm{~B}_{2}(8.33 \%), \mathrm{AB}_{3}$ (25\%), and $\mathrm{B}_{4}(8.33 \%)$. The other ones are sterically driven cross condensation and polymer-supported exclusive preparation of the $\mathrm{A}_{3} \mathrm{~B}$-type congener. Interested readers are advised to consult the seminal review by Mack and Kobayashi. ${ }^{65}$

\subsubsection{Lanthanide-tetrapyrrole complexation methods}

(a) Lanthanide porphyrinates. In 1974, Horrocks Jr.'s group reported a lanthanide complexation method with symmetrical free base porphyrins. ${ }^{66}$ In general, $\mathrm{H}_{2}$ TPP and two equivalents of tris(2,4-pentanedionate)europium(III) were refluxed in TCB for 3-4 $\mathrm{h}$ and the crude product was then chromatographed to yield the desired complex. This method is still widely in use nowadays, as exemplified by Zhang's group in the 2010s (Scheme 3). ${ }^{67,68}$ An alternative method for preparing cationic lanthanide monoporphyrinates was reported by Wong's group in 1999 using lanthanide amide complexes as synthetic precursors. ${ }^{47}$ The lanthanide amide complex $\operatorname{Ln}\left[\mathrm{N}\left(\mathrm{SiMe}_{3}\right)_{2}\right]_{3}$. $x\left[\mathrm{LiCl}(\mathrm{THF})_{3}\right]$ was first generated in situ in excess by reacting $\mathrm{Ln}^{\mathrm{III}}$ trichloride with lithium bis(trimethylsilyl)amide in THF. The free base porphyrin $\left(\mathrm{H}_{2} \mathrm{TTP}\right.$ or $\left.\mathrm{H}_{2} \mathrm{TMPP}\right)$ was subsequently added and the reaction was refluxed in a bis(2-methoxyethyl) ether-tetrahydrofuran mixture for $48 \mathrm{~h}$ to give the air-stable cationic $\left[\mathrm{Ln}^{\mathrm{III}}(\mathrm{TTP})\left(\mathrm{H}_{2} \mathrm{O}\right)_{2}(\mathrm{THF})\right] \mathrm{Cl}$ and $\left[\mathrm{Ln}^{\mathrm{III}}(\mathrm{TMPP})\left(\mathrm{H}_{2} \mathrm{O}\right)_{3}\right] \mathrm{Cl}$ complexes, respectively. Both purple crystals were then subjected to the following procedure: (i) extraction with $\mathrm{CH}_{2} \mathrm{Cl}_{2}$, filtration and then concentration to dryness, (ii) washing with
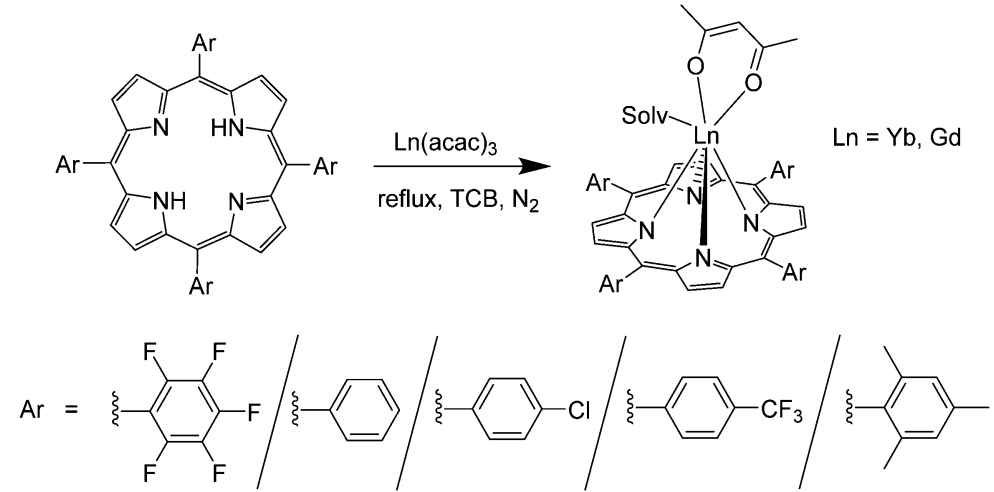

Scheme 3 Lanthanide complexation to porphyrins by Zhang's group following the procedure developed by Horrocks Jr.'s group. Redrawn from ref. 67. 

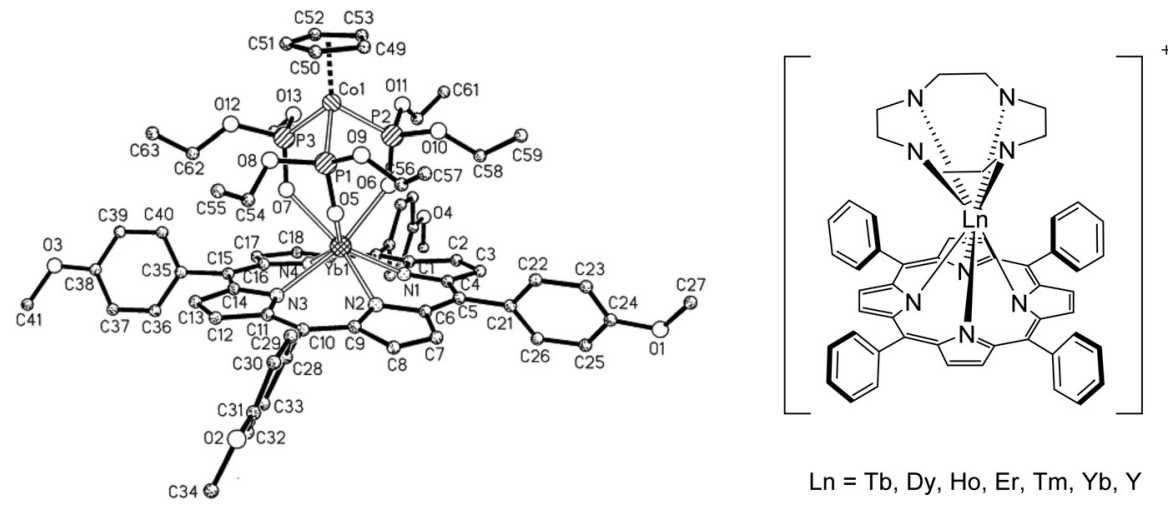

Fig. 4 (Left) X-Ray crystal structure of the cationic Yb-porphyrinate complex. Reprinted with permission from ref. 69, copyright (2000) Elsevier B.V. (Right) Porphyrin-cyclen sandwich lanthanide complex. Redrawn from ref. 73.

$n$-hexane and diethyl ether, and (iii) extraction with THF and filtration before (iv) final crystallization. Since then, this synthetic procedure for cationic porphyrin complexes was continuously used by Wong's group (Fig. 4, left). ${ }^{69,70}$

As mentioned above, in Yu's solid state synthesis, ${ }^{48} \mathrm{H}_{2} \mathrm{TPP}$ and $\operatorname{Ln}(\mathrm{acac})_{3}$ were mixed in a $1: 3$ mass ratio and ground in a mortar, followed by transferring the mixture into a nitrogen atmosphere. The solids were slowly heated to $140-150{ }^{\circ} \mathrm{C}$ causing their melting and blackening. The temperature was then increased to $220-230{ }^{\circ} \mathrm{C}$ and maintained for $2 \mathrm{~h}$ to give a blue-purple reaction crude that was cooled and chromatographed on neutral $\mathrm{Al}_{2} \mathrm{O}_{3}$ with the use of a gradient $\mathrm{CH}_{2} \mathrm{Cl}_{2}$ :MeOH eluent.

Boncella's group in 2002 reported the preparation of anhydrous lanthanide chloride complexes with tetraphenylporphyrin by a salt metathesis reaction of $\mathrm{LnCl}_{3}(\mathrm{Ln}=\mathrm{Yb}, \mathrm{Tm}, \mathrm{Er}$, Ho) and an equimolar quantity of di-lithiotetraphenylporphyrin bis(dimethoxyethane) under reflux conditions (Scheme 4). ${ }^{71}$ Upon metathesis, the lithium chloride could be easily separated by hot filtration and the reaction yield reached $85 \%$. The same group improved their method for the synthesis of Ln(TPP) complexes capped with multidentate ligands that had higher yields and could be scaled up to gram-scale synthesis. ${ }^{72}$

Ishikawa $e t$ al. reported an interesting saturation of lanthanide coordination using two macrocycles. ${ }^{73,74}$ Freshly made hydrated lanthanide chloride was heated at high temperature with $\mathrm{H}_{2}$ TPP in DMF containing DBU for $12-36 \mathrm{~h}$. After simple work-up to obtain the monoporphyrinato intermediate complex, it was redissolved in methanol and 1,4,7,10tetraazacyclododecane (cyclen) was added. The lanthanide centre in the final product $[\operatorname{Ln}(\mathrm{TPP})($ cyclen)]Cl was sandwiched between the porphyrin and the cyclen, with each macrocycle contributing 4 nitrogen atoms for coordination (Fig. 4, right). Purification of the product was achieved by crystallization by liquid-liquid diffusion of hexane and $\mathrm{CH}_{2} \mathrm{Cl}_{2}$.

In 2008 , He et al. disclosed another facile approach to prepare neutral monoporphyrinate lanthanide(III) complexes by, for example, reacting $\mathrm{Yb}(\mathrm{OAc})_{3} \cdot 3 \mathrm{H}_{2} \mathrm{O}$ with $\mathrm{H}_{2}$ TPP in TCB at $210{ }^{\circ} \mathrm{C}$ under $\mathrm{N}_{2}$ for $48 \mathrm{~h}$, followed by stirring with methanol at $70{ }^{\circ} \mathrm{C}$ for $2 \mathrm{~h}$. The desired product, seven-coordinated $\left[\mathrm{Yb}(\mathrm{TPP})\left(\mathrm{OOCCH}_{3}\right)\left(\mathrm{CH}_{3} \mathrm{OH}\right)_{2}\right]$, where acetate is monocoordinated, was exclusively obtained. It was used as a precursor for introducing bidentate ligands by exchange of the two labile methanol molecules, resulting in coordinatively saturated eight-coordinated monoporphyrinate $\mathrm{Yb}^{\mathrm{III}}$ complexes in which the acetate anion acts as a bidentate ligand after methanol substitution. ${ }^{75}$

(b) Lanthanide phthalocyaninates. Although the first examples of lanthanide-phthalocyanine complexes date back to as early as the $1960 \mathrm{~s}^{76}$ it was not until the 1980 s that a large interest flourished in this research field. In 1983, through refluxing di-lithium phthalocyanine aggregate and tris(2,2,6,6tetramethylheptane-3,5-dionato) $\mathrm{Ln}^{\mathrm{III}}$ in anhydrous THF under

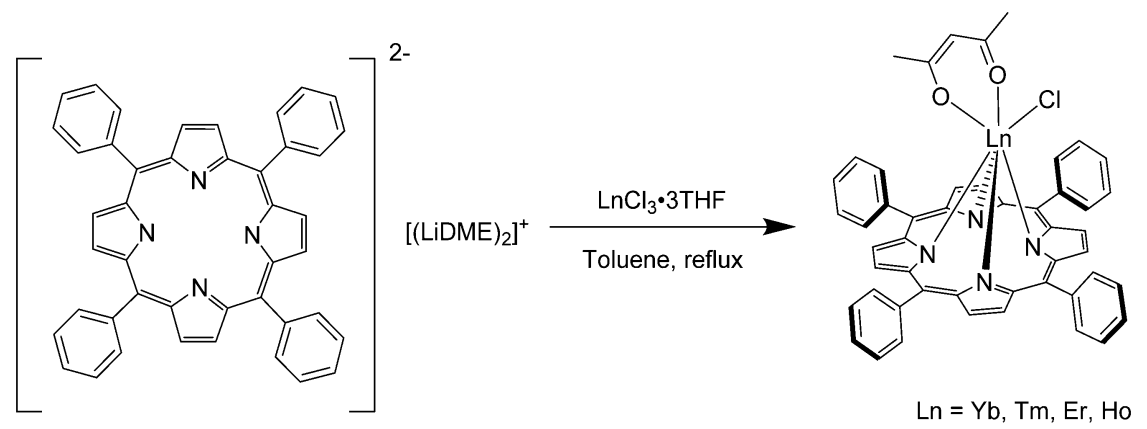

Scheme 4 Salt metathesis reaction for lanthanide complexation proposed by Boncella's group. Redrawn from ref. 71. 

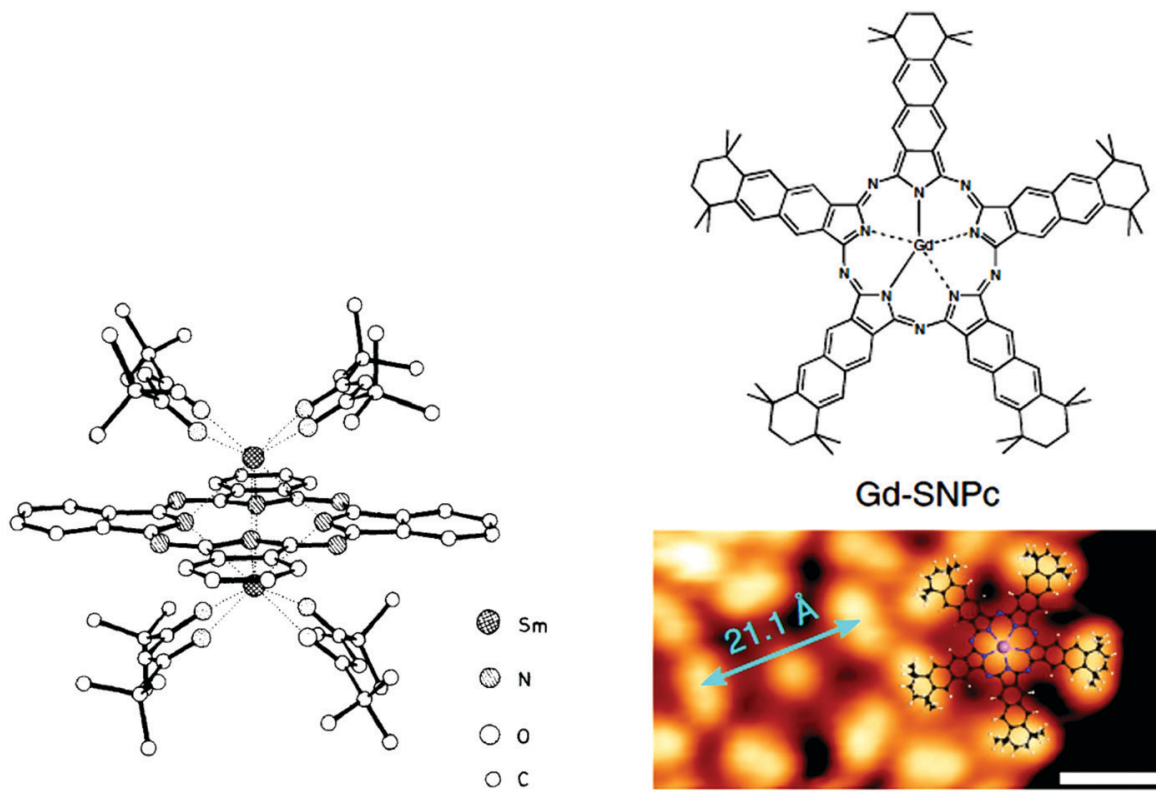

\section{Gd-SNPc}

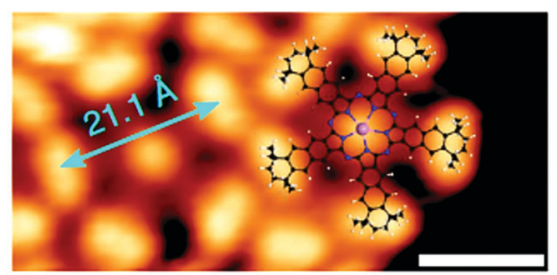

Fig. 5 (Left) Crystal structure of dinuclear disamarium phthalocyaninate. Reproduced with permission from ref. 77, copyright (1983) The Royal Society of Chemistry. (Right) Magnified view of the STM image taken on a Ag(111) surface after subsequent deposition of a low coverage of gadolinium (0.06 monolayer) on the ADN monolayer, followed by annealing to $450 \mathrm{~K}$, overlaid with a molecular model of Gd-SNPc. Reproduced with permission from ref. 82, copyright (2019) Nature Publishing Group.

an argon atmosphere, that is, via the metal displacement strategy, Sugimoto et al. obtained a series of dinuclear $[(\mu-$ phthalocyaninato)(diketonato) $\left.{ }_{4} \mathrm{Ln}_{2}\right]$ complexes, where the phthalocyanine ring served as a bridging ligand (Fig. 5, left). ${ }^{77}$ Intriguingly, the authors found that the reaction gave the 1:1 complexes instead in the presence of oxygen. Weiss et al. reported the synthesis and structure of $\left[\mathrm{LuPc}(\mathrm{OAc})\left(\mathrm{H}_{2} \mathrm{O}\right)_{2}\right]$. $\mathrm{H}_{2} \mathrm{O} \cdot 2 \mathrm{CH}_{3} \mathrm{OH}$, as well as of the sandwich $\left[\mathrm{LuPc}_{2}\right] \cdot \mathrm{CH}_{2} \mathrm{Cl}_{2}$ in 1985, exploiting the metal-templating method, by refluxing $\mathrm{Lu}(\mathrm{OAc})_{3} \cdot x \mathrm{H}_{2} \mathrm{O}$, 1,2-dicyanobenzene, and DBU in boiling 1hexanol. ${ }^{78}$ Adding a larger proportion of the lanthanide salt and shortening the heating time could slightly increase the yield of the monophthalocyaninate complex. With the same in situ generated $\mathrm{Ln}\left[\mathrm{N}\left(\mathrm{SiMe}_{3}\right)_{2}\right]_{3} \cdot x\left[\mathrm{LiCl}(\mathrm{THF})_{3}\right]$ reagent used for complexing the lanthanide ion, like in previous work, ${ }^{47}$ Wong et al. prepared a series of tripodal ligand-capped (monophthalocyaninato)lanthanide complexes in $2009 .^{79}$ This procedure afforded green crystals of $\left[\mathrm{Ln}(t-\mathrm{Bu}) 4 \mathrm{Pc}\left(\mathrm{L}_{\mathrm{OMe}}\right)\right], \mathrm{Ln}=\mathrm{Yb}$ and $\mathrm{Er}$, with yields up to $65 \%$.

More recently, in 2015, Znoiko et al. demonstrated the successful synthesis of mixed 2-naphthoxy- and benzotriazolyl disubstituted lanthanide phthalocyaninates (NOBNPc, Scheme 1) with $\mathrm{LnCl}_{3} \cdot 6 \mathrm{H}_{2} \mathrm{O}(\mathrm{Ln}=\mathrm{Er}, \mathrm{Yb})$ in the presence of urea at 190-195 ${ }^{\circ} \mathrm{C}$, but the regioselectivity issue was not mentioned. ${ }^{80}$ The product was purified by, in sequence, (i) grinding in a mortar, (ii) washing with water and then acetone to remove the salt excess and unreacted phthalonitrile, respectively, and (iii) extraction with chloroform, before routine column chromatography (silica gel M 60, eluent: chloroform). In 2018, Dubinina et al. demonstrated that both templated and multi-step methods can be applied for efficiently synthesizing new lanthanide pyrazinoporphyrazine complexes with the assistance of both thermal and microwave irradiation techniques; the products were purified by simple precipitation from a $\mathrm{MeOH}: \mathrm{H}_{2} \mathrm{O}(20: 1 \mathrm{v} / \mathrm{v})$ mixture, followed by washing with $\mathrm{H}_{2} \mathrm{O}, \mathrm{MeOH}$ and acetone. ${ }^{81}$ In 2019, by taking advantage of the larger size of $\mathrm{Gd}^{\mathrm{III}}$ compared to $\mathrm{Fe}^{\mathrm{II}}$, Gottfried's group serendipitously obtained the template-controlled on-surface cyclopentamerization, rather than the expected formation of bis(phthalocyaninato) double deckers. ${ }^{78}$ The resulting gadolinium(III) supernaphthalocyanine Gd-SNPc could be observed via scanning tunnelling microscopy (STM) (Fig. 5, right). ${ }^{82}$

Most phthalocyanine-based lanthanide complexes and multi-deckers have been symmetrically designed, similarly prepared, and strategically studied for modern applications such as organic semiconductors, field-effect transistors, and single-molecule magnets. ${ }^{83}$ These aspects have been recently reviewed and are beyond the scope of this review so the following sub-sections will concentrate more on describing kaleidoscopes of lanthanide-porphyrin coordination compounds.

2.1.3 Complexation with meso-substituted porphyrins. Liu's group reported the synthesis of a series of symmetrical porphyrins with extended planar meso-substituents. First, they reported the synthesis of 5,10,15,20-tetra[4-(4chlorobenzoyloxy)phenyl]porphyrin $\left(\mathrm{H}_{2}(\mathrm{ClBOP})_{4} \mathrm{P}\right)$ in 2000 (Fig. 6). The free base porphyrin was prepared by dropping 4chlorobenzoyl chloride into a benzene solution of tetra(4hydroxyphenyl)porphyrin and triethylamine at $70{ }^{\circ} \mathrm{C}$ and further refluxed for $8 \mathrm{~h}$ before purification with neutral aluminium oxide column which afforded the porphyrin. ${ }^{84}$ 


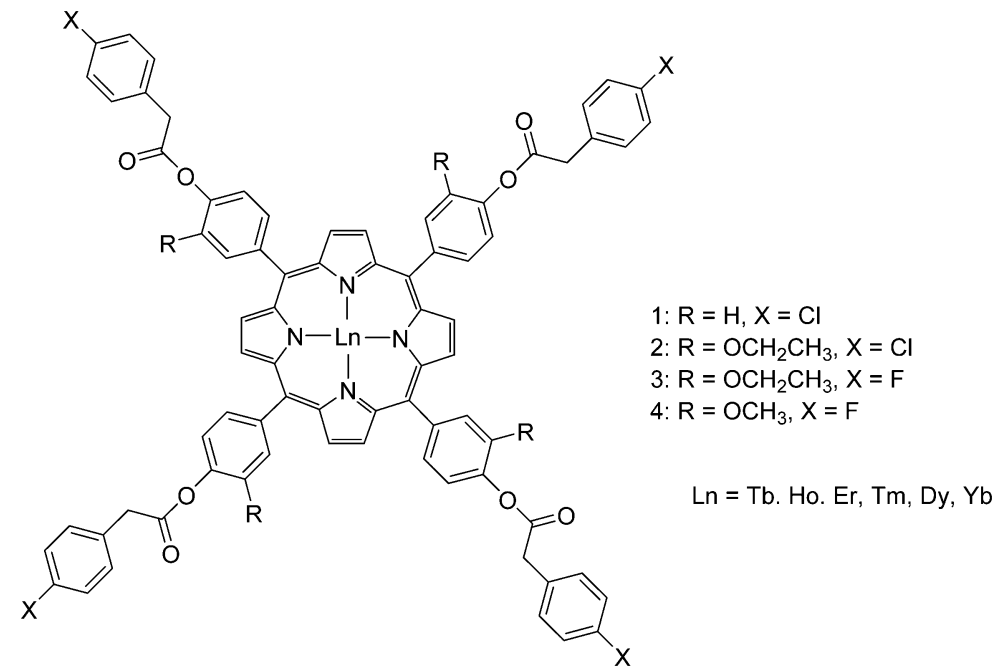

Fig. 6 Symmetrical porphyrins with extended planar meso-substituents. Redrawn from ref. 84-87.

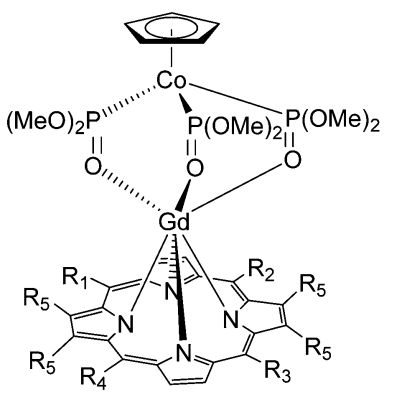

1: $R_{1}=P h, R_{2}=P h, R_{3}=P h, R_{4}=P h, R_{5}=H$

2: $R_{1}=P h C N, R_{2}=P h C N, R_{3}=P h C N, R_{4}=P h C N, R_{5}=H$

3: $R_{1}=p y, R_{2}=$ py, $R_{3}=$ py, $R_{4}=p y, R_{5}=H$

4: $R_{1}=p y, R_{2}=p y, R_{3}=P h, R_{4}=P h, R_{5}=H$

5: $R_{1}=$ PhoTMS, $R_{2}=$ PhMe, $R_{3}=$ PhoTMS, $R_{4}=P h M e, R_{5}=H$

6: $\mathrm{R}_{1}=\mathrm{Ph}(\mathrm{OMe})_{3}, \mathrm{R}_{2}=\mathrm{Ph}(\mathrm{OMe})_{3}, \mathrm{R}_{3}=\mathrm{Ph}(\mathrm{OMe})_{3}, \mathrm{R}_{4}=\mathrm{Ph}(\mathrm{OMe})_{3}, \mathrm{R}_{5}=\mathrm{H}$

7: $\mathrm{R}_{1}=\mathrm{C}_{6} \mathrm{~F}_{5}, \mathrm{R}_{2}=\mathrm{C}_{6} \mathrm{~F}_{5}, \mathrm{R}_{3}=\mathrm{C}_{6} \mathrm{~F}_{5}, \mathrm{R}_{4}=\mathrm{C}_{6} \mathrm{~F}_{5}, \mathrm{R}_{5}=\mathrm{H}$

8: $R_{1}=P h, R_{2}=P h, R_{3}=P h, R_{4}=P h, R_{5}=B r$

Fig. 7 A series of Gd-monoporphyrinate complexes with various electron-donating and electron-withdrawing meso-substituents. Redrawn from ref. 52 .

By changing the precursor porphyrin to 5,10,15,20-tetra(parahydroxy-meta-ethyloxy)phenylporphyrin $\left(\mathrm{H}_{2}(\mathrm{THEP}){ }_{4} \mathrm{P}\right), 5,10,15,20-$ tetra[para-(4-chlorobenzoyloxy)-meta-ethyloxy]phenylporphyrin $\left(\mathrm{H}_{2}(\mathrm{ClBOEP}){ }_{4} \mathrm{P}\right)$ was obtained (Fig. 6) ${ }^{85}$ Similarly, replacing the reactants by 4 -fluorobenzoyl chloride and 5,10,15,20-tetra(parahydroxy-meta-ethoxy)phenylporphyrin gave $\mathrm{H}_{2}(\text { FBOEP })_{4} \mathrm{P}^{86}$ and 5,10,15,20-tetra[para-(4-fluorobenzoyloxy)-meta-methoxy]porphyrin (Fig. 6). ${ }^{87}$ Liu's group subsequently reported the synthesis of three 5,10,15,20-tetra[(4-alkoxy-3-ethyloxy)phenyl]porphyrin ligands with a similar synthetic strategy. ${ }^{88}$ 1-Bromododecane, 1-bromotetradecane and 1-bromohexadecane were refluxed with $\mathrm{H}_{2}$ (THEP) ${ }_{4} \mathrm{P}$ in benzene for $3 \mathrm{~h}$ to obtain the respective porphyrins. The lanthanide complexes of all these ligands were obtained by heating with the corresponding lanthanide acetylacetonate in TCB under nitrogen for $5 \mathrm{~h}$.

To unravel the effect of substituents on the photophysical properties of porphyrins, Wong's group systematically modified the electron-donating and electron-withdrawing substituents at the meso-position of the porphyrin phenyl rings (Fig. 7). ${ }^{52}$ Highly symmetric tetra-substituted porphyrin free bases with phenyl, cyanophenyl, pyridyl, pentafluorophenyl and 3,4,5-trimethoxyphenyl substituents were prepared by condensation of the respective benzaldehydes and pyrrole in propionic acid, following Lindsey's improved Rothemund's method. ${ }^{46,89}$ On the other hand, the less symmetric porphyrin free bases were obtained via the condensation of benzaldehyde and the respective dipyrromethene using trifluoroacetic acid or boron trifluoride diethyl etherate as acid catalysts (Fig. 8). ${ }^{90-92}$ These authors continued to employ the widely used complexation methodology starting from lanthanide amide precursors. ${ }^{47}$ Column chromatography was performed, followed by recrystallization via diffusion of methanol into $\mathrm{CH}_{2} \mathrm{Cl}_{2}$ solution.

In 2012, Kim et al. reported a new series of porphyrins with four triazole groups at the ortho-positions of the phenyl rings of TPP with copper-mediated click chemistry (Fig. 9). ${ }^{93}$ The

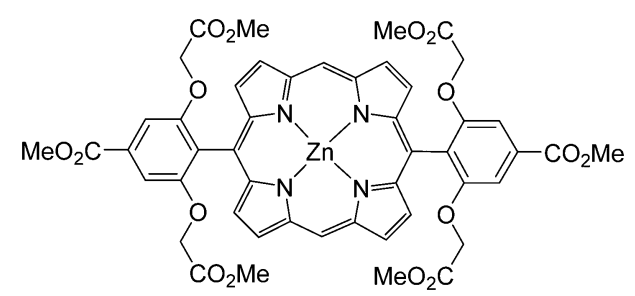

Fig. 8 An example of a less symmetrical metalated monoporphyrinate complex. Redrawn from ref. 90. 


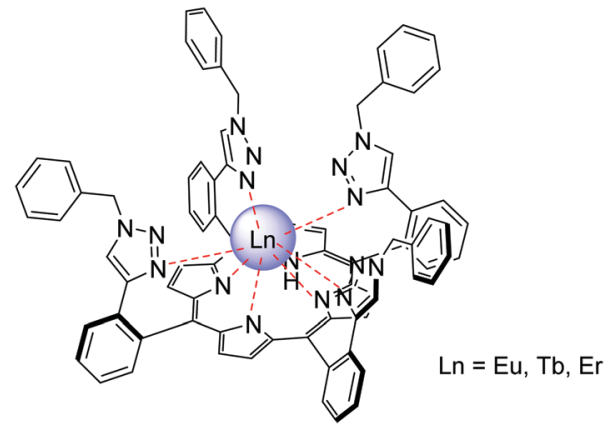

Fig. 9 Porphyrin ligand bearing triazole groups prepared by coppermediated click chemistry. Redrawn from ref. 93.

precursor $\mathrm{Zn}^{\mathrm{II}}$ porphyrin complex, with meta-alkynyl substituents, was prepared by first reacting meta-substituted benzaldehyde with pyrrole and trifluoracetic acid in $\mathrm{CH}_{2} \mathrm{Cl}_{2}$ and then mixing with zinc acetate after purification. ${ }^{94}$ Then, benzyl azide and the precursor complex-with the trimethylsilane group deprotected by tetrabutylammonium fluoride-were reacted according to an alkyne-azide click reaction catalysed by $\mathrm{Cu}(\mathrm{I})$. The desired product was obtained in good yield as the major product and was purified by column chromatography and recrystallization. The free base porphyrin was obtained by demetallation using trifluoroacetic acid and complexation was achieved according to Wong group's route using the lanthanide amide complex.

In 2013, Zhang et al. decided to introduce carbazole branches onto the porphyrin ring and imparted their intrinsic photophysical and redox properties to a lanthanide porphyrin complex. $^{95}$ They reported the synthesis of three 5,10,15,20tetrakis[alkylcarbazole]porphyrins with dodecyl, tetradecyl and hexadecyl alkyl chains. The porphyrins were synthesized by refluxing the bromoalkyl carbaldehyde with pyrrole in xylene using $p$-nitrobenzoic acid to catalyse the reaction. A hydroxy complex was prepared by reacting lanthanide trichloride with the porphyrin in molten imidazole under dry and inert conditions for $2 \mathrm{~h}$ (Fig. 10).

2.1.4 Complexation with porphyrins containing long alkyl tails. Porphyrins bearing long alkyl or alkoxy chains have been prepared in view of investigating liquid crystalline properties of their double-decker complexes with lanthanides. The first such compounds were reported in 1985 with Pc bearing eight $\mathrm{C}_{8}, \mathrm{C}_{12}$, or $\mathrm{C}_{18}$ alkoxy substituents, $\left[\mathrm{Lu}\left(\mathrm{OR}_{8} \mathrm{Pc}\right)_{2}\right]$. Ref. 96 summarizes

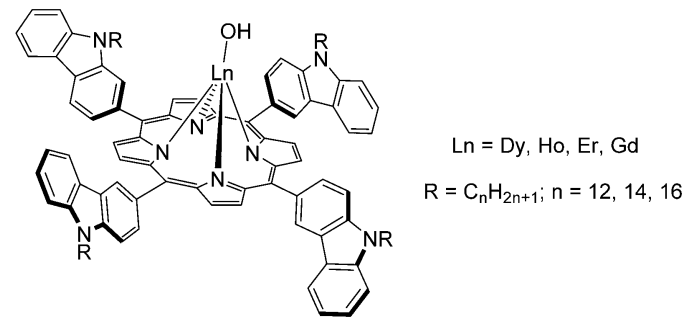

Fig. 10 Lanthanide monoporphyrinate complexes with carbazole branches exhibiting redox properties. Redrawn from ref. 95.

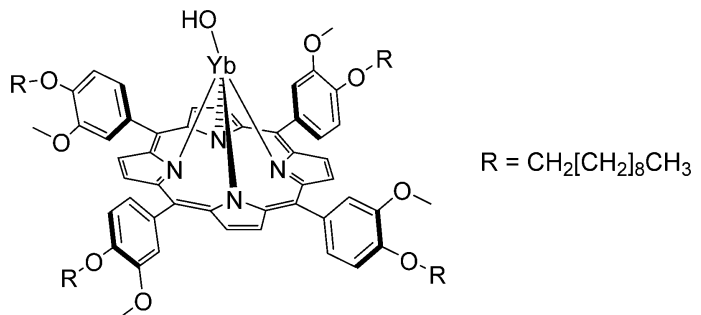

Fig. 11 Monoporphyrinate $\mathrm{Yb}^{\mathrm{III}}$ complex with alkyl tails. Redrawn from ref. 97.

the synthesis of numerous such compounds and their liquidcrystalline properties. More recently, Liu's group reported the isolation of lanthanide monoporphyrinates bearing four alkyl tails. $^{97}$ The ligand 5,10,15,20-tetra[( $p$-decyloxy- $m$-methyloxy)phenyl]porphyrin was prepared by usual procedures from the reaction between $p$-decyloxy- $m$-methyloxybenzaldehyde and pyrrole in propionic acid. The porphyrin was complexed with anhydrous $\mathrm{YbCl}_{3}$ in molten imidazole and the complex is the first lanthanide(III) monoporphyrinate liquid crystal (Fig. 11).

2.1.5 Complexation with multi-halogenated porphyrins. In 1990, Dolphin's group encountered difficulties in the $\beta$-polychlorination of meso-tetraphenylporphyrin derivatives using $N$-chlorosuccinimide, as they could obtain the monosubstituted product only. Ultimately, they discovered that TPP with meta-chlorophenyl rings could be $\beta$-perchlorinated in $85 \%$ yield using chlorine gas in $o$-dichlorobenzene in the presence of anhydrous $\mathrm{FeCl}_{3}$ at $140{ }^{\circ} \mathrm{C}$. The same chlorination procedure could also be used to $\beta$-perchlorinate meso-pentachlorinated TPP to perchloro-TPP in 70\% yield (Fig. 12, top). Nevertheless, when unsubstituted TPP was used as the substrate, decomposition of the macrocycle ensued. ${ }^{98}$ Coutsolelos' group followed Dolphin's synthesis for $\beta$-tetra- or octa-chlorinated 5,10,15,20tetraphenylporphyrins and prepared the $\beta$-tetrabromo and octabrominated analogues by refluxing Ni(TPP) with different equivalents of $\mathrm{N}$-bromosuccinimide in 1,2-o-dichlorobenzene for $3 \mathrm{~h}$. The nickel centre was demetalated with concentrated sulfuric acid and terbium(III) complexation was carried out by refluxing lanthanide acetylacetonate in TCB (Fig. 12, bottom left). ${ }^{99}$

Zhang and Gao's group designed and synthesized a series of $\mathrm{Yb}^{\mathrm{III}}$ complexes with octafluorinated porphyrins and obtained then-unprecedented in 2017, sizeable near-infrared luminescence quantum yields for this class of complexes as the $\mathrm{C}-\mathrm{H}$ oscillators are completely replaced by $\mathrm{C}-\mathrm{F}$ oscillators which minimizes luminescence quenching (Fig. 12, bottom right). ${ }^{100}$ The octafluoroporphyrins were prepared by Lindsey's method ${ }^{46}$ via the boron trifluoride etherate-catalysed condensation of 3,4-difluoropyrrole and the respective benzaldehydes (pentafluorobenzaldehyde, 2,6-difluorobenzaldehyde and 4-trifluoromethylbenzaldehyde). Again, the desired products were isolated using silica gel chromatography and recrystallized from $\mathrm{CH}_{2} \mathrm{Cl}_{2} / n$-hexane.

2.1.6 Complexation with water-soluble porphyrins. One would easily imagine that porphyrins, with their extended conjugation system and a mainly planar structure, would have 

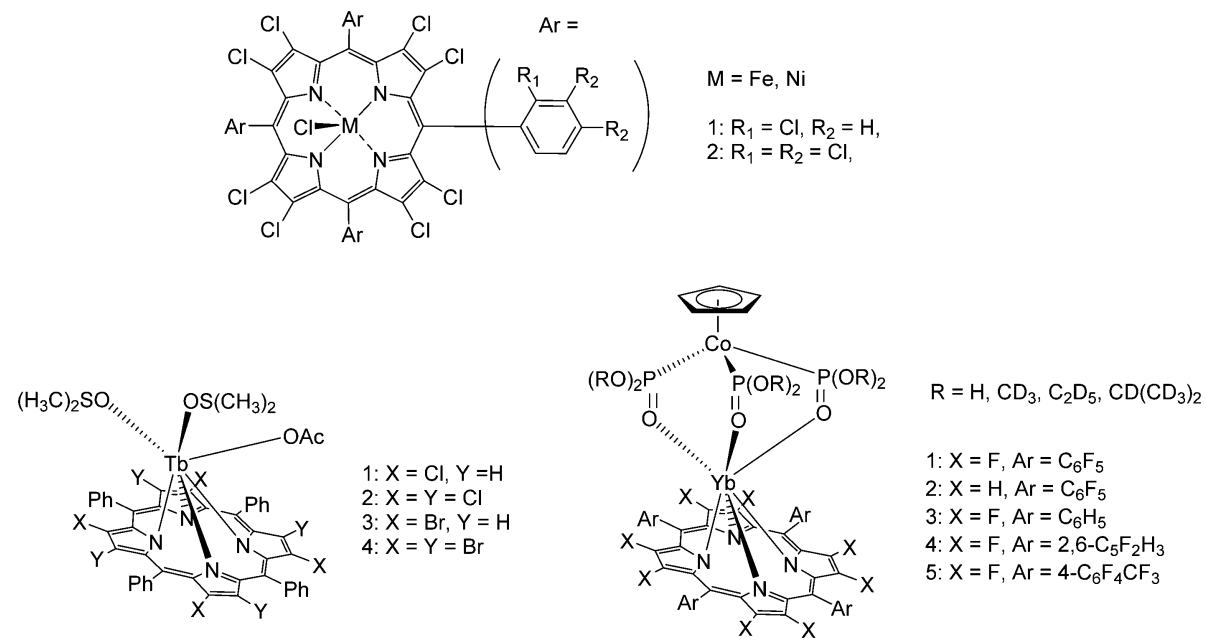

Fig. 12 Examples of multi-halogenated lanthanide porphyrinates at various positions of the porphyrin backbone. Redrawn from ref. 99 and 100.
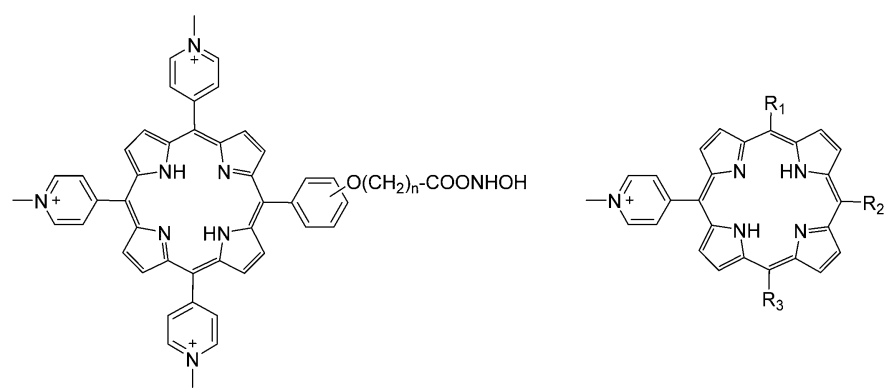

$R_{1}=R_{3}=4-p y-M e, R_{2}=$ hydroxamic

$R_{1}=R_{2}=$ hydroxamic, $R_{3}=4$-py-Me

$R_{1}=R_{3}=$ hydroxamic, $R_{2}=4-p y-M e$

Fig. 13 Examples of water-soluble porphyrins functionalized with hydroxamic derivatives. Redrawn from ref. 102 and 103.

poor water-solubility which thus hinders their utilization in bio-applications. As a result, researchers have focused on improving their biocompatibility by devising synthetic routes for water-soluble porphyrins. In 2006, Itoh et al. reported the synthesis of a tetratoluenesulfonate salt of the cationic meso-tetrakis(4- $N, N$-dimethylaminophenyl)porphyrin (TDMAPP, Scheme 1). ${ }^{101}$ To start with, TDMAPP was synthesized by first refluxing $p$-dimethylaminobenzaldehyde in propionic acid for $30 \mathrm{~min}$, followed by the addition of a propionic acid solution of pyrrole for further reflux. TDMAPP was subsequently mixed with methyl $p$-toluenesulfonate and heated for $3 \mathrm{~h}$, and the product was obtained in its salt form through recrystallization. Coutsolelos' group reported a series of porphyrin-hydroxamic acid derivatives derived from the well-known 5,10,15,20-tetrakis ( $p$-methylpyridine)porphyrin ( $\mathrm{H}_{2}$ TMPyP) (Fig. 13). ${ }^{102,103}$ In general, they first synthesized a porphyrin-ester precursor by the condensation of pyrrole, 4-pyridinecarboxaldehyde and a pre-functionalized aldehyde. Saponification of the esters gave the corresponding porphyrin-carboxylic acids in good yields before coupling with hydroxylamine hydrochloride, followed by methylation with excess methyl iodide to improve the watersolubility of the porphyrin-hydroxamic acid derivatives. The improved water-solubility enabled the study of the nuclease activity of the cationic porphyrins through interactions with DNA and RNA.
Wong's group also reported a systematic study on a series of water-soluble lanthanide porphyrinates with pyridyl substituents in the meso positions (Fig. 14). ${ }^{104}$ A convenient one-pot synthesis with pyrrole, benzaldehyde and 4-pyridinecarboxaldehyde in propionic acid yielded variously substituted and ionic porphyrins that were separated by column chromatography. The tricationic lanthanide porphyrinates were found to exhibit binding interactions with double-stranded DNA and moderate self-stacking was observed.

In recent years, Zhang's group reported the synthesis of porphyrinates with carboxylate and cationic phosphonium groups for the preparation of water-soluble ytterbium

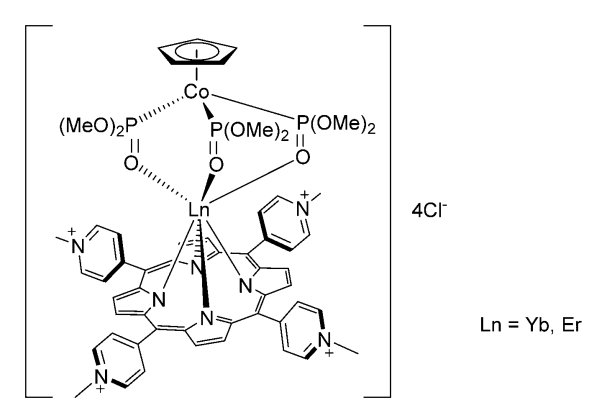

Fig. 14 Water-soluble capped lanthanide porphyrinates with pyridylsubstituents. Redrawn from ref. 104. 

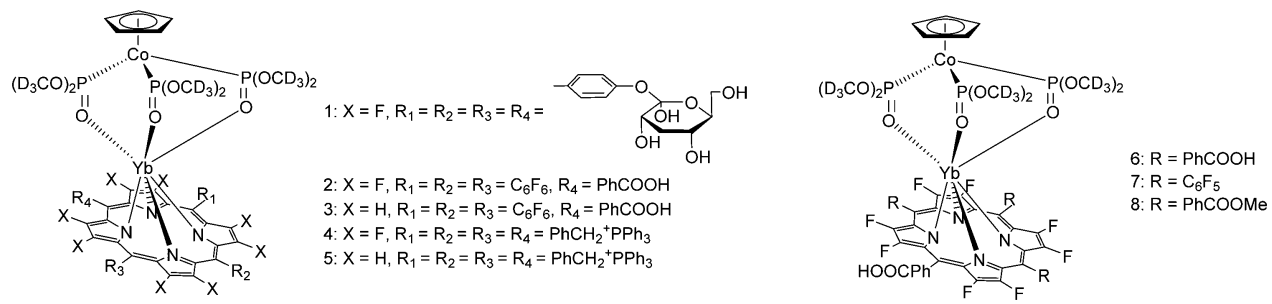

Fig. 15 Examples of water-soluble octafluorinated $\mathrm{Yb}^{\prime \prime \prime}$-porphyrinate complexes with hydrophilic substituents such as carboxyl, glycosyl and triphenylphosphonium groups. Redrawn from ref. 105 and 106.

complexes for conducting live cell NIR bioimaging. Based on their previous work on octafluorinated porphyrins, ${ }^{100}$ they modified the meso positions of the porphyrin phenyl rings with water-soluble moieties such as carboxyl, glycosyl and triphenylphosphonium using methyl $p$-formylbenzoate, 4-(2,3,4,6-tetraacetyl-glucopyranobenzyl)aldehyde, and $p$-chloromethylbenzaldehyde and reacted them with 2,6-difluoropyrrole for the porphyrin synthesis. ${ }^{105}$ The resultant porphyrins were then complexed by refluxing with lanthanide acetylacetonate in TCB overnight, followed by the addition of partially deuterated Kläui's tripodal ligand, sodium [(cyclopentadienyl)tris(di(methyld3)phosphito)cobaltate $\left(\mathrm{Na}\left\{\left(\eta^{5}-\mathrm{C}_{5} \mathrm{H}_{5}\right) \mathrm{Co}\left[\mathrm{P}(=\mathrm{O})\left(\mathrm{OMe}^{\mathrm{D}}\right)_{2}\right]_{3}\right\}\right)$ or in short $\mathrm{CoP}^{\mathrm{CD} 3}$ (Fig. 15). The anionic carboxylate porphyrin required an additional deprotection of the ester, while the cationic triphenylphosphonium terminal was obtained by reaction with excess triphenylphosphine. The water-solubility of the anionic carboxylate porphyrin was even good enough ( $\sim 2 \mathrm{mM}$ in water) to be utilized as an in vivo NIR lifetime probe. $^{106}$

2.1.7 Porphyrinate/phthalocyaninate dyads and triphthalocyaninate conjugates. Members of the Wong group were creative in their porphyrin chemistry in 2007 when they reported the synthesis of a heterodimetallic bisporphyrin by conjugating two precursor porphyrins, 5-( $p$-hydroxyphenyl)10,15,20-triphenylporphyrin $\left(p-\mathrm{OH}-\mathrm{TPPH}_{2}\right)$ and 5-[ $p$-(3-bromopropoxy)phenyl]-10,15,20-triphenylporphyrin $\left(p-\mathrm{BrC}_{3} \mathrm{O}-\mathrm{TPPH}_{2}\right){ }^{107}$ The bisporphyrin complex was constructed by linking a lanthanide porphyrinate with a transition-metal porphyrinate by a 3C flexible alkyl linker (Fig. 16, top); $p-\mathrm{OH}-\mathrm{TPPH}_{2}$ was prepared by heating benzaldehyde and $p$-hydroxybenzaldehyde in propionic acid at $130{ }^{\circ} \mathrm{C}$. Freshly distilled pyrrole in propionic acid was added slowly and the reaction mixture was refluxed for additional $30 \mathrm{~min}$. $p$-OH-TPPH $\mathrm{H}_{2}$ was then refluxed with excess ytterbium amide complex $\mathrm{Yb}\left[\mathrm{N}\left(\mathrm{SiMe}_{3}\right)_{2}\right]_{3} \cdot\left[\mathrm{LiCl}(\mathrm{THF})_{3}\right]$ under nitrogen in toluene; excess $\mathrm{Na}\left\{\left(\eta^{5}-\mathrm{C}_{5} \mathrm{H}_{5}\right) \mathrm{Co}[\mathrm{P}(=\mathrm{O})\right.$ $\left.(\mathrm{OMe})_{2}\right]_{3}$ \} was subsequently added and the work-up gave the $\mathrm{Yb}$-porphyrinate $\left[\mathrm{Yb}(p-\mathrm{OH}-\mathrm{TPP})\left(\mathrm{CoP}^{\mathrm{Me}}\right)\right]$. Alternatively, $5-[p-(3-$ bromopropoxy)phenyl]-10,15,20-triphenylporphyrin $\quad\left(p-\mathrm{BrC}_{3} \mathrm{O}-\right.$ $\mathrm{TPPH}_{2}$ ) was prepared by reacting $p$-OH-TPPH ${ }_{2}$ with excess $1,3-$ dibromopropane in the presence of $\mathrm{K}_{2} \mathrm{CO}_{3}$; the bisporphyrin dyad was obtained by reacting $p-\mathrm{BrC}_{3} \mathrm{O}-\mathrm{TPPH}_{2}$ with $\mathrm{Yb}(p-\mathrm{OH}-$ $\mathrm{TPP})\left(\mathrm{CoP}^{\mathrm{Me}}\right)$ in dry $\mathrm{THF}$ and $\mathrm{K}_{2} \mathrm{CO}_{3}$ at $60{ }^{\circ} \mathrm{C}$ overnight, followed by chromatography on silica gel. In 2012, the same group reported similar rigid acetylene-bridged $\mathrm{Zn}^{\mathrm{II}}$ porphyrinmonophthalocyaninato $\mathrm{Yb}^{\mathrm{III}}$ hybrids, ZnPor-YbPc, through convergent Sonogashira coupling (in 58\% yield) between meso-ethynyl $\mathrm{Zn}^{\mathrm{II}}$-porphyrin and $\mathrm{I}(t \text { - } \mathrm{Bu})_{3} \mathrm{Pc}$; selective $\mathrm{Zn}^{\mathrm{II}}$ demetallation using conc. $\mathrm{HCl}$ afforded $\mathrm{H}_{2} \mathrm{Por}-\mathrm{YbPc}$ in $93 \%$ yield; then re-metalation with $\mathrm{Pd}^{\mathrm{II}}$ acetate afforded PdPor-PcYb in $71 \%$ yield (Fig. 16, bottom). ${ }^{109}$

In 2015, upon mixing and refluxing 4,5-bis-[4-tertbutyl phenoxy]-phthalonitrile, pre-synthesized 2,4,6-tris(3-thiopthalonitrile)-s-triazine, $\mathrm{LnCl}_{3} \cdot x \mathrm{H}_{2} \mathrm{O}(\mathrm{Ln}=\mathrm{Yb}, \mathrm{Lu})$ and $\mathrm{DBU}$ in 1-pentanol in open air for $21 \mathrm{~h}$, the Nyokong group isolated trimeric dendron-like lanthanide phthalocyanines in $69-77 \%$ yields; the products were purified by silica gel column chromatography by eluting first with a chloroform/hexane mixture $(\mathrm{v} / \mathrm{v}=1: 1)$ and then with a chloroform/ethanol mixture $(\mathrm{v} / \mathrm{v}=$ $3: 1$ ) (Fig. 17). ${ }^{108}$

2.1.8 Complexation with crown-porphyrins. Korovin et al. prepared crown-porphyrins (Fig. 18) according to the Thanabal
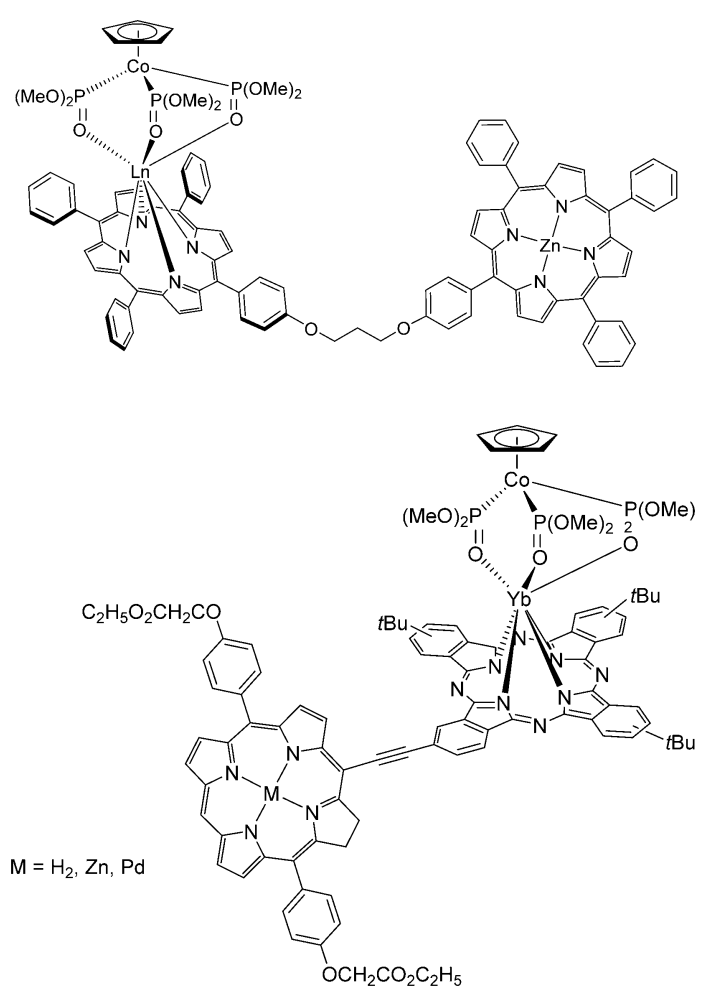

Fig. 16 Heterodimetallic $3 d-4 f$ (top) bisporphyrin and (bottom) porphyrin-phthalocyanine lanthanide complexes designed and synthesized by the Wong group. Redrawn from ref. 107 and 108 . 


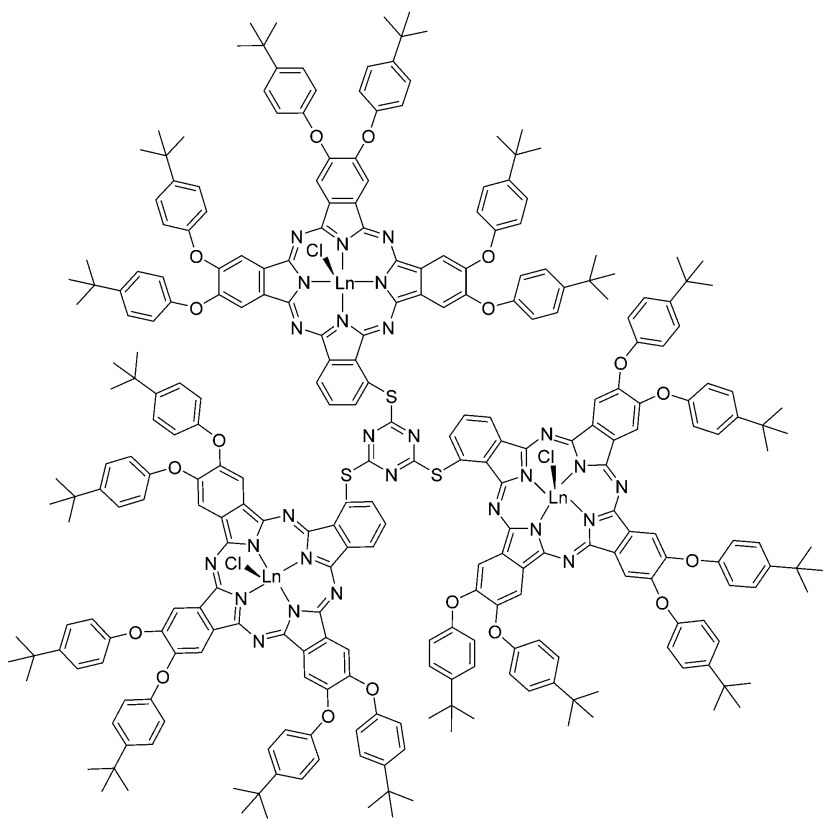

Fig. 17 Dendron-like lanthanide triphthalocyaninate conjugates reported by the Nyokong group. Redrawn from ref. 109.

and Krishnan method, ${ }^{110,111}$ which involves the reaction between a $4^{\prime}$-aldehyde crown ether and pyrrole in propionic acid under reflux conditions for $45 \mathrm{~min}$. The work-up procedures were similar to TPP syntheses and the product was obtained after purification by column chromatography on basic alumina with chloroform-THF-MeOH as the eluent. Lanthanide complexation was achieved by refluxing equimolar $\operatorname{Ln}(\text { acac })_{3}$ with the free base porphyrin in TCB for $4 \mathrm{~h}$. Alternatively, Tsukube et al. suggested another method for the synthesis of a porphyrin/benzo-18-crown-6 ligand (Fig. 2). ${ }^{50}$ They first treated benzo-18-crown-6 with oxalyl chloride, and the intermediate was added to a dichloromethane solution of 5-(3-aminophenyl)-10,15,20-triphenylporphine $\quad\left(m-\mathrm{H}_{2} \mathrm{APTPP}\right.$, Scheme 1)-synthesized according to the Lindsey method ${ }^{46}$ - and triethylamine. The crude product was washed with water and chromatographed on silica gel to obtain a purple solid product for complexation with lanthanide tris-2,4-pentanedionate using Horrocks Jr.'s procedures.

2.1.9 Complexation with porphyrins containing external chelating groups. The Semenishyn group was interested in synthesizing bimetallic lanthanide complexes with porphyrins conjugated with aminopolycarboxylic acids such as ethylenediaminetetraacetic acid (EDTA) and diethylenetriaminepentaacetic acid (DTPA). In 2009, they reported the synthesis of mono$p$-aminotetraphenylporphyrin $\left(\mathrm{H}_{2} \mathrm{ATPP}\right)$-DTPA in which equimolar quantities of $\mathrm{H}_{2}$ ATPP and DTPA dianhydrides were mixed in dry DMF at $70{ }^{\circ} \mathrm{C}$ for $3 \mathrm{~min}$ in the presence of triethylamine. EDTA dianhydride was used for the synthesis of $\mathrm{H}_{2}$ ATPP-EDTA (Fig. 19). ${ }^{112,113}$ Both the porphyrin and the EDTA/DTPA units were complexed with lanthanides. They then reported the synthesis of a series of modified tetraphenylporphyrins and corroles conjugated to EDTA and DTPA using the same procedure (Fig. 20). ${ }^{114,115}$

The Wong group designed porphyrin with an appended $\beta$ diketonate which would help fulfil the $\mathrm{Ln}^{\text {III }}$ coordination requirements in addition to the porphyrin $\mathrm{N}$ atoms (Fig. 21). ${ }^{116}$ The synthesis started with the condensation of pyrrole, benzaldehyde and $o$-hydroxybenzaldehyde in a molar ratio of $4: 1: 3$ to give 5-(2-hydroxylphenyl)-10,15,20triphenylporphyrin $\left(o-\mathrm{OHTPPH}_{2}\right)$. Then, the porphyrin was mixed with 1,4-dibromobutane in dry DMF using $\mathrm{K}_{2} \mathrm{CO}_{3}$ as the base to give 5-(2-(4-bromobutyl)-phenyl)-10,15,20triphenylporphyrin which was subsequently reacted with diethyl malonate in dry DMF in the presence of sodium methoxide to give 5-[2-(5,5'-ethoxycarbonyl)pentoxy]phenyl10,15,20-triphenylporphyrin in high yield. Complexation was achieved with the reaction of a lanthanide amide complex precursor with the porphyrin free base, while purification was accomplished by silica gel column chromatography with chloroform : methanol $(\mathrm{v} / \mathrm{v}=5: 1)$.

2.1.10 Complexation with functional porphyrins. Another common chelating agent for lanthanide ions is hydroxyquinoline and it is no surprise that the Hosseini and De Cola groups reported a tetrafunctionalized porphyrin free base, as well as a $\mathrm{Pd}^{\mathrm{II}}$-porphyrin, with four 8-hydroxyquinolinyl units to trap and sense $\mathrm{Nd}^{\mathrm{III}}$ (Fig. 22). Although the structural geometry of the

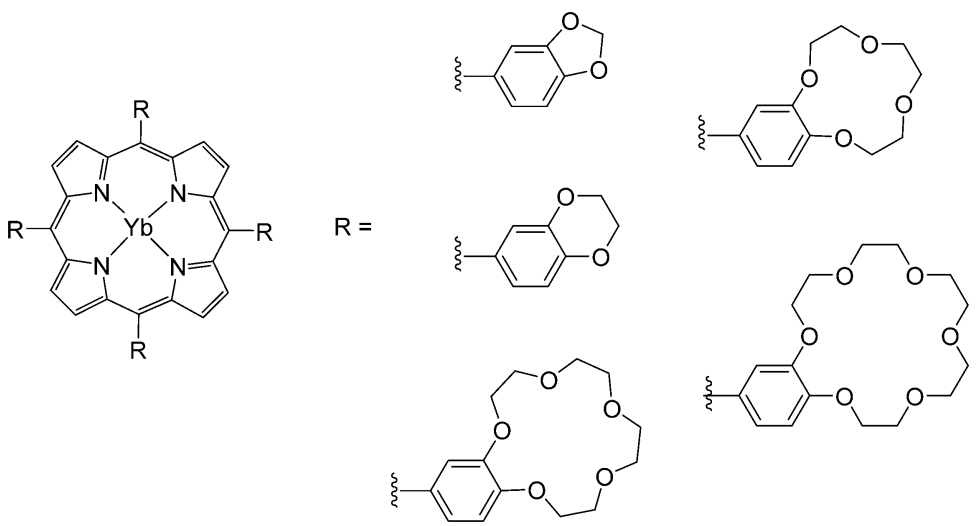

Fig. 18 Examples of lanthanide crown-porphyrinates prepared by Korovin et al. Redrawn from ref. 110 and 111. 

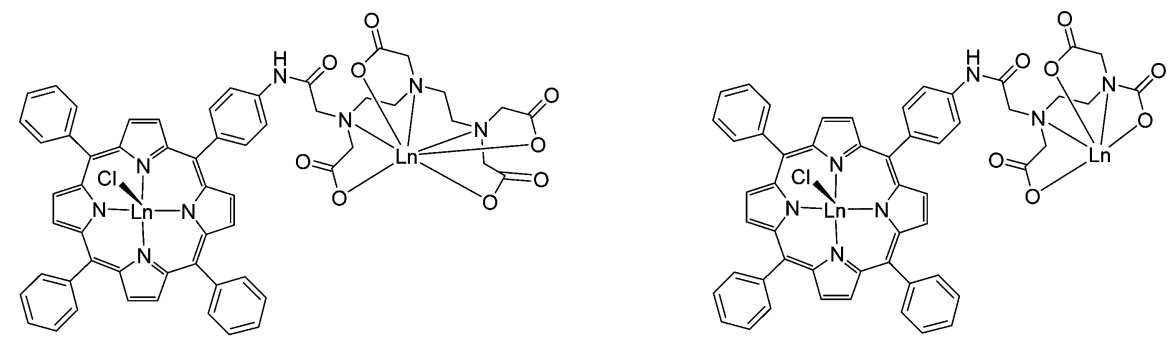

$\mathrm{Ln}=\mathrm{Yb}, \mathrm{Lu}$

Fig. 19 Structures of bimetallic lanthanide porphyrinates with EDTA and DTPA incorporated into the ligand design. Redrawn from ref. 112.
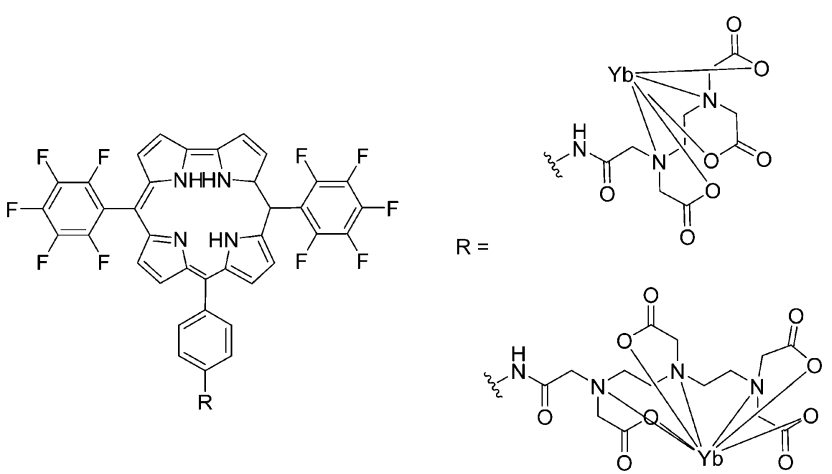

Fig. 20 Corrole ligands conjugated with EDTA and DTPA synthesized with similar procedures as for porphyrin counterparts. Redrawn from ref. 115 .

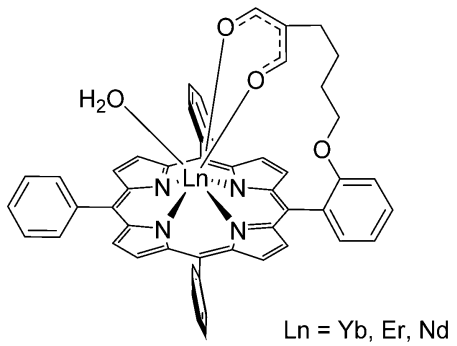

Fig. 21 Monometallic lanthanide porphyrinate complex with a coordinating $\beta$-diketonate moiety conjugated to the porphyrin backbone. Redrawn from ref. 116

over-crowded porphyrin core (as the $\alpha_{4}$-atropisomer) made it impossible for $\mathrm{Nd}^{\mathrm{III}}$ to be coordinated in the centre, the pendant 8-hydroxyquinoline units could chelate $\mathrm{Nd}^{\mathrm{III}}$ externally; a heterodinuclear $\mathrm{Pd}^{\mathrm{II}}-\mathrm{Nd}^{\mathrm{III}}$ porphyrinate could even be conspicuously formed by a stepwise metalation protocol. ${ }^{117,118}$ The authors first synthesized a meso-tetrakis(o-aminophenyl) porphyrin using the Lindsey method. ${ }^{119}$ This compound was dissolved in $\mathrm{CH}_{2} \mathrm{Cl}_{2}$ along with 4 -( $N, N$-dimethylamino)pyridine (DMAP), 3-[bis(dimethylamino)methyliumyl]-3H-benzotriazol1-oxide hexafluorophosphate (HBTU, Scheme 1), and 7-carboxy8-hydroxyquinoline in $\mathrm{CH}_{2} \mathrm{Cl}_{2}$ and the mixture was stirred for 4 days under argon and in the dark. Complexation was carried out by adding a solution of tetrabutylammonium hydroxide in methanol to a solution of the porphyrin in $\mathrm{CH}_{2} \mathrm{Cl}_{2}$, followed by degassing and briefly heating to reflux under argon. A solution of $\mathrm{Nd}(\mathrm{acac})_{3}\left(\mathrm{H}_{2} \mathrm{O}\right)_{2}$ in $\mathrm{CH}_{2} \mathrm{Cl}_{2}$ was then added dropwise, followed by refluxing under argon for $7 \mathrm{~h}$; the reaction was performed at room temperature in order to avoid atropisomerization. For the heterobimetallic complex, meso-tetrakis $(o$ aminophenyl)porphyrin was first refluxed with $\mathrm{Pd}(\mathrm{OAc})_{2}$ in $\mathrm{CHCl}_{3} / \mathrm{MeOH}$ for $9 \mathrm{~h}$ under argon and in the dark; the solution was then enriched in the $\alpha_{4}$-atropisomeric $\mathrm{Pd}^{\mathrm{II}}$-porphyrinate by heating in toluene in the presence of silica and purified by column chromatography. The porphyrin $\mathrm{Pd}^{\mathrm{II}}$ complex was then coupled with 8-hydroxy-7-quinolinecarboxylic acid and chelated with $\mathrm{Nd}^{\mathrm{III}}$ in sequence. Purification of the products was achieved by column chromatography on alumina.

In 2011, the Wong group began designing porphyrin complexes appended to an external dye to explore the potential of photophysical properties of ytterbium porphyrinates (Fig. 23). They designed an unsymmetrical porphyrin with three pentafluorophenyl substituents at the meso position and attached one $p$-conjugated linker for covalent conjugation with a rhodamine B dye. The rhodamine B moiety was also functionalized with a short PEG chain to improve the overall water-solubility of the complex. The $\mathrm{F}_{15} \mathrm{TPP}$ “ $\mathrm{A}_{3} \mathrm{~B}$ ” porphyrin was obtained via condensation of pentafluorobenzaldehyde, 4-[2-(trimethylsilyl) ethynyl]benzaldehyde and pyrrole using Lindsey's protocol. ${ }^{58,119}$ Complexation was performed via the established route of using a lanthanide amide complex precursor and the addition of a $\mathrm{CoP}^{\mathrm{Me}}$ anion to cap the $\mathrm{Yb}^{\mathrm{III}}$ porphyrinate. The trimethylsilyl (TMS) group was subsequently deprotected with tetrabutylammonium fluoride to give an alkynyl terminal group. The latter was subjected to a Sonogashira coupling reaction to produce an extended linker with a hydroxy terminal for conjugation with iodo-PEGfunctionalized rhodamine $B$. The complex demonstrated its potential in a wide spectrum of applications, such as photophysical properties in aqueous solution, ${ }^{70}$ NIR imaging, ${ }^{120}$ photodynamic therapy, ${ }^{121}$ and cancer cell imaging. ${ }^{122}$ Furthermore, the synthetic flexibility offered by the linker for conjugation with various moieties allowed the properties of the porphyrinate complex to be modified relatively easily through the linker instead of on the porphyrin skeleton; it has allowed Wong's group to transform the rhodamine B moiety into a BODIPY-conjugate as a $\mathrm{Hg}^{\mathrm{II}}$-selective sensor, ${ }^{123}$ binding unit towards anionic phospholipids, ${ }^{124}$ or peptide-based integrin $\alpha_{v} \beta_{3}$ binding unit 

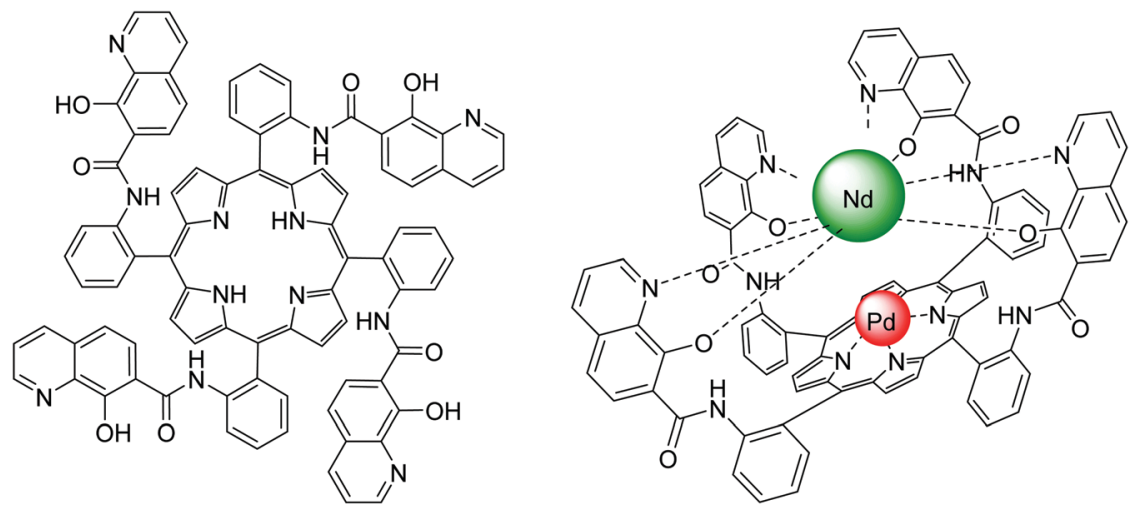

Fig. 22 Structures of (left) the 8-hydroxyquinoline tetrafunctionalized porphyrin ligand and (right) the heterobimetallic Pd"/Nd"' porphyrinate; the steric hindrance and competition from 8-hydroxyquinolinyl units resulted in no lanthanide coordination in the porphyrin cavity. Redrawn from ref. 117 and 118.

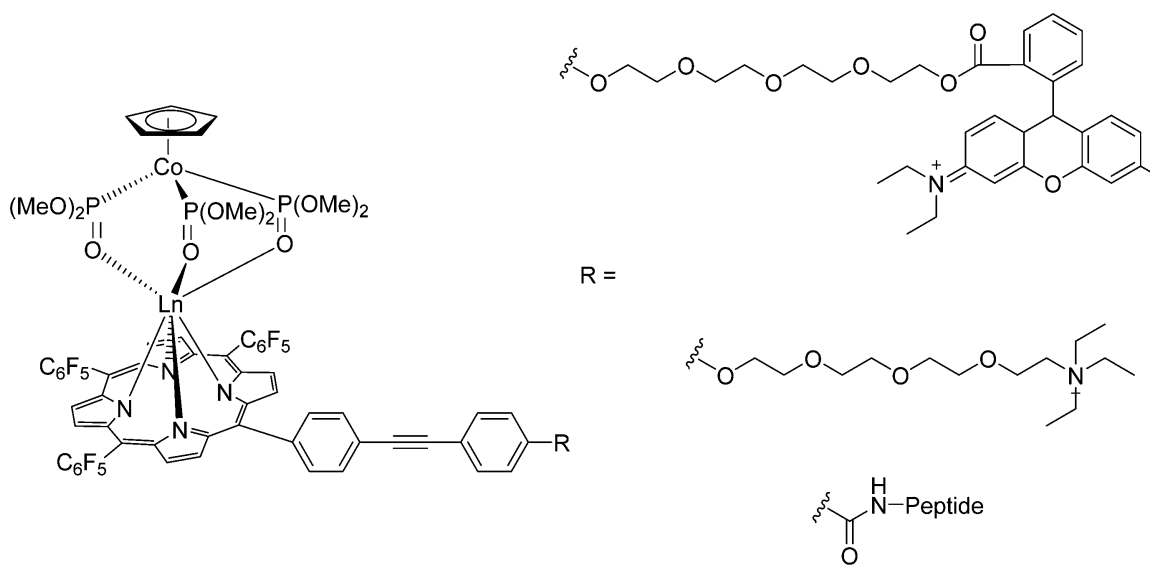

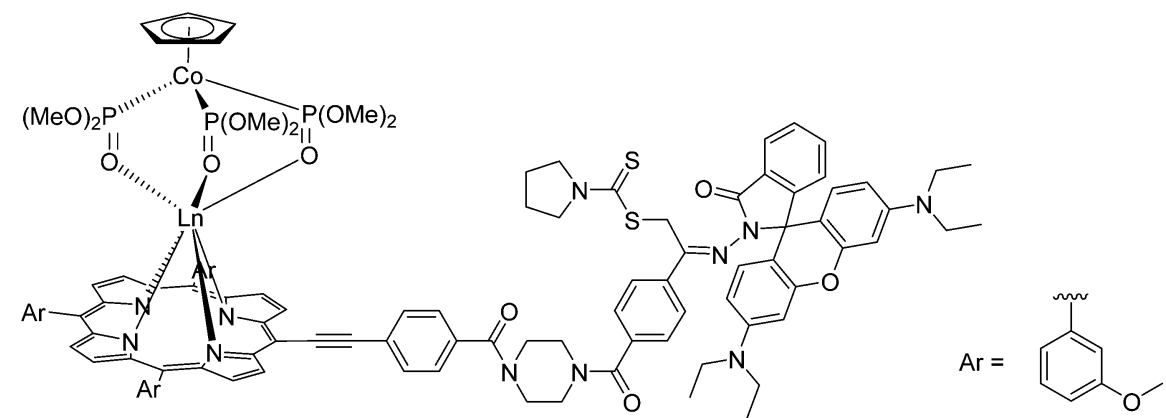

Fig. 23 Structures of lanthanide monoporphyrinates with extended conjugation to functional moieties. Redrawn from ref. 70 and $120-126$.

with $\mathrm{NIR}^{125}$ and $\mathrm{MRI}^{126}$ imaging capabilities. The purification of peptide-conjugated lanthanide-porphyrin systems requires several rounds of HPLC.

2.1.11 Complexation with unsymmetrical porphyrins. In addition to several examples mentioned above, Liu's group devoted much effort in designing and preparing unsymmetrical porphyrins featuring creative properties. Back in 1994, Liu's group presented the synthesis of 5-(4-hydroxyphenyl)-10,15,20triphenylporphyrin $\left(\mathrm{H}_{2} \mathrm{HPTPP}\right.$, Scheme 1$)$ by mixing 4hydroxybenzaldehyde and benzaldehyde. ${ }^{127}$ The corresponding lanthanide complex was obtained by reacting the unsymmetric porphyrin with $\operatorname{Ln}(\mathrm{acac})_{3}$ in TCB at $210{ }^{\circ} \mathrm{C}$ for $3 \mathrm{~h}$. In 2000 , they reported the synthesis of an unsymmetrical $o$-nitrobenzaldehyde Schiff-base porphyrin (Fig. 24, top left). ${ }^{128}$ First, (5(p-nitrophenyl)-10,15,20-triphenyl porphyrin $\left(\mathrm{H}_{2} \mathrm{NOTPP}\right.$, Scheme 1) was synthesized according to the procedures developed by Hasegawa et al. ${ }^{129}$ The nitro group on the unsymmetrical porphyrin was reduced with tin chloride in the presence of hydrochloric acid and further purified by filtration and column chromatography to give the product 5 -aminophenyl10,15,20-triphenyl porphyrin $\left(\mathrm{H}_{2} \mathrm{ATPP}\right.$, Fig. 19). Subsequent refluxing with $o$-nitrobenzaldehyde in DMF afforded the final 

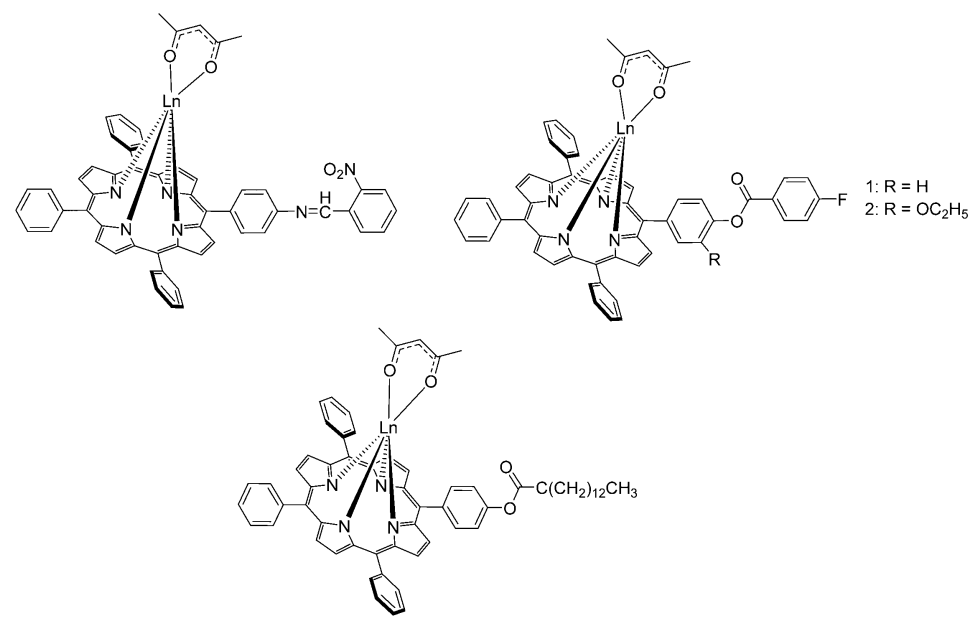

Fig. 24 Examples of unsymmetrical lanthanide porphyrinates. Redrawn from ref. 127 and 130-132.

Schiff-base porphyrin and the complex was obtained in a similar way as mentioned above.

The same authors further modified the hydroxyl group on $\mathrm{H}_{2}$ HPTPP by refluxing with 4-fluorobenzoyl chloride and triethylamine in benzene for $8 \mathrm{~h}$ to give 5 -[ $p$-(4-fluorobenzoyloxy)]-phenyl-10,15,20-triphenyl porphyrin $\left(\mathrm{H}_{2} \mathrm{FBOPTPP}\right.$, Fig. 24, top right). ${ }^{130}$ They also reacted $\mathrm{H}_{2} \mathrm{HPTPP}$ with myristyl chloride under similar experimental conditions to give 5-(4myristyloxy)phenyl-10,15,20-triphenyl porphyrin $\left(\mathrm{H}_{2} \mathrm{MPTPP}\right.$, Fig. 24, bottom) and eventually its acac ${ }^{-}$complex. ${ }^{131}$ In 2011, Cui et al. reported an unsymmetrical 5-[ $p$-(4-fluorobenzoyloxy)$m$-ethyloxy]phenyl-10,15,20-triphenylporphyrin $\left(\mathrm{H}_{2}\right.$ FBOEPTPP, Fig. 24, top right) referencing to Liu's synthetic procedures for $\mathrm{H}_{2} \mathrm{HPTPP}$ as the precursor. ${ }^{132}$ The corresponding lanthanide complex was obtained by heating the free base porphyrin with lanthanide acetylacetonate in molten imidazole under dry nitrogen for $3.5 \mathrm{~h}$, a procedure reported by Srivastava in $1978^{133}$ and also used by Che et al. in $2013 .^{134}$

2.1.12 Preferential formation of atropisomers. In 1980, Lindsey studied the synthesis of meso-tetrakis(o-aminophenyl) porphyrin. The purified $\alpha, \alpha, \alpha, \alpha$-atropisomer $\left(\alpha_{4}\right)$, where $\alpha=$ pendant pointing upward and $\beta=$ pendant pointing downward, is one of the four atropisomers that represents $12.5 \%$ of the statistical mixture at equilibrium and was obtained using Collman's synthetic method. ${ }^{135}$ Despite being experimentally feasible, it is impractical to purify the $\alpha_{4}$-atropisomer by chromatography and repeated re-equilibration-chromatography cycles to maximize the yield. Lindsey therefore rationalized that a suitable solvent would shift the equilibrium to maximize the conversion of atropisomers. Ultimately, using benzene as the solvent and at the same time utilizing the $\alpha_{4^{-}}$ atropisomer's highest affinity for silica gel, a yield in the range of $60-70 \%$ was achieved. This technique to increase the yield of $\alpha_{4}$-isomers was also used by Hosseini's group ${ }^{117}$ and De Cola's group ${ }^{118}$ in the purification of the $\alpha_{4^{-}}$ atropisomer of meso-tetrakis-8-hydroxyquinolinylamide porphyrin, as described above.

\subsection{Complexation with N-confused porphyrins}

Compared with normal porphyrins, N-confused porphyrins or "NC-P" have been discovered much more recently. The first NC-P was synthesized in 1994 as a new isomer of tetraphenylporphyrin by two different research groups, and different synthesis mechanisms were proposed. ${ }^{136,137}$ Looking at the structure of this macrocycle, one of the "confused" pyrrole rings is linked through its $\alpha-\beta^{\prime}$ axis rather than a common $\alpha-\alpha$ one. ${ }^{138}$ Based on the traditional acid-catalysed condensation for preparing tetraphenylporphyrin, $\mathrm{N}$-confused ones were synthesized with propionic acid, $t$-BuOH$/ \mathrm{CH}_{2} \mathrm{Cl}_{2}$ (1:1), and concentrated $\mathrm{HBr} .{ }^{136}$ Researchers kept investing efforts into exploring more derivatives of $\mathrm{N}$-confused porphyrins and metalloporphyrins with novel synthetic methods during the past few decades, ${ }^{139-142}$ including the introduction of "neoconfused porphyrins" (Fig. 25). ${ }^{143}$ Although some comprehensive studies on the preparation of NC-Ps and meso-substituted NC-Ps have been published, ${ }^{144,145}$ there are only a few examples for metalation of NC-P or its derivatives, and even less involving lanthanide-based complexes because of their lability. In 2005, Wong et al. reported the first synthesis of lanthanide NC-P complexes ${ }^{146}$ using the tripodal anion $\mathrm{CoP}^{\mathrm{Et}}$ in view of its ability to stabilize labile trivalent lanthanide porphyrinates. ${ }^{51,69}$ The facile preparation of this first lanthanide-based $\mathrm{N}$-confused-porphyrin complex consisted in adding an excess of $\operatorname{Ln}\left[\left(\mathrm{N}\left(\mathrm{SiMe}_{3}\right)_{2}\right]_{3} \cdot\left[\mathrm{LiCl}(\mathrm{THF})_{3}\right]_{x}(\mathrm{Ln}=\right.$ $\mathrm{Yb}, \mathrm{Er})$ to $\mathrm{N}$-confused tetraphenylporphyrin in refluxing toluene, followed by addition of an excess of $\mathrm{NaCoP}^{\mathrm{Et}}$ at room temperature. The crude products were purified by column chromatography, and the resulting air-stable green crystals were characterized as the final product in $75 \%$ yield. The researchers also found that no complex could be obtained if there was no addition of $\mathrm{NaCoP}^{\mathrm{Et}}$ to stabilize the intermediates. Unfortunately, there is little research on lanthanide complexes with $\mathrm{N}$-confused porphyrins because the investigations on $\mathrm{Ln}^{\mathrm{III}}$-NC-P did not show improved spectroscopic performance over regular porphyrinates. ${ }^{67}$ 
(A)

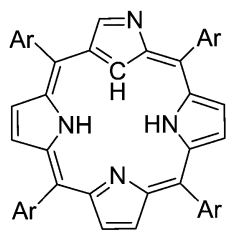

(B)

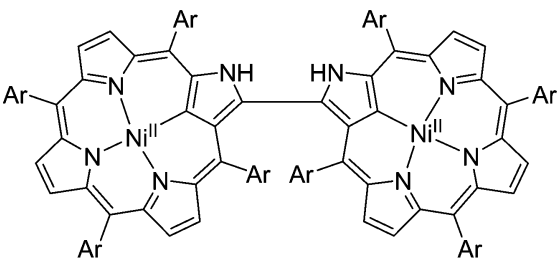

(C)

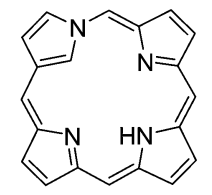

(D)

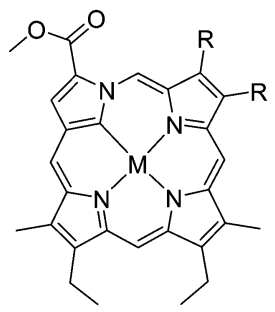

(E)

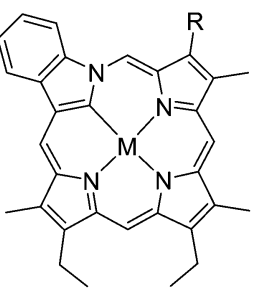

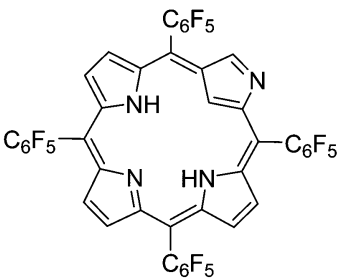

$\mathrm{R}=\mathrm{Me}$ or $\mathrm{Et} ; \mathrm{M}=2 \mathrm{H}, \mathrm{Ni}$ or $\mathrm{Pd}$

Fig. 25 Examples of $\mathrm{N}$-confused porphyrins. (A) $\mathrm{N}$-Confused tetraphenylporphyrin; ${ }^{136}$ (B) $\mathrm{N}$-confused porphyrin dimer; ${ }^{139}$ (C) neo-confused porphyrin; ${ }^{143}$ (D) metallo-neo-confused porphyrinates; ${ }^{141}$ (E) pentafluorophenyl-substituted $\mathrm{N}$-confused porphyrins. ${ }^{142}$

\subsection{Complexation with expanded porphyrins (texaphyrins)}

Expanded porphyrins, as referred to by their name, are a group of porphyrinogen-like macrocycles containing more than four pyrrole units and therefore their cavities are larger than in regular porphyrins (Fig. 26). We note that some systems are sometimes considered as expanded porphyrins: although including larger polypyrrolic macrocycles, they neither have the typical carbon bridges as porphyrins nor show overall aromaticity. ${ }^{147}$ In principle, sapphyrin, which contains five pyrrole units directly linked by four methine groups, is considered being the first expanded porphyrin. ${ }^{148}$ Unfortunately, Bauer et al. only succeeded in isolating $\mathrm{Zn}^{\mathrm{II}} / \mathrm{Co}^{\mathrm{II}}$ complexes, and there was no report describing lanthanide-based sapphyrin complexes until the 1990s.

The core ring of texaphyrin contains five nitrogen donor atoms and was reported by Sessler and co-workers in $1987 .{ }^{149}$ The first lanthanide-metalation of texaphyrin was described
(A)

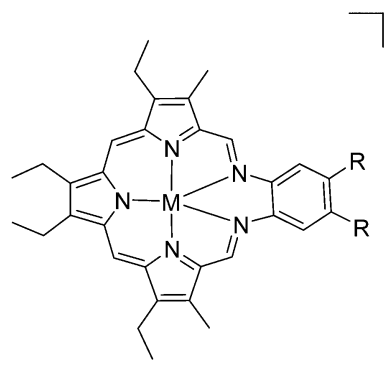

(C)

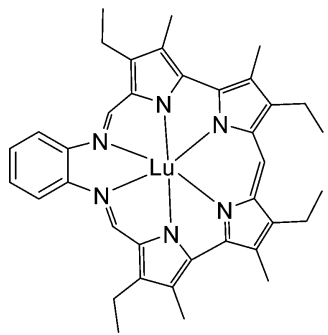

(B)

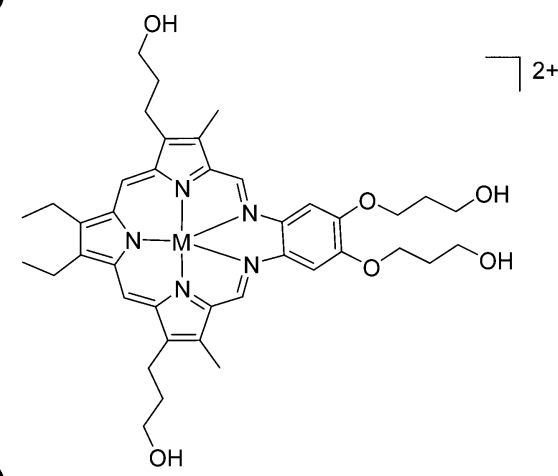

(D)<smiles>O=C(O)CN1CCN(CC(=O)O)CCN(CC(=O)O)CCN(CC(=O)O)CC1</smiles>

DOTA

Fig. 26 Examples of expanded porphyrinates: ( $A$ and $B) L n^{\prime \prime \prime}$ texaphyrinates prepared by Sessler et al. $\left(M=H\right.$ or $L n$, except $P m ; R=\mathrm{CH}_{3}, O C H_{3}$ or $\left.\mathrm{O}\left(\mathrm{CH}_{2}\right)_{3} \mathrm{OH}\right)$; (C) Lu'II-grandephyrin. Redrawn from ref. 150 and 155. The structure of DOTA is given for comparison. 
five years later by the same research group. ${ }^{150}$ They prepared this new class of tripyrrane-containing macrocycles in $44 \%$ yield by direct acid-catalysed condensation between diformyltripyrrane and $o$-phenylenediamine in the presence of concentrated $\mathrm{HCl}$. It is worth noting that a metal template can facilitate this condensation because the addition of $\mathrm{Pb}(\mathrm{SCN})_{2}$ or $\mathrm{UO}_{2} \mathrm{Cl}_{2}$ improved the overall yields to $69 \%$ and $61 \%$, respectively. In these three preparation methods, the pure products can be crystallized from dichloromethane, followed by washing with hexane.

Gadolinium(III)-based chelates are known since the 1980s for their clinical applications in imaging while coordinated to polyaminocarboxylate ligands, including DTPA or 1,4,7,10tetraazacyclododecane-1,4,7,10-tetraacetic acid (DOTA, Fig. 26), for instance. Therefore, Sessler and co-workers tried to put trivalent lanthanide ions into alkyl-substituted texaphyrins (Fig. 26). ${ }^{150}$ A comprehensive study on a series of lanthanides embedded into expanded porphyrins has been performed: lanthanide salts and proton sponge $\left(N, N^{\prime \prime}, N^{\prime \prime}, N^{\prime \prime \prime}\right.$-tetramethyl1,8-diaminonaphthalene) were reacted with texaphyrin in a chloroform/methanol mixed solvent at room temperature. ${ }^{151}$ Pure complexes were difficult to obtain in reasonable yields by direct chromatography on either silica gel or lipophilic Sephadex. A better optimized method made use of oxygenated methanol as the solvent into which a mixture of $\operatorname{Ln}\left(\mathrm{NO}_{3}\right)_{3}$. $x \mathrm{H}_{2} \mathrm{O}$ and triethylamine was heated. The yields increased from $25 \%$ to $55-70 \%$ for heavier lanthanide texaphyrin complexes (Nd-Lu, except $\mathrm{Pm}$ ), while it remains around $30 \%$ for lighter ones (La-Pr). A water-soluble texaphyrin was also specifically designed for complexation with $\mathrm{Gd}^{\mathrm{III}}$ for potential application as a MRI contrast agent. ${ }^{152}$ The diamine portion of the macrocycle-a source of the fourth and fifth $N$ atoms-was synthesized by nitration of $o$-bis-((3-hydroxypropyl)oxy)benzene to give a dinitro diacid intermediate, which was then reduced with borane-THF to give terminal hydroxy groups and further reduced. Then, condensation between the diamine and 2,5-bis((3-ethyl-5-formyl-4-methylpyrrol-2-yl)methyl)-3,4diethylpyrrole yielded the targeted texaphyrin. However, the poor water-solubility of the complexes prompted modifications into a tetrahydroxylated texaphyrin. The presence of the four peripheral hydroxyl groups was vital to increasing the water-solubility of the texaphyrin complexes. Two lanthanide complexes with texaphyrin have been tested for medical applications: a $\mathrm{Gd}^{\mathrm{III}}$ complex, as a radiation sensitizer in radiotherapy, and a $\mathrm{Lu}^{\mathrm{III}}$ complex generating singlet oxygen for photodynamic treatment of cancer. Both complexes localize preferentially in tumour cells. For further information, the reader can refer to a recent review which covers the field comprehensively. ${ }^{153}$

Even though there are many other types of expanded porphyrins, ${ }^{153}$ only grandephyrin ${ }^{154}$ showed successful complexation with lutetium: bis(trimethylsilyl)amide of $\mathrm{Lu}^{\mathrm{III}}$ was added into the free-base macrocycle in THF solution and in the absence of water and oxygen. Unfortunately, the resulting $\mathrm{Lu}^{\mathrm{III}}$ grandephyrin adduct was unstable and slowly decomposed upon exposure to air and moisture (Fig. 26). ${ }^{155}$

\subsection{Complexation as double, triple and multiple deckers}

Ever since the advent of metalloporphyrins, attention has been drawn to their stacked arrangements. The conventional construction of multiple-decker metalloporphyrins is either through the coordination of a metal ion sandwiched between two macrocycles or with the help of bridging ligands (see Fig. 1). In the case of lanthanides, most of the multisandwiched complexes reported are double or triple deckers and some of the provided ligands are shown in Fig. 27.

Weiss et al. reported lanthanide-based double/triple-decker arrangements without bridging ligands, for instance, $\mathrm{Ce}^{\mathrm{IV}}$ bis(octaethylporphyrinate) $\left[\mathrm{Ce}(\mathrm{OEP})_{2}\right]$ and dicerium(III) tris(octaethylporphyrinate) $\left[\mathrm{Ce}_{2}(\mathrm{OEP})_{3}\right]$, in the $1980 \mathrm{~s}^{18}$ The direct preparation of these complexes was to reflux $\mathrm{Ce}(\mathrm{acac})_{3}$. $3 \mathrm{H}_{2} \mathrm{O}$ with $\mathrm{H}_{2}(\mathrm{OEP})$ in TCB for $20 \mathrm{~h}$. [Ce(OEP $\left.)_{2}\right],\left[\mathrm{Ce}_{2}(\mathrm{OEP})_{3}\right]$, and $\left[\mathrm{Ce}_{2}(\mathrm{OEP})_{3}\right] \cdot 2 \mathrm{TCB}$ were isolated by chromatography on an alumina column and eluted with toluene and methanol. The authors mentioned that two intermediates [Ce(OEP)(acac)] and $\left[\mathrm{CeH}(\mathrm{OEP})_{2}\right]$ were formed, and they hypothesized that two pathways were responsible for the production of the final products: (i) condensation, [Ce(OEP)acac] losing $\mathrm{H}$ (acac), and (ii) autooxidation, $\left[\left(\mathrm{CeH}(\mathrm{OEP})_{2}\right]\right.$ being oxidized into $\left[\mathrm{Ce}(\mathrm{OEP})_{2}\right]$. In 1992, Jiang et al. ${ }^{156}$ reported the synthesis of another series of lanthanide-porphyrin sandwich complexes: bis(tetrapyridylporphyrinato)cerium(Iv), [Ce(tptp) $\left.)_{2}\right]$, and bis(tetramethylpyridylporphyrinato)cerium(Iv), [Ce(tmpyp) $)_{2}$. They used $\mathrm{Li}_{2} \mathrm{~T}$ PyP and $\mathrm{Li}_{2}$ TMPyP obtained by the reaction between porphyrins and $n$-butyllithium to improve reactivity and solubility. In the following years, although other porphyrin/phthalocyanine-based homoleptic/heteroleptic complexes have been prepared, ${ }^{157,158}$ Chabach et al. were the pioneers in studying trivalent central metal ions in this context. They reported porphyrin-phthalocyanine sandwich-type complexes $(\mathrm{Ln}=\mathrm{La}$, Pr, Nd, Eu, Gd, Er, Lu, and Y), ${ }^{159}$ as well as mixed-metal tripledecker complexes with the porphyrin-phthalocyanine-porphyrin system. ${ }^{160}$ The smaller lanthanide ions (Er, Lu) were found to form double deckers with phthalocyanines more easily than the larger counterparts; ${ }^{159}$ their acetylacetonate salts were reacted with di-lithium phthalocyanine $\left(\mathrm{Li}_{2} \mathrm{Pc}\right)$ in boiling TCB for $3 \mathrm{~h}$ and then tetraphenylporphyrin was added. By contrast, the larger lanthanide ions (La-Gd) were heated first with $\mathrm{H}_{2}$ TPP in TCB for $4 \mathrm{~h}$ and then with $\mathrm{Li}_{2} \mathrm{Pc}$, since they coordinated more readily to porphyrin to form more stable sandwich complexes. The yields of neutral heteroleptic complexes with smaller lanthanide ions were around $85 \%$, while those for the larger ions were in the range of $36-56 \%$. All double deckers were neutral, except the one with $\mathrm{La}^{\mathrm{III}}$ which was first isolated in its protonated form, requiring further oxidation by phenoxathiinylium hexachloroantimonate into the neutral form. The first preparation of heteronuclear triple-decker complexes was achieved by the same research group: they reacted the metal acetylacetonate with metal-free porphyrin in refluxing TCB and then with the as-synthesized heteroleptic sandwich complexes. However, during the preparation of homonuclear porphyrin/phthalocyanine-based homoleptic/ heteroleptic triple-decker complexes, $\mathrm{Ng}$ et $a .^{161}$ mentioned 

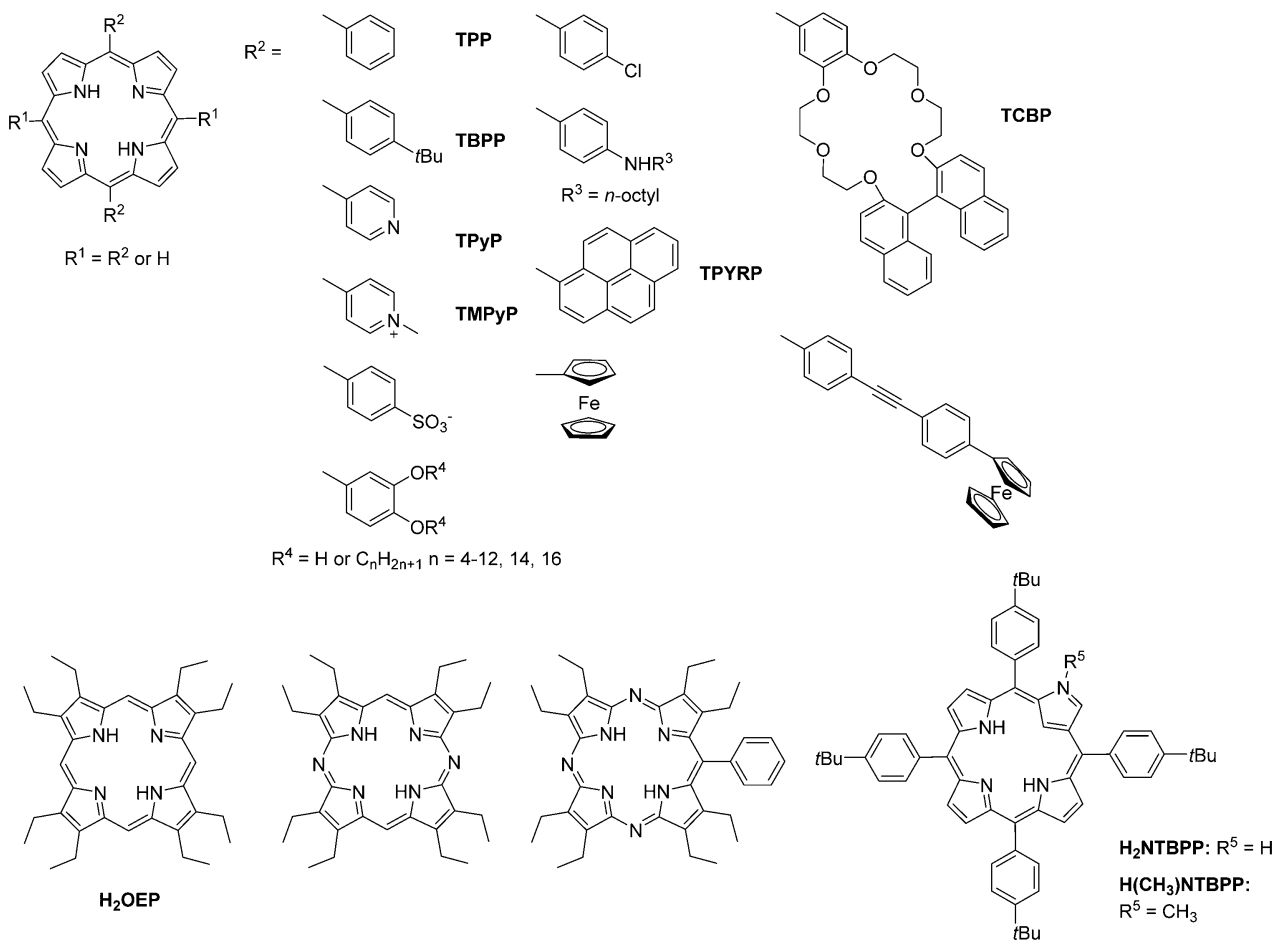

Fig. 27 Examples of functionalized porphyrins (top), of modification of $\mathrm{H}_{2} \mathrm{OEP}$ (bottom left and middle) and of $\mathrm{N}$-confused porphyrins (bottom right) used in constructing homoleptic/heteroleptic multiple-decker lanthanide complexes.

that $[\mathrm{Ln}(\mathrm{Pc}) \mathrm{TPP}](\mathrm{Ln}=\mathrm{Er}, \mathrm{Lu}$, and $\mathrm{Y})$ were the sole products, and triple deckers can only be obtained if 5,10,15,20-tetrakis(4methoxyphenyl)porphyrin ( $\left.\mathrm{H}_{2} \mathrm{TMPP}\right)$ was used instead of $\mathrm{H}_{2} \mathrm{TPP}$, yielding $\left[\mathrm{Ln}_{2}(\mathrm{Pc})_{2}(\mathrm{TMPP})\right]$. Many other porphyrin derivatives were also tested using similar synthetic procedures. For instance, the Shinkai group ${ }^{162}$ studied $\mathrm{Ce}^{\mathrm{IV}}$-based doubledeckers with tetrakis(4-pyridyl)porphyrin derivatives; the Ohta group $^{163}$ investigated $\mathrm{Ce}^{\mathrm{IV}}$-based triple-decker complexes containing tetraalkoxylated terphenyl groups at the 5,15-positions of their parent porphyrin; the Lindsey group ${ }^{164}$ prepared two dyads by applying Sonogashira and Glaser coupling reactions on $\mathrm{Eu}^{\mathrm{III}}$ triple-deckers.

The usage of DBU in the preparation of sandwich-like lanthanide(III) complexes was reported in $1997 .{ }^{165}$ However, $\mathrm{Ng}$ 's group only treated the corresponding phthalonitriles with $\mathrm{Ln}(\mathrm{acac})_{3} \cdot n \mathrm{H}_{2} \mathrm{O}$ and $\mathrm{DBU}$ in amyl alcohol and obtained bis(phthalocyaninato)lanthanide(III) complexes, not porphyrinato complexes. The same group reported the one-pot preparation of [ $\mathrm{Ln}(\mathrm{Nc})$ (TBPor) $]$ complexes ( $\mathrm{Ln}=\mathrm{La}, \mathrm{Pr}, \mathrm{Nd}, \mathrm{Sm}, \mathrm{Eu}, \mathrm{Gd}$, Tb, Dy, Y, Ho, Er, Tm; Nc = 2,3-naphthalocyanine; TBPor = 5,10,15,20-tetrakis(4-tert-butylphenyl)porphyrin, Scheme 1) by using DBU and $n$-octanol, ${ }^{166}$ and avoided the prior generation of the half-sandwich complexes [Ln(TBPor)(acac)] as in the conventional methods. Although the products $\left[\mathrm{Eu}\left[\mathrm{Nc}(t-\mathrm{Bu})_{4}\right]_{2}\right]$ and $\left[\mathrm{Eu}\left[\mathrm{Nc}\left(\mathrm{SC}_{12} \mathrm{H}_{25}\right)_{8}\right]_{2}\right]$ were unambiguously characterized by various methods, they contained traces of impurities that could not be removed by gel-permeation chromatography and recrystallization. They also further synthesized the first Nc-containing heteroleptic triple-decker complexes $\left[\mathrm{Ln}_{2}(\mathrm{Nc})(\mathrm{OEP})_{2}\right](\mathrm{Ln}=\mathrm{Nd}$,
Eu) based on similar procedures. ${ }^{167}$ Again, the synthetic yields varied depending on the size of the lanthanide ion: complexes with smaller metal centres have increasing steric compression of the two macrocyclic ligands. Similar observations and explanations were also reported in previous researches. ${ }^{168,169}$ Microwave irradiation was tested to accelerate the reaction: Liu et $a{ }^{170}$ provided a successful example in forming the [Lu(TBPor)Pc] double-decker in which all ligands and complexes were prepared in a microwave oven (240-560 W, 5-10 min) and the purification was performed via conventional column chromatography. Microwave-assisted synthesis is still a commonly used method: Jin et al. used microwave irradiation to overcome the low reactivity resulting from the steric hindrance from bulky peripheral groups of the lanthanide porphyrin-bis(phthalocyanine) triple-deckers. ${ }^{171}$

In 2014, Dumoulin's group studied and reported an expeditious one-step method to secure functionalized heteroleptic "A7B-type" lanthanide-phthalocyanine double-decker complexes via an optimized statistical method by changing the ratio of two different phthalonitriles (A = with hexylsulfanyl substitution; B = with long alkyl chains bearing polar $\mathrm{OH}$, OMs and $\mathrm{N}_{3}$ tails). ${ }^{172}$

Once the standard procedures for preparing $\mathrm{Ln}^{\mathrm{III} / \mathrm{IV}}$-based multiple-deckers had been well established, researchers started to pay more attention to modifying the sidechains of the macrocycles and investigating their potential applications. ${ }^{173-176}$ Ohta et $a{ }^{163,177}$ reported a series of phenyl-substituted porphyrins coordinating with $\mathrm{Ce}^{\mathrm{IV}}$ and forming multiple deckers with long alkoxy sidechains; they emphasized that the chain length did not 
affect the reactivity. However, a longer reaction time gave improved yields, and the complexation time was usually longer when reacting with tetra-phenyl porphyrins than with bi-phenyl porphyrins because of steric hindrance. Also, as mentioned previously, ${ }^{164}$ Lindsey's group continued exploring more lanthanide triple-deckers including $S$-acetylthiomethyl groups ${ }^{178}$ or triallyl tripods ${ }^{179}$ incorporated on the porphyrinic moiety, while complexation procedures were still operated classically. It is worth noting that these examples ${ }^{164,178,180}$ proved that a coupling reaction could occur on the substituted phenyl groups of porphyrins without disrupting the as-formed double-decker structures. Besides, similar dyads (or triads) could also be formed in good yields by direct cross-condensation through an ester linkage between the metal-free 5-(4-acylchloride-phenyl)-10,15,20-tris(4tert-butylphenyl)porphyrin and protonated $\mathrm{Y}^{\mathrm{III}}$ double-deckers (Fig. 28). ${ }^{181}$

In order to explore more functionalities, other series of porphyrin derivatives were designed with sophisticated substituents at the interconnecting $\alpha$-carbon. For example, porphyrins with four pyrenyl groups in the meso-positions were used to form $\mathrm{Eu}^{\mathrm{III}}$ multiple-decker complexes. ${ }^{182}$ Heteroleptic porphyrinate $\left[\operatorname{Ln}_{2}(\mathrm{Pc})_{2}(\mathrm{TCBP})\right]$ (TCBP = meso-tetrakis[3,4-(11,12, 13,14-di(1', $2^{\prime}$-naphtho)-1,4,7,10,15,18-hexaoxacycloeicosa-2,11,13triene)-phenyl]porphyrin, Fig. 27) featuring nonlinear optical activity were also prepared, ${ }^{183}$ where the $\alpha$-carbon is derivatised with crown ether substituents. In heteroleptic porphyrin-containing multiple-decker complexes, it is common that one macrocycle is a crown-phthalocyanine instead of a porphyrin derivatised with crown ethers. ${ }^{184,185}$ As an alternative to coupling reactions for incorporating ferrocene onto a porphyrin ring through phenyl-ethynyl-phenyl links, ${ }^{180}$ ferrocenyl units can be directly attached to the $\alpha$-carbon during the preparation of metal-free porphyrins (Fig. 27), ${ }^{186}$ and previously described experimental conditions can be applied for lanthanide complexation.

Finally, efforts have been put in the synthesis and characterization of homoleptic 5,15-diazaporphyrinato lanthanide sandwich complexes $\left[\mathrm{Ln}_{2} \mathrm{DAB}_{3}\right]$ (DAB $=2,8,12,18$-tetraethyl3,7,13,17-tetramethyl-5,15-diazaporphyrinate, Scheme 1; Ln = $\mathrm{Ce}, \mathrm{Eu}){ }^{187}$ The metal-free diazaporphyrin was simply reacted with $\left[\mathrm{Ln}(\mathrm{acac})_{3} \cdot \mathrm{H}_{2} \mathrm{O}\right]$ in refluxing TCB, yielding the desired triple-decker in a one-pot synthesis. Other complexes with diazaporphyrin were isolated by Pushkarev et al.: mixing of 27-phenyl-29H,31 $H$-tetrabenzo[ $b, g, l, q][5,10,15]$-triazaporphyrin $\left(\mathrm{H}_{2}{ }^{\mathrm{Ph}}\right.$ TBTAP, Scheme 1) with $\mathrm{Ln}(\mathrm{OAc})_{3}$ or $\operatorname{Ln}(\text { acac })_{3}$ to afford the monoporphyrinate and the homoleptic double-deckers $\left[\mathrm{Ln}\left({ }^{\mathrm{Ph}}\right.\right.$ TBTAP $\left.) A c\right]$ and $\left[\mathrm{Ln}\left({ }^{\mathrm{Ph}} \mathrm{TBTAP}\right)_{2}\right]$, respectively $(\mathrm{Ln}=\mathrm{Eu}$, $\mathrm{Lu})$. Heteroleptic double-decker compounds [Ln( $\left.\left({ }^{\mathrm{Ph}} \mathrm{TBTAP}\right) \mathrm{Pc}\right]$ were obtained upon the interaction of $\mathrm{H}_{2}{ }^{\mathrm{Ph}}$ TBTAP with the corresponding monoporphyrinates. ${ }^{188}$ Unexpected formation of partially and completely de-phenylated side products was observed for both the monoporphyrinates and the double

(A)

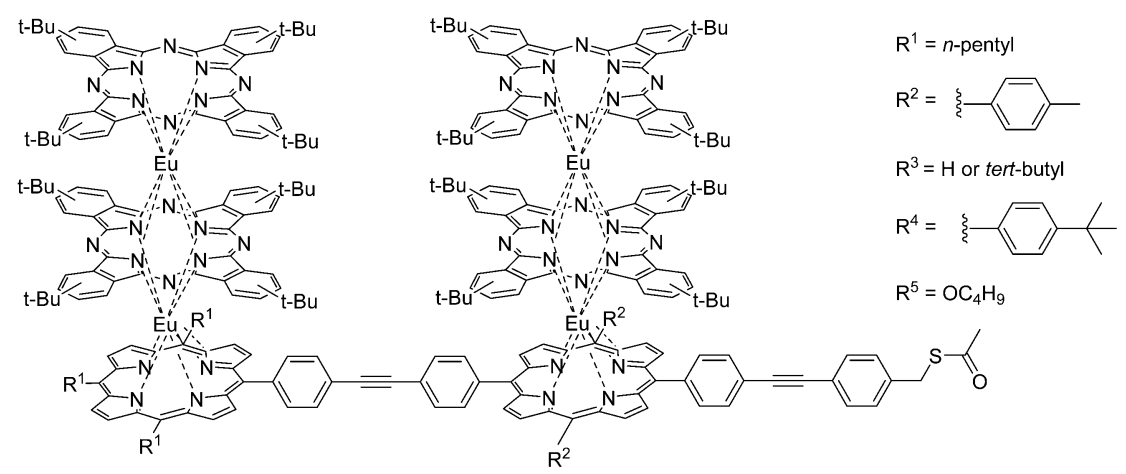

(B)

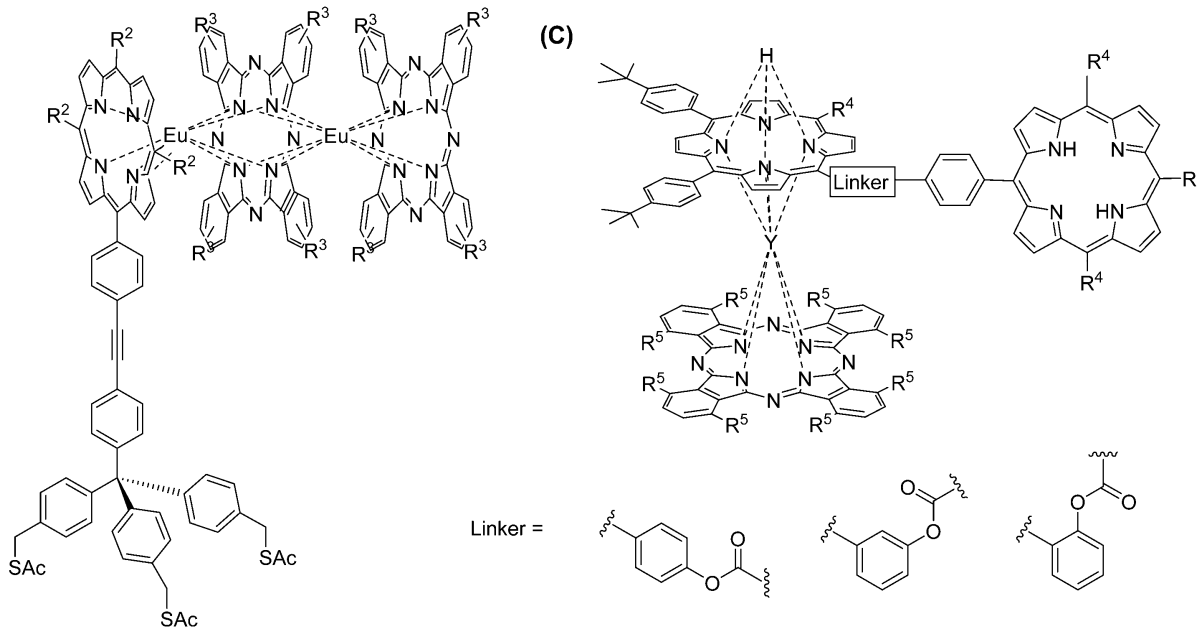

Fig. 28 Examples of multiple-decker lanthanide porphyrinates with additional covalent attachments. Redrawn from ref. 178,179 and 181. 

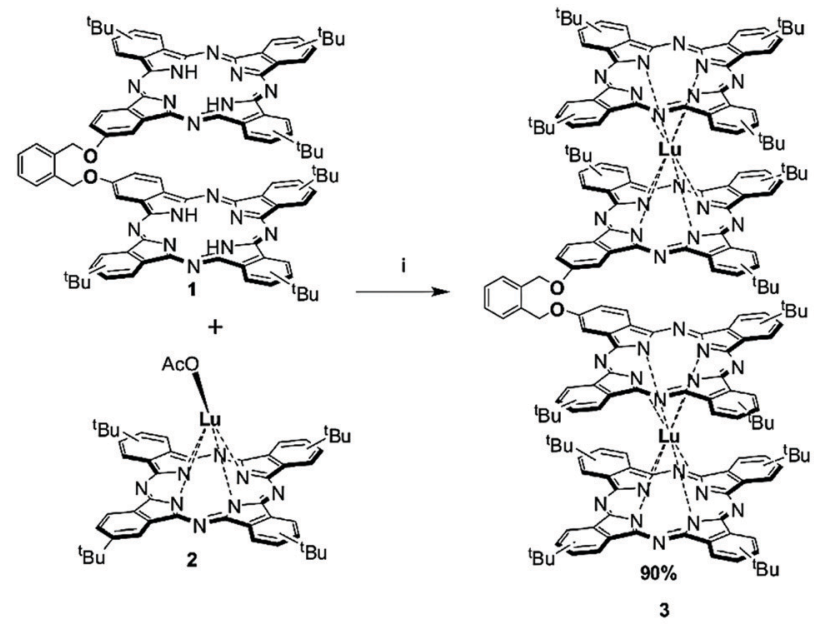

i: MeOLi, TCB/C ${ }_{16} \mathrm{H}_{33} \mathrm{OH}, 215^{\circ} \mathrm{C}$
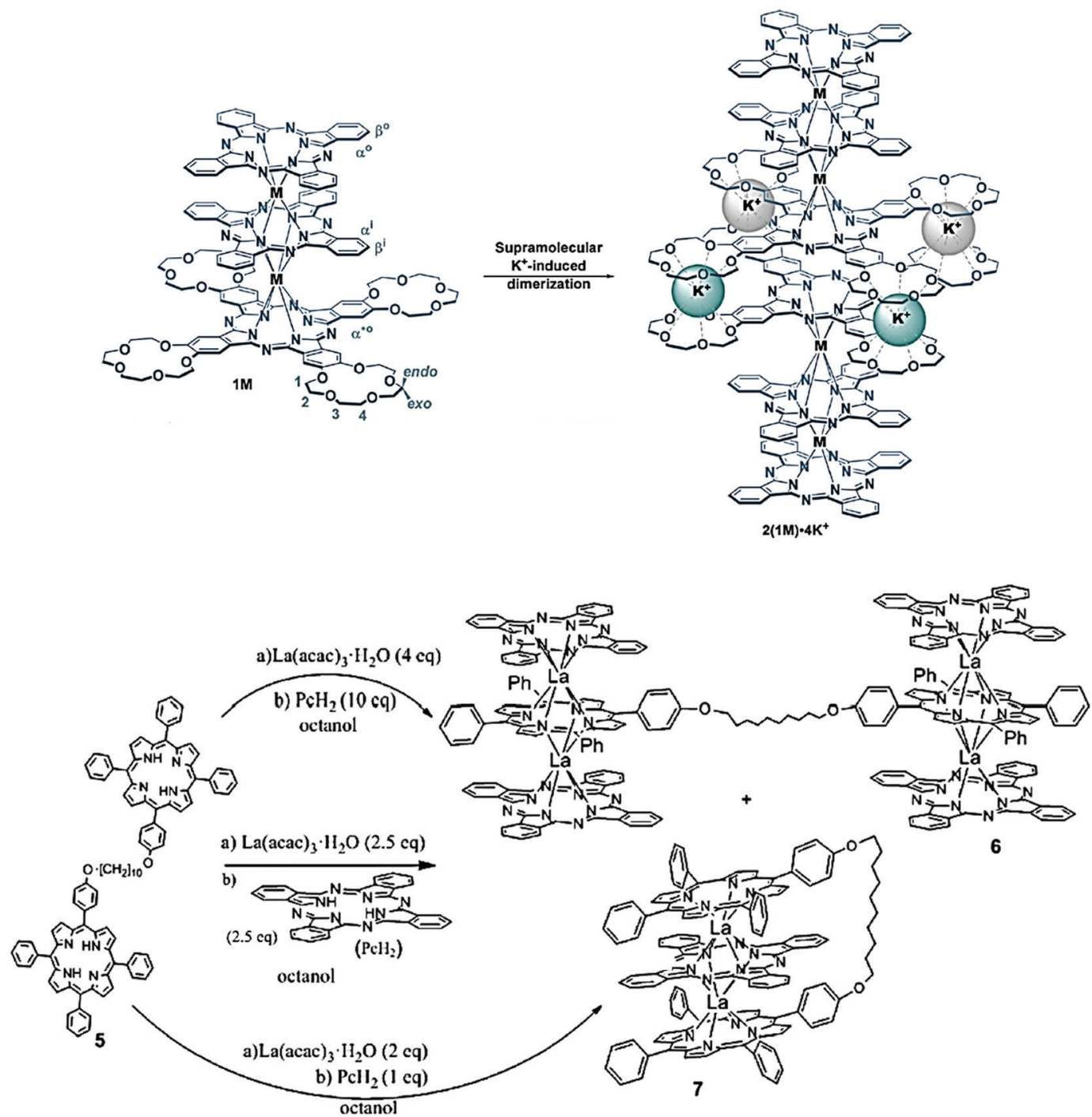

Fig. 29 Synthetic schemes for (top) clamshell-type quadruple-decker dinuclear lanthanide phthalocyaninates. Reprinted with permission from ref. 25, (C) 2018 Elsevier B.V.; (middle) self-assembled heteroleptic lanthanide crown-phthalocyaninates induced by potassium. Reprinted with permission from ref. 193, (C) 2020 The American Chemical Society; and (bottom) bigger clamshell-type heteroleptic lanthanide porphyrin-phthalocyanine-porphyrin triple decker. Reprinted with permission from ref. 194, copyright (2020) Wiley-VCH Verlag GmbH \& Co. KGaA. 
deckers. A triple-decker $\left[\mathrm{Eu}_{2}\left({ }^{\mathrm{Ph}} \mathrm{TBTAP}\right)_{3}\right]$ was also isolated with a very low yield of $4 \%$.

$\mathrm{N}$-Confused porphyrins were similarly tested for synthesizing lanthanide double-deckers. The first example came from the reaction between $\mathrm{H}_{2} \mathrm{NTBPP}$ (N-confused 5,10,15,20tetrakis[(4-tert-butyl)phenyl]porphyrin, Fig. 27) or its N2position methylated analogue $\mathrm{H}\left(\mathrm{CH}_{3}\right) \mathrm{NTBPP}$ (Fig. 27) and half-sandwich complexes $\left[\mathrm{Ln}^{\mathrm{III}}(\mathrm{Pc})(\mathrm{acac})\right]{ }^{189}$ With more comprehensive studies on lanthanide-porphyrin multiple-decker complexes progressing, it is also promising to modify the pyrrole units. Birin et al. ${ }^{190}$ demonstrated a new family of multiple-decker complexes bearing heterocycle-appended porphyrins.

Tetra-15-crown-5-phthalocyanines afforded a wide range of lanthanide mono-, double- and triple-decker homoleptic/heteroleptic complexes and pose long-standing synthetic challenges. Tsivadze et al. systematically screened different reaction conditions (e.g. solvent, reagent ratio, concentration and refluxing duration) and discovered that (i) monophthalocyaninato lanthanide complexes could be synthesized quantitatively in $o$-dichlorobenzene for some of the smaller lanthanides (i.e., $\mathrm{Sm}, \mathrm{Eu}, \mathrm{Gd}, \mathrm{Tb}, \mathrm{Yb}, \mathrm{Lu}$ ), the organic base used, like DBU, being then always coordinated as the axial ligand; (ii) 1-chloronaphthalene was the best solvent to obtain the double/triple-sandwich complexes (except for La and Nd). ${ }^{191}$ The remaining synthetic enigma with Er was finally resolved by changing the solvent and temperature, as well as via either direct metalation or metal-templated strategies. ${ }^{192}$

For more structurally novel multiple phthalocyaninato lanthanide complexes, Tomilova et al. documented the direct preparation of clamshell-type quadruple-decker dinuclear lanthanide phthalocyaninates by reacting their bisphthalocyanine-type clamshell ligand and $\mathrm{Lu}^{\mathrm{III}}$ monophthalocyaninate at $215{ }^{\circ} \mathrm{C}$, in the mixed $\mathrm{TCB} / \mathrm{C}_{16} \mathrm{H}_{33} \mathrm{OH}$ solvent and in the presence of the LiOMe base (Fig. 29, top) ${ }^{25}$ In 2020, Martynov et al. reported potassium-induced dimerization of heteroleptic triple-decker crown-phthalocyaninates $\left[(15 \mathrm{C} 5)_{4} \mathrm{Pc}\right] \operatorname{Ln}(\mathrm{Pc}) \operatorname{Ln}(\mathrm{Pc})$ $(\mathrm{Ln}=\mathrm{Y}$, Tb; Fig. 29 , middle $) .{ }^{193}$ Cammidge's group disclosed a facile and controlled synthetic protocol for bridged and clamshell-type heteroleptic lanthanide porphyrin-phthalocyanine-porphyrin triple-decker assemblies, where the two porphyrins are conjugated with a flexible carbon-chain spacer (Fig. 29, bottom). ${ }^{194}$ Generally speaking, column chromatography is a common technique for purification of multiple-decker metalloporphyrins, and silica gel columns are suitable to remove unreacted ligands. However, repeated gel permeation chromatography is often applied afterward for better purification.

\subsection{Complexation as oligomers and polymers}

The large coordination numbers of lanthanide ions and the diversity of porphyrin macrocycles provide researchers with the chance of exploring unusual structures of lanthanidecontaining materials. In addition to several classes of materials mentioned in the previous sections, the focus here will be on preparing polynuclear Ln-Por-based molecules, from dimeric ones to framework polymers.
Years after the emerging lanthanide-based double-decker complexes, bridged single-decker complexes with two lanthanide cores were introduced. Jubb and Gambarotta ${ }^{195}$ used alkylderivatized porphyrinogen for nitrogen fixation. The encapsulation of dinitrogen was achieved by firstly mixing $\left[\mathrm{SmCl}_{3}(\mathrm{THF})_{3}\right]$ and $\mathrm{Li}_{4} \mathrm{OEPg}-(\mathrm{THF})_{4}(\mathrm{OEPg}=$ octaethylporphyrinogen) in THF under an argon atmosphere and then reducing the product with metallic lithium, resulting in the precipitation of green crystals. The latter were recrystallized under a nitrogen atmosphere, affording orange-red crystals with formula $\left[\left(\mathrm{THF}_{2} \mathrm{Li}(\mathrm{OEPG}) \mathrm{Sm}^{\mathrm{III}}\right]_{2}\left(\mathrm{~N}_{2} \mathrm{Li}_{4}\right)\right.$. Magnetic measurements confirmed the presence of $\mathrm{Sm}^{\text {III }}$, while the green crystals contained $\mathrm{Sm}^{\mathrm{II}}$; the crystal structure determination showed that the $\mathrm{N}-\mathrm{N}$ distance is very long and compatible with a single bond, i.e. the last reaction step corresponds to a formal reduction of $\mathrm{N}_{2}$ into $\mathrm{N}_{2}{ }^{4-}$. Campazzi et al. later reported two other meso-octaethylporphyrinogen-dinitrogen complexes containing $\operatorname{Pr}^{\mathrm{III}}$ and $\mathrm{Nd}^{\mathrm{III}}$, respectively, ${ }^{196}$ where sodium was used instead of lithium to avoid possible reduction of $\mathrm{N}_{2}$ (Fig. 30A).

The same half-sandwich compounds $\left[\left\{\left(\eta^{5}: \eta^{1}: \eta^{5}: \eta^{1}\right.\right.\right.$ $\left.\left.\left.\mathrm{Et}_{8} \mathrm{~N}_{4}\right) \operatorname{Ln}\right\} \mathrm{Na}(\mathrm{THF})_{2}\right](\mathrm{Ln}=\mathrm{Pr}, \mathrm{Nd})$ were used to establish other types of bridging (Fig. 30B). ${ }^{197}$ When the reaction was carried out with 18-crown-6, fixation of ethylene or acetylene was accomplished and the lanthanide cores were bridged by $\left[\mathrm{C}_{2} \mathrm{H}_{4}\right]^{2-}$ or $\left[\mathrm{C}_{2}\right]^{2-}$ anions. Wong et al. ${ }^{22}$ prepared other types of dinuclear $\mathrm{Ln}^{\mathrm{III}}$ porphyrinates having hydroxide bridging groups (Fig. 30C): $\left[\mathrm{Yb}^{\mathrm{III}}\left(\mathrm{NPh}_{2}\right)_{3} \cdot x\left[\mathrm{LiCl}(\mathrm{THF})_{3}\right]\right.$ was generated from the mixture of $\mathrm{YbCl}_{3}$ and $\mathrm{LiNPh}_{2}$ in THF and then refluxed with $\mathrm{H}_{2}$ TTP or $\mathrm{H}_{2}$ TMPP in bis(2-methoxyethyl) ether, resulting in dinuclear bis(porphyrin) complexes $\left\{\left[\mathrm{Yb}^{\mathrm{III}}(\mathrm{TMPP})(\mu-\mathrm{OH})\right]_{2}\right\}$ and $\left\{\mathrm{Yb}^{\mathrm{III}}(\mathrm{TTP})_{2}(\mu-\mathrm{OH})\left(\mu-\mathrm{OCH}_{2} \mathrm{CH}_{2} \mathrm{OCH}_{3}\right)\right\}$. The purification steps were, in sequence, simple filtration, washing with ether, extraction with toluene, and another filtration. The final products were obtained as purple crystals from concentrated solutions. Although another starting material, $\mathrm{Ln}\left[\mathrm{N}\left(\mathrm{SiMe}_{3}\right)_{2}\right]_{3}$. $x\left[\mathrm{LiCl}(\mathrm{THF})_{3}\right]$, could react with the same metal-free porphyrins and give the cationic $\mathrm{Ln}^{\mathrm{III}}$ monoporphyrinates in high yields, ${ }^{47}$ it could not form the bis(porphyrin) complexes because of the electric charges of the different intermediates. Comprehensive studies on the dimerization of these lanthanide monoporphyrinates, $\left[\mathrm{Yb}(\mathrm{Por})\left(\mathrm{H}_{2} \mathrm{O}\right)_{3}\right] \mathrm{Cl}\left(\mathrm{Por}=\mathrm{TPP}^{2-}\right.$, $\mathrm{TTP}^{2-}$, and $\left.\mathrm{TMPP}^{2-}\right)$, were performed by the same group, and different dimer bridges were formed under different conditions. ${ }^{198}$ TCB is not only widely applied in the preparation of multi-decker complexes, but it is also unexpectedly helps in the formation of the acetatebridged dimer. He et al. documented a facile preparation method for the bridged dinuclear porphyrinates, in which ytterbium(III) acetylacetonate hydrate reacted with free base porphyrins in refluxing TCB (Fig. 30D). ${ }^{75}$ Besides internal bridging between two single-porphyrin complexes, polynuclear complexes were also produced by the direct linking between porphyrin rings through coupling reactions. ${ }^{178,179,199}$

Metal-organic frameworks (MOFs) as one important subclass of coordination polymers ${ }^{200}$ are also drawing much attention in the fields of lanthanide-based materials. Thanks to the large size and high coordination numbers of 
(A)

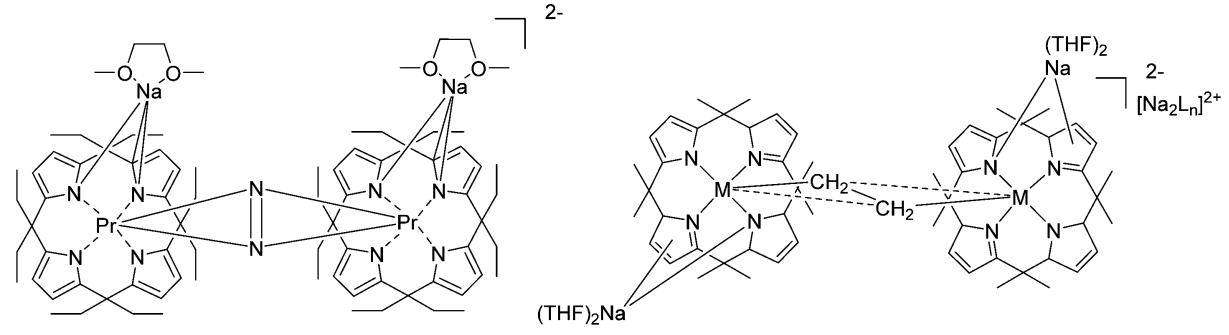

(B)
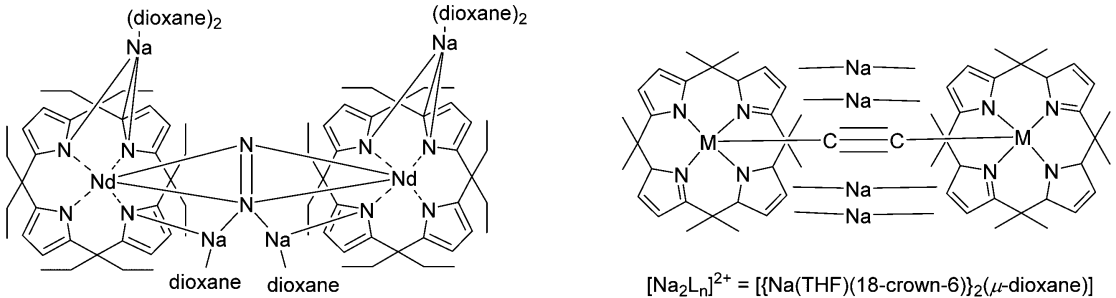

$\left[\mathrm{Na}_{2} \mathrm{~L}_{n}\right]^{2+}=\left[\{\mathrm{Na}(\mathrm{THF})(18-\mathrm{crown}-6)\}_{2}(\mu-\right.$ dioxane $\left.)\right]$

(C)
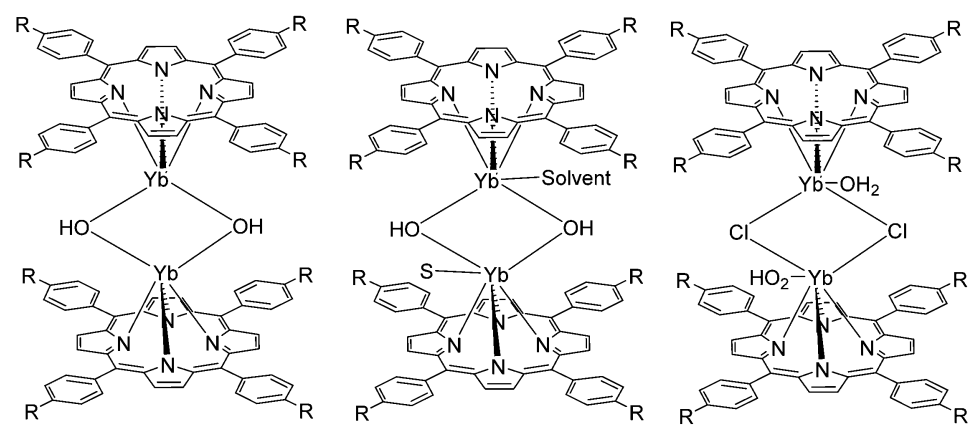

(D)
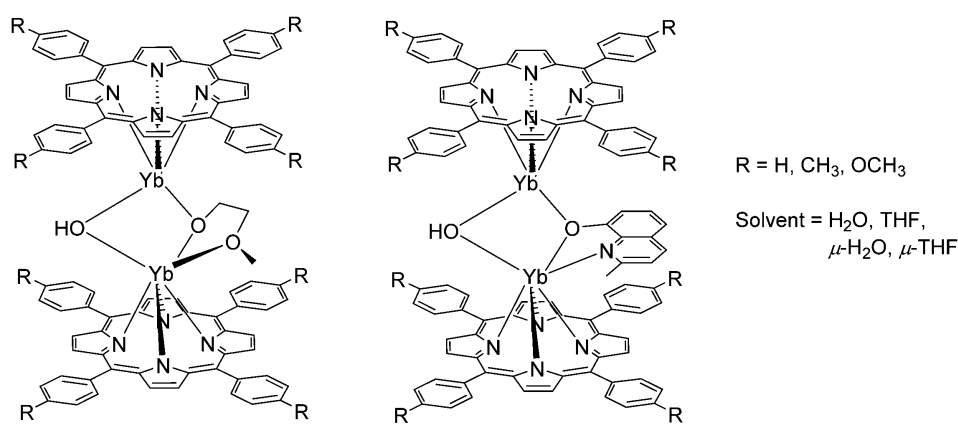

Fig. 30 Examples of bridged lanthanide-porphyrin complexes. Redrawn from ref. 196 (A), ref. 197 (B), ref. 22 (C), and ref. 198 (D).

lanthanides, some researchers prefer using them rather than transition metals in building MOFs despite their lack of directionality. Porphyrins are common building blocks because of their tetradentate functionality and square-planar geometry. Goldberg's group had been putting efforts for years in preparing porphyrin frameworks assembled with the aid of lanthanide-bridging ions: the first example of hybrid architectures was obtained by hydrothermal techniques using free-base tetra(4-carboxyphenyl)porphyrin reacting with $\operatorname{Ln}_{2}$ (oxalate) hydrated salts $\left(\right.$ Ln $=$ Dy, Nd) (Fig. $31 \mathrm{~A}$ and B). ${ }^{201}$ The second group of MOFs containing meso-tetra(carboxyphenyl)porphyrin species and polynuclear acetate/oxalate-bridged clusters was prepared by similar procedures where a dilute $\mathrm{NaOH}$ solution was used to enhance deprotonation of the carboxylic groups and a dilute $\mathrm{HCl}$ solution was provided to increase the reactivity of lanthanide salts (Fig. $31 \mathrm{C}$ and D). ${ }^{202}$ Later, another series of hybrid assemblies were synthesized, which were composed of meso-tetrapyridylporphyrin and various lanthanide complexes. ${ }^{203}$ Carbon dioxide fixation has been realized with a 2D bi-layered MOF consisting of 5,10,15,20-tetrakis(4carboxylatophenyl)porphyrinato-zinc (ZnTCPP) linkers and $\left[\mathrm{Ln}_{2} \mathrm{Na}_{3}\left(\mathrm{NO}_{3}\right)\left(\mathrm{H}_{2} \mathrm{O}\right)_{3}\right]^{8+}$ connecting clusters. ${ }^{204}$ Purification and isolation of the above-mentioned lanthanide-porphyrin polymers were achieved by crystallization where the reaction mixtures were heated and cooled down very slowly. Because of the different compositions of lanthanide-porphyrin MOFs, 
(A)

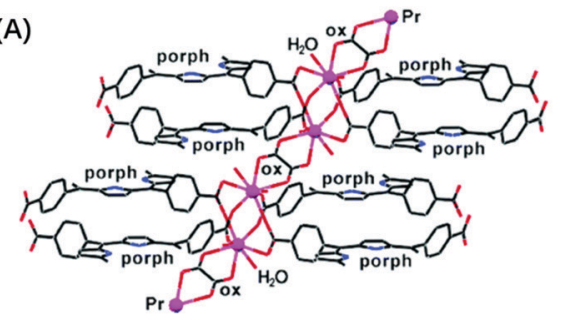

(C)

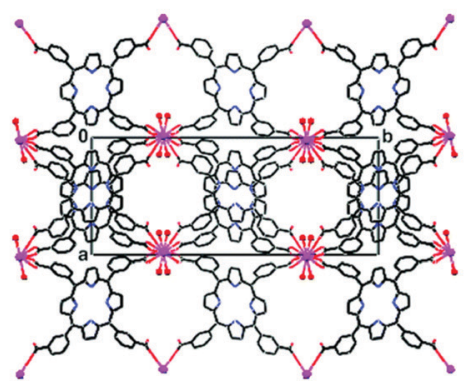

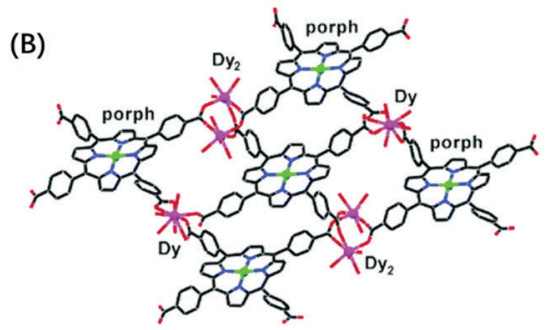

(D)

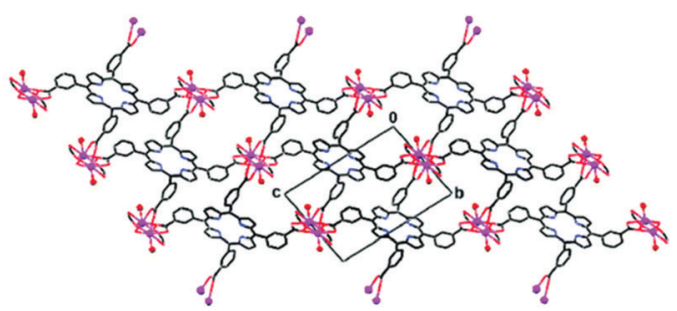

Fig. 31 Examples of MOFs consisting of a Ln-bridged porphyrin layer. (A) 2:1 Pr: ${ }^{\mathrm{R} P o r} ;{ }^{201}$ (B) 4:3 Dy: ${ }^{\mathrm{R}}$ Por $\left({ }^{\mathrm{R}} \mathrm{Por}=\right.$ tetra(4-carboxyphenyl)porphyrin); ${ }^{201}$ (C) $1: 1 \mathrm{La}:{ }^{\mathrm{R}^{\prime}}$ Por; ${ }^{202}$ and (D) $2: 1 \mathrm{Pr}:{ }^{\prime}$ Por $\left(\mathrm{R}^{\prime}\right.$ Por $=$ tetra(m-carboxyphenyl)porphyrin) ${ }^{202}$ Reproduced with permission from ref. 201 and 202, copyright (2006 and 2007) The American Chemical Society.

solvothermal methods used various solvents, water ${ }^{205-208}$ or organic solvents, ${ }^{203,204,209,210}$ as well as different reaction times and temperatures. Unfortunately, most lanthanide-based MOFs did not take advantage of the special spectroscopic properties of lanthanides, and the choice of lanthanides was not really targeted for a given property, but because most of these ions have similar size and coordination numbers.

In addition to serving as structural clusters in the formation of MOFs, lanthanide ions can also play the role of core in porphyrin dendrons (Fig. 32). Several kinds of metalloporphyrin-containing $\mathrm{Er}^{\mathrm{III}}$-cored complexes are known. ${ }^{211,212}$ In these complexes, the porphyrins were first coordinated with other metals $\left(\mathrm{Pt}^{\mathrm{II}} / \mathrm{Zn}^{\mathrm{II}}\right)$, and then the core $\mathrm{Er}^{\mathrm{III}}$ ion was coordinated by carboxyl groups from the porphyrin sidechains and by terpyridine. This novel synthetic method implies using a strong base, potassium hydride, for deprotonating the ligands, then followed by the addition of $\mathrm{ErCl}_{3}$. A dipicolinic acid (dpa) framework was also used to coordinate to a $\mathrm{Ln}^{\mathrm{III}}$ core. $^{213}$ The lanthanide complexation was easily achieved in $\mathrm{H}_{2} \mathrm{O} / \mathrm{THF}$ in which the corresponding salts were mixed with chlorin to form $\left[\mathrm{Ln}(\mathrm{dpa})_{2} \mathrm{ChlPd}\right]^{3-}(\mathrm{Chl}=$ chlorin $)$.

Lastly, some works focused on blending lanthanide-porphyrin complexes into conjugated or nonconjugated polymer hosts such as polystyrene, poly(methyl methacrylate), poly( $n$-butyl methacrylate), poly(bisphenol A-carbonate), poly(arylene-ethynylene), polytertbutylmethacrylate, and methylcellulose with routine fabrication methods. ${ }^{214-216}$ The lanthanide-porphyrin complexes used there were common and easy to prepare.

\section{Redox properties}

The extended $\pi$ systems of metallo-porphyrinates and phthalocyaninates result in a rich redox chemistry itself generating fascinating electronic and spectroscopic properties. Indeed, the macrocyclic ligands can be easily oxidized or reduced and their electrical status, negatively charged, neutral, or positively charged, can be tuned, creating different electronic states and consequently largely different absorption spectra and colours. Electronic interactions between tetrapyrrole $\pi$-systems in close proximity play an essential role in photosynthetic bacteria, such as cyanobacteria, or in molecular organic conductors. Complexes with lanthanides are appealing models for understanding their redox and electrochromic properties. A good example is the historical $\left[\mathrm{Lu}\left(\mathrm{Pc}_{2}\right]\right.$ double-decker coordination compound synthesized more than 50 years ago by Kirin et al. ${ }^{19}$ and which, according to EPR studies, could be formulated as $\left[\mathrm{Lu}(\mathrm{Pc})\left(\mathrm{Pc}^{\bullet-}\right)\right]$ since (i) the EPR spectrum displays a sharp signal at $g=2.0022^{217}$ (Fig. 33) and (ii) the magnetic susceptibility follows a Curie-Weiss behaviour with $\mu_{\text {eff }}=1.76 \mathrm{BM}$, typical of a one-electron radical. ${ }^{218}$ In fact, modern analysis reveals that the unpaired electron is significantly delocalized on the two rings. Moreover, various forms of the complex exist depending on the oxidation state and have different colours, as usually determined on Langmuir-Blodgett (LB) films since there is enough space in the LB channels to facilitate charge-compensating ion transport during oxidation or reduction. For instance, oxidation of the green, paramagnetic $\left[\mathrm{Lu}(\mathrm{Pc})_{2}\right]$ yields first a redbrown and diamagnetic form, $\left[\mathrm{Lu}(\mathrm{Pc})_{2}\right]^{+}$, then a red and diamagnetic compound $\left[\mathrm{Lu}(\mathrm{Pc})_{2}\right]^{2+}$. Reduction steps switch the green paramagnetic form $\left[\mathrm{Lu}(\mathrm{Pc})_{2}\right]$ into a blue diamagnetic form $\left[\mathrm{Lu}(\mathrm{Pc})_{2}\right]^{-}$and finally into a blue-violet and paramagnetic compound $\left[\mathrm{Lu}(\mathrm{Pc})_{2}\right]^{2-}$. The complexes are sometimes written as their protonated forms, ${ }^{219}\left[\mathrm{Lu}(\mathrm{Pc})_{2} \mathrm{H}\right]^{2+}$ (yellow-red), $\left[\mathrm{Lu}(\mathrm{Pc})_{2} \mathrm{H}\right]^{+}$(green), $\left[\mathrm{Lu}(\mathrm{Pc})_{2} \mathrm{H}\right]$ (blue), and $\left[\mathrm{Lu}(\mathrm{Pc})_{2} \mathrm{H}\right]^{-}$(violet). The redox properties of complexes with tetrapyrrole macrocycles can be exploited in electrochromic devices (ECDs) such 
(A)
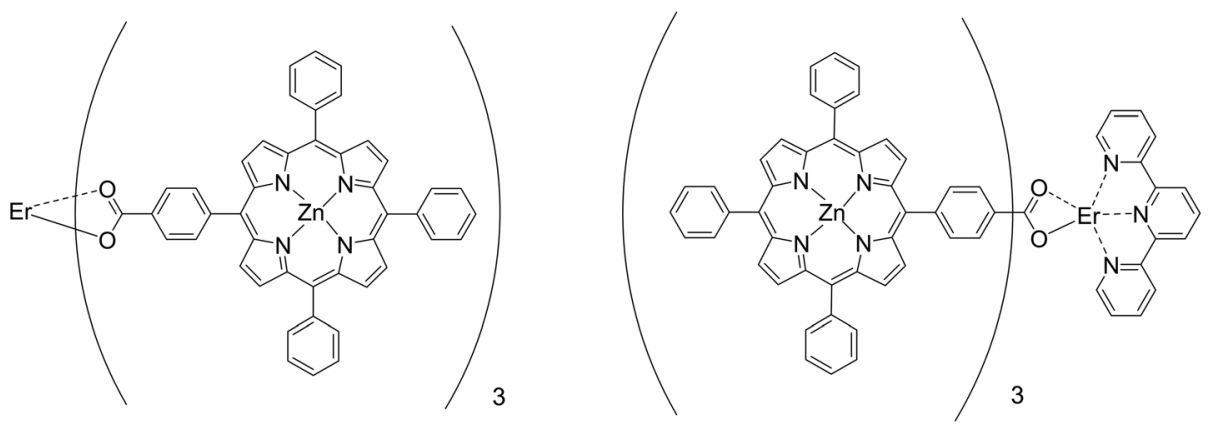

$\mathrm{Er}^{3+}-(\mathrm{Zn}-\text { por } 1)_{3}$

$\mathrm{Er}^{3+}-(\mathrm{Zn} \text {-por 1) })_{3}$ (terpy)

(B)

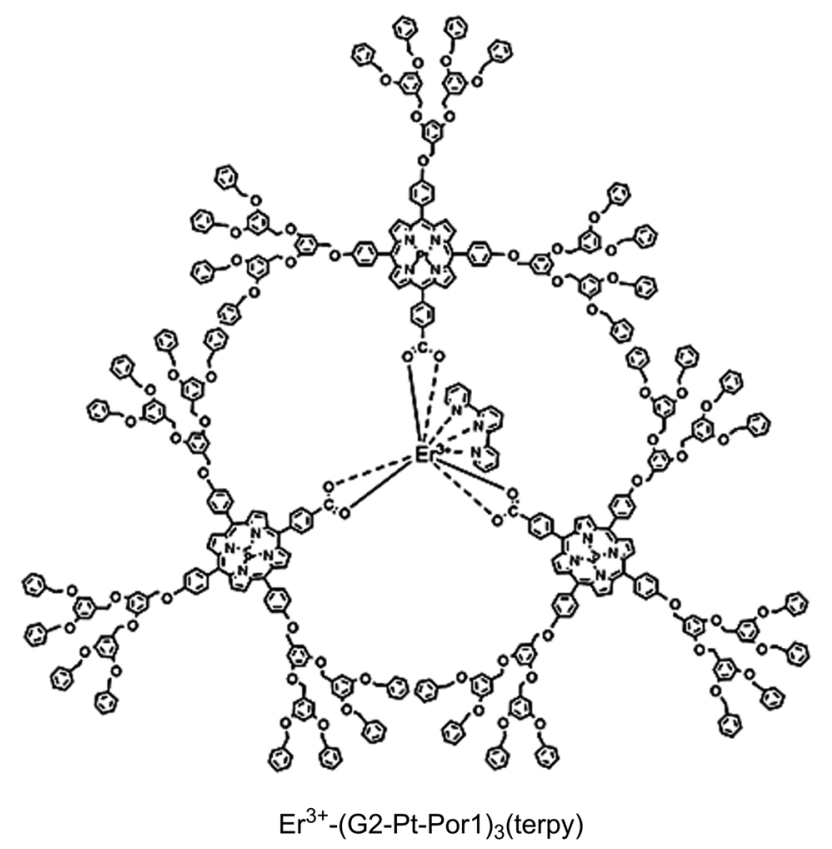

(C)

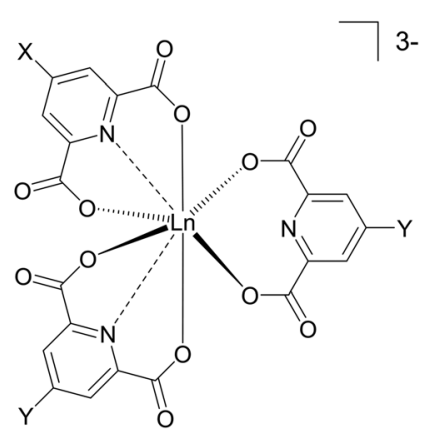

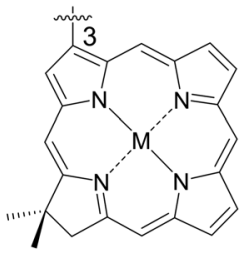

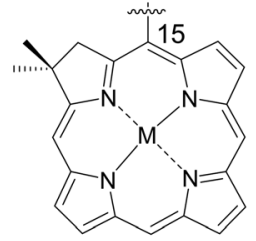

Homoleptic complexes:

$\mathrm{M}=\mathrm{Pd},\left[\mathrm{Ln}\left(\mathrm{Chl}^{3} \mathrm{Pd}\right)_{3}\right]^{3-}$

$\mathrm{M}=2 \mathrm{H},\left[\mathrm{Ln}\left(\mathrm{Chl}^{3} \mathrm{FB}\right)_{3}\right]^{3-}$

Heteroleptic complex:

$\mathrm{Y}=\mathrm{H}, \mathrm{X}=\mathrm{Chl}^{3} \mathrm{Pd}$,

$\left[\mathrm{Ln}(\mathrm{dpa}) 2 \mathrm{Chl}^{3} \mathrm{Pd}\right]^{3-}$

Homoleptic complexes:

$\mathrm{M}=\mathrm{Pd},\left[\mathrm{Ln}\left(\mathrm{Chl}^{15} \mathrm{Pd}\right)_{3}\right]^{3-}$

$\mathrm{M}=2 \mathrm{H},\left[\mathrm{Yb}\left(\mathrm{ChI}{ }^{15} \mathrm{FB}\right)_{3}\right]^{3-}$

Heteroleptic complexes:

$\mathrm{Y}=\mathrm{H}, \mathrm{X}=\mathbf{C h} \mathbf{l}^{15} \mathbf{P d}$,

[Ln(dpa) $\left.{ }_{2} \mathrm{ChI}^{15} \mathrm{Pd}\right]^{3-}$

$\mathrm{Y}=\mathrm{H}, \mathrm{X}=\mathrm{Chl}^{15} \mathrm{FB}$,

[Ln(dpa) $\left.{ }_{2} \mathrm{ChI}^{15} \mathrm{FB}\right]^{3-}$

Fig. 32 Examples of lanthanide-cored supramolecular complexes. (A) Redrawn from ref. 211; (B) reproduced with permission from ref. 212, copyright (2005) Elsevier B.V.; (C) redrawn from ref. 213. 


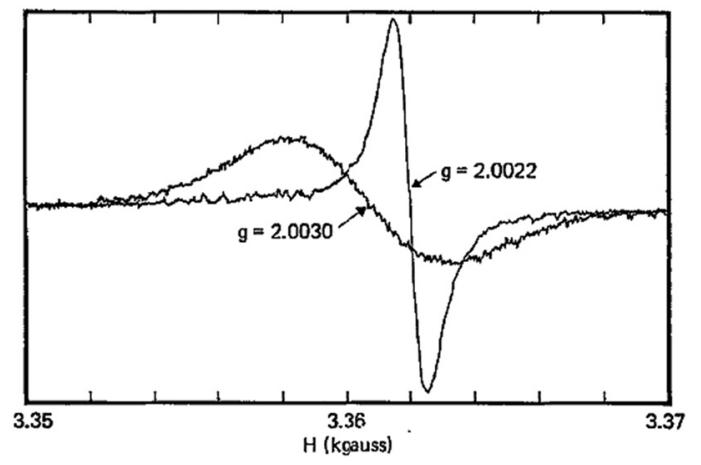

Fig. $33 \mathrm{X}$-Band EPR spectra of $\left[\mathrm{Lu}(\mathrm{PC})_{2}\right]$ (green, $g=2.0022$ ) and $\left[\mathrm{Lu}(\mathrm{PC})_{2}\right]^{2-}$ (violet, $g=2.0030$ ) at room temperature (power: $5 \mathrm{~mW}$, modulation: $0.63 \mathrm{G}$, gain: $2.5 \times 10^{5}$ ). Reproduced with permission from ref. 217, copyright (1979) The Electrochemical Society.

as rear-view mirrors, fitted in millions of cars, adjustable darkening windows in aircrafts, and displays; regarding the latter, organic liquid crystals are serious rivals but ECDs may be interesting for larger screens. ${ }^{220}$ Moreover, since the redox process is fairly reversible and can be cycled many times without altering the ECD component, another application is in molecular data storage. ${ }^{178}$ Finally, $\left[\mathrm{Lu}(\mathrm{Pc})_{2}\right]$ behaves as an intrinsic molecular semiconductor and features high carrier mobility, making it a potential candidate for the design of fieldeffect transistors. $^{221}$

In the following, we describe first the basic redox properties of lanthanide phthalocyaninates and some of the porphyrinates before giving a few hints on potential applications. It is noteworthy that investigations usually involve electrochemical studies coupled with absorption spectroscopy and magnetic measurements.

\subsection{Mixed-ligand monophthalocyanine lanthanide complexes}

In mono-phthalocyaninate complexes $[\operatorname{Ln}(\mathrm{Pc})(\mathrm{acac})]$ and $\left[\mathrm{Ln}(\mathrm{Pc})(\mathrm{acac})_{2}\right]^{-}$, one oxidation and two reduction processes are seen; the half-wave potentials of oxidation and of the first reduction are quasi-insensitive to the nature of the Ln ion, while that of the second reduction step increases with increasing charge density on the metal ion. ${ }^{22}$ A study of similar complexes with other $\beta$-diketonate ancillary ligands confirms, by EPR measurements, the radical nature of the macrocycle and the various redox steps have been characterized by electronic absorption spectroscopy. ${ }^{223}$

\subsection{Homoleptic phthalocyaninato lanthanide sandwich complexes}

Most of the reported works have focused on the redox properties of $\left[\mathrm{Ln}(\mathrm{Pc})_{2}\right]$ double deckers, with main emphasis on seeking to determine how the nature of the lanthanide ion as well as that of the substituents on the periphery of the Pc framework influence the values of the redox potentials. The state of the sample - solid, thin film, or solution - and the exact experimental conditions, including the $\mathrm{pH}$, also play important roles. It is worth noting that the purity of the final sample, which may depend on the synthetic method used, is crucial in such studies.

Regarding the influence of the nature of the lanthanide ion on redox potentials, initial cyclic voltammetry studies in the 1980s reported variable results. For instance, the electrochemical properties of $\left[\mathrm{Ln}(\mathrm{Pc})_{2} \mathrm{H}\right]$ have been analysed in acidic (1 M $\mathrm{HCl})$ and neutral aqueous media. The working electrode was a glass electrode, coated with $10 \mathrm{~nm}$ of sputtered platinum, on which the complexes were sublimed. The voltammograms are reversible and in acidic medium, during the second and subsequent cycles, oxidation potentials $v s$. saturated calomel electrode $\left(\mathrm{Hg} / \mathrm{Hg}^{+}, \mathrm{SCE}\right)$ occur at $+0.38 \mathrm{~V}$ and $+0.6 \mathrm{~V}$ (orange-red form), while the reduction peak also occurs at $+0.38 \mathrm{~V}$ (blue form), demonstrating chemical reversibility; the most reduced form (violet) appears at $-0.2 \mathrm{~V}$. The presence of oxygen and water influences the process, suggesting some interaction with the complexes, but apparently not the lanthanide ion ( $\mathrm{La}, \mathrm{Nd}$, $\mathrm{Eu}, \mathrm{Gd}, \mathrm{Dy}, \mathrm{Er}, \mathrm{Yb}, \mathrm{Lu})$, consistent with the redox reactions occurring at the ligands. In neutral medium and for $\mathrm{Eu}, \mathrm{Gd}, \mathrm{Dy}$, $\mathrm{Er}$, and $\mathrm{Yb}$, there is only one oxidation step at $+0.7 \mathrm{~V}$ (orangered) but two reduction steps at $-0.6 \mathrm{~V}$ (blue form) and $-1.4 \mathrm{~V}$ (violet form). However, no electrochemical behaviour is observed for La and Nd. A close look into the absorption spectra of these complexes reveals that they correspond to the reduced (blue) form $\left[\mathrm{Ln}(\mathrm{Pc})_{2}\right]^{-}$which is electro-inactive. After a few weeks the solutions turn green with an electronic absorption spectrum identical to that of the free $\mathrm{H}_{2} \mathrm{Pc}$; in addition, there is formation of a blue precipitate, pointing to the probable occurrence of a small amount of a triple-decker complex, $\left[\mathrm{Ln}_{2} \mathrm{Pc}_{3}\right]$. Apparently the presence of labile hydrogen is necessary for the complexes to display electrochemical behavior. ${ }^{224}$ The ambiguity noted above regarding the formulae of the lutetium bis(phthalocyanine) complexes, with or without "loosely bound" protons, arises from the fact that indeed, depending on the $\mathrm{pH}$, acid-base reactions may also be an explanation to some observed colour changes. ${ }^{225}$

Half-wave potentials for the oxidation and reduction reactions of green $\mathrm{NBu}_{4}\left[\mathrm{Ln}(\mathrm{Pc})_{2}\right]$ in $o$-dichlorobenzene are displayed in Fig. 34 for $\mathrm{Ln}=\mathrm{Y}$, Pr-Lu (except Tm). ${ }^{226}$ The reduction potentials show no dependence on the ionic radii, whereas oxidation potentials increase linearly with increasing ionic radii, with a slope of about $1.5 \pm 0.2 \mathrm{~V}^{-1}$. In sandwich-type bis(tetrapyrrole) rare earth compounds the distance between the two isoindole $4 \mathrm{~N}$ planes is very small; therefore, the proximity of the two conjugated $\pi$-systems in a face-to-face configuration induces splitting of the molecular orbitals. The dependence of the half-wave potentials upon ionic radii can then be reasonably explained by increasing ring-ring distance with increasing ionic radius and consequently decreasing $\pi$ interaction between the aromatic rings, rendering the removal of electrons more difficult. A similar trend is observed for double-decker complexes with benzyloxy substituted phthalocyanines. $^{227}$ Characteristic parameters often referred to are the differences between the two oxidation potentials, which is here $\Delta E_{\mathrm{O} 2-\mathrm{o} 1}=0.45 \mathrm{~V}$, and between the first oxidation and first reduction potentials, which is here $\Delta E_{\mathrm{o} 1-\mathrm{r} 1}=1.19 \mathrm{~V}$; 


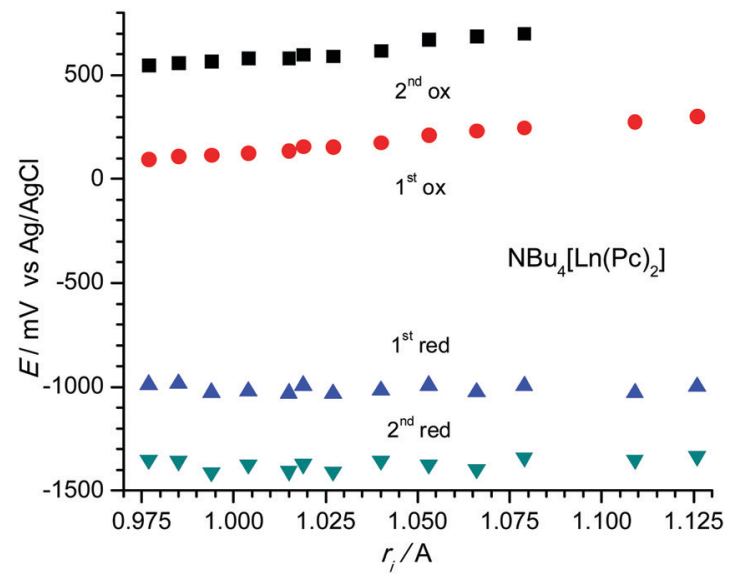

Fig. 34 Redox potentials vs. $\mathrm{Ag} / \mathrm{AgCl}$ (saturated $\mathrm{KCl}$ ) of $\left[\mathrm{Ln}(\mathrm{PC})_{2}\right]^{-}$in $\mathrm{O}^{-}$ dichlorobenzene as a function of ionic radii for the coordination number 8 . Drawn from data reported in ref. 226.

the latter reflects the molecular electrochemical band gap, i.e., the energy difference between HOMO and LUMO orbitals.

Peripheral octa-substitution by various alkyl groups, such as methyl, ethyl, $n$-butyl, $t$-butyl, or O-propyl, ${ }^{228-230}$ or mixed substitution $^{231}$ can be used to modulate the redox potentials and therefore the colour of the complexes. A third reduction potential is found for some of the complexes with derivatized Pc, with $E_{1 / 2}$ only slightly negative, which, like the oxidation potentials, varies slightly with the nature of the lanthanide ion. This is, for instance, the case for Pc derivatized with one benzyloxy and six $t$-butyl groups. ${ }^{231}$ This third reduction potential corresponds to the filling of the semi-occupied molecular orbital (SOMO) of the radial-anionic ligand.

Peripheral substitution of the macrocyclic ligand is used for several purposes, including increasing solubility in organic solvents or water, and sensing purposes, in which, for instance, the side chains, such as crown ethers, are complexation agents for metal ions. ${ }^{232,233}$ These substituents do not influence the basic structure of $\left[\operatorname{Ln}(\mathrm{Pc})_{2}\right]$ with one macrocycle bearing a single negative charge; this is demonstrated by the EPR spectrum of a double-decker functionalized with 6-hydroxyhexylthio groups featuring a single signal with $g=2.001 .^{234}$ However, redox properties are influenced, with respect to not only shifts in half-wave potentials but also the number of redox processes that can be triggered. For instance, the sandwich complexes with 6-hydroxyhexylthio-derivatised Pc display one oxidation step only but up to 5 reduction steps. An electrochemical study of double-decker complexes of the entire lanthanide series with Pc ligands derivatized with $t$-butyl, heptyl, butyloxy, pentyloxy, and octyloxy groups revealed five reduction steps and two oxidation steps, except for Ce. The first reduction potential is small and increases linearly from Lu to $\mathrm{La}(-0.02$ to $+0.27 \mathrm{~V})$ in parallel with the first oxidation step $(+0.40$ to $+0.61 \mathrm{~V})$; the other reduction potentials have no Ln dependence and lie between -1.1 and $-1.9 \mathrm{~V}$. It is noteworthy that the latter potentials arise from the fact that the first and second LUMOs are close in energy and can accept up to four electrons. Experimentally, observation of several resolved redox processes is facilitated by the use of a glassy carbon disk resulting in less interaction between the electrochemically generated species and the electrode, ${ }^{235}$ as well as by complementing cyclic voltammetry measurements with differential pulse voltammetry data. The number of observed redox potentials evidently depends on the electrochemical window available under the given experimental conditions, where the solvent plays a crucial role.

A way to fine-tune the energy of the HOMO and LUMO orbitals of phthalocyaninates, i.e., tuning their redox potentials, is to play with the electron withdrawing or electron donating properties of the substituents. Jiang et al. have investigated a series of 17 metal-free phthalocyanines derivatized with alkoxy, alkylthio, alkyl, alkynyl, phenyloxy, and phenylthiol groups and concluded that the effects of peripheral and non-peripheral substitution on the values of half-wave potentials can be explained by considering the energy of the frontier orbitals. The tuning range is large, on the order of $0.45 \mathrm{~V}$ for the first three reduction potentials and between 0.6 and $0.8 \mathrm{~V}$ for the two oxidation potentials, while $\Delta E_{01-\mathrm{r} 1}$ values span about $0.7 \mathrm{~V} \cdot{ }^{236}$ In addition to generating planned electronic effects, the choice of substituents is also guided by practical considerations, such as ease of processing thin films or mesophases. In an effort towards this goal, Bian et al. have introduced eight bulky 2,6-dimethylphenoxy groups on the periphery of Pc. The structure of the double-decker complexes with $\mathrm{Pr}, \mathrm{Sm}$, and $\mathrm{Nd}$ is similar to those of other homoleptic lanthanide phthalocyaninates, with the peculiar feature however that the Pc rings adopt a domed conformation towards the metal centres with dihedral angles being much larger than those observed for complexes with alkyl, alkylthio or phenoxy substituted Pc. This can be attributed to the presence of the bulky methyl groups on the substituents. With respect to unsubstituted $\left[\mathrm{Ln}(\mathrm{Pc})_{2}\right]$, incorporation of these 2,6dimethylphenoxy groups on the phthalocyanine ligands results in slightly more difficult oxidation and slightly easier reduction, consistent with the electron-withdrawing nature of the substituent and in accord with results obtained previously with phenoxy octasubstituted Pc. ${ }^{237}$

The search for practical electrochromic materials is a big drive for investigating various $\left[\operatorname{Ln}(\mathrm{Pc})_{2}\right]$ complexes. For instance, double-deckers of Sm, Eu, Gd, Dy, and Lu with octa2,2,3,3-tetrafluoropropoxy-substituted Pc have been evaluated toward this goal. Langmuir-Blodgett thin films of the complexes coated on ITO electrodes display three distinctive colours (green, orange, red); the Dy thin films were found to be ideal neutral and anodic colouring materials with short response times ( $4.3 \mathrm{~s}$ for green and $2.1 \mathrm{~s}$ for red, first cycle) and high optical stability. ${ }^{238}$

Naphthalocyanine ( $\mathrm{Nc}$ ) sandwich complexes with lanthanides behave similarly to phthalocyaninates with respect to their electrochromic properties (Fig. 35); however, interest for Nc compounds stems from their NIR-shifted absorptions by as much as $200 \mathrm{~nm} .{ }^{239}$ The series of double deckers formed by tetra( $t$-but)-derivatized $\mathrm{Nc}$ (TBNc) with $\mathrm{La}-\mathrm{Lu}$, except Ce and Pm, display a rich electrochemistry, with $2-3$ oxidation steps 

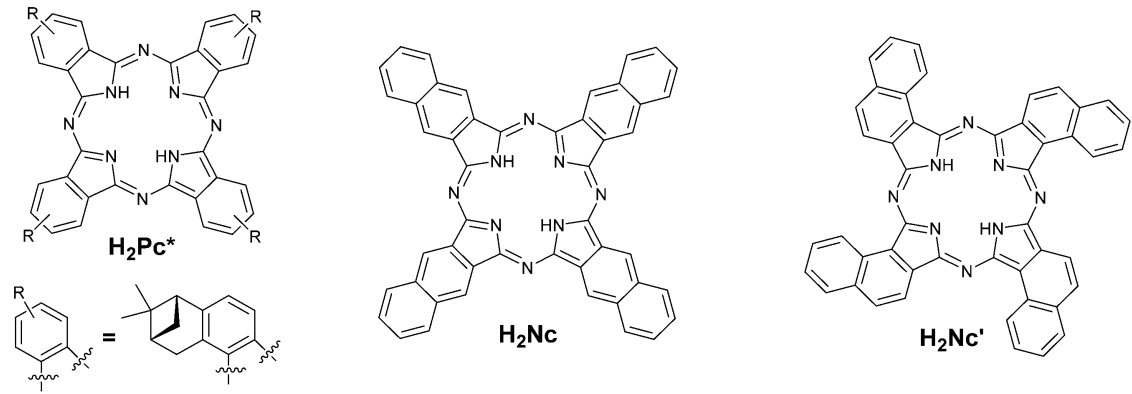

Fig. 35 Chemical formulae of pinene-substituted phthalocyanine $\mathrm{H}_{2} \mathrm{Pc}^{*}, 2,3$-naphthalocyanine $\mathrm{H}_{2} \mathrm{Nc}$, and the $\mathrm{C}_{4 \mathrm{v}}$ form of 1,2-naphthalocyanine $\mathrm{H}_{2} \mathrm{Nc}^{\prime}$.

and 4-5 reduction processes, as shown by the differential pulse voltammogram for $\left[\mathrm{Lu}(\mathrm{TBNc})_{2}\right]$ (Fig. 36, top). The dependence of the half-wave potentials on ionic radii is presented in Fig. 36
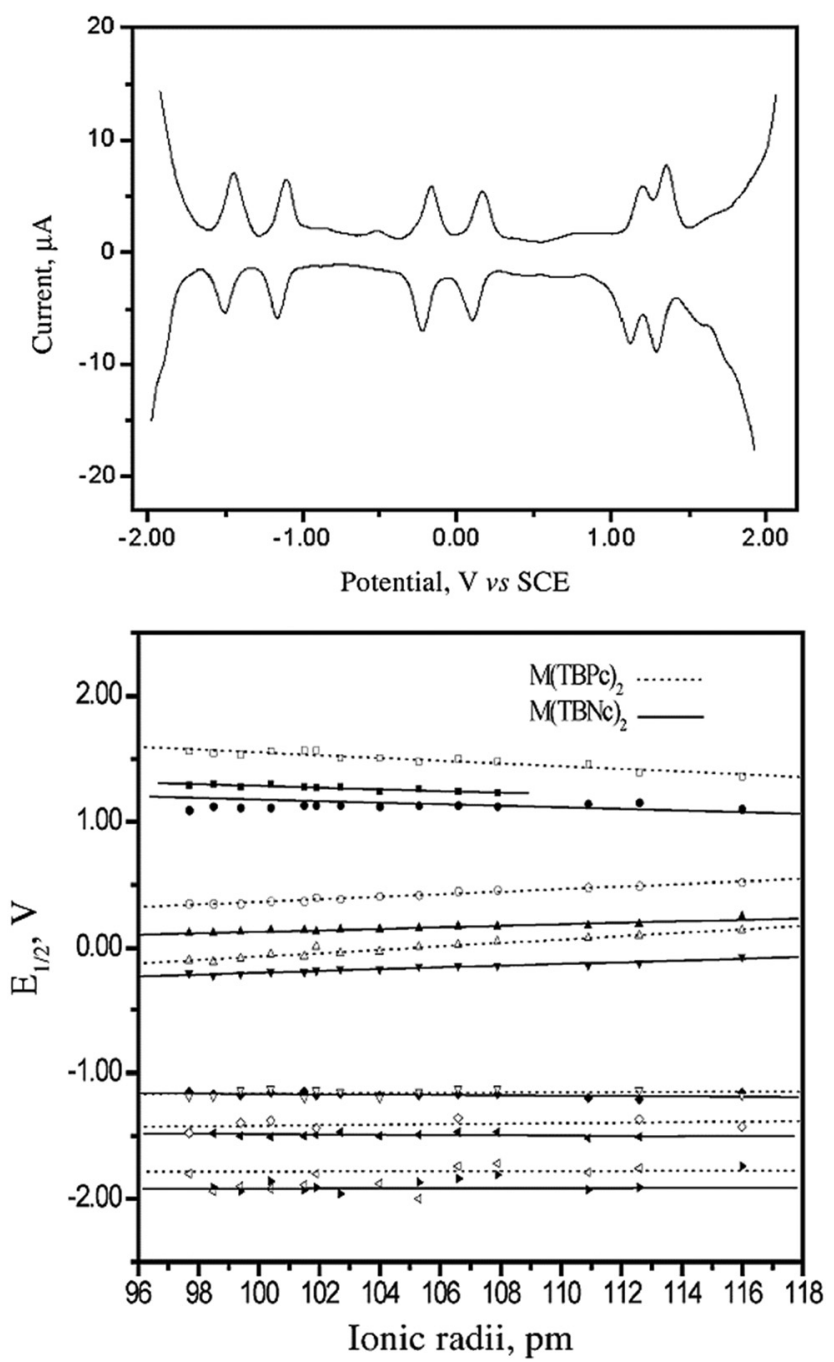

Fig. 36 (Top) Difference pulse voltammograms for [ $\left.\mathrm{Lu}(\mathrm{TBNC})_{2}\right]$ in methylene chloride containing $0.1 \mathrm{M}(\mathrm{NBu})_{4} \mathrm{NClO}_{4}$; the scan rate is $10 \mathrm{mV} \mathrm{s}^{-1}$. (Bottom) Dependence of half-wave potentials for $\left[\mathrm{Ln}(\mathrm{TBNC})_{2}\right]$ and $\left[\mathrm{Ln}(\mathrm{TBPC})_{2}\right]$ as a function of the ionic radii of the trivalent lanthanide ions. Reproduced with permission from ref. 240, copyright (2005) Society of Porphyrins and Phthalocyanines. (bottom) and compared with that for similar double deckers with tetra( $t$-butyl)-derivatized Pc (TBPc). The three most negative reduction potentials have essentially no dependence on the radii, while the first reduction potential correlates linearly with these radii, as does the first oxidation potential, with values slightly increasing with increasing radii. The half-wave potentials for the second and third oxidation steps are also linearly dependent on the ionic radii of the metal ions but the slopes of the lines are opposite to those of the first oxidation and reduction potentials. When oxidation processes involve the same HOMO of the ligands, i.e., the 2nd and 3rd potentials, the slope of the potential dependence on ionic radii is the same. Comparison with $\left[\operatorname{Ln}(\mathrm{TBPc})_{2}\right]$ reveals that the first two oxidation potentials and the first reduction potential of $\left[\mathrm{Ln}(\mathrm{TBNc})_{2}\right]$ are less affected by the change in ionic radius, the corresponding gradients being about $40-50 \%$ less steep. The extension of the conjugated $\pi$ system in going from Pc to $\mathrm{Nc}$ therefore attenuates the inter-ring separation effect on the redox potentials. In turn, the HOMO-LUMO energy separation is smaller; theoretical calculations give a $0.29 \mathrm{eV}\left(\sim 2350 \mathrm{~cm}^{-1}\right)$ difference for the un-complexed ligands, explaining why $\mathrm{Nc}$ compounds are more readily oxidized than Pc compounds. ${ }^{240}$

In going from monophthalocyaninate [Ln(OPPc)acac] $\left(\mathrm{H}_{2} \mathrm{OPPc}\right.$ is octaphenyl Pc, Scheme 1) to homoleptic double $\left[\mathrm{Ln}(\mathrm{OPPc})_{2}\right]$ and triple $\left[\mathrm{Ln}_{2}(\mathrm{OPPc})_{3}\right]$ deckers, the number of redox processes increases from 4 to 6 and 10, respectively. For $\left[\mathrm{Eu}_{2}(\mathrm{OPPc})_{3}\right]$ in $o$-dichloro benzene, 6 reduction and 4 oxidation steps are observed and are completely reversible. The first oxidation $(+0.67 \mathrm{~V} v s .+0.63 \mathrm{~V})$ and the first reduction $(+0.16 \mathrm{~V} v s$. $+0.16 \mathrm{~V})$ half-wave potentials are very similar to those for the analogue double decker, with $\Delta E_{\mathrm{o} 1-\mathrm{r} 1}$ reaching $0.51 \mathrm{~V}$ compared with $0.47 \mathrm{~V}$. Assignment of all half-wave potentials was performed by inspection of absorption spectra. $^{239}$

Cerium double- and triple-deckers deserve special attention since, in addition to redox processes centred on the ligands, the metal ion could theoretically be switched between +3 and +4 oxidation states and therefore these compounds could display extra colours with respect to the other lanthanide derivatives. The reality appears to be subtle as the oxidation state of cerium depends on the ligand nature and/or the complex stoichiometry. For instance, cerium retains its trivalent oxidation state in a double decker with $t$-butyl-substituted naphthalocyanine for 
which no additional redox process was observed compared with other Ln complexes with the same ligand. ${ }^{241}$ On the other hand, in most other tetrapyrrole double deckers, cerium is predominantly tetravalent, such as in $\left[\mathrm{Ce}^{\mathrm{IV}}(\mathrm{OEP})_{2}\right]\left(\mathrm{H}_{2} \mathrm{OEP}\right.$ is octaethylporphyrin), with valence calculated from EXAFS data between 3.59 and 3.68. The first reduction wave at a slightly negative potential is then assigned to $\mathrm{Ce}^{n} / \mathrm{Ce}^{\mathrm{III}}$ ( $n$ between 3 and 4). ${ }^{242}$ A Langmuir-Blodgett thin film made of cerium bis[tetra(15-crown-5)-phthalocyaninate] displays a similar behavior. $^{243}$

\subsection{Heteroleptic phthalocyaninato lanthanide sandwich complexes}

Using two different tetrapyrrole ligands with different redox and optical properties to form dissymmetric lanthanide double deckers provides interesting information on the electronic structure of each ligand and, particularly, on charge delocalization in these macrocycles. ${ }^{43,244}$ Earlier studies focused on Por/ Pc and Por/Por' double deckers, demonstrating that, for instance, in $\left[\mathrm{Ce}^{\mathrm{IV}}(\mathrm{TPP})(\mathrm{Pc})\right]^{+}$, the electronic hole (positive charge) resides mainly on the phthalocyanine ring, while in $\left[\mathrm{Ce}^{\mathrm{IV}}(\mathrm{TPP})(\mathrm{OEP})\right]^{+}$it is mainly delocalized on OEP. In general, the redox properties of mixed lanthanide double deckers feature several oxidation and reduction steps with dependences on the ionic radii similar to those evidenced for the homoleptic complexes. ${ }^{159,245,246}$

In order to explore new electrochromic behaviours, novel tetrapyrrole rings have been synthesized. An example is given in Fig. 37 for the heteroleptic sandwich complex [Lu(Pc)(PTBTPor)] $\left(\mathrm{H}_{2} \mathrm{PTBTPor}\right.$ is meso-phenyl-tetrabenzo-triazaporphyrin) which, like the homoleptic compound with PTBTPor, undergoes three quasi-reversible reductions and one quasi-reversible oxidation. The potential difference $\Delta E_{\mathrm{o} 1-\mathrm{r} 1}$ amounts to $0.45 \mathrm{~V}$, which is at the higher end of the range usually observed for homoleptic Pc double deckers $(0.35-0.45 \mathrm{~V})$, meaning that the ring-to-ring interaction is larger compared with homoleptic Pc analogues. ${ }^{188,247}$

Owing to the remarkable redox properties of tetrathiafulvalene (TTF), such as oxidation at relatively low half-wave potentials converting its dithiolylidene rings into $6 \pi$-electron
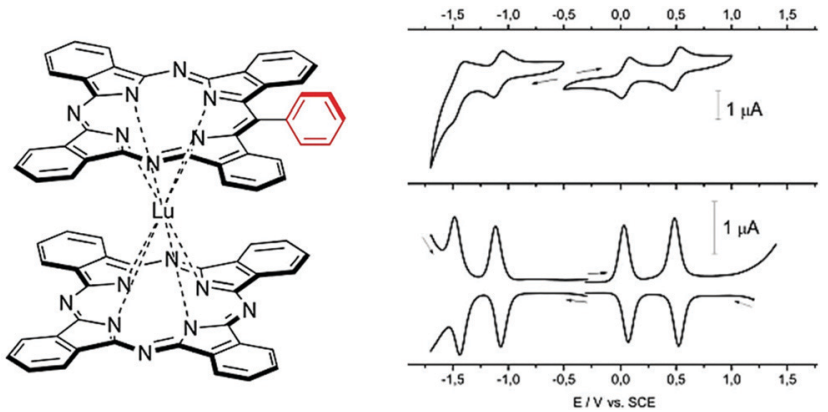

Fig. 37 (left) Structure of the heteroleptic lutetium complex with Pc and meso-phenyl-tetrabenzo-triazaporphyrin ( $\mathrm{H}_{2} \mathrm{PTBTPor}$ ). (right) Cyclic voltammograms (top) and square-wave voltammograms (bottom) of the complex in dichloromethane containing $0.15 \mathrm{M} \mathrm{Bu}_{4} \mathrm{NBF}_{4}$ (scan rate: $10 \mathrm{~V} \mathrm{~s}^{-1}$ ). Reproduced with permission from ref. 247, copyright (2013) The Royal Society of Chemistry. aromatic systems and use of its salts $\left(\right.$ e.g. $\left.[\mathrm{TTF}]^{+} \mathrm{Cl}^{-}\right)$as semiconductors or components of optoelectronic devices including sensitized solar cells, bis(thiopentyl)-derivatized TTF units have been fused with phthalocyanine rings. Heteroleptic double deckers $\left[\mathrm{Eu}(\mathrm{Pc})\left(\mathrm{PcTTF}_{n}\right)\right](n=1-4)$ have been isolated which display four reduction and two oxidation steps with some of them having half-wave potentials substantially shifted with respect to the homoleptic unsubstituted complex $\left[\mathrm{Eu}(\mathrm{Pc})_{2}\right]$ for which two oxidation steps and three reduction processes are observed. All steps are reversible, except the second oxidation process. The shifts depend on the number of TTF substituents but in a nonlinear way. The first oxidation potential increases from $0.62 \mathrm{~V}$ (vs. SCE) to $0.65 \mathrm{~V}$ in going from the mono- to the tetra-substituted Pc, while it amounts to $0.54 \mathrm{~V}$ for the unsubstituted reference compound. The first reduction potential decreases from $0.17 \mathrm{~V}(n=1)$ to $0.13 \mathrm{~V}(n=4)$, the second increases from $-1.06 \mathrm{~V}$ to $-0.96 \mathrm{~V}$, the third from $-1.35 \mathrm{~V}$ to $-1.27 \mathrm{~V}$ and the forth from $-1.66 \mathrm{~V}$ to $-1.59 \mathrm{~V}$. The difference $\Delta E_{\mathrm{o} 1-\mathrm{r} 1}$ increases from $0.45 \mathrm{~V}$ to $0.52 \mathrm{~V}$, compared with $0.43 \mathrm{~V}$ for the unsubstituted reference compound. These data reflect un-doubtful contribution of the TTF units to the electronic structure of the double deckers and represent a welcome tuning possibility for future electrochromic devices. ${ }^{248}$

As seen above, inter-ring $\pi-\pi$ interactions in multidecker tetrapyrrole lanthanide complexes confer to these assemblies remarkable optical, electrical, and electrochemical properties. Researchers have consequently looked for ligands that may further enhance these properties. Good candidates are corroles (Cor) and their derivatives (Fig. 20). Corroles are contracted 18$\pi$ electron macrocycles containing a direct carbon-carbon single bond between two pyrrole rings; since they have three $\mathrm{NH}$ groups in the inner core, they act as trianionic ligands. The first lanthanide complexes with corroles were reported in $2013^{249}$ and the first heteroleptic lanthanide triple-deckers with tri-substituted corroles in 2015, with the formulae $\left\{\operatorname{Ln}_{2}[\mathrm{Pc}(\mathrm{O}-\right.$ But $\left.\left.)_{8}\right]_{2}\left[\mathrm{Cor}(\mathrm{PhCl})_{3}\right]\right\}^{250}$ and $\left\{\mathrm{Eu}_{2}\left[\mathrm{Pc}(\mathrm{OBut})_{8}\right]_{2}\left[\mathrm{Cor}(\mathrm{Ph})_{n}\left(\mathrm{PhNO}_{2}\right)_{3-n}\right]\right\}$ $(n=0-3) .{ }^{251}$ For the first series $(\mathrm{Ln}=\mathrm{Pr}-\mathrm{Tb}$, except Tm), halfwave potentials for five oxidation and three reduction steps were determined. For $\mathrm{Ln}=\mathrm{Eu}$, the first oxidation and the three reduction potentials are similar to those observed for the homoleptic double-decker $\left\{\mathrm{Eu}\left(\mathrm{Pc}(\mathrm{OOct})_{8}\right]_{2}\right\}$, and so is $\Delta E_{01-\mathrm{r} 1}$ at $0.44 \mathrm{~V}$ versus $0.42 \mathrm{~V}$ for the reference; the other four oxidation potentials are more similar to those found for the triple-decker $\left\{\mathrm{Eu}_{2}\left[\mathrm{Pc}(\mathrm{OOct})_{8}\right]_{2}(\mathrm{Pc})\right\}$. Replacing the butoxy groups with pentoxy or octaoxy substituents has little influence on the half-wave potentials. But the nature of the lanthanide ion has, as all potentials display a linear dependence on the ionic radii, usually increasing with increasing size, except for the 2nd oxidation potential which is fairly insensitive, while the 4 th one displays an opposite trend (Fig. 38). In the second series of heteroleptic triple deckers, the nitrophenyl substituents are redox active, which leads to the observation of two additional reduction potentials between -1.19 and $-1.33 \mathrm{~V} v s$. SCE. All potentials, except the third oxidation one, vary with the number of nitrophenyl substituents. Regarding assignment, the first and fifth oxidation steps as well as the first reduction step arise 
(a) Oxidation

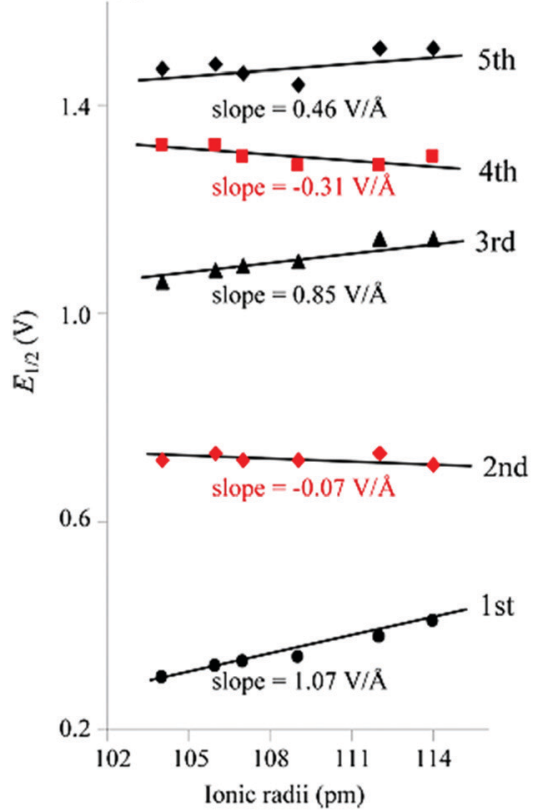

(b) Reduction

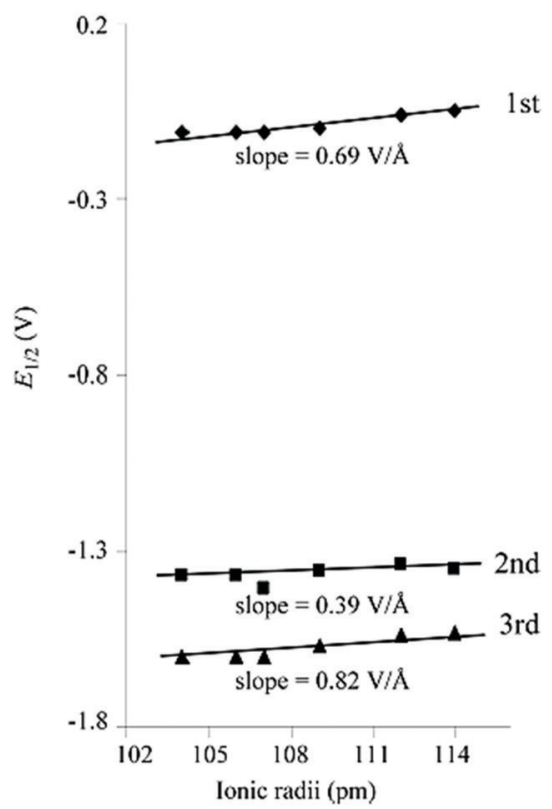

Fig. 38 Half-wave potentials for $\left\{\mathrm{Ln}_{2}\left[\mathrm{Pc}(\mathrm{OBut})_{8}\right]_{2}\left[\mathrm{Cor}(\mathrm{PhCl})_{3}\right]\right\}(\mathrm{Ln}=\mathrm{Pr}-\mathrm{Tb}$, except $\mathrm{Tm})$ in $\mathrm{CH}_{2} \mathrm{Cl}_{2}$ containing $0.1 \mathrm{M} \mathrm{Bu}_{4} \mathrm{NClO}_{4}$. Reproduced with permission from ref. 250, copyright (2015) American Chemical Society.

from the corrole ligand, while the second and third reduction processes are localized on the nitrophenyl substituents and the other processes on the phthalocyanine ring. ${ }^{251}$ The analogue dysprosium triple deckers with pentoxy octasubstituted Pc and either fluoro or chloro trisubstituted Cor have electrochemical behavior similar to $\left\{\mathrm{Y}_{2}\left[\mathrm{Pc}(\mathrm{OPent})_{8}\right]_{2}\left[\mathrm{Cor}(\mathrm{PhCl})_{3}\right]\right\}$ with five

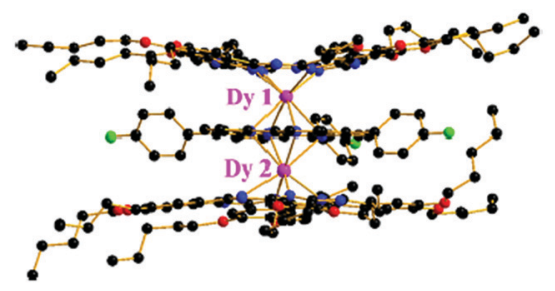

(a) $\mathrm{Dy}_{2}\left[\mathrm{Pc}\left(\mathrm{OC}_{5} \mathrm{H}_{11}\right)_{8}\right]_{2}\left[\mathrm{Cor}(\mathrm{FPh})_{3}\right] 1$

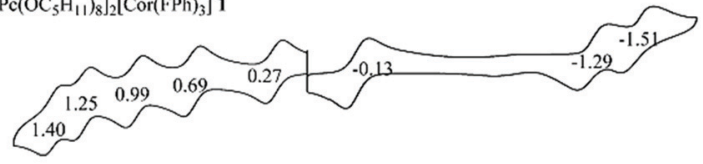

(b) $\mathrm{Dy}_{2}\left[\mathrm{Pc}\left(\mathrm{OC}_{5} \mathrm{H}_{11}\right)_{3}\right]_{2}\left[\mathrm{Cor}(\mathrm{CIPh})_{3}\right] 2$

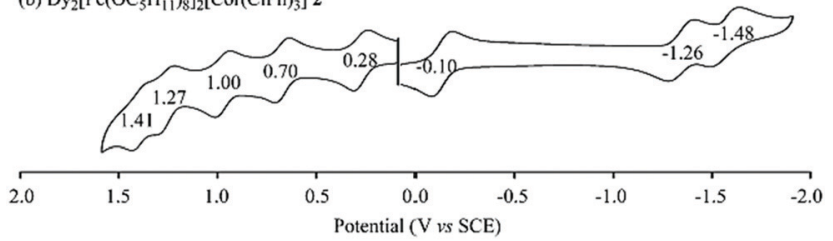

Fig. 39 Cyclic voltammograms of $\left\{\mathrm{Dy}_{2}\left[\mathrm{Pc}(\mathrm{OPent})_{8}\right]_{2}\left[\mathrm{Cor}(\mathrm{PhX})_{3}\right](\mathrm{X}=\mathrm{F}, \mathrm{Cl})\right.$ in $\mathrm{CH}_{2} \mathrm{Cl}_{2}$ containing $0.1 \mathrm{M} \mathrm{Bu}_{4} \mathrm{NClO}_{4}$. The top structure corresponds to the fluorinated complex. Reproduced with permission from ref. 252, copyright (2017) American Chemical Society. oxidation steps and three reduction steps; $\Delta E_{\mathrm{o} 1-\mathrm{r} 1}=0.40 \mathrm{~V}$ (fluoro) and $0.38 \mathrm{~V}$ (chloro), compared with $0.39 \mathrm{~V}$ for the yttrium compound (Fig. 39). ${ }^{252}$

Heteroleptic complexes with phthalocyanine and naphthalocyanine can be obtained by a one-pot procedure and their redox and spectroscopic properties follow the same trends along the lanthanide series as porphyrin/phthalocyanine complexes, governed by the increased $\pi$-interaction between the aromatic rings. Double deckers $\left\{\operatorname{Ln}(\mathrm{Nc})\left[\mathrm{Pc}(\alpha \text {-OPent })_{4}\right]\right\}(\mathrm{Ln}=$ $\mathrm{Sm}, \mathrm{Eu}, \mathrm{Y}$ ) feature four oxidation and five reduction processes; $\Delta E_{01-\mathrm{r} 1}$ is almost constant, $0.34-0.35 \mathrm{~V}$, while $\Delta E_{\mathrm{r} 1-\mathrm{r} 2}$, which represents the HOMO-LUMO gap of the reduced forms $\left\{\mathrm{Ln}(\mathrm{Nc})\left[\mathrm{Pc}(\alpha-\mathrm{OPent})_{4}\right]\right\}^{-}$, decreases from $1.21 \mathrm{~V}$ to $1.16 \mathrm{~V}$ and $1.09 \mathrm{~V}$ for $\mathrm{Sm}, \mathrm{Eu}$, and $\mathrm{Y}$, respectively. ${ }^{253}$

\subsection{Porphyrinato lanthanide complexes}

The electrochemical properties of lanthanide porphyrinates have similarities with those described above for the phthalocyaninates so that we limit the description to a few examples. The europium double-decker complex with octaethylporphyrin $\left[\mathrm{Eu}(\mathrm{OEP})_{2}\right]$ displays an EPR spectrum typical of an organic radical $(g \sim 2.0)$ meaning that one macrocycle is in the form of a radical mono anion. This and similar double deckers undergo several oxidation/reduction steps with concomitant colour changes. It is worth noting that, like the phthalocyaninates, protonation/deprotonation reactions also occur depending on the $\mathrm{pH}$ and sometimes lead to equilibria between two different species in solution. Electrochemical data are available for many complexes, including homoleptic and heteroleptic double deckers. For instance, octachloro-substituted 
tetraphenyl porphyrin $\left(\mathrm{H}_{2} \mathrm{Cl}_{8} \mathrm{TPP}\right)$ displays two oxidative and two reductive reversible one-electron processes in THF containing $0.1 \mathrm{M} \mathrm{Bu}_{4} \mathrm{NClO}_{4}$; the potentials do not vary much upon coordination to $\mathrm{Tb}$ in $\left[\mathrm{Tb}\left(\mathrm{Cl}_{8} \mathrm{TPP}\right)(\mathrm{OAc})\right]$ but the complex displays a third oxidation step at a higher potential (1.63 vs. SCE); the $\Delta E_{01-\mathrm{r} 1}$ difference is quite large, around $1.9 \mathrm{~V}$. In principle, the electron withdrawing nature of the chloro substituents should result in porphyrins that are easier to reduce and harder to oxidize. This is however not the case and the reason is that the addition of eight relatively bulky groups on $\beta$-pyrrolic positions results in ring deformation leading to substantially modified redox properties due to a destabilization of the HOMO and to a macrocyclic ring that is easier to oxidize. The ring deformation depends on the number (4 or 8 ) and nature (chloro or bromo) of the substituents. ${ }^{99}$ The molecular structures of three oxidation forms of $\left[\mathrm{Tb}(\mathrm{TPP})_{2}\right]^{n}$ and $\left[\mathrm{Tb}(\mathrm{OEP})_{2}\right]^{n}$ $(n=-1,0,+1)$ have been determined by single-crystal X-ray diffraction and point to the redox state controlling the azimuthal rotation angle $\phi$ between the two porphyrin rings. For the TPP double decker this angle decreases with each oxidation step, from $44^{\circ}$ to $34^{\circ}$, and $30^{\circ}$. Oxidation results in a shortening of the average $\mathrm{Tb}-\mathrm{N}$ bond length, increasing the $\pi-\pi$ interaction between the rings and the steric repulsion between the phenyl rings of one ligand and the $\beta$-hydrogen atoms on the other one. The eight ethyl groups on the porphyrin macrocycle of $\mathrm{H}_{2} \mathrm{OEP}$ seem to have a much smaller steric effect since the $\phi$ angle is equal to $45^{\circ}$ for $n=-1$ and 0 and decreases to only $36^{\circ}$ for $n=+1 .{ }^{254}$

In the series [ $\mathrm{Ln}(\mathrm{Nc})(\mathrm{TBPP})]$, where $\mathrm{H}_{2} \mathrm{TBPP}$ is meso-tetra(4-tbutylphenyl)porphyrin, three quasi-reversible, one-electron oxidation and one reduction steps are revealed by cyclic voltammetry in methylene chloride at ambient temperature. ${ }^{166} \mathrm{~A}$ second reduction could not be detected owing to solvent breakdown. Linear correlations are observed between the measured potentials and the ionic radii of the trivalent lanthanide ions; the first oxidation and reduction steps have positive gradients, while the second and third oxidation potentials have negative gradients (Fig. 40). It is noteworthy that $\Delta E_{\mathrm{o} 1-\mathrm{r} 1}$ is large, with values in the range of 0.50 to $0.55 \mathrm{~V}$, without a clear trend with respect to ionic radii. This is much larger than that in the bis(phthalocyaninate) analogues $\left[\mathrm{Ln}(\mathrm{Nc})_{2}\right](0.29-0.47 \mathrm{~V})$ and slightly larger than that in the related $[\mathrm{Ln}(\mathrm{Pc})(\mathrm{TPP})]$ double deckers $(0.45-0.48 \mathrm{~V})$.

Both ferrocene and tetrapyrroles are extensively used in molecular electronics so that connecting them together has been tempted with the aim of tuning electronic coupling between ferrocene units. Two such ferrocene units have been grafted in syn configuration at the meso positions of the porphyrin framework $\left(\mathrm{H}_{2} \mathrm{PorFc}_{2}\right)$, and heteroleptic complexes $\left[\mathrm{Ln}(\mathrm{Pc})\left(\mathrm{PorFc}_{2}\right)\right] \quad(\mathrm{Ln}=\mathrm{Eu}, \quad \mathrm{Y}, \quad \mathrm{Ho}, \quad \mathrm{Lu})$ and $\left[\mathrm{Eu}_{2}(\mathrm{Pc})_{2}\left(\mathrm{PorFc}_{2}\right)\right]$ have been prepared. The two tetrapyrrole ligands in the double deckers and the outer two macrocyclic ligands in the triple decker adopt a domed conformation, the degree of which depends on the nature of the metal ion, which enables the tuning of the ferrocene interaction. Indeed, the steric hindrance generated by the Pc ring in the sandwich
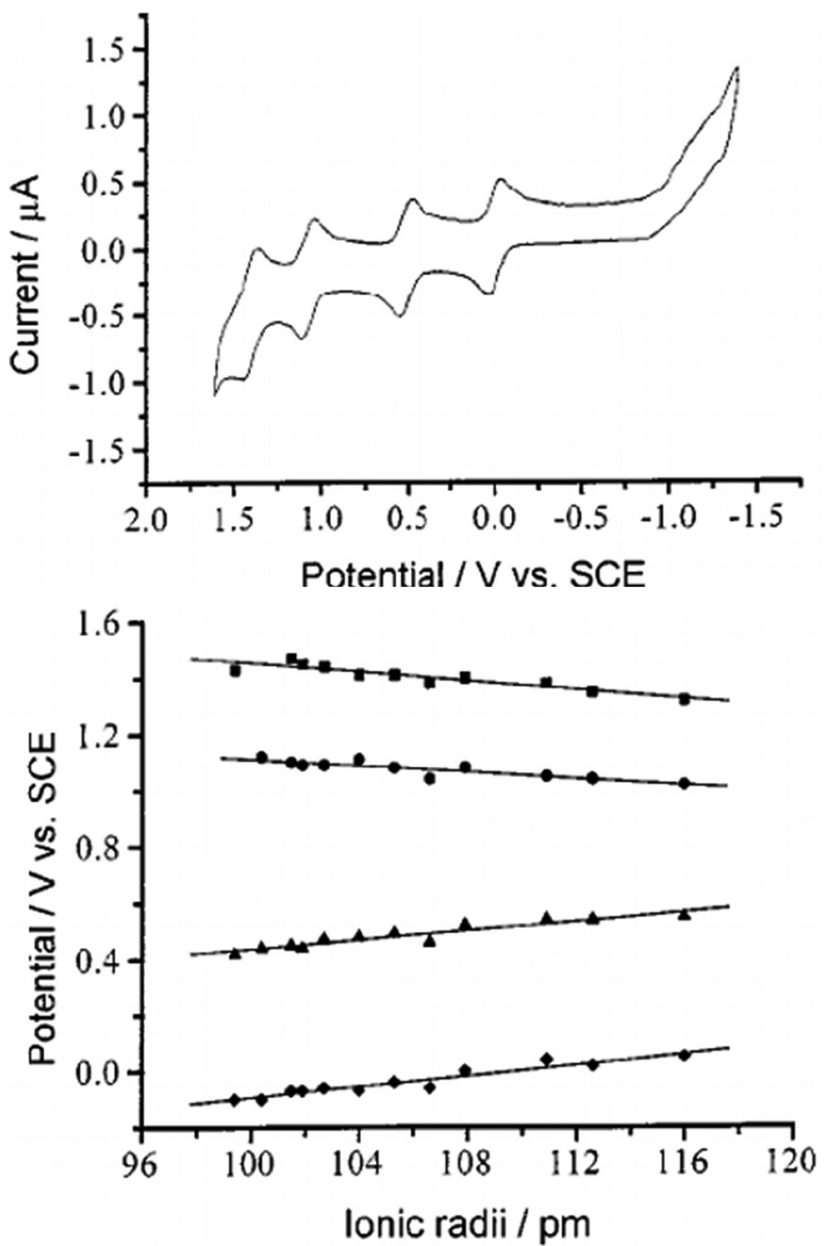

Fig. 40 (Top) Cyclic voltammogram of [ $\mathrm{Sm}(\mathrm{Nc})(\mathrm{TBPP})]$ in $\mathrm{CH}_{2} \mathrm{Cl}_{2}$ containing $0.1 \mathrm{M} \mathrm{Bu}_{4} \mathrm{NPF}_{6}$ (scan rate: $100 \mathrm{mV} \mathrm{s}^{-1}$ ). (Bottom) Dependence of the redox potentials of [ $\mathrm{Ln}(\mathrm{NC})(\mathrm{TBPP})]$ on ionic radii. Reproduced with permission from ref. 166, copyright (2001) Wiley VCH Verlag GmbH.

complexes restricts the rotation of the ferrocene groups. Within the electrochemical window of $\mathrm{CH}_{2} \mathrm{Cl}_{2}$, all doubledecker complexes exhibit three quasi-reversible one-electron oxidations and two quasi-reversible one-electron reductions (Fig. 41). Comparisons with reference compounds reveal that the first two reductions and the third oxidation involve the tetrapyrrole ligands, while the first two oxidations are clearly due to the ferrocenyl groups. By contrast, a single ferrocene-centred two-electron oxidation is detected in the free ligand $\mathrm{H}_{2} \mathrm{PorFc}_{2}$ pointing to the lack of an electronic interaction due to free rotation. The two ferrocene-centred oxidations occur between $-42(\mathrm{Eu})$ and $-84(\mathrm{Lu}) \mathrm{mV}$ and +39 $(\mathrm{Eu})$ and $+72(\mathrm{Lu}) \mathrm{mV}$, respectively, exhibiting the classical dependence on ionic radii. Their difference increases considerably, from $81(\mathrm{Eu})$ to $156(\mathrm{Lu}) \mathrm{mV}$, with shrinking ionic radius, reflecting an increasing electronic interaction. This difference is much smaller $(46 \mathrm{mV})$ for the triple-decker Eu complex, a consequence of the less domed conformation of the outer tetrapyrrole rings reducing the ferrocene interaction. ${ }^{186}$ 

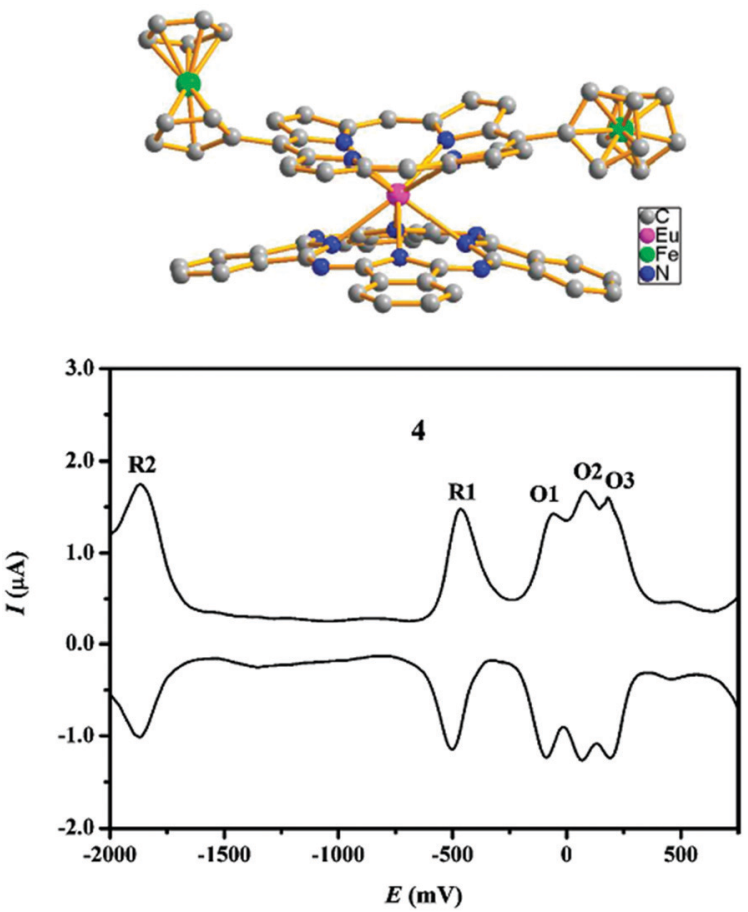

Fig. 41 Molecular structure of $\left[\mathrm{Eu}(\mathrm{Pc})\left(\mathrm{PorFc}_{2}\right)\right]$ and differential pulse voltammetry of $\left[\mathrm{Lu}(\mathrm{PC})\left(\mathrm{PorFC}_{2}\right)\right]$ in $\mathrm{CH}_{2} \mathrm{Cl}_{2}$ containing $0.1 \mathrm{M} \mathrm{Bu}_{4} \mathrm{NClO}_{4}$ (scan rate: $10 \mathrm{mV} \mathrm{s}^{-1}$ ). Reproduced with permission from ref. 186, copyright (2012) The American Chemical Society.

\section{NIR luminescence of tetrapyrrole complexes}

The characteristics of trivalent lanthanide luminescence are well suited for essential photonic applications, including biomedical analyses, in view of narrow emission bands covering the entire spectroscopic range from UV to NIR-by suitable choice of the emitting ion, of long excited state lifetimes ( $\mu$ s to $\mathrm{ms}$ ) enabling time-resolved detection, and of good resistance to photobleaching. However, since the implied transitions have very weak intensities owing to the Laporte's forbidden nature of electric dipole $\mathrm{f}-\mathrm{f}$ transitions, a sensitization mechanism is needed. Photons are absorbed by the ligands surrounding the metal ion and energy is then transferred from a donor state, often a triplet state in coordination compounds, to the metal ion. The energy transfer is most efficient if the energy gap between the donor state of the ligands and the excited state of the emitting ion lies in the range of $2-5000 \mathrm{~cm}^{-1}$. 255

Applications in bioscience often require the use of NIR light in order to avoid too much absorption and scattering by the biological tissues. Looking into Fig. 42 which depicts schematically the main transitions of the NIR-emitting lanthanide ions, one realizes that, ideally, the donor states of the ligands should be located between 10000 and $15000 \mathrm{~cm}^{-1}$. Several classes of ligands are suitable for sensitizing the NIR luminescence of lanthanide ions ${ }^{256}$ and, among them, tetrapyrrole derivatives are especially well-adapted in view of their extended NIR spectroscopic properties.

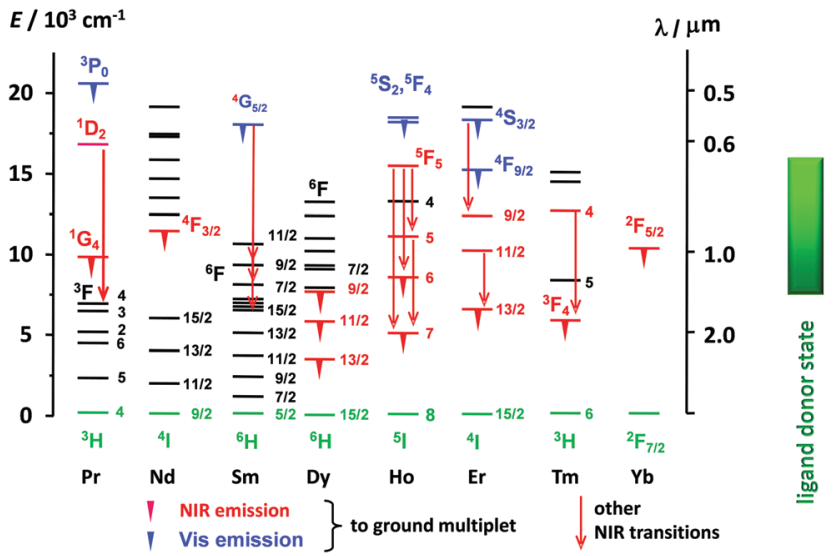

Fig. 42 Partial energy diagram of the principal NIR-emitting trivalent lanthanide ions with main NIR transitions. The green rectangle indicates the ideal energy of the donor state of the ligand for efficient energy transfer. Adapted with permission from ref. 256, copyright (2007) Elsevier B.V.

\subsection{Electronic spectra of tetrapyrroles and their lanthanide complexes}

The electronic spectra of simple metalloporphyrins, e.g. [ $\mathrm{M}^{\mathrm{II}}($ por $\left.)\right]$ with tetragonal symmetry, display one intense absorption with a maximum around $400-425 \mathrm{~nm}$ and $\log \varepsilon=\sim 4.5-5.5$, corresponding to a $S_{2} \leftarrow S_{0}$ transition and called the Soret (B) band; two other absorptions of lower intensities are detected in the spectral range of 500-650 nm, with $\log \varepsilon \sim 3-4$ and assigned to two components of the $\mathrm{S}_{1} \leftarrow \mathrm{S}_{0}$ transition, labelled $\mathrm{Q}(0,0)$ or $\mathrm{Q}_{0}$ and $\mathrm{Q}(1,0)$ or $\mathrm{Q}_{1}$. When the tetragonal symmetry is broken as in the free ligand due to the presence of the $\mathrm{NH}$ protons, the $\mathrm{Q}$ bands are each split into two components labelled $\mathrm{Q}_{x 0}$, $\mathrm{Q}_{x 1}, \mathrm{Q}_{y 0}$, and $\mathrm{Q}_{y 1}$. A similar situation occurs for $\left[\mathrm{Ln}^{\mathrm{III}}(\mathrm{Por}) \mathrm{L}\right]$ complexes as shown in Fig. 43 for [Tb(TPP)(acac)] and $\mathrm{H}_{2} \mathrm{TPP}$. Upon excitation in the Soret band, emission from $\mathrm{S}_{1}$ is observed at $\sim 650$ and $\sim 714 \mathrm{~nm}$ for both coordinated and free TPP, corresponding to the $\mathrm{Q}(0,0)$ and $\mathrm{Q}(0,1)$ components, respectively. ${ }^{257}$ At $77 \mathrm{~K},[\mathrm{Gd}(\mathrm{TPP})(\mathrm{Ac})]$ (Ac is acetate) displays a structured emission band between 600 and $1200 \mathrm{~nm}$ corresponding to the phosphorescence of the porphyrin ring triplet state. ${ }^{258}$

In going from porphyrin to phthalocyanine, large spectroscopic changes occur. For instance, for $\left[\mathrm{Ln}\left(\mathrm{Pc}^{*}\right)_{2}\right]\left(\mathrm{Pc}^{*}\right.$ is tetrapinene substituted Pc, Fig. $35 ; \mathrm{Ln}=\mathrm{Eu}, \mathrm{Er}, \mathrm{Lu}),{ }^{259}$ the Soret band is blue-shifted to about $330-360 \mathrm{~nm}$, while the $\mathrm{Q}$ band presents two components at 623 and $709 \mathrm{~nm}$, the latter being as intense as the Soret band. In addition, two $\pi$-radical related weak bands are seen at 504-525 $\mathrm{nm}$ (blue valence band, BV also called blue vibronic band) and 932-945 $\mathrm{nm}$ (red valence band, RV - also called red vibronic band) as well as a broad structured feature with maxima between 1620 and $1944 \mathrm{~nm}$, assigned to the intervalence transition (IV) between the secondhighest HOMO and the SOMO, corresponding to one electron hopping from one ring to the other. ${ }^{50} \mathrm{~A}$ partial molecular orbital diagram is shown in Fig. 44; the orbitals from which the Pc B bands originate are lower lying $\mathrm{a}_{2 \mathrm{u}}$ and $\mathrm{b}_{2 \mathrm{u}}$ and are not 

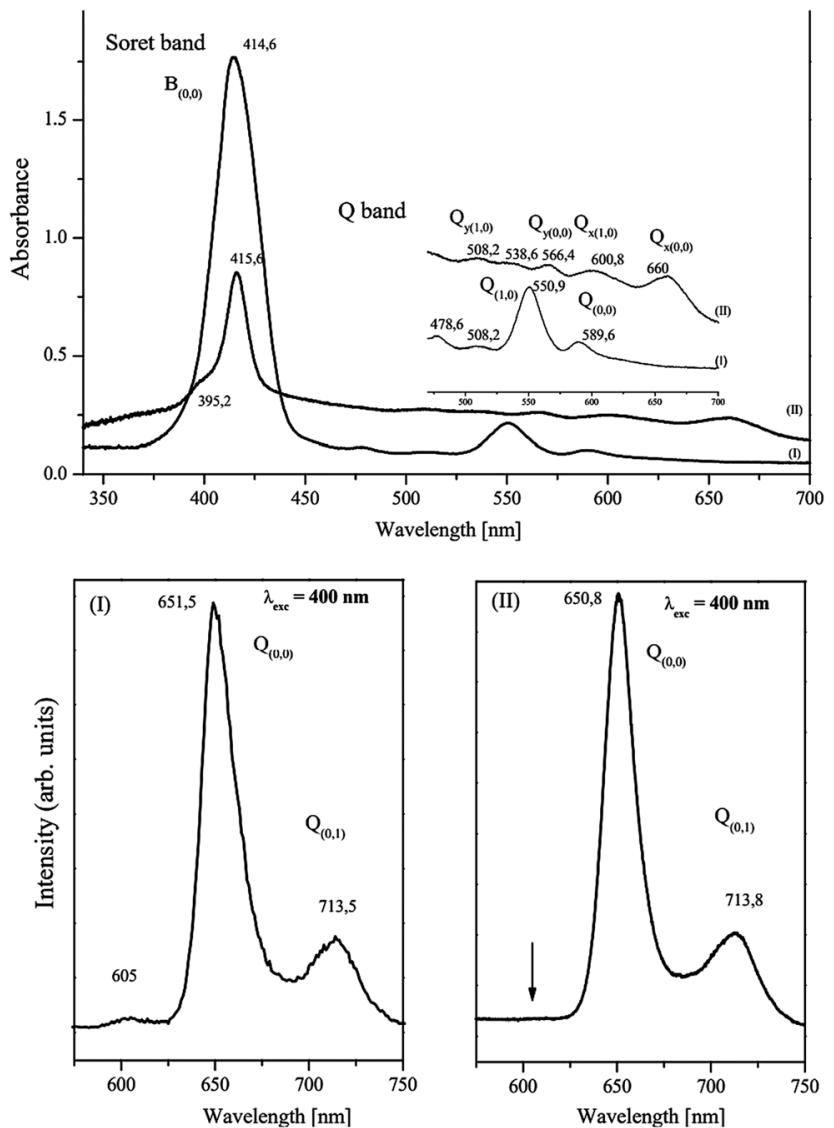

Fig. 43 Absorption spectra (top) of [Tb(TPP)(acac)] (I) and $\mathrm{H}_{2}$ TPP (II) in Nujol and emission spectra of the same compounds $\left(10^{-5} \mathrm{M}\right)$ in $\mathrm{MeOH}$ (bottom). Adapted with permission from ref. 257, copyright (2004) Elsevier B.V.

shown. Note that the intervalence band disappears when the two macrocycles bear the same $2^{-}$charge.

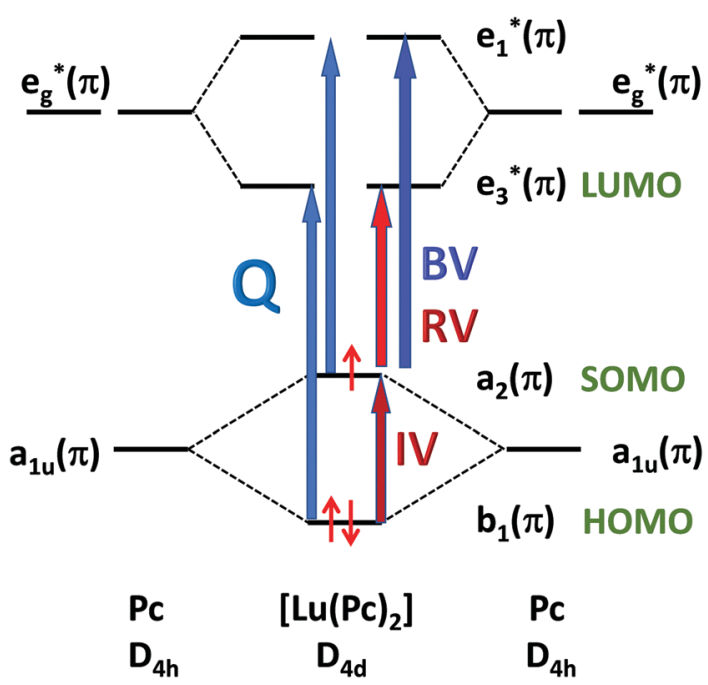

Fig. 44 Frontier molecular orbitals for the $\pi$ system in $\left[\mathrm{Lu}(\mathrm{PC})_{2}\right]$. Redrawn according to ref. 260.

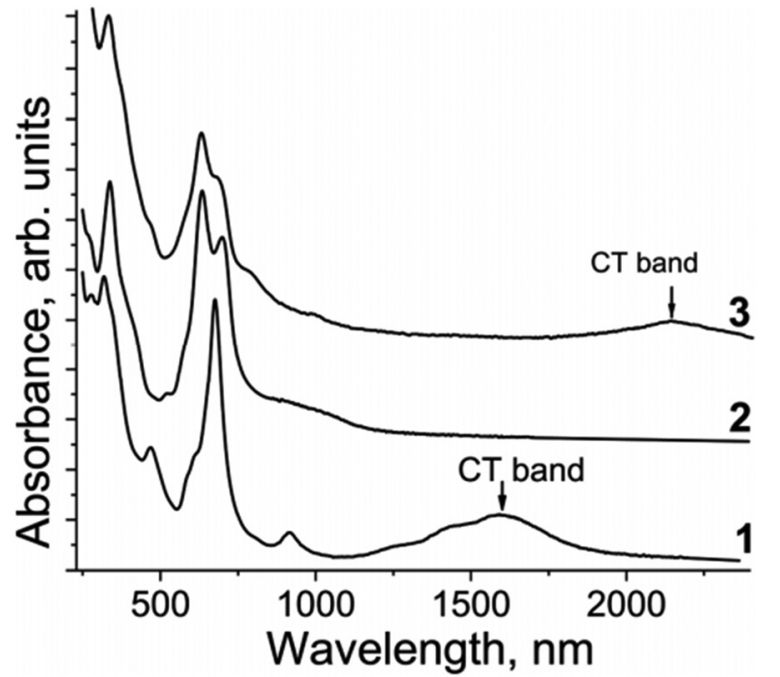

Fig. 45 Absorption spectra of $\left[\left(\mathrm{Pc}^{2-}\right) \mathrm{Tb}\left(\mathrm{Pc}^{\bullet-}\right)\right]^{0}(\mathbf{1}),\left[\mathrm{Tb}\left(\mathrm{Pc}^{2-}\right)_{2}\right]^{-}(\mathbf{2})$, and $\left[\left(\mathrm{PC}^{2-}\right) \mathrm{Tb}\left(\mathrm{PC}^{\cdot 3-}\right)\right]^{2-}(3)$ in $\mathrm{KBr}$ pellets. Reproduced with permission from ref. 262, copyright (2019) The American Chemical Society.

In the triple-decker series $\left[(\mathrm{Pc}) \operatorname{Ln}\left(\mathrm{Pc}(\mathrm{OEt})_{8}\right) \operatorname{Ln}(\mathrm{Pc})\right]$, the energies of the two $\mathrm{Q}$ bands shift linearly as a function of the ionic radii reflecting the increasing $\pi$-interaction between the macrocyclic rings along with the lanthanide contraction. ${ }^{261}$ Redox processes influence the absorption spectra, more particularly the intervalence band: when $\left[\left(\mathrm{Pc}^{2-}\right) \mathrm{Tb}\left(\mathrm{Pc}^{\bullet-}\right)\right]^{0}$ is reduced with 3 equivalents of $\mathrm{Na}\left[\mathrm{CpCo}(\mathrm{CO})_{2}\right]\left(\mathrm{Cp}^{-}\right.$is the cyclopentadienyl anion) to produce the di-anionic species $\left[\left(\mathrm{Pc}^{2-}\right) \mathrm{Tb}\left(\mathrm{Pc}^{\bullet 3-}\right)\right]^{2-}$, the charge transfer (intervalence) band of the radical anions shifts from about $1600 \mathrm{~nm}$ to about $2130 \mathrm{~nm}$, while the other transitions sustain little changes (Fig. 45). The reduced species can be isolated with two $\mathrm{Na}[\operatorname{cryptand}(2,2,2)]^{+}$as counter cations. $^{262}$

Absorption spectra of the naphthalocyaninate complexes retain the main features of their analogues with phthalocyaninates having, however, all absorption bands substantially redshifted due to more extended $\pi$-conjugation. Dependences on the nature of the metal ion are also similar. For instance, in the double-decker series with tetra(t-butyl) substituted Nc, $\left[\operatorname{Ln}\left(\mathrm{NctBut}_{4}\right)_{2}\right](\mathrm{Ln}=\mathrm{La}-\mathrm{Tb}$, except Tm, Y, and Er), the Soret band sustains little changes, remaining in the range of 334-328 nm, while both components of the Q band (694-685 and 799-767 $\mathrm{nm}$ ) as well as the (blue) $\pi$-radical anion band (648-593 $\mathrm{nm})$ are blue-shifted with decreasing ionic radii of the metal ions. On the other hand, the red $\pi$-radical anion transition is red-shifted with decreasing ionic radii (1052-1084 nm). The spectra also display a broad NIR intervalence absorption, blue-shifted (2346-1818 nm) with the lanthanide contraction (Fig. 46, top). ${ }^{241}$ A comparable shift, $\sim 1400 \mathrm{~cm}^{-1}$ between $\mathrm{Nd}$ and $\mathrm{Lu}$, is observed in double-decker complexes with tetra (hexylthio)-derivatized phthalocyanine (Fig. 46, bottom). ${ }^{263} \mathrm{~A}$ direct comparison between the spectra of $\left[\operatorname{Er}(\mathrm{OPPc})_{2}\right](\mathrm{OPPc}$ is octaphenyl $\mathrm{Pc}$ ) and $\left[\mathrm{Eu}(\mathrm{OPNc})_{2}\right]$ (OPNc is octaphenyl $\mathrm{Nc}$ ) is shown in Fig. 47, exemplifying an approximate bathochromic 

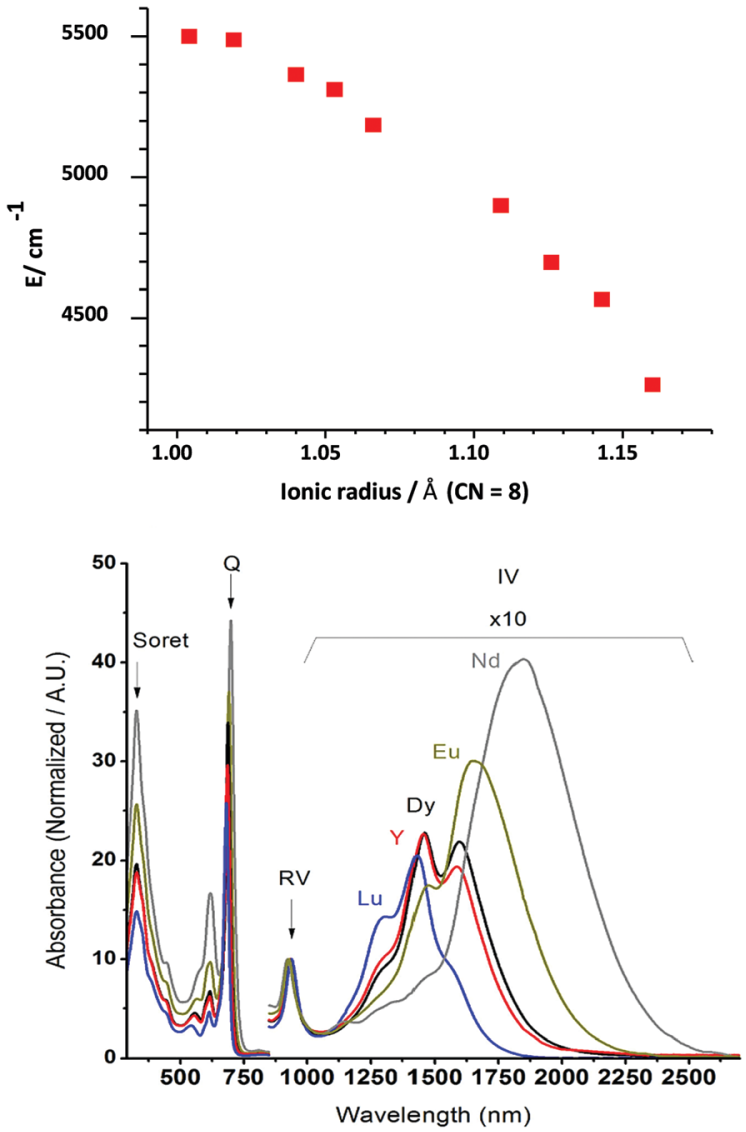

Fig. 46 (Top) Dependence of the energy of the NIR intervalence band on ionic radii in the double-decker series [ $\left.\mathrm{Ln}\left(\mathrm{NctBut}_{4}\right)_{2}\right](\mathrm{Ln}=\mathrm{La}-\mathrm{Tb}$, except $\mathrm{Pm}, \mathrm{Y}$, and Er). Drawn from the data in ref. 241. (Bottom) Absorption spectra of oxidized $\left[\mathrm{Ln}\left(\mathrm{SHex}_{4} \mathrm{Pc}^{\cdot-}\right)_{2}\right]^{+}$showing the large blue shift of the IV band with decreasing ionic radius. Reproduced with permission from ref. 263, copyright (2014) The American Chemical Society.

shift of $100 \mathrm{~nm}$ for the $\mathrm{Q}$ bands and up to $200 \mathrm{~nm}$ for the intervalence bands. ${ }^{239}$

As for the complexes with other corrole ligands, electronic spectra of the lanthanide naphthalocyaninates change with their oxidation state. An earlier study on double- and tripledecker complexes with 1,2-naphthalocyanine and 2,3naphthalocyanine (Fig. 35) sheds light on this aspect by recording the absorption spectra of the double deckers $\left[\mathrm{Lu}\left(\mathrm{Nc}^{\prime}\right)_{2}\right]^{n}(n=$ $-2,-1,0,+1)$ and the triple deckers $\left[\mathrm{Lu}_{2}\left(\mathrm{Nc}^{\prime}\right)_{3}\right]^{n}(n=-4,-3$, $-2,-1,0,+1$, and +2$).{ }^{264}$ Since only the first reduced and oxidized forms of these compounds are stable, spectra of more reduced or oxidized forms have been acquired under electrochemical conditions. The first reduction of neutral $\left[\mathrm{Lu}^{3+}\left(\mathrm{Nc}^{\prime}\right)^{2-}\left(\mathrm{Nc}^{\prime}\right)^{\bullet-}\right]$ in benzonitrile does not influence much the Soret band but leads to a splitting of the $\mathrm{Q}$ band at $674 \mathrm{~nm}$ into two components (638 and $718 \mathrm{~nm}$ ) for $\left[\mathrm{Lu}^{3+}\left(\mathrm{Nc}^{\prime}\right)^{2-}\left(\mathrm{Nc}^{\prime}\right)^{2-}\right]^{-}$and, upon further reduction to $\left[\mathrm{Lu}^{3+}\left(\mathrm{Nc}^{\prime}\right)^{2-}\left(\mathrm{Nc}^{\prime}\right)^{\bullet 2-}\right]^{2-}$, into three components $(\sim 590, \sim 640$, and $\sim 700 \mathrm{~nm})$. The first reduction also suppresses the $\pi$ radical anion band at $509 \mathrm{~nm}$. Compared with $\left[\mathrm{Lu}(\mathrm{Pc})_{2}\right]$, the red shift of the $\mathrm{Q}$ band of $\left[\mathrm{Lu}\left(\mathrm{Nc}^{\prime}\right)_{2}\right]$ is modest $(18 \mathrm{~nm})$, but considerable for $\left[\mathrm{Lu}(\mathrm{Nc})_{2}\right](102 \mathrm{~nm})$. Oxidation of $\left[\mathrm{Lu}^{3+}\left(\mathrm{Nc}^{\prime}\right)^{2-}\left(\mathrm{Nc}^{\prime}\right)^{\bullet-}\right]$ yielding $\left[\mathrm{Lu}^{3+}\left(\mathrm{Nc}^{\prime}\right)^{\bullet-}\left(\mathrm{Nc}^{\prime}\right)^{\bullet-}\right]^{+}$leads to a large splitting of the $\mathrm{Q}$ band into two components, at $550 \mathrm{~nm}$ and $710 \mathrm{~nm}$, similarly to what is observed for $\left[\mathrm{Lu}(\mathrm{Pc})_{2}\right]$ and $\left[\mathrm{Lu}(\mathrm{Nc})_{2}\right]$. Triple deckers display larger changes in their electronic spectra upon reduction and oxidation. Comparison between the double and triple deckers shows that stacking one $\left[\mathrm{Lu}\left(\mathrm{Nc}^{\prime}\right)^{2-}\right]^{+}$moiety over $\left[\mathrm{Lu}\left(\mathrm{Nc}^{\prime}\right)^{2-}\left(\mathrm{Nc}^{\prime}\right)^{2-}\right]^{-}$extends the delocalization over three rings and modifies significantly the electronic levels. In fact the observed spectrum in the region of the $\mathrm{Q}$ bands is very similar to a summation of the transitions of the neutral $\left[\mathrm{Lu}^{3+}\left(\mathrm{Nc}^{\prime}\right)^{2-}\left(\mathrm{Nc}^{\prime}\right)^{--}\right]$and reduced $\left[\mathrm{Lu}^{3+}\left(\mathrm{Nc}^{\prime}\right)^{2-}\left(\mathrm{Nc}^{\prime}\right)^{2-}\right]^{-}$forms.

\subsection{Sensitization of NIR-emitting lanthanide ions}

The emissive properties of lanthanide ions are governed by the ease with which energy transfer from the donor ligands can be optimized and nonradiative deactivation paths minimized. Furthermore, selection rules forbidding electric dipole $\mathrm{f}-\mathrm{f}$ transitions have to be somewhat relaxed. Important

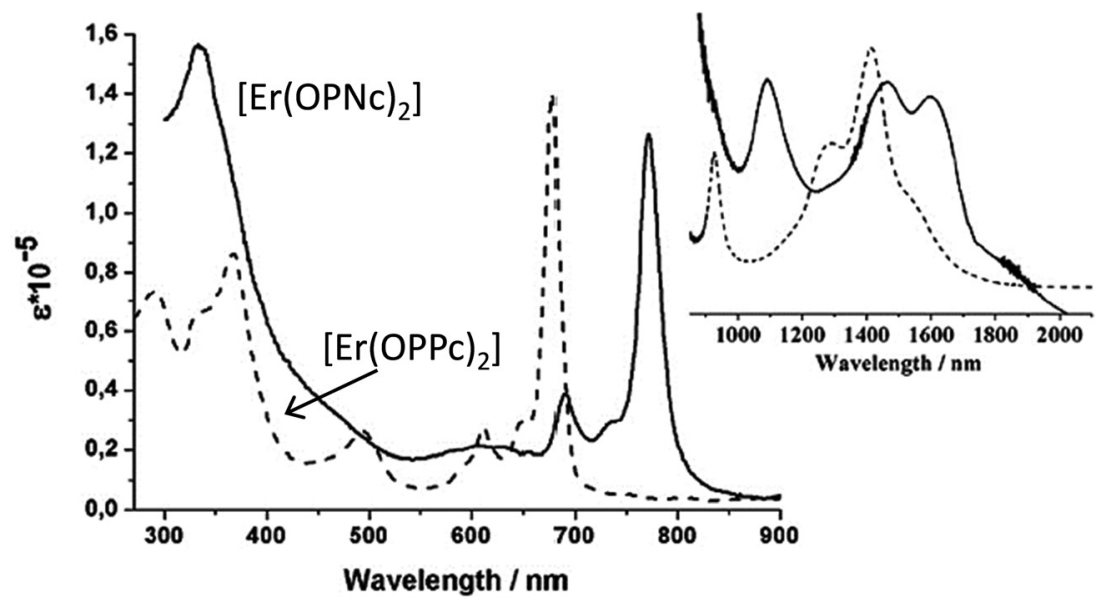

Fig. 47 Comparison between the absorption spectra of $\left[\mathrm{Er}(\mathrm{L})_{2}\right]$ with $\mathrm{L}=\mathrm{OPPc}$ and OPNc. Adapted with permission from ref. 239, copyright (2014) The Royal Society of Chemistry. 
mechanisms are the $J$-mixing and the mixing with oppositeparity wavefunctions such as $5 \mathrm{~d}$ orbitals, ligand orbitals, or charge transfer states. However, in view of the shielding of the $4 \mathrm{f}$ orbitals by the filled $5 \mathrm{~s}^{2} 5 \mathrm{p}^{6}$ subshells, the degree of mixing remains small. Coupling with vibrational modes is ambivalent; on the one hand it lowers the symmetry around the metal ion, resulting in more allowed transitions, but on the other hand it opens efficient non-radiative deactivation channels. While optimizing energy transfer from the surroundings to the emitting metal ion is relatively well understood and mastered despite its complexity involving several electronic levels and mechanisms, ${ }^{265}$ shutting down nonradiative deactivation mechanisms is much more difficult, particularly if the energy gap between the excited and ground states is small, which is the case for NIR emitting ions. This is predominantly true for coordination complexes with organic ligands which bring highenergy vibrations (e.g. O-H, N-H. C-H) in close proximity with the emitting ion. As a consequence, until recently, the quantum yields of NIR-emitting lanthanide coordination complexes with organic ligands were rather low, especially in the case of $\mathrm{Nd}^{\mathrm{III}}$ and $\mathrm{Er}^{\mathrm{III}}$. Ytterbium has a larger energy gap so that the quantum yields of a few percent have been routinely achieved. ${ }^{256}$ As will be described below, tetrapyrrole complexes have largely contributed to substantial improvements to this field.

Sensitization of lanthanide luminescence is described by the following equations (Fig. 48). To quantify it, two different quantum yields have to be determined: the overall quantum yield $Q_{\mathrm{Ln}}^{\mathrm{L}}$ obtained by excitation into the ligand levels (eqn (1)) and the intrinsic quantum yield $Q_{\mathrm{Ln}}^{\mathrm{Ln}}$ measured upon direct excitation into the excited states of the lanthanide ion (eqn (2)):

$$
Q_{\mathrm{Ln}}^{\mathrm{L}}=\frac{\text { number of photons emitted by the metal ion }}{\text { number of photons absorbed by the ligand }}=\frac{I_{\mathrm{Ln}}(E)}{I_{\mathrm{L}}(A)}
$$

$Q_{\mathrm{Ln}}^{\mathrm{Ln}}=\frac{\text { number of photons emitted by the metal ion }}{\text { number of photons absorbed by the metal ion }}=\frac{I_{\mathrm{Ln}}(E)}{I_{\mathrm{Ln}}(A)}$

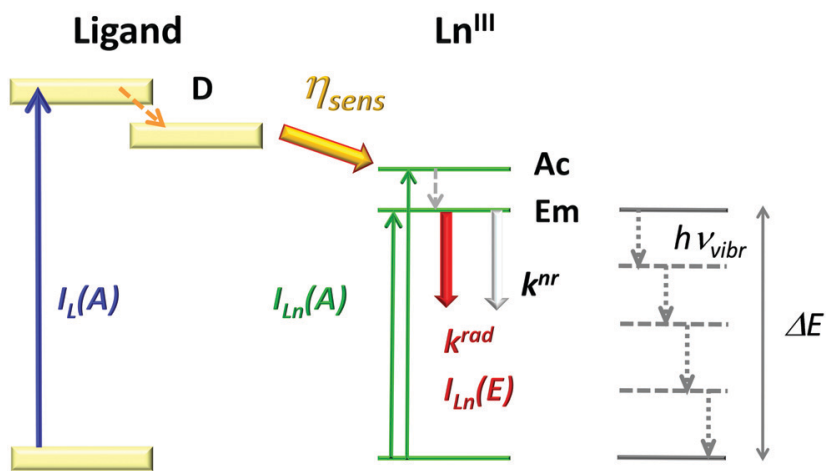

Fig. 48 Simplified schematic energy diagram of the sensitization of lanthanide luminescence. $A$ is absorption; $E$, emission; $D$, the ligand donor state; Ac and Em, the accepting and emitting states of the metal ion, respectively; $k s$ are first order rate constants.
The overall quantum yield is always smaller than the intrinsic quantum yield or at most equal. External and internal quantum yields are sometimes used to define these two quantities, but since these have different meanings in other fields of photonics, they should be avoided here. ${ }^{266}$ The sensitization efficiency of the chromophoric ligand is then simply defined as

$$
\eta_{\text {sens }}=\frac{Q_{\mathrm{Ln}}^{\mathrm{L}}}{Q_{\mathrm{Ln}}^{\mathrm{Ln}}}
$$

Experimentally, measurement of the overall quantum yield is a commonly used procedure and, except for the necessary precautions to be exercised, ${ }^{267}$ is relatively straightforward even if experimental uncertainties are on the order of at least $\pm 10 \%$. Determination of $Q_{\mathrm{Ln}}^{\mathrm{Ln}}$ is more difficult because $\mathrm{f}-\mathrm{f}$ transitions have faint cross sections and are often overlapped by intense and large absorption bands from the ligands. One way out is to consider the following equation:

$$
Q_{\mathrm{Ln}}^{\mathrm{Ln}}=\frac{k^{\mathrm{rad}}}{k^{\mathrm{rad}}+\sum k^{\mathrm{nr}}}=\frac{\tau_{\mathrm{obs}}}{\tau_{\mathrm{rad}}}
$$

which shows the intrinsic quantum yield depending only on the observed and radiative lifetimes. The latter is the lifetime of the emitting excited state in the absence of any nonradiative deactivation process. For lanthanide ions, it can be calculated in several ways. The first relies on the fact that $\tau_{\text {rad }}$ is related to Einstein's rates of spontaneous emission $W$ from an initial state $\left|\Psi_{J}\right\rangle$, characterized by a quantum number $J$, to a final state $\left|\Psi_{J^{\prime}}^{\prime}\right\rangle$ :

$$
\begin{aligned}
W\left(\Psi_{j}, \Psi_{J^{\prime}}^{\prime}\right) & =k_{\mathrm{rad}}=\frac{1}{\tau_{\mathrm{rad}}} \\
& =\frac{64 \pi^{4} \tilde{\nu}^{3}}{3 h(2 J+1)}\left[\frac{n\left(n^{2}+2\right)^{2}}{9} D_{\mathrm{ED}}+n^{3} D_{\mathrm{MD}}\right]
\end{aligned}
$$

where $\bar{\nu}$ is the barycentre of the transition, $n$ the refractive index, and $D_{\mathrm{ED}}$ and $D_{\mathrm{MD}}$ the electric dipole and magnetic dipole oscillator strengths, respectively. Calculations are relatively involved since they necessitate the determination of Judd-Ofelt parameters. ${ }^{268}$ A more straightforward approach can be adopted if the corresponding absorption spectrum can be recorded, i.e., if the emissive transition terminates in the ground state:

$$
\frac{1}{\tau_{\text {rad }}}=2303 \times \frac{8 \pi c n^{2} \tilde{\nu}^{2}(2 J+1)}{N_{\mathrm{A}}\left(2 J^{\prime}+1\right)} \int \varepsilon(\tilde{\nu}) \mathrm{d} \tilde{\nu}
$$

where $N_{\mathrm{A}}$ is Avogadro's number and $\varepsilon(\bar{\nu})$ the absorption spectrum expressed in terms of molar absorption versus wavenumbers. In the case of $\mathrm{Eu}^{\mathrm{III}}$, the situation simplifies because the excited ${ }^{5} \mathrm{D}_{0}$ level has $J=0$ and the ${ }^{5} \mathrm{D}_{0} \rightarrow{ }^{7} \mathrm{~F}_{1}$ transition is purely magnetic dipolar. Then, $\tau_{\text {rad }}$ can be simply determined from the emission spectrum and the refractive index:

$$
W\left(\Psi_{J}, \Psi_{J^{\prime}}^{\prime}\right)=\frac{1}{\tau^{\mathrm{rad}}}=W_{\mathrm{MD}, 0} \cdot n^{3}\left(\frac{I_{\mathrm{tot}}}{I_{\mathrm{MD}}}\right)
$$

where $W_{\mathrm{MD}, 0}$ is equal to $14.65 \mathrm{~s}^{-1}$ and $I \mathrm{~s}$ are integrated emission spectra of all ${ }^{5} \mathrm{D}_{0} \rightarrow{ }^{7} \mathrm{~F}_{J}(J=0-6)$ transitions and of 


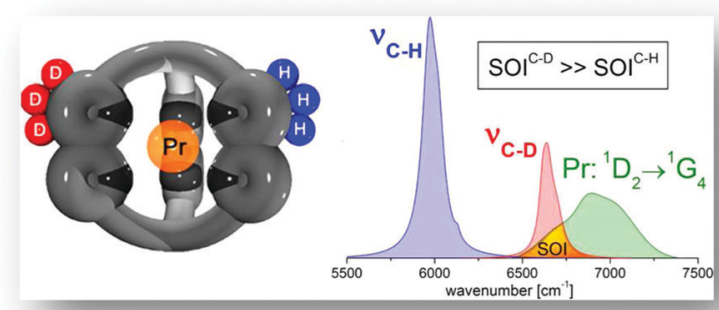

Fig. 49 Spectral overlap integrals between the second $\nu_{C-D}$ overtone and the first $\nu_{\mathrm{C}-\mathrm{H}}$ overtone with the ${ }^{1} \mathrm{D}_{2} \rightarrow{ }^{1} \mathrm{G}_{4}$ emission band of a Pr ${ }^{\prime \prime \prime}$ cryptate. Reproduced with permission from ref. 269, copyright (2012) The American Chemical Society.

the ${ }^{5} \mathrm{D}_{0} \rightarrow{ }^{7} \mathrm{~F}_{1}$ transition, respectively. Then eqn (3) becomes

$$
\eta_{\text {sens }}=Q_{\mathrm{Ln}}^{\mathrm{L}} \times \frac{\tau_{\mathrm{rad}}}{\tau_{\mathrm{obs}}}
$$

Such an analysis has unfortunately rarely been done for lanthanide complexes with tetrapyrrole ligands and even quantum yield and lifetime data are not systematically reported. Moreover, due to the difficulty in measuring the overall quantum yields of NIR emitting complexes, intrinsic quantum yields determined with eqn (4) are given, based on the estimated $\tau_{\text {rad }}$ values taken from other (often inorganic) compounds, wrongly assuming that $\tau_{\mathrm{rad}}$ is a constant for a given ion, while it depends on the particular emitting level, on the chemical environment of the ion, and on the refractive index. Therefore, in the following we shall favour the description of works reporting experimentally measured quantitative data.

For NIR-emitting lanthanides, a major hurdle to highly luminescent materials is minimization of nonradiative processes. Indeed, the energy gap $\Delta E$ is small and can easily be bridged by vibrations and their overtones (see the right-hand side of Fig. 48). To put it simply, two models describe the situation. The first one, the "energy-gap law," relates the nonradiative rate constant to the ratio of the energy gap divided by the most energetic vibrational mode in the molecule or matrix into which the luminescent ion is doped:

$$
k_{\mathrm{nr}}^{\mathrm{vibr}}=A \cdot \mathrm{e}^{-B\left(\Delta E / h \nu_{\max }\right)}
$$

Therefore, decreasing $h \nu_{\max }$ will increase the number of phonons necessary for bridging the energy gap and decrease $k_{\mathrm{nr}}$. This is a reason why a standard experimental practice is to replace $\mathrm{X}-\mathrm{H}$ vibrators with $\mathrm{X}-\mathrm{D}$ or $\mathrm{X}$-hal ones $(\mathrm{X}=\mathrm{C}, \mathrm{N}, \mathrm{O}$; hal = $\mathrm{F}, \mathrm{Cl}$ ). A common rule of thumb is to try to design luminescent materials for which $h \nu_{\max }$ is smaller than $\Delta E / 6$. But, as for all simple models, the energy gap law has its limitations. In particular, it implicitly considers vibrations being harmonic, while anharmonic oscillators should be used, then several vibrations may contribute to the quenching while only one is considered and, finally, since the mechanism of quenching is of dipole-dipole nature, the spectral overlap integral (SOI) between the absorption band(s) of the vibration(s) and/or overtone(s) and the emission spectrum of the quenched ion should be considered: ${ }^{269}$

$$
k_{\mathrm{nr}}^{\mathrm{vibr}}=\frac{161.9 \cdot k_{\mathrm{rad}} \cdot \kappa^{2}}{\pi^{2} \cdot n^{4} \cdot N_{\mathrm{A}} \cdot r^{6}} \times \int \varepsilon_{\mathrm{vibr}}(\tilde{\nu}) \cdot I_{\mathrm{em}}(\tilde{\nu}) \cdot \tilde{\nu}^{4} \cdot \mathrm{d} \tilde{\nu}
$$

where $\kappa$ is a factor depending on the relative orientation of the transition dipole moment of the lanthanide ion and the acceptor oscillator; $r$ is the distance between $\mathrm{Ln}^{\mathrm{III}}$ and the oscillator. The case of a $\operatorname{Pr}^{\mathrm{III}}$ cryptate with (bpy, bpy, bpy) is illustrative of this model: upon partial deuteration, the intensity of the emission from the $\operatorname{Pr}^{\mathrm{III}}\left({ }^{1} \mathrm{D}_{2}\right)$ level decreases, while an increase was expected; the reason is a much larger SOI between the second overtone of $\nu_{\mathrm{C}-\mathrm{D}}\left(3 \times 2300=6900 \mathrm{~cm}^{-1}\right)$ and the ${ }^{1} \mathrm{D}_{2} \rightarrow$ ${ }^{1} \mathrm{G}_{4}$ emission band (6500-7600 $\mathrm{cm}^{-1}$ ), compared with the overlap with the first overtone of $\nu_{\mathrm{C}-\mathrm{H}}\left(2 \times 3100=6200 \mathrm{~cm}^{-1}\right)$, as shown in Fig. 49.

As can be seen from eqn (4), shortening the radiative lifetime would be beneficial in that this would increase the intrinsic quantum yield. This can be done either by increasing the polarizability of the Ln-ligand bonds, not easy to achieve, or by modifying the refractive index: increasing the refractive index by doping the luminescent compound into a matrix, for instance, will decrease $\tau_{\text {rad }}, c f$. eqn (5)-(7).

\subsection{NIR-emissive lanthanide-porphyrin complexes}

The combination of tetrapyrrole ligands with rare earth ions has been studied since the mid-1960s and this is also true for their luminescence properties, in particular when the ligand is a porphyrin. Indeed, due to low-energy electronic states, phthalocyanines and naphthalocyanines, particularly multipledecker compounds, are less well suited for sensitizing NIRemitting lanthanide ions. The field has been reviewed regularly since the turn of the century, ${ }^{32,256,260,270-274}$ including applications to bioanalysis and bioimaging. ${ }^{275-278}$ In some instances, polyaminocarboxylic acid groups ${ }^{115,279}$ or tris(dipicolinates) ${ }^{213}$ have been attached to porphyrins or to their transition metal complexes $(\mathrm{M}=\mathrm{Zn}, \mathrm{Pd}, \mathrm{Pt})$; the flexibility of the resulting assemblies is large enough to bring the $\mathrm{Ln}^{\mathrm{III}}$ ions close to the porphyrin core which then can sensitize their luminescence. Such work is not discussed in detail here.

Porphyrin complexes with ytterbium are the most studied because the relatively large energy gap of this ion $\left(\sim 10000 \mathrm{~cm}^{-1}\right)$ limits nonradiative deactivations and because the triplet states of porphyrins (12-15000 $\left.\mathrm{cm}^{-1}\right)$ have adequate energy for efficient energy transfer onto $\mathrm{Yb}^{\mathrm{III}}$. On the other hand, $\mathrm{Yb}^{\mathrm{III}}$ has only two spectroscopic levels, ${ }^{2} \mathrm{~F}_{7 / 2}$ (ground level) and ${ }^{2} \mathrm{~F}_{5 / 2}$, so that energy transfer is limited to the latter, contrary to other ions such as $\mathrm{Nd}^{\mathrm{III}}$ or $\mathrm{Er}^{\mathrm{III}}$ which feature several higher energy levels (Fig. 42) rendering energy transfer processes easier. Since sensitization of $\mathrm{Yb}^{\mathrm{III}}$ luminescence by ligands with donor states of relatively high energy $\left(20-25000 \mathrm{~cm}^{-1}\right)$ has also been identified, alternative mechanisms have been proposed: either a phonon-assisted energy transfer or an electron-transfer path during which $\mathrm{Yb}^{\mathrm{III}}$ is first reduced to $\mathrm{Yb}^{\mathrm{II}}$ producing a ligand radical cation which in turn re-oxidizes $\mathrm{Yb}^{\mathrm{II}}$ producing excited $\mathrm{Yb}^{\text {III }}{ }^{256}$ 
4.3.1 Ytterbium monoporphyrinates. When reacting a lanthanide ion with a porphyrin macrocycle, the cation strongly binds to the tetraaza core of the macrocycle but in order to complete its coordination sphere up to a coordination number of usually 8 (or 7), additional ligands also bind, e.g., solvent molecules, anions, or ancillary ligands. These ligands are often labile, rendering the complexes unstable in solution; they decompose yielding the free porphyrin base or, under special conditions, they may form double or triple deckers. One way to stabilize monoporphyrinate complexes is to use strongly coordinating ligands such as diketonates, e.g. acetylacetonate (acac), or capping tripodal ligands, e.g. hydrido-tris(pyrazol-1yl)borate $\left(\mathrm{Tp}^{\mathrm{H}}\right)^{55}$ or Kläui's ligand $\left(\mathrm{CoP}^{\mathrm{Et}}\right),{ }^{51}$ as depicted in Fig. 50. The tripodal ligands protect the monoporphyrinates from interaction with the solvent and overall quantum yields of $3.2 \%$ and $2.4 \%$ have been reported for $[\mathrm{Yb}(\mathrm{TPP})(\mathrm{L})]$ in $\mathrm{CH}_{2} \mathrm{Cl}_{2}$ with $\mathrm{L}=\mathrm{Tp}^{\mathrm{H}}$ and $\mathrm{CoP}^{\mathrm{Et}}$, respectively. Protection from solvent interaction is demonstrated by the overall quantum yield of $\left[\mathrm{Yb}(\mathrm{TPP})\left(\mathrm{Tp}^{\mathrm{H}}\right)\right]$ increasing to only $3.4 \%$ in going from $\mathrm{CH}_{2} \mathrm{Cl}_{2}$ to $\mathrm{CD}_{3} \mathrm{Cl}^{72}$ Replacing water and chloride in $\left[\mathrm{Yb}\left(\mathrm{PorR}_{4}\right)\left(\mathrm{H}_{2} \mathrm{O}\right)_{3}\right] \mathrm{Cl}$ ( $\mathrm{R}$ is $p$-hydroxyphenyl and substitution is in the meso positions) with $\mathrm{CoP}^{\mathrm{Et}}$ leads to a 4.4-fold increase in the peak intensity of the $\mathrm{Yb}^{\mathrm{III}}$ luminescence in ethanol, with lifetime reaching $40 \mu \mathrm{s} .{ }^{69}$ In another study the water molecules in $\left[\mathrm{Yb}(\mathrm{TPP})\left(\mathrm{H}_{2} \mathrm{O}\right)_{3}\right] \mathrm{Cl}$ have been replaced with various bi- and tridentate ligands to yield [Yb(TPP)L $\left.\left(\mathrm{H}_{2} \mathrm{O}\right)\right]$ with $\mathrm{L}=$ 8-hydroxyquinolinate, 1-hydroxy-7azabenzotriazolate $\left(\mathrm{BTA}^{-}\right)$, 2-benzimidazolylguanidinate, and hexafluoro-acetylacetonate $\left(\mathrm{hfa}^{-}\right)$or $\mathrm{Tp}^{\mathrm{H}}$, in which all inner sphere water molecules are removed; the intrinsic quantum yield in dichloromethane, calculated with a literature value of $\tau_{\text {rad }}=1.2 \mathrm{~ms}$, improved from $0.1 \%$ to $1.7 \%$ for $\mathrm{BTA}^{-}$and $\mathrm{Tp}^{\mathrm{H}-} \cdot{ }^{280}$ The capping ligand $\mathrm{Tp}^{\mathrm{H}-}$ has also been used to isolate $\left[\mathrm{Nd}\left(\mathrm{TP}^{\mathrm{R}} \mathrm{P}\right)\left(\mathrm{Tp}^{\mathrm{H}}\right)\right]$ with $\mathrm{P}^{\mathrm{R}}=p$-substituted phenyl $(\mathrm{R}=\mathrm{H}$, OMe, $\mathrm{Me}, \mathrm{Cl}, \mathrm{F}$ ); intrinsic quantum yields in toluene are in the range of $0.1-0.33 \% ;^{281}$ similar values $(0.18-0.28 \%)$ are obtained with $\mathrm{CoP}^{\mathrm{Et}}$ as the tripodal ligand. ${ }^{54}$

Neutral bidentate ligands such as phenanthroline and its derivatives are equally efficient for replacing the solvent molecules in $\left[\mathrm{Yb}(\mathrm{TPP})(\mathrm{Ac})(\mathrm{Solv})_{2}\right]$ and improving the photophysical properties, with the intrinsic quantum yield, calculated assuming $\tau_{\text {rad }}=1.2 \mathrm{~ms}$, increasing from $0.13 \%$ to about $1.5 \%$ in toluene. $^{282}$

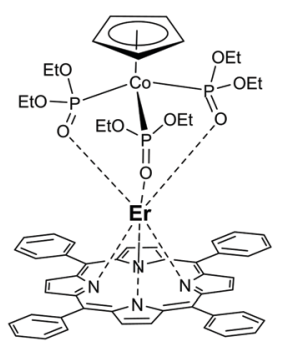

$\left[\operatorname{Er}(\mathrm{TPP})\left(\mathrm{CoP}^{\mathrm{Et}}\right)\right]$

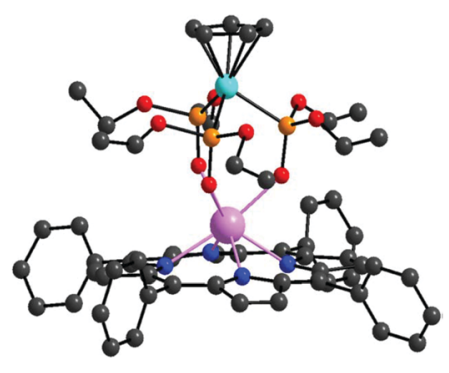

Fig. 50 Stabilization of a monoporphyrinate complex with Kläui's tripodal capping ligand. Drawn from data in ref. 51.

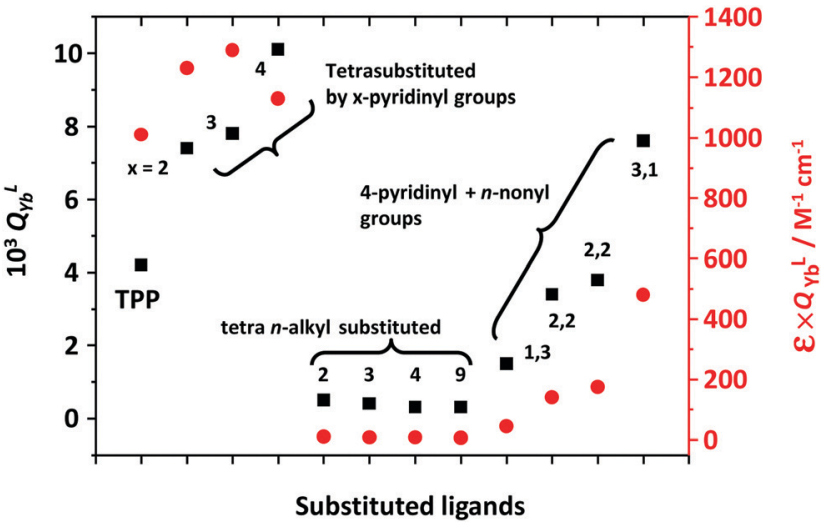

Fig. 51 Quantum yield (black squares) and brightness (red circles) of [Yb(subst-Por)(acac)] complexes in methanol where Por is mesosubstituted with different pyridinyl and alkyl groups. For alkyl groups, the numbering indicates the length of the carbon chain; for mixed substitution, the numbering refers to the number of pyridinyl/alkyl groups; there are two positional isomers for $(2,2)$. Drawn from data reported in ref. 283.

Influence of meso substitution of porphyrin by various alkyl (ethyl, n-propyl, n-butyl, n-nonyl and 2-, 3-, and 4-pyridinyl groups) on $\mathrm{Yb}^{\mathrm{III}}$ luminescence has been elucidated; the quantum yield and brightness $\left(B=\varepsilon \times Q_{\mathrm{Ln}}^{\mathrm{L}}\right)$ obtained by excitation in the Soret band are displayed schematically in Fig. 51 along with those for $[\mathrm{Yb}(\mathrm{TPP})(\mathrm{acac})]$ as a reference. The lowest quantum yields are obtained with the alkyl-substituted ligands and they decrease with increasing chain length, probably due to an increased number of $\mathrm{C}-\mathrm{H}$ groups and to a larger flexibility of the alkyl chain leading to more vibrational quenching, reflected by a decrease in lifetime from 1.7 to $0.9 \mu \mathrm{s}$. Replacing the phenyl groups by pyridinyl ones results in a substantial increase of the quantum yield which reaches a maximum (1\%) for 4-pyridinyl groups; this can be explained by better $\pi$ conjugation. The mixed substitution confirms these findings and exemplifies the positive effect of 4-pyridinyl groups on the quantum yield. Interestingly, the brightness of the monoporphyrinates with phenyl or pyridinyl substituents remains high ( 1000-1300 $\mathrm{M}^{-1} \mathrm{~cm}^{-1}$ ) despite the small quantum yields, owing to the large molar absorption coefficients $(\log \varepsilon=5.0-$ 5.2). It is noteworthy that the best brightness, an important parameter for practical applications, does not necessarily correspond to the largest quantum yield. Finally, the influence of the additional ligand has also been tested. Among $\mathrm{Cl}^{-}, \mathrm{Br}^{-}$, $\mathrm{acac}^{-}$, $\mathrm{ba}^{-}$(benzoyl acetonate), and $\mathrm{tta}^{-}$(thenoyltrifluoroacetonate), acac $^{-}$yields the best performance. ${ }^{283}$

A relatively large intrinsic quantum yield has been reported for 8-coordinated [ $\mathrm{Yb}(\mathrm{TPP})(\mathrm{acac})(4-\mathrm{MePhen})], 0.86 \%$ in methylene chloride based on $\tau_{\mathrm{obs}}=17.3 \mu \mathrm{s}$ and by using $\tau_{\text {rad }}=2 \mathrm{~ms}{ }^{75}$ which is too long. $\mathrm{Yb}^{\mathrm{III}}$ radiative lifetimes determined for 8coordinated benzoxazole-substituted 8-hydroxyquinoline complexes in methylene chloride are in the range of $0.7-0.75 \mathrm{~ms}$ with an overall quantum yield of up to $2.6 \%$ and $\tau_{\text {obs }}$ of up to $20 \mu \mathrm{s},{ }^{284}$ so that the intrinsic quantum yield of [Yb(TPP)(acac)(4-MePhen)] is more probably in the range of $2.1-2.4 \%$. 
Tetraphenylporphyrin has been unsymmetrized by adding one $\mathrm{R}$ substituent in position 7 (also designed as $\beta$-position). Among the substituents tested, chalcones gave the best photophysical results. For $\mathrm{R}=1$-methyl-prop-2-en-1-one and $\mathrm{R}=1$-phenyl-prop-2-en-1-one, the overall quantum yields of $\left[\mathrm{Yb}\left(\mathrm{TPP}^{\mathrm{R}}\right)(\mathrm{acac})\right]$ in DMF solutions $\left(5 \times 10^{-5} \mathrm{M}\right)$ amount to $1.3 \%$ and $4.7 \%$, respectively; at the time of publication, the latter figure was one of the largest values reported for monoporphyrinates. ${ }^{285}$ One of the phenyl groups of TPP has also been derivatized in the 4-position by a polyaminocarboxylate group (EDTA or DTPA); mononuclear complexes $(1 \mu \mathrm{M})$ in DMF show a low overall quantum yield, $0.11-0.14 \%$, but when a second $\mathrm{Yb}^{\mathrm{III}}$ ion is bound to the polyaminocarboxylate moiety, this figure goes up to $0.28-0.32 \% .^{286}$

A decisive step was achieved by a systematic investigation of deuteration and fluorination effects. Tetrakis(pentafluorophenyl) porphyrin $\left(\mathrm{F}_{20} \mathrm{TPP}\right)$ has been $\beta$-substituted by deuterium or fluorine and the photophysical properties of the complexes with a non-deuterated or partially deuterated Kläui's tripodal ligand $\left[\mathrm{Yb}\left(\mathrm{F}_{20} \mathrm{TPP}^{\mathrm{X}}\right)\left(\mathrm{CoP}^{\mathrm{R}}\right)\right]$, where $\mathrm{X}=\mathrm{H}, \mathrm{D}$, or $\mathrm{F}$ and $\mathrm{R}=\mathrm{CH}_{3}$, $\mathrm{CD}_{3}, \mathrm{C}_{2} \mathrm{D}_{5}$ or $\mathrm{C}\left(\mathrm{CD}_{3}\right)_{2}$, have been determined in methylene chloride and compared. ${ }^{100}$ Deuteration of the methyl groups in Kläui's ligand increases the overall quantum yield from $5.1 \%$ for $\left[\mathrm{Yb}\left(\mathrm{F}_{20} \mathrm{TPP}^{\mathrm{F}}\right)\left(\mathrm{CoP}^{\mathrm{CH} 3}\right)\right]$ to $25 \%$ for $\left[\mathrm{Yb}\left(\mathrm{F}_{20} \mathrm{TPP}^{\mathrm{F}}\right)\left(\mathrm{CoP}^{\mathrm{CD} 3}\right)\right]$ (Fig. 52), while the lifetime increases from 49 to $285 \mu \mathrm{s}$. Replacing the deuterated methyl groups with deuterated ethyl or isopropyl groups has no influence so that subsequent measurements have been performed with the $\mathrm{CD}_{3}$-derivatized tripodal ligand. The influence of the $\beta$-substituents is also quite dramatic, the quantum yield increasing from $3.9 \%(\mathrm{H})$ to $15 \%$ (D) and $25 \%(\mathrm{~F})$, with lifetime increasing from 54 to 180 and $285 \mu \mathrm{s}$, respectively. On the other hand, the hydrogen atoms of the phenyl substituents have less effect with the quantum yield of $\left[\mathrm{Yb}\left(\mathrm{TPP}^{\mathrm{F}}\right)\left(\mathrm{CoP}^{\mathrm{CD} 3}\right)\right]$ remaining high at $20 \%$, with a lifetime of $197 \mu \mathrm{s}$. As a comparison, $\left[\mathrm{Yb}(\mathrm{TPP})\left(\mathrm{CoP}^{\mathrm{Et}}\right)\right]$ shows an overall quantum yield of only $2.4 \%$. Therefore, the combined complete fluorination of the macrocycle and partial deuteration of the tripodal ligand improves the quantum yield by one order of magnitude! In deuterated methylene chloride the quantum yield of $\left[\mathrm{Yb}\left(\mathrm{F}_{20} \mathrm{TPP}^{\mathrm{F}}\right)\left(\mathrm{CoP}^{\mathrm{CD} 3}\right)\right]$ reaches $63 \%$ with a lifetime of $714 \mu \mathrm{s} .{ }^{100}$ Until then the largest quantum
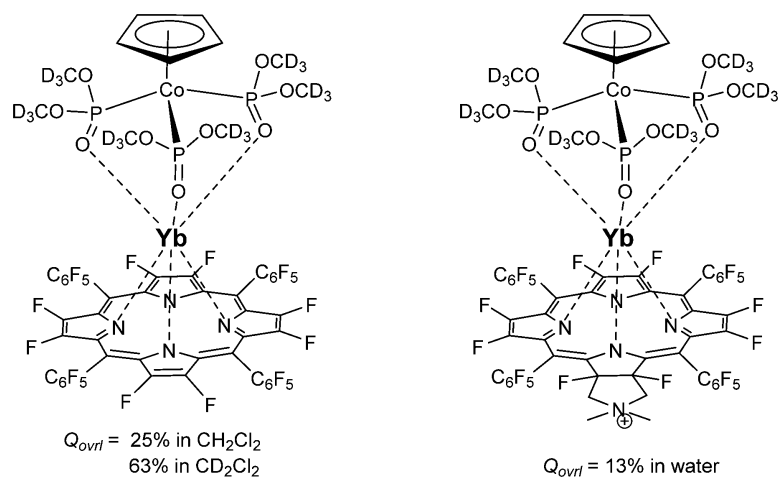

Fig. 52 Ytterbium $\beta$-fluorinated tetrakis(pentafluorophenyl)porphyrinates with high overall quantum yields. ${ }^{100,105}$ yield reported for $\mathrm{Yb}^{\mathrm{III}}$ was $12 \%$ for a deuterated cryptate in deuterated methylene chloride.

Biomedical applications require water-soluble luminescent probes. A water-soluble ytterbium monoporphyrinate has been designed for this purpose. The porphyrin features three pentafluorophenyl groups, while the fourth phenyl group is parasubstituted with a water-soluble moiety bearing either a quaternary amine (Lig-N) or a rhodamine B functionality (Lig-RhB). The ytterbium complex with Lig-N has a quantum yield of $2.7 \%$ in water and a lifetime of $12 \mu$ s upon excitation in the Soret band. It is efficient as a phospholipid marker and can differentiate between cancerous and normal cells in vitro. ${ }^{122}$ The other ligand has been designed for targeting mitochondria and the coordination is completed by the capping ligand $\mathrm{CoP}^{\mathrm{Me}}$ (Fig. 23). In water, the overall quantum yield of this bioprobe reaches $2.5 \%$ under excitation in the Soret band at $430 \mathrm{~nm}$ and the $\mathrm{Yb}\left({ }^{2} \mathrm{~F}_{5 / 2}\right)$ lifetime amounts to $18 \mu \mathrm{s}$. An additional feature of this probe is its ability to be excited at $860 \mathrm{~nm}$ by a two-photon process, with a sizable cross section of $375 \mathrm{GM}^{70}$ When one or two BODIPY chromophores are linked by ethynyl or phenylethynyl groups to the porphyrin framework, replacing phenyl group(s) or pentafluorophenyl groups(s) or triphenylamine substituents, the lifetime increases in the range of 37-43 $\mu$ s and the corresponding [ $\mathrm{Yb}($ subst-Por $\left.)\left(\mathrm{CoP}^{\mathrm{Me}}\right)\right]$ complex can be excited specifically in the BODIPY substituent at $528 \mathrm{~nm}$; however, due to a relatively weak coupling with the porphyrin moiety the antenna effect of BODIPY remains modest, resulting in an overall quantum yield in the range of 0.35 to $0.73 \%$ only (Fig. 53, top). ${ }^{287} \mathrm{~A}$ useful aspect is that the two-photon cross section upon excitation at $800 \mathrm{~nm}$ (corresponding to excitation in the porphyrin Soret band) increases to 1000-2200 GM, so that these complexes are valuable NIR-to-NIR bioprobes. An attempt to introduce two BODIPY units as co-sensitizers of $\mathrm{Yb}^{\mathrm{III}}$ luminescence in [Yb(TPP)(Ac)(DBP-Phen)] (Fig. 53, bottom) resulted in a 2.4-fold increase in the intensity of the $\mathrm{Yb}^{\mathrm{III}}$

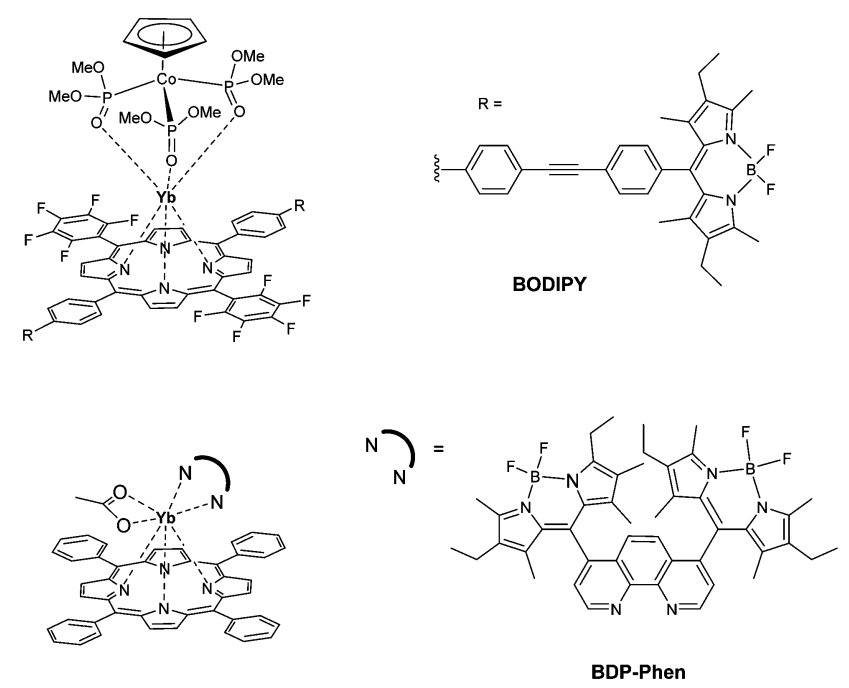

Fig. 53 Molecular structures of porphyrin-based $\mathrm{Yb}^{\text {III }}$ complexes conjugated to co-photosensitizers BODIPY and bis(BODIPY)phenanthroline. Redrawn from ref. 287 and 288. 
luminescence with respect to $[\mathrm{Yb}(\mathrm{TPP})(\mathrm{Ac})(\mathrm{Me}-\mathrm{Phen})]$ and a broader excitation window, but in a somewhat smaller intrinsic quantum yield. ${ }^{288}$

In other water-soluble bioprobes, the phenyl groups of TPP have been replaced with 1 to 4 pyridyl functions and, when at least two pyridyl groups are present, the $\mathrm{Yb}\left({ }^{2} \mathrm{~F}_{5 / 2}\right)$ lifetime amounts to $30 \mu \mathrm{s} .{ }^{104}$ As the literature demonstrates that fluorinating the $\mathrm{C}-\mathrm{H}$ groups of organic ligands is beneficial to NIR luminescence, the $\beta$-positions of porphyrin have been fluorinated, whereas various water-soluble substituted phenyl groups have been grafted onto the meso positions. The complexes with a partially deuterated Kläui's tripodal ligand, $\left[\mathrm{Yb}\left(\mathrm{F}_{8} \mathrm{TP}^{\mathrm{R}} \mathrm{P}\right)\left(\mathrm{CoP}^{\mathrm{CD} 3}\right)\right]$, display sizeable overall quantum yields upon excitation in the Soret band: $5-13 \%$ in water and $9-23 \%$ in DMSO with lifetimes in the range of 56-173 $\mu$ s in water and 84-249 $\mu$ s in DMSO. The best performances are reached with $\mathrm{F}_{28} \mathrm{TPP}^{\mathrm{pyrr}} \mathrm{P}$, the completely fluorinated tetrakis(pentafluoro) porphyrin having one pyridinyl group fused with dimethylpyrrolidinium for water solubility. This porphyrinate has a remarkable photostability of over $3 \mathrm{~h}$ in water containing $0.1 \%$ DMSO upon $405 \mathrm{~nm}$ irradiation $\left(0.2 \mathrm{~W} \mathrm{~cm}^{-2}\right)$. In phosphate buffer saline $(\mathrm{pH}=5)$, the same irradiation leads to a $10 \%$ decrease of the $\mathrm{Yb}^{\mathrm{III}}$ emission intensity after $4 \mathrm{~h}$, while the corresponding non- $\beta$-fluorinated complex sustains $55 \%$ photobleaching. ${ }^{105}$ The ytterbium $\beta$-fluorinated porphyrinates are therefore adequate probes for NIR bioimaging ${ }^{277,289}$ or for the quantitative visualization of molecular events in vivo, such as $\mathrm{pH}$ determination. ${ }^{106}$

4.3.2 Ytterbium double and triple deckers. There are very few studies dealing with NIR sensitization of $\mathrm{Yb}^{\mathrm{III}}$ with porphyrin double or triple deckers. A recent example is making use of a simple porphyrin derivatized in 5,15 with diethyleneglycol $p$-substituted phenyl groups for enhancing solubility $\left(\mathrm{H}_{2}\right.$ DEGPor). The corresponding $\left[\mathrm{Yb}(\text { DEGPor })_{2}\right]$ double decker has a quantum yield of $2.8 \%$ in water under excitation at $425 \mathrm{~nm}$, which is comparable to the quantum yield of the monoporphyrinate with Lig-N (vide supra), but the lifetime is longer, 23.6 vs. $12 \mu \mathrm{s}$, and the brightness is higher, $2540 v s .1850 \mathrm{M}^{-1} \mathrm{~cm}^{-1}$, a definite advantage for bio-applications. ${ }^{122}$

4.3.3 Other lanthanide porphyrinates. N-Confused porphyrins are isomers of porphyrins in which one of the pyrrole rings is connected to the meso carbon atoms at the $\alpha$ - and $\beta$-positions. These porphyrins bind heavy lanthanide ions such as $\mathrm{Er}^{\mathrm{III}}$ and $\mathrm{Yb}^{\mathrm{III}}$ in the same way as regular porphyrins with an $\eta^{2}$ agostic interaction between $\mathrm{Yb}^{\mathrm{III}}$ and the inner-core $\mathrm{C}-\mathrm{H}$ groups. As the resulting compounds have the tendency to decompose in air, stabilization by a tripodal ligand is usually required. A series of complexes with tetraphenyl-N-confused porphyrins with the phenyl group bearing various substituents (Me, F, CN, C $\equiv \mathrm{C}(\mathrm{TMS})$ ) revealed that sensitization of NIR luminescence is less efficient than in complexes with corresponding regular porphyrins, as shown by the $\mathrm{Yb}\left({ }^{2} \mathrm{~F}_{5 / 2}\right)$ lifetime in toluene remaining short, $0.19-0.38 \mu \mathrm{s.} .^{290}$

The luminescence of other NIR-emitting lanthanide ions is also sensitized in monoporphyrinates, but far less quantitative data are at hand. Overall quantum yields of $0.2 \%$ and $0.1 \%$ were reported for $\left[\mathrm{Ln}(\mathrm{TPP})\left(\mathrm{CoP}^{\mathrm{Et}}\right)\right], \mathrm{Ln}=\mathrm{Nd}$ and $\mathrm{Er}$, respectively; the corresponding values for $\left[\operatorname{Ln}(\mathrm{TPP})\left(\mathrm{Tp}^{\mathrm{H}}\right)\right]$ are $0.24 \%$ and $0.09 \%$, respectively. ${ }^{72}$ A series of $\mathrm{Nd}^{\mathrm{III}}$ tetraphenyl monoporphyrinates have been studied, with the phenyl groups substituted with various functions $(\mathrm{H}, \mathrm{Me}, \mathrm{OMe}, \mathrm{F}, \mathrm{Cl}, \mathrm{Br})$, and intrinsic quantum yields in toluene were estimated to lie between 0.19 and $0.28 \%$ taking into account a literature radiative lifetime of $0.25 \mathrm{~ms}$. The best sensitization was obtained for the bromo-substituted complex. ${ }^{54}$ With $\mathrm{Tp}^{\mathrm{H}}$ as a capping ligand, intrinsic quantum yields between $0.1 \%(\mathrm{~F})$ and $0.33 \%$ $(\mathrm{H}, \mathrm{Me}, \mathrm{Cl})$ were obtained in the same solvent. ${ }^{281}{ }^{8-}$ Hydroxyquinoline is known to be a good sensitizer of lanthanide NIR luminescence and was attached to the $\alpha_{4}$-atropisomer of TPP. These groups bind $\mathrm{Nd}^{\mathrm{III}}$, while the core of the porphyrin can be coordinated to a divalent transition metal ion such as $\mathrm{Pd}^{\mathrm{II}}$, which acts as a co-sensitizer of $\mathrm{Nd}^{\mathrm{III}}$ luminescence. The quantum yield upon excitation into the 8-hydroxyquinoline group amounts to $4.3 \times 10^{-3} \%$ for the $\mathrm{Nd}^{\mathrm{III}}$ porphyrinate alone and to $9.9 \times 10^{-3} \%$ when $\mathrm{Pd}^{\mathrm{II}}$ is coordinated into the core, exemplifying the double sensitization process (Fig. 22). ${ }^{118}$

Because of the telecommunication applications of $\mathrm{Er}^{\mathrm{III}}$ doped materials and bio-applications of some $\mathrm{Er}^{\mathrm{III}}$ complexes emitting in the second NIR biological window which are also tumour-selective probes, ${ }^{125}$ several $\mathrm{Er}^{\mathrm{III}}$ porphyrinates were investigated; however, few quantitative data are reported often in view of too faint emission. An overall quantum yield value of $0.04 \%$ has been reported for $[\operatorname{Er}(\mathrm{TPP})(\mathrm{acac})]$ in chloroform; doping this complex in a film of the poly(arylene-ethynylene) polymer increases its NIR emission intensity in view of efficient Förster energy transfer from the polymer to the porphyrin ligand. ${ }^{215}$ A slight increase in quantum yield is observed upon fluorination of the phenyl groups $\left(\mathrm{F}_{20} \mathrm{TPP}\right)$, while the value approximately doubles when the $\beta$-positions are additionally fully brominated $\left(\mathrm{Br}_{8} \mathrm{~F}_{20} \mathrm{TPP}\right) .{ }^{291}$ Hybridization of

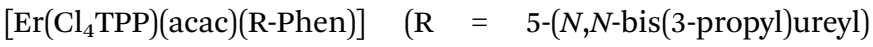
results in a homogeneous and transparent material that could be useful, but the lifetime ( $2 \mu \mathrm{s}$ in toluene, $\mathrm{R}=\mathrm{Me}$ ) is reduced $50-70 \%$, pointing to quenching from the outer coordination sphere. $^{56}$

4.3.4 Lanthanide complexes with porpholactones. Studies on the relationship between the structure and photophysical properties of natural chlorophylls evidenced the importance of $\beta$-peripheral modification of the core macrocycle, triggering numerous attempts to transpose these conclusions on lanthanide porphyrinates in order to enhance their photophysical properties. Adjustment of the extent of $\pi$-conjugation and the degree of distortion from the planarity of the macrocycle, as well as introduction of various substituents in the meso and $\beta$ positions, as described above, has been attempted with variable results so that the fine-tuning of photophysical properties still remains a challenge. In an effort to explore new horizons, Zhang's group started to investigate the possibilities offered by tetra(pentafluorophenyl)porpholactones (Fig. 54A) that were discovered serendipitously in 1989 and in which a $\beta$-pyrrolic double bond of meso- $\mathrm{C}_{6} \mathrm{~F}_{5}$-tetrasubstituted porphyrin ( $\mathrm{F}_{20} \mathrm{TPP}$ ) has been replaced with a lactone group. ${ }^{292}$ With respect to 
(A)

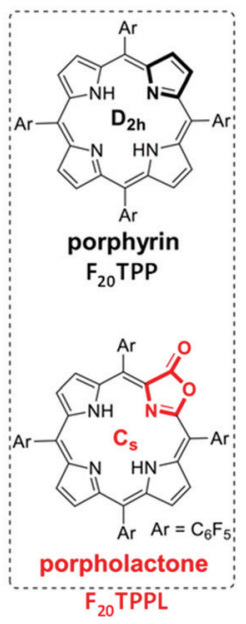

(B)

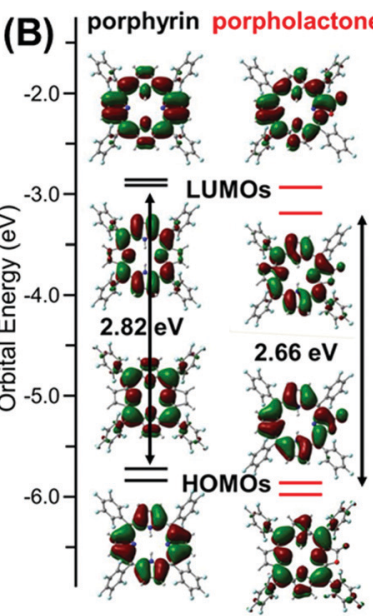

(C)

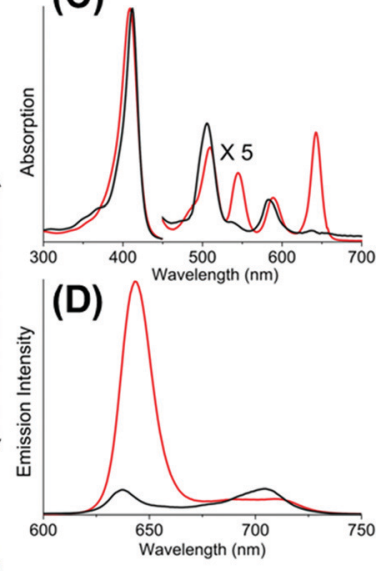

Fig. 54 Comparison between tetrakis(pentafluorophenyl)-substituted porphyrin and porpholactone: (A) chemical formulae; (B) molecular orbitals; and absorption (C) and emission (D) spectra. Adapted with permission from ref. 292, copyright (2019) The American Chemical Society.

porphyrins, porpholactones have a lower symmetry resulting in a larger splitting of the LUMO and LUMO+1 orbitals so that the HOMO-LUMO gap is reduced, from $\sim 22750 \mathrm{~cm}^{-1}$ in $\mathrm{F}_{20} \mathrm{TPP}$ to $\sim 21450 \mathrm{~cm}^{-1}$ in $\mathrm{F}_{20}$ TPPL (Fig. 54B). While the Soret band at $\sim 420 \mathrm{~nm}$ is hardly affected in going from the porphyrin to the porpholactone frameworks, the absorption spectra of the $\mathrm{Q}$ bands display more changes, particularly with respect to their intensity (Fig. 54C), and this is also true for the emission bands (Fig. 54D). On the other hand, the coordinative properties of the two macrocycles remain very comparable, so that porpholactones appear to be valuable alternatives to porphyrins for developing luminescent platforms for bio-applications. ${ }^{292}$

The ytterbium complexes $[\mathrm{Yb}(\mathrm{L})(\mathrm{acac})], \mathrm{L}=\mathrm{F}_{20} \mathrm{TPP}$ and $\mathrm{F}_{20} \mathrm{TPPL}$, present similar spectral signatures, with a small redshift of the Soret band ( $3 \mathrm{~nm})$, larger red-shifts of the two Q bands (17 and $26 \mathrm{~nm}$ ) and a much larger intensity of the more red-shifted $\mathrm{Q}$ band (8.3-fold). As a result, the overall quantum yield of $\left[\mathrm{Yb}\left(\mathrm{F}_{20} \mathrm{TPPL}\right)(\mathrm{acac})\right]\left(4 \times 10^{-6} \mathrm{M}\right)$ in methylene chloride, under excitation of the Soret band, amounts to $3.3 \%$, a $50 \%$ increase compared with $\left[\mathrm{Yb}\left(\mathrm{F}_{20} \mathrm{TPP}\right)(\mathrm{acac})\right]$. The $\mathrm{Yb}\left({ }^{2} \mathrm{~F}_{5 / 2}\right)$ lifetime is also slightly longer in the porpholactone complex, 26.5 $\mu$ s versus $23.5 \mu \mathrm{s}$. The relative sensitization efficiency of the two macrocyclic ligands has been estimated, under the reasonable assumption that $\tau_{\text {rad }}$ is the same for the two complexes since they have the same coordination environment, and found to be
1.33, meaning that $\mathrm{F}_{20}$ TPPL is a better sensitizer of $\mathrm{Yb}^{\mathrm{III}}$ luminescence. ${ }^{67}$ The influence of several aryl substituents has been tested: pentafluorophenyl $\left(\mathrm{F}_{5} \mathrm{P}\right)$, phenyl $(\mathrm{P})$, chlorophenyl (ClP), trifluoromethylphenyl $\left(\mathrm{F}_{3} \mathrm{CP}\right)$, and 1,3,5-trimethylphenyl $\left(\mathrm{Me}_{3} \mathrm{P}\right)$ and the corresponding photophysical properties are presented in Table 1 . The porpholactone derivatives are better than the porphyrin ones for all substituents; the best quantum yields $(2.5 \%$ and $4.1 \%)$ are obtained with $\mathrm{F}_{3} \mathrm{CP}$ and this is also true for the highest brightness.

When $\mathrm{F}_{20}$ TPPL is combined with a partially deuterated Kläui's tripodal ligand, $\mathrm{CoP}^{\mathrm{CD} 3}$, and the resulting $\mathrm{Yb}^{\mathrm{III}}$ complex $\left[\mathrm{Yb}\left(\mathrm{F}_{20} \mathrm{TPPL}\right)\left(\mathrm{CoP}{ }^{\mathrm{CD} 3}\right)\right]$ dissolved into deuterated $\mathrm{CD}_{2} \mathrm{Cl}_{2}$, large increases in both the overall quantum yield (6.8\%) and lifetime (75 $\mu \mathrm{s}$ ) are observed, pointing to the benefit of replacing $\mathrm{C}-\mathrm{H}$ vibrators with lower energy $\mathrm{C}-\mathrm{F}$ ones. Therefore, in order to further minimize nonradiative deactivation induced by $\mathrm{C}-\mathrm{H}$ vibrations, $\mathrm{F}_{20}$ TPPL has been fully fluorinated ( $\left.\mathrm{F}_{28} \mathrm{TPPL}\right)$ and its complex with $\mathrm{Yb}^{\mathrm{III}}$ synthesized, $\left[\mathrm{Yb}\left(\mathrm{F}_{28} \mathrm{TPPL}\right)\left(\mathrm{CoP}^{\mathrm{CD} 3}\right)\right]$. The outcome is remarkable, with a lifetime of $525 \mu \mathrm{s}$ and an overall quantum yield of $58 \% ;^{293}$ these figures are comparable to those for the corresponding complex with fully fluorinated porphyrin $\left(\tau=714 \mu \mathrm{s}, \mathrm{Q}_{\mathrm{Ln}}^{\mathrm{L}}=63 \%\right) .{ }^{100}$ Experiments with two isomers of the porpholactol derivative of $\mathrm{F}_{28}$ TPPL evidenced that, as expected, $\mathrm{O}-\mathrm{H}$ vibrations quench more than $\mathrm{C}-\mathrm{H}$ oscillators and that the formation of an intramolecular $\mathrm{H}$-bond between the $\mathrm{OH}$ group

Table 1 Comparison of the photophysical properties of $[\mathrm{Yb}(\mathrm{L})(\mathrm{acac})], \mathrm{L}=$ tetrakis(aryl) substituted TPP and TPPL, in methylene chloride: molar absorption coefficient $\varepsilon$ of the Soret band at $\sim 420 \mathrm{~nm}$, overall quantum yield $Q_{\text {ovl }}\left(\lambda_{\text {exc }}=420-425 \mathrm{~nm}\right.$ ), average lifetime $\tau_{\mathrm{av}}\left(\lambda_{\mathrm{an}}=975 \mathrm{~nm}\right)$, brightness $B\left(=\varepsilon \times Q_{\mathrm{Ln}}^{L}\right)$, relative sensitization efficiency $\eta_{\mathrm{O}} / \eta_{\mathrm{y}}$, and relative brightness $B_{\odot} / B_{\mathrm{y}}$ (subscripts $\circ$ and y refer to porpholactone and porphyrin, respectively). Data from ref. 67

\begin{tabular}{|c|c|c|c|c|c|c|c|c|c|c|}
\hline \multirow[b]{2}{*}{ Substituent } & \multicolumn{4}{|c|}{ Porphyrin } & \multicolumn{4}{|c|}{ Porpholactone } & \multirow[b]{2}{*}{$\eta_{\mathrm{O}} / \eta_{\mathrm{y}}$} & \multirow[b]{2}{*}{$B_{\mathrm{O}} / B_{\mathrm{y}}$} \\
\hline & $\log \varepsilon$ & $Q_{\text {ovl }} / \%$ & $\tau_{\mathrm{av}} / \mu \mathrm{s}$ & $B / \mathrm{M}^{-1} \mathrm{~cm}^{-1}$ & $\log \varepsilon$ & $Q_{\text {ovl }} / \%$ & $\tau_{\mathrm{av}} / \mu \mathrm{s}$ & $B / \mathrm{M}^{-1} \mathrm{~cm}^{-1}$ & & \\
\hline $\mathrm{F}_{5} \mathrm{P}$ & 5.62 & 2.2 & 23.5 & 9171 & 5.51 & 3.3 & 26.5 & 10679 & 1.33 & 1.16 \\
\hline ClP & 5.62 & 1.5 & 26.3 & 6253 & 5.55 & 3.1 & 29.9 & 10999 & 1.82 & 1.76 \\
\hline $\mathrm{F}_{3} \mathrm{CP}$ & 5.66 & 2.5 & 26.5 & 11427 & 5.52 & 4.1 & 25.5 & 13576 & 1.70 & 1.19 \\
\hline $\mathrm{Me}_{3} \mathrm{P}$ & 5.67 & 1.1 & 23.4 & 5145 & 5.53 & 2.4 & 25.7 & 8132 & 1.99 & 1.58 \\
\hline
\end{tabular}




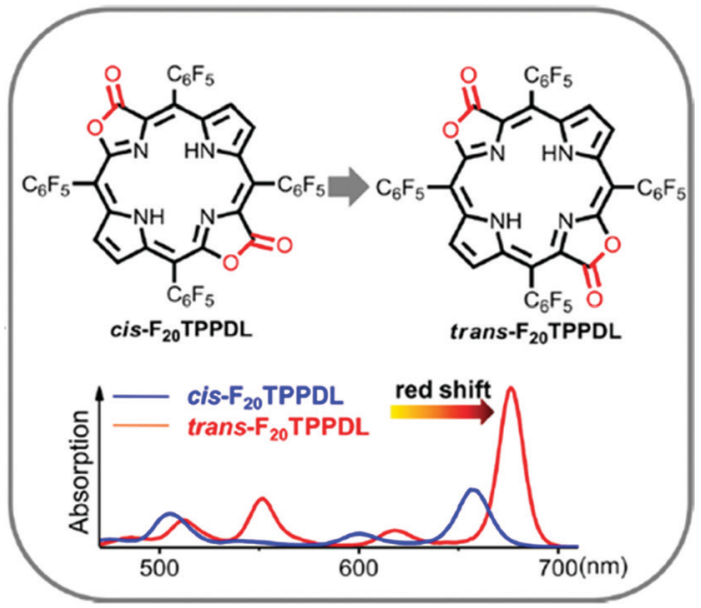

Fig. 55 Effect of cis/trans isomerism in the absorption spectrum of $\mathrm{F}_{20}$ TPPDL porphodilactone. Reproduced with permission from ref. 295, copyright (2017) The American Chemical Society.

and Kläui's tripodal ligand shortens the distance between the hydroxyl groups and the metal centre, thus leading to reduced NIR emission intensity. ${ }^{294}$ Furthermore, configurational isomerism in cis/trans $-\mathrm{F}_{20}$ TPPDL porphodilactone (Fig. 55) not only red-shifts the absorption spectrum of the ligand but also results in a large difference in the NIR emission of $\mathrm{Yb}^{\mathrm{III}}$ in $\left[\mathrm{Yb}\left(\mathrm{F}_{20} \mathrm{TPPDL}\right)\left(\mathrm{CoP}^{\mathrm{Me}}\right)\right]$ : the overall quantum yield of the cisisomer amounts to $3.3 \%, 8$-fold larger than that of the transisomer $(0.44 \%)$. The corresponding sensitization efficiencies estimated using $\tau_{\text {rad }}$ calculated from the absorption spectrum ( $0.79 \mathrm{~ms})$ are $84 \%$ and $12 \%$, respectively. Furthermore, the cisisomer presents a useful oxygen-dependent thermosensitivity in air-saturated $\mathrm{CH}_{2} \mathrm{Cl}_{2}$ between 293 and $193 \mathrm{~K}\left(4 \% \mathrm{~K}^{-1}\right)$ with a concomitant increase of the lifetime from 13.6 to $31 \mu \mathrm{s}^{295}$

When a non-NIR luminescent lanthanide ion, such as $\mathrm{Gd}^{\mathrm{III}}$ or $\mathrm{Lu}^{\mathrm{III}}$, is coordinated to porpholactones, ligand phosphorescence is observed in the range of 700-1200 nm, depending on the porpholactone. These complexes serve as efficient photosensitizers for the production of singlet oxygen ${ }^{68}$ or as triplet sensitizers for photon upconversion based on triplet-triplet annihilation. ${ }^{295}$

\subsection{Lanthanide phthalocyaninates and naphthalocyaninates}

Most of the reported complexes are with alkyl- or alkyloxy- $\beta$ substituted phthalocyanines but quantitative data are quasiabsent. Monophthalocyaninate complexes are usually stabilized with acac ${ }^{-296}$ or with Kläui's tripodal ligand. ${ }^{79}$ Sensitization of lanthanide NIR luminescence is weak because the triplet states are quite low in energy, $\sim 11000 \mathrm{~cm}^{-1}$ for Pc, and has essentially been observed in monophthalocyaninates, but not in double or triple deckers. Back energy transfer may be a reason. ${ }^{297}$ A few papers report NIR sensitization; for instance, $\mathrm{Er}^{\mathrm{III}}$ luminescence is seen at $1530 \mathrm{~nm}$ for $\left[\operatorname{Er}\left(\operatorname{Pc}\left(\beta-\mathrm{R}_{4}\right)\right.\right.$ acac $](\mathrm{R}=$ $t$-but, $\mathrm{O}-\mathrm{C}_{4} \mathrm{H}_{9}$ ) upon excitation into the $\mathrm{Q}$ band around $680 \mathrm{~nm}$; the $\operatorname{Er}\left({ }^{4} \mathrm{I}_{11 / 2}\right)$ lifetime amounts to $12.5-13 \mu \mathrm{s}$ in solid state. When doped into PMMA, the resulting NIR luminescence increases up to $8 \mathrm{wt} \%$ concentration but then decreases due to resonant energy transfer ${ }^{296}$ In fact even ligand fluorescence and phosphorescence are weak; as an example, the three complexes $\left[\mathrm{Lu}\left(\mathrm{PcR}_{4}\right)(\mathrm{OAc})\right],\left[\mathrm{Dy}\left(\mathrm{PcR}_{4}\right)_{2}\right]$, and $\left[\mathrm{Er}\left(\mathrm{PcR}_{4}\right) \mathrm{Cl}\right]$ with $\mathrm{R}_{4}=\mathrm{OPh}$ have fluorescence quantum yields smaller than $1 \%$ and the triplet state lifetime could only be determined for the Lu complex (25 $\mu \mathrm{s}$, in DMSO). ${ }^{298}$ Very weak $\mathrm{Nd}^{\mathrm{III}}$ sensitization was obtained for $\left[\mathrm{Nd}_{2}\left(\mathrm{PcOR}_{4}\right)_{3}\right]$ in DMSO. ${ }^{299}$ Metal-centred luminescence was observed upon excitation in the Soret band for $[\mathrm{Yb}(\mathrm{Pc})(\mathrm{OAc})]$ incorporated into PMMA and silica gel. ${ }^{300}$

\section{Nonlinear optical applications}

\subsection{Definition}

A nonlinear optical (NLO) medium is a dielectric medium in which electric polarization, expressing the density of induced electric dipoles, responds nonlinearly to the external electric field generated by light. This nonlinearity is observed for very high light intensities, i.e., usually produced by laser sources. There are two main phenomena associated with this situation: two- (or multiple-) photon absorption (TPA) and second (or higher) harmonic generation (SHG). The first one has been predicted in 1931 by the Nobel prize winner Maria GöppertMayer and observed in 1961 with the detection of two-photon excited luminescence in $\mathrm{CaF}_{2}: \mathrm{Eu}^{\mathrm{II}}$. In this process, two photons, of the same energy or different energies, are absorbed sequentially to reach an excited electronic state after transiting through a virtual state. The rate of transition differs from linear absorption in that it depends on the square of the light intensity and the cross section is expressed in units of Göppert-Mayer, $1 \mathrm{GM}=10^{-50} \mathrm{~cm}^{4} \mathrm{~s}_{\text {photon }}{ }^{-1}$. There are several applications of TPA, optical imaging - particularly bioimaging since TPA allows one to excite in the biologically friendly NIR range, optical power limiting to protect expensive optical sensors and/or human eyes of laser damages, 3D photopolymerization, or 3D optical data storage, among others. In the second process, SHG, two photons of the same energy interact with a nonlinear material, resulting in the production of a photon with double the frequency, so that the phenomenon is also termed frequency doubling. Adequate materials are crystals without an inversion centre and a common example is potassium dihydrogen phosphate $\left(\mathrm{KH}_{2} \mathrm{PO}_{4}\right)$ used for doubling the frequency of the YAG: $\mathrm{Nd}^{\mathrm{III}}$ laser line at $1064 \mathrm{~nm}$ to obtain the popular green $532 \mathrm{~nm}$ line. Third harmonic generation, which depends on the third-order electric susceptibility $\chi^{(3)}$, yields the $354 \mathrm{~nm}$ line. Both inorganic and metal complexes with organic ligands can present these phenomena and, in this respect, porphyrins, phthalocyanines and naphthalocyanines are particularly well-suited ligands.

Regarding material requirements for efficient nonlinear optical properties, one has to consider the following equations expressing the dependence of the induced molecular dipole moment $\mu$ on the electric field, which is expressed as a series: ${ }^{301}$

$$
\mu=\alpha \cdot E+\beta \cdot E E+\gamma \cdot E E E+\ldots
$$


where $\alpha$ is the molecular linear polarizability, $\beta$ the quadratic polarizability, and $\gamma$ the cubic polarizability or hyperpolarizability. This and the following equations are simplified; for more detailed treatments, see the related references. ${ }^{301,302}$ The second and third terms only become important when the applied field is large, e.g. when it stems from an intense laser pulse. The macroscopic induced polarization is then expressed as

$$
P=\varepsilon_{0}\left[\chi^{(1)} \cdot E+\chi^{(2)} \cdot E E+\chi^{(3)} \cdot E E E+\ldots\right]
$$

where $\chi^{(1)}$ is the linear susceptibility, $\chi^{(2)}$ the second-order (quadratic) susceptibility and $\chi^{(3)}$ the third-order (cubic) susceptibility; in the above equation they are tensors. The relationship between $\chi^{(3)}$ and $\gamma$ is given by ${ }^{303}$

$$
\gamma=\frac{\chi^{(3)}}{\left(n^{2}+2\right)^{4} N}
$$

where $N$ is the concentration of the medium in number of molecules per unit volume. The requirements for non-zero $\chi^{(2)}$ is a non-centrosymmetric material.

The second-order effect is proportional to a change in dipole moment between the ground and excited states and to the square of the oscillator strength; conversely it is inversely proportional to the energy differences between the two states; moreover, a push-pull type of molecule with charge-transfer behaviour is favourable for large $\beta$ values. For third harmonic generation, the requirement for a large $\chi^{(3)}$ is mainly an extended delocalized $\pi$-system. It is noteworthy that $\chi^{(3)}$ is a complex number and literature often reports only either the imaginary part or the bulk value:

$$
\chi^{(3)}=\chi_{\mathrm{R}}^{(3)}+\mathrm{i} \chi_{\mathrm{I}}^{(3)} \text { and }\left|\chi^{(3)}\right|=\sqrt{\left(\chi_{\mathrm{R}}^{(3)}\right)^{2}+\left(\chi_{\mathrm{I}}^{(3)}\right)^{2}}
$$

In nonlinear systems, the refractive index changes with the light beam intensity so that a nonlinear refractive index is defined, which adds to the linear refractive index $n_{0}$ :

$$
n=n_{0}+n_{2} \cdot I=n_{0}+\Delta n
$$

where $I$ is the light irradiance (in $\mathrm{W} \mathrm{m}^{-2}$ ), so that the SI unit of $n_{2}$ is $\mathrm{m}^{2} \mathrm{~W}^{-1}$ or, in the cgs system, $\mathrm{cm}^{2} \mathrm{~s} \mathrm{erg}^{-1}$. The change in refractive index can be positive or negative and the values of $n_{2}$ are very small, usually on the order of $10^{-16}-10^{-20} \mathrm{~m}^{2} \mathrm{~W}^{-1}$. The nonlinear refractive index $n_{2}$ is related to the real part of the third order susceptibility $\chi^{(3)}$, while the imaginary part depends on $\beta:^{304,305}$

$$
\begin{aligned}
\chi_{\mathrm{R}}^{(3)} & =\frac{4 n_{0}^{2} \varepsilon_{0} c}{3} n_{2} \text { (SI units) } \\
\chi_{\mathrm{R}}^{(3)} & =\frac{n_{0}}{3 \pi} n_{2} \text { (cgs units) } \\
\chi_{\mathrm{I}}^{(3)} & =\frac{n_{0}^{2} \varepsilon_{0} c \lambda}{3 \pi} \beta \text { (SI units) } \\
\chi_{\mathrm{I}}^{(3)} & =n_{0} c \lambda \beta \text { (cgs units) }
\end{aligned}
$$

where $c$ is the speed of light and $\varepsilon_{0}$ the electric permittivity $(8.85 \times$ $10^{-12} \mathrm{~F} \mathrm{~m}^{-1}$ ); these relations are only valid when the absorption is small.
There are several techniques for the determination of the nonlinear parameters defined above and of the nonlinear index of refraction $n_{2}$. One technique is electric field-induced SHG (EFISHG) where a strong electric field is applied to the sample in solution, causing a bias in the average orientation of the molecules, partially removing isotropy, and allowing second-harmonic generation to occur. The product of the permanent dipole $\mu$ by $\beta$ is gained from the intensity of the second-harmonic light; separate measurement of $\mu$ leads to the determination of $\beta$. A second, well-spread technique is the degenerate four-wave mixing (DFWM) for the characterization of third-order properties. In this process, three coherent waves are incident on a nonlinear medium, and a fourth wave (the phase conjugate wave) is generated with a strength depending on a coupling coefficient proportional to the effective $\chi^{(3)}$. Henceforth, measurements of the phase conjugate intensity under various polarizations of the four beams yield the $\chi^{(3)}$ tensor components of the medium. However only the moduli of these components can be determined, and extraction of the real and imaginary components requires additional techniques.

Another common technique is the so-called Z-scan where the transmittance of a nonlinear optical material is measured with a circular Gaussian laser beam in a tight focus geometry as a function of the position $z$ of the sample. If the beam then goes through a finite aperture (Fig. 56, top) the sample behaves as a weak $z$-dependent lens and the detector identifies small distortions in the initial light beam; the technique is referred to as closed aperture Z-scan and this set-up is used to determine the real part of $n_{2}$ using an appropriate model to interpret data. If the aperture is removed, the whole signal is measured by the detector, small distortions become unimportant, and the $z$ dependent signal is entirely due to the nonlinear absorption coefficient. The sample must be thin, namely thinner than Rayleigh length $z_{0}$ :

$$
z_{0}=\frac{\pi \cdot n \cdot w_{0}^{2}}{\lambda}
$$

with $w_{0}$ being the beam radius at the focal point $(z=0), n$ the refractive index, and $\lambda$ the wavelength at which transmission is measured. The nonlinear absorption coefficient $\beta$ can be extracted from the measurement of transmission $T(z)$ in an open-aperture scan:

$$
T(z)=\frac{C}{q_{0}(z) \sqrt{\pi}} \int \ln \left(1+q_{0}(z) \mathrm{e}^{-t^{2}}\right) \mathrm{d} t
$$

with

$$
q_{0}=\frac{\beta \cdot I_{0} \cdot \ell_{\mathrm{eff}}}{1+\left(\frac{z}{z_{0}}\right)^{2}}
$$

and

$$
\ell_{\mathrm{eff}}=\frac{\left(1-e^{-\alpha \ell}\right)}{\alpha}
$$

where $C$ is a proportionality coefficient, $I_{0}$ the irradiance of the laser source, $\alpha$ the linear absorption coefficient, and $\ell$ the physical length of the sample. 

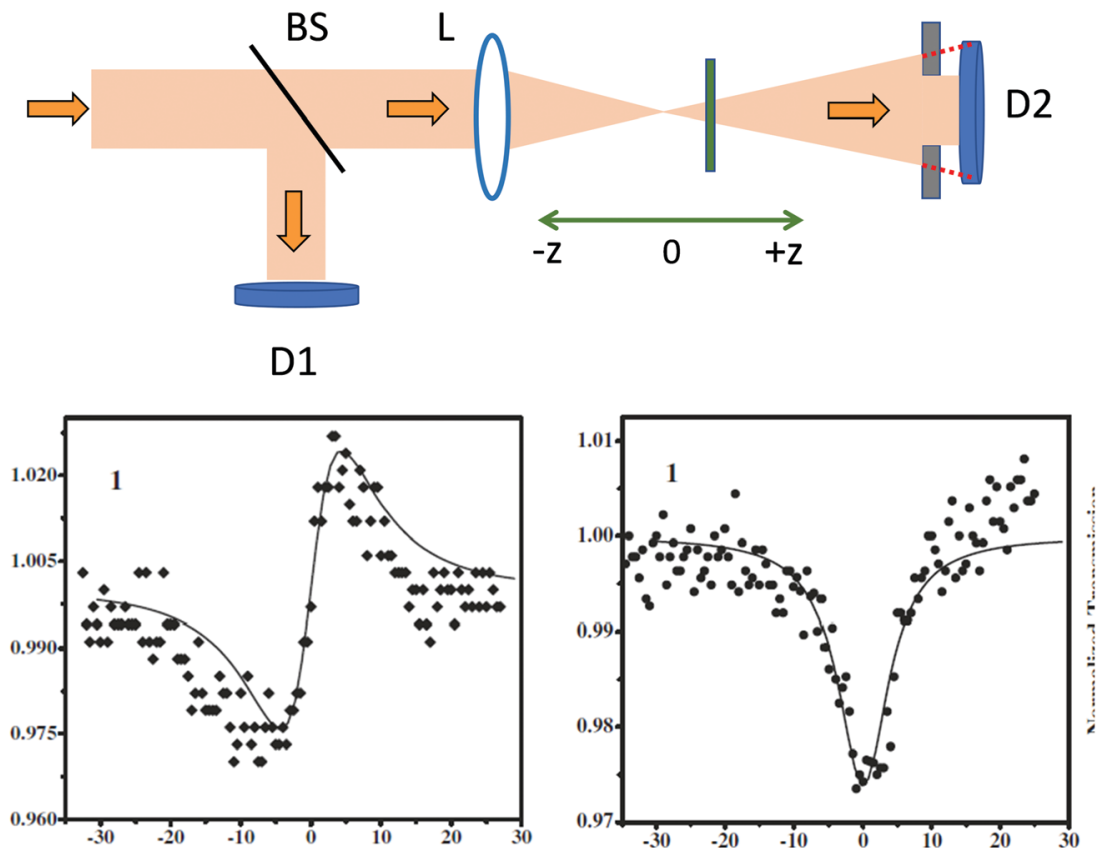

Fig. 56 (Top left) Schematic set-up for a closed aperture Z-scan experiment: BS, beam-splitter; D1 and D2, detectors; L, lens; the dotted red lines show measurement of the entire beam with the open aperture set-up. (Bottom) Normalized transmission at a wavelength of $1064 \mathrm{~nm}$ (20 ps pulses) of $\left[\mathrm{Eu}(\mathrm{Pc})\left(\mathrm{Pyrenyl}{ }_{4} \mathrm{Por}\right)\right]$ in $\mathrm{CHCl}_{3}$ versus $z / z_{0}$ obtained from closed aperture (left) and open aperture (right) Z-scans. Adapted with permission from ref. 306, copyright (2012) Elsevier B.V.

The two-photon absorption cross section $\sigma_{2}$ is related to the two-photon absorption coefficient $\beta$ by the following formula:

$$
\sigma_{2}=\frac{h \nu}{N} \beta
$$

The imaginary component of the third-order nonlinear susceptibility $\chi_{\mathrm{I}}^{(3)}$ can then be calculated from $\beta$. Fig. 56 (bottom) shows the Z-scans for $\left[\mathrm{Eu}(\mathrm{Pc})\left(\right.\right.$ Pyrenyl $_{4}$ Por $\left.)\right]$ expressed in terms of normalized transmission versus the ratio $z / z_{0}$. The extracted parameters for this double decker are $n_{2}=9.44 \times$ $10^{-17} \mathrm{~m}^{2} \mathrm{~W}^{-1}, \beta=1.04 \times 10^{-30}$ (esu), and $\chi^{(3)}=1.54 \times 10^{-13}$ (esu). ${ }^{306}$ Since the cgs-esu system is still often used in the field, some conversions to the SI system are listed in Table 2.

Metallo-porphyrinates and phthalocyaninates offer interesting possibilities for NLO performances. Indeed, there exists a correlation between the number of $\pi$-bonds in an organic $\pi$ delocalized system and $\chi^{(3)}$, and tetracorroles and their complexes display extensive $\pi$-systems that even develop in 3D in double or triple deckers. Moreover, these compounds have large thermal stability, up to $400{ }^{\circ} \mathrm{C}$, rendering the processing easy, and variation of both the central metal ion and ring peripheral substituents is a practical tool for modulating their electronic properties. Electron delocalization may also be extended by the formation of polymers, aggregation, or multiple-decker compounds.

\subsection{Nonlinear optical parameters for some lanthanide tetrapyrrole complexes}

Nonlinear optical parameters for lanthanide tetrapyrrole complexes have been reported by several authors (see for instance ref. 299, 302, and 306-315) and have been partially reviewed. ${ }^{271,301}$ Data are however not consistent from one study to the other in that experimental conditions are different and usually only a few lanthanides have been studied each time.

Table 2 Conversion between the SI and cgs systems of units for some parameters used in nonlinear optics ${ }^{302}$

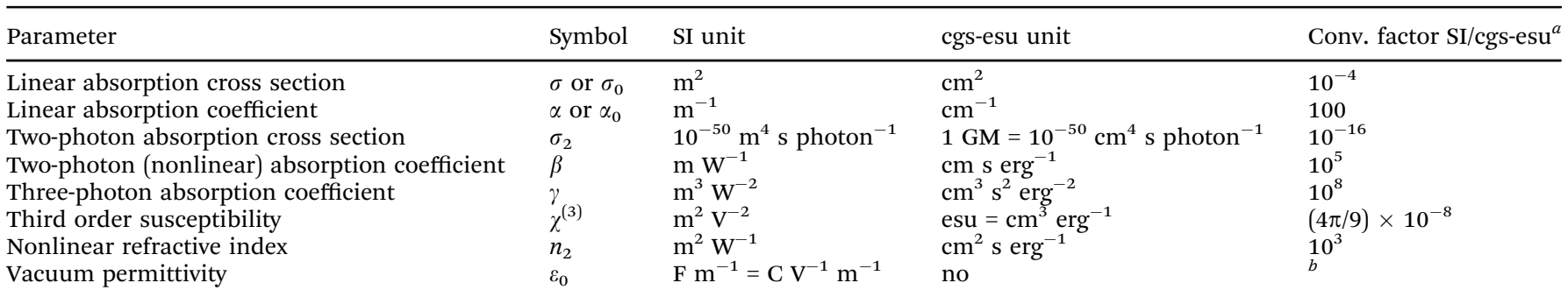

${ }^{a}$ Parameter $(\mathrm{SI})=$ conversion factor $\times$ parameter (cgs-esu), e.g. $\sigma(\mathrm{SI})=10^{-4} \times \sigma(\mathrm{cgs}) .{ }^{b} \varepsilon_{0}=8.85 \times 10^{-12} \mathrm{~F} \mathrm{~m}^{-1}$ (SI); in the Gaussian (cgs-esu) system of equations, there is no $\varepsilon_{0}$ (see eqn (16) and (17)). 
5.2.1 Third-order hyperpolarizability and susceptibility. Some earlier data are reported in Table 3 for the double deckers $\mathrm{LnPc}_{2}$ and a few comparative compounds, along with the linear absorption cross section at the studied wavelength. For the $\mathrm{LnPc}_{2}$ series, the phase conjugate signal varied with the laser irradiance to the power $3.0 \pm 0.3$ up to $35 \mathrm{GW} \mathrm{cm}^{-2}$, except for $\mathrm{ScPc}_{2}$ for which saturation starts to occur at a large pump power density. The measured hyperpolarizabilities $\gamma$ are large in comparison with metal-free Pc $\left(0.2 \times 10^{-32} \mathrm{esu}\right)$ or monoporphyrinates of transition metals. ${ }^{301}$ They vary with several parameters, including the nature of the metal ion and of the ligand, Pc vs. Nc for instance, as well as of the solvent, polar solvents enhancing nonlinear properties; it has also been demonstrated that $\chi^{(3)}$ is linearly proportional to the concentration of the sample. ${ }^{316}$ Another, spectral, factor is the position of the NIR intervalence band: when it shifts toward shorter wavelengths it influences more the absorption cross section at $1064 \mathrm{~nm}$ and the nonlinear optical parameters tend to increase. The $\gamma$ parameters reported in Table 3 have been theoretically rationalized in terms of configuration interaction of the $4 \mathrm{f}^{\mathrm{n}}$ ground electronic configuration with $4 \mathrm{f}^{n-1} 5 \mathrm{~d}, 4 \mathrm{f}^{n-1} 6 \mathrm{~s}$, and $4 \mathrm{f}^{n-1} 6 \mathrm{p}$ excited configurations and found to be determined by the energy difference $\Delta E_{\mathrm{fs}}-\Delta E_{\mathrm{fd}}$ with $\Delta E_{\mathrm{fd}}$ and $\Delta E_{\mathrm{fs}}$ being equal to the excitation energies $4 \mathrm{f}^{n} \rightarrow 4 \mathrm{f}^{n-1} 5 \mathrm{~d}$ and $4 \mathrm{f}^{n} \rightarrow 4 \mathrm{f}^{n-1} 6 \mathrm{~s}$, respectively. ${ }^{317}$ The results of the calculations are reported in Fig. 57 along with the experimental ones. As expected, the parameter $\gamma$ increases with decreasing ionic radius, i.e., with increasing $\pi-\pi$ interaction between the two aromatic rings. Consistent with this argument, it seems that Nc produces a larger effect than Pc and that monophthalocyaninates are less amenable to nonlinear effects compared with double deckers (Table 3).

Comparisons between double- and triple-decker properties are available. One comparison deals with complexes with octa(t-but-phenoxy) substituted $\mathrm{Pc}, \mathrm{Pc}(t \text { butPO })_{4}$. For $3.4 \times$ $10^{-4} \mathrm{M}$ solutions in $\mathrm{CH}_{2} \mathrm{Cl}_{2}$ and with a $532 \mathrm{~nm}$ laser as the excitation source, $\gamma$ and $\chi_{\mathrm{I}}^{(3)}$ increase slightly (+5\%) in going from $\left\{\mathrm{Sm}\left[\mathrm{Pc}(\text { tbutPO })_{4}\right]_{2}\right\}$ to $\left\{\mathrm{Sm}_{2}\left[\mathrm{Pc}(\text { tbutPO })_{4}\right]_{3}\right\} .{ }^{318}$ Another study involves heteroleptic complexes with $\mathrm{Pc}$ and tetra(1pyrenyl) substituted porphyrin, TPYRP. Replacing one

Table 3 Absorption coefficient $\alpha$ at $1064 \mathrm{~nm}$ and nonlinear optical parameters for $\mathrm{LnPc}_{2} 2 \times 10^{-4} \mathrm{M}$ in $\mathrm{CHCl}_{3}$ and $\mathrm{LaPc}_{1} \mathrm{SmPc}_{2}$, and $\mathrm{EuNc}_{2}$ in DMF (at $532 \mathrm{~nm}$ ) determined with the DFWM method. Experimental uncertainty on relative values of $\gamma$ is estimated to $\pm 25 \%{ }^{301}$

\begin{tabular}{llll}
\hline Compound & $\alpha / \mathrm{cm}^{-1}$ & $\gamma / 10^{-32} \mathrm{esu}$ & $\chi^{(3)} / 10^{-15} \mathrm{esu}$ \\
\hline $\mathrm{ScPc}_{2}$ & 3.5 & 48 & 210 \\
$\mathrm{YPc}_{2}$ & 0.62 & 26 & 124 \\
$\mathrm{NdPc}_{2}$ & 0.53 & 15 & 106 \\
$\mathrm{EuPc}_{2}$ & 0.51 & 22 & 102 \\
$\mathrm{GdPc}_{2}$ & 0.58 & 22 & 116 \\
$\mathrm{YbPc}_{2}$ & 1.5 & 41 & 150 \\
$\mathrm{LuPc}_{2}$ & 1.3 & 34 & 130 \\
$\mathrm{LaPc}^{a b}$ & 0.30 & 24 & 139 \\
$\mathrm{SmPc}_{2}{ }^{a}$ & 0.48 & 43.6 & 180 \\
$\mathrm{EuNc}_{2}{ }^{a}$ & 0.55 & 55 & 160
\end{tabular}

${ }^{a} 0.1-0.3 \mathrm{mM}$ in DMF and DFWM at $532 \mathrm{~nm} .{ }^{303 b}$ Monoporphyrinate.

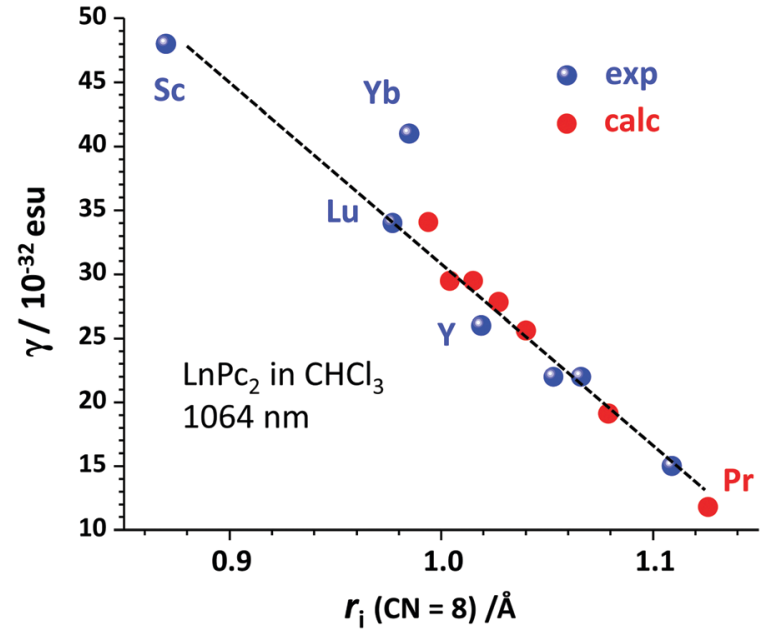

Fig. 57 Third-order hyperpolarizabilities at $1024 \mathrm{~nm}$ for $\mathrm{LnPc}_{2}$ in $\mathrm{CHCl}_{3}$. Redrawn from data reported in ref. 317.

phthalocyaninate ring in $\left[\mathrm{EuPc}_{2}\right]$ with TPYRP to yield $[\mathrm{Eu}(\mathrm{Pc})(\mathrm{TPYRP})]$ leads to increases in $\gamma$ from 22 to $104 \times$ $10^{-32}$ esu and in $\chi^{(3)}$ from 102 to $154 \times 10^{-15}$ esu $(0.72 \times$ $10^{-4} \mathrm{M}$ in $\mathrm{CHCl}_{3}$ ). On the other hand the triple-decker $\left[\mathrm{Eu}_{2}(\mathrm{Pc})_{2}(\mathrm{TPYRP})\right]\left(1.19 \times 10^{-4} \mathrm{M}\right)$ in $\mathrm{CHCl}_{3}$ has smaller nonlinear parameters, $\gamma=41 \times 10^{-32}$ esu and $\chi^{(3)}=100 \times 10^{-15}$ esu. The double decker with TPYRP has also a larger $n_{2}$ value than the triple decker, 9.44 vs. $5.81 \times 10^{-13} \mathrm{~cm} \mathrm{~s} \cdot \mathrm{erg}^{-1}$. The working wavelength was the same as that for $\left[\mathrm{EuPc}_{2}\right]$ but the techniques were different, Z-scan vs. DFWM. That the double decker has larger nonlinear parameters than the triple decker is not usual and can be attributed to the fact that the intervalence band for the double decker around $1330 \mathrm{~nm}$ partly overlaps with the probe wavelength at $1064 \mathrm{~nm}$ resulting in enhanced nonlinear effects, while the triple decker has no intervalence band. ${ }^{306}$ Adding the TPP ligand to $\left[\mathrm{SmPc}_{2}\right]$ to get the triple-decker $\left[\mathrm{Sm}_{2} \mathrm{Pc}_{2} \mathrm{TPP}\right]$ increases the value of $\chi^{(3)}$ from $180 \times 10^{-15} \mathrm{esu}$ $\left(10^{-4} \mathrm{M}\right.$ in DMF, $\left.532 \mathrm{~nm}\right)$ to $210 \times 10^{-15} \mathrm{esu}\left(5 \times 10^{-5} \mathrm{M}\right.$ in $\left.\mathrm{CHCl}_{3}, 830 \mathrm{~nm}\right)$; this value increases to $260 \times 10^{-15}$ esu for $\left[\mathrm{Sm}_{2} \mathrm{PcTPP}_{2}\right]\left(4.6 \times 10^{-5} \mathrm{M}\right.$ in $\left.\mathrm{CHCl}_{3}, 830 \mathrm{~nm}\right)$. The authors attribute this large increase to the fact that the $\mathrm{B}$ band of TPP has its maximum at $415 \mathrm{~nm}$, while the pump wavelength at $830 \mathrm{~nm}$ is exactly the double, so that part of the enhancement may arise from two-photon resonance. ${ }^{316}$ This shows that many factors influence nonlinear phenomena that are not always obvious to detect and therefore a detailed record of all experimental parameters is necessary when reporting such phenomena.

5.2.2 Two-photon absorption cross sections. The propensity of complexes with tetrapyrrole ligands to have a large twophoton absorption cross section is stimulating several applications. One, optical limiting, will be discussed in the next section. Another one, photodynamic therapy, is described in Section 6. Improving two-photon cross sections has therefore stirred considerable efforts leading to the synthesis of new porphyrin and phthalocyanine derivatives. Revealing the factors influencing the magnitude of two-photon absorption cross 
sections has also been a red thread in these studies and homoleptic and heteroleptic lanthanide double and triple deckers appeared to be adequate compounds in view of the relatively large and tuneable $\pi-\pi$ inter-ring interactions.

Within the frame of the work centred on developing efficient photodynamic procedures, hybrid systems were tested in which two macrocycles were linked by, for instance, acetylene bridges. One example is mixed $\mathrm{M}$-porphyrin/Yb-phthalocyanine bimetallic complexes, with $\mathrm{M}=\mathrm{H}_{2}$, Zn, and Pd (Fig. 16, bottom). Excitation at $416 \mathrm{~nm}$ in the Soret band results in singlet-oxygen quantum yields of $1.30,1.38$, and 1.07 for $\mathrm{PH}_{2}-\mathrm{PcYb}, \mathrm{PZn}-$ $\mathrm{PcYb}$, and $\mathrm{PPd}-\mathrm{PcYb}$, respectively. Quantum yields are larger than one because ${ }^{1} \mathrm{O}_{2}$ can be produced by both the singlet and triplet states. When excitation is set at $675 \mathrm{~nm}$, the quantum yields are less than 1 . The two-photon absorption cross section $\sigma_{2}$ is large for these systems: 2347, 3301, and $2365 \mathrm{GM}$, respectively. ${ }^{108}$ Boron dipyrromethene (BODIPY) is known for its light-harvesting and electron-acceptor properties. It has therefore been linked to phthalocyanine using phenyl-ethynyl bridges to form $\left[\mathrm{Yb}\left(\right.\right.$ Subst-Pc) $\left.\mathrm{CoP}^{\mathrm{Me}}\right]$ with Pc bearing different substituents: 2 BODIPY and $2 \mathrm{C}_{6} \mathrm{~F}_{5}$ (Fig. 53, top), 1 BODIPY and $2 \mathrm{C}_{6} \mathrm{~F}_{5}$ (2), 1 BODIPY and 2 triphenylamine (TPA) (3), and 1 BODIPY and 2 phenyl (4). The measured $\sigma_{2}$ cross sections of $10^{-4} \mathrm{M}$ solutions in DMSO at $800 \mathrm{~nm}$ and acquired with the open-aperture Z-scan technique amount to 1417, 1048, 2226, and $1191 \mathrm{GM}$, respectively. The largest cross section is obtained with the strongest electron donor groups (TPA) because this conjugate has the most appropriate $\mathrm{D}-\mathrm{A}$ push-pull structure. The length of the binding unit has some influence: replacing the phenylethynyl bridge with a shorter ethynyl bridge in (4) increases $\sigma_{2}$ to $1446 \mathrm{GM}(+21 \%)$. The power dependence of the two-photon absorption has been checked for conjugates 1 and 3 and the slopes of the log-log plots amount to 2.02 and 1.94, respectively, confirming the two-photon mechanism. ${ }^{287}$

In fact, despite the acetylene or phenylacetylene bridges, the electronic communication between the two entities, BODIPY and $\mathrm{Pc}$, remains small so that attention has turned towards double deckers, with good success. Table 4 reports $\sigma_{2}$ values for a series of $\left[\mathrm{Ln}\left(\mathrm{OOct}_{8} \mathrm{Pc}\right)_{2}\right]$ and $\left[\mathrm{Ln}(\mathrm{Pc})\left(\mathrm{OOct}_{8} \mathrm{Pc}\right)\right]$ complexes. They are larger by factors of 10-60 compared with the monoporphyrinates. In the homoleptic series, the cross section increases 3.4 times between $\mathrm{Ce}$ and $\mathrm{Lu}$, in line with increasing $\pi-\pi$ interaction with decreasing ionic radius of the metal ion. Interestingly, the heteroleptic complexes have larger $\sigma_{2}$ values than the homoleptic double deckers. This may be explained by the heteroleptic structure in that the hydrogen atoms on the unsubstituted Pc function as electron donors, while octyloxy groups of the substituted Pc are electron attractive so that the complex can be visualized as a D-A system connected by a large conjugated $\pi$ system (D- $\pi-A)$ and this type of configuration is known in organic chemistry for generating large nonlinear optical effects. $^{310}$

\subsection{Optical limiting properties}

Optical limiters are materials that are transparent at normal light intensities but become opaque under larger light irradiation. They are essentially used for the protection of human eyes and sensitive optical components such as detectors when they are suddenly and, often, unexpectedly exposed to intense laser pulses. Therefore, these materials must possess fast response speeds. The present interest focuses on materials with small ground-state absorption cross sections and high excited-state cross sections, achieving optical limiting by reverse saturable absorption (RSA). Metalloporphyrins are ideally suited because they allow high transmission in a window between the Soret and $\mathrm{Q}$ bands, around 500-550 $\mathrm{nm}$ (see for instance Fig. 43), a range ideal for excitation with the $532 \mathrm{~nm}$ YAG: $\mathrm{Nd}^{\mathrm{III}}$ laser line. Nonlinear properties of many lanthanide tetrapyrrole complexes have been investigated with attention focused mainly on optical limiting properties and it was soon discovered that these complexes have often better characteristics than more classical materials such as $\mathrm{C}_{60}$ or transition metal phthalocyaninates. For instance, the erbium complex with tetrakis( $p$-diphenylaminophenyl)porphyrine (Scheme 1), [Er(TDPAPP) $\left.\left(\mathrm{CoP}^{\mathrm{Me}}\right)\right]$, has optical limiting threshold $J_{\lim }=0.093 \mathrm{~J} \mathrm{~cm}^{-2}$, compared with 0.15 and about $0.1 \mathrm{~J} \mathrm{~cm}^{-2}$ for $\mathrm{C}_{60}$ and $\mathrm{MPc}(\mathrm{M}=\mathrm{Si}, \mathrm{Ge})$, respectively. ${ }^{271}$

A common model for interpreting optical limiting data is the so-called 5-level model depicted in Fig. 58.

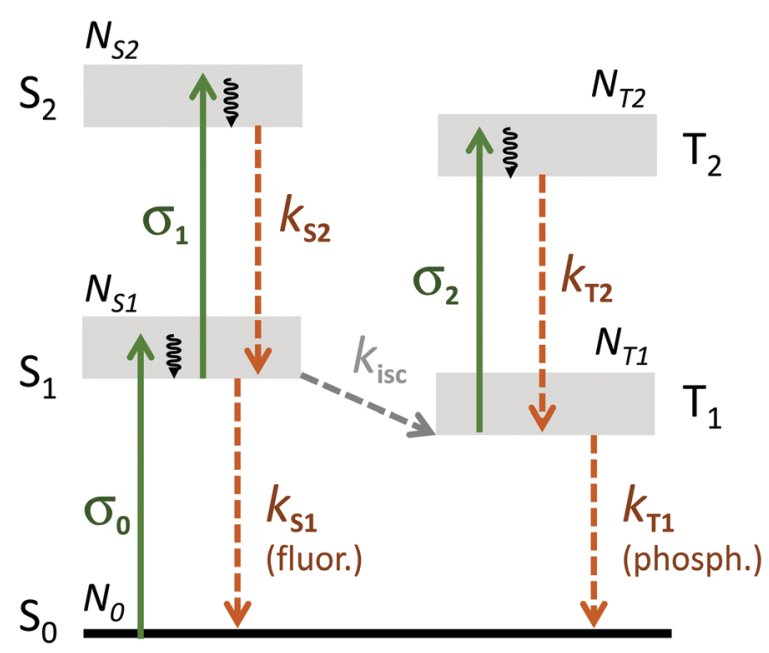

Fig. 58 Five-level model corresponding to the RSA mechanism for optical limiting. $\sigma$ 's are absorption cross sections and $k s$ are first-order rate constants reflecting the lifetime of various levels $(\tau=1 / k)$.

Table 4 Two-photon absorption cross sections of a series of homoleptic $\left[\mathrm{Ln}(\mathrm{PcOOct})_{2}\right](\mathrm{Ln}=\mathrm{Ce}, \mathrm{Sm}, \mathrm{Lu})$ and heteroleptic $\left[\mathrm{Ln}(\mathrm{Pc})\left(\mathrm{OOCt}{ }_{8} \mathrm{Pc}\right)\right]$ double deckers determined for solutions in $\mathrm{CHCl}_{3}$ at $800 \mathrm{~nm}$ by the $\mathrm{Z}$-scan technique

\begin{tabular}{|c|c|c|c|c|c|c|c|c|c|c|}
\hline Ln & $\sigma_{2} / 10^{5} \mathrm{GM}$ & Ln & $\sigma_{2} / 10^{5} \mathrm{GM}$ & Ln & $\sigma_{2} / 10^{5} \mathrm{GM}$ & Ln & $\sigma_{2} / 10^{5} \mathrm{GM}$ & $c / \mathbf{M}$ & $I_{0} / \mathrm{GW} \mathrm{cm} \mathrm{cm}^{-2}$ & Ref. \\
\hline $\mathrm{Ce}$ & 0.35 & Sm & 0.93 & $\mathrm{Lu}$ & 1.20 & - & - & $5 \times 10^{-4}$ & 114.8 & 319 \\
\hline $\mathrm{Y}$ & 1.28 & Ho & 1.26 & $\mathrm{Er}$ & 1.83 & $\mathrm{Yb}$ & 1.50 & $10^{-3}$ & 118.5 & 310 \\
\hline
\end{tabular}


A set of differential equations describe the population dynamics of the various levels:

$$
\begin{gathered}
\frac{\mathrm{d} N_{0}}{\mathrm{~d} t}=-\frac{I}{h \nu} \cdot \sigma_{0} N_{0}+k_{\mathrm{S} 1} N_{\mathrm{S} 1}+k_{\mathrm{T} 1} N_{\mathrm{T} 1} \\
\frac{\mathrm{d} N_{\mathrm{S} 1}}{\mathrm{~d} t}=\frac{I}{h \nu}\left(\sigma_{0} N_{0}-\sigma_{\mathrm{S} 1} N_{\mathrm{S} 1}\right)-k_{\mathrm{S} 1} N_{\mathrm{S} 1}-k_{\mathrm{isc}} N_{\mathrm{S} 1}+k_{\mathrm{S} 2} N_{\mathrm{S} 2} \\
\frac{\mathrm{d} N_{\mathrm{S} 2}}{\mathrm{~d} t}=\frac{I}{h \nu} \cdot \sigma_{\mathrm{S} 1} N_{\mathrm{S} 1}-k_{\mathrm{S} 2} N_{\mathrm{S} 2} \\
\frac{\mathrm{d} N_{\mathrm{T} 1}}{\mathrm{~d} t}=-\frac{I}{h \nu} \cdot \sigma_{\mathrm{T} 1} N_{\mathrm{T} 1}+k_{\mathrm{isc}} N_{\mathrm{S} 1}+k_{\mathrm{T} 2} N_{\mathrm{T} 2}-k_{\mathrm{T} 1} N_{\mathrm{T} 1} \\
\frac{\mathrm{d} N_{\mathrm{T} 2}}{\mathrm{~d} t}=\frac{I}{h \nu} \cdot \sigma_{\mathrm{T} 1} N_{\mathrm{T} 1}-k_{\mathrm{T} 2} N_{\mathrm{T} 2}
\end{gathered}
$$

where $I$ is the irradiance of the light source and $\nu$ the frequency. In fact, the lifetimes of $S_{2}$ and $T_{2}$ are very short and these states rapidly relax to $S_{1}$ and $T_{1}$, respectively, so that their populations can be assumed to be zero; the model then reduces to a threelevel model and the above set of equations become ${ }^{320}$

$$
\begin{gathered}
\frac{\mathrm{d} N_{0}}{\mathrm{~d} t}=-\frac{I}{h \nu} \cdot \sigma_{0} N_{0}+k_{\mathrm{S} 1} N_{\mathrm{S} 1}+k_{\mathrm{T} 1} N_{\mathrm{T} 1} \\
\frac{\mathrm{d} N_{\mathrm{S} 1}}{\mathrm{~d} t}=\frac{I}{h \nu} \sigma_{0} N_{0}-N_{\mathrm{S} 1}\left(k_{\mathrm{isc}}+k_{\mathrm{S} 1}\right) \\
\frac{\mathrm{d} N_{\mathrm{T} 1}}{\mathrm{~d} t}=k_{\mathrm{isc}} N_{\mathrm{S} 1}-k_{\mathrm{T} 1} N_{\mathrm{T} 1}
\end{gathered}
$$

Typical parameters for double deckers $\left[\operatorname{Ln}\left(\mathrm{PcBut}_{8}\right)_{2}\right]$ are reported in Table 5. One notes the large $\sigma_{\mathrm{T} 1} / \sigma_{0}$ ratio, suggesting that RSA is mainly determined by triplet absorption.

Assuming steady-state approximation, i.e. that the populations of the states remain constant for the duration of the laser pulse, the intensity-dependent absorption coefficient can be written as

$$
\begin{aligned}
\alpha\left(I, I_{\mathrm{sat}}, \kappa\right) & =\frac{\alpha_{0}}{1+\frac{I}{I_{\mathrm{sat}}}}\left(1+\kappa \frac{I}{I_{\mathrm{sat}}}\right) \text { with } \\
I_{\mathrm{sat}} & =h \nu \frac{k_{\mathrm{S} 1}}{\sigma_{0}} \text { and } \kappa=\frac{\sigma_{\mathrm{T} 1}}{\sigma_{0}}
\end{aligned}
$$

In the above equation, $I_{\text {sat }}$ is the intensity at which the absorption coefficient drops to half of its linear value. In fact, the ratio

Table 5 Photophysical parameters for [ $\left.\mathrm{Ln}\left(\mathrm{PCBut}_{8}\right)_{2}\right](\mathrm{Ln}=\mathrm{Eu}, \mathrm{Dy}, \mathrm{Er}, \mathrm{Lu})$ in THF. ${ }^{321}$ Determined at $532 \mathrm{~nm}$ with the Z-scan technique. See Fig. 58 for the definition of the parameters

\begin{tabular}{llrrrr}
\hline Parameter & Units & Eu & Dy & Er & \multicolumn{1}{c}{ Lu } \\
\hline$\sigma_{0}$ & $10^{-17} \mathrm{~cm}^{2}$ & 4.7 & 2.6 & 2.9 & 4.5 \\
$\sigma_{\mathrm{S} 1}$ & $10^{-17} \mathrm{~cm}^{2}$ & 1.8 & 0.9 & 1.0 & 1.6 \\
$\sigma_{\mathrm{T} 1}$ & $10^{-17} \mathrm{~cm}^{2}$ & 22.0 & 14.5 & 20.0 & 16.5 \\
$\sigma_{\mathrm{T} 1} / \sigma_{0}$ & - & 4.7 & 5.6 & 6.9 & 3.7 \\
$k_{\mathrm{S} 1}{ }$ & $10^{8} \mathrm{~s}^{-1}$ & 5.0 & 5.0 & 5.0 & 5.0 \\
$k_{\mathrm{isc}}$ & $10^{8} \mathrm{~s}^{-1}$ & 3.85 & 3.45 & 3.33 & 3.85
\end{tabular}

${ }^{a}$ Fixed and taken equal to the experimental value for $\left[\mathrm{LuPc}_{2}\right]$.
$I / I_{\text {sat }}$ can be replaced with $F / F_{\text {sat }}$ where $F$ is the energy density of the laser pulse. If $\sigma_{\mathrm{T} 1}>\sigma_{0}$, RSA is observed as an increase in the normalized energy-density-dependent absorption coefficient $\alpha / \alpha_{0}$ with respect to increasing normalized energy density of the pulse, $F / F_{\text {sat }}$. On the contrary, if $\sigma_{\mathrm{T} 1}<\sigma_{0}$, then saturated absorption is observed with $\alpha / \alpha_{0}$ decreasing with increasing $F / F_{\text {sat }}$. Many studies on optical limiting make use of the openaperture Z-scan technique to gain nonlinear parameters. The reported parameters are usually $\alpha_{0}, \alpha_{\mathrm{ex}}=\alpha_{\mathrm{T} 1}$ (or their ratio), nonlinear absorption coefficient $\beta$ (or $\beta_{\text {eff }}$ ), $\chi_{\mathrm{I}}^{(3)}, \gamma_{\mathrm{I}}$, and $F_{\text {sat }}$ (or $I_{\text {sat }}$ ) but they are all rarely reported in a given paper.

Some recent data are listed in Table 6 for mono, double, triple, quadruple and sextuple phthalocyaninates. The optical limiting properties are reflected by $F_{\text {sat }}$ values which are largely inferior to $1 \mathrm{~J} \mathrm{~cm}^{-2}$ and even reach values in the range of $0.05-$ $0.25 \mathrm{~J} \mathrm{~cm}^{-2}$, while transmission can be reduced up to $80 \%$. The reduced forms of the phthalocyaninates have the tendency to yield lower $F_{\text {sat }}$ values. ${ }^{322}$ Introducing the optical limiting complexes into polymeric thin films is generally beneficial. For instance, when embedded into poly(bisphenol A carbonate) thin films (PBC), $F_{\text {sat }}$ values of tris(monophthalocyaninate) complexes $\left[\mathrm{Ln}_{3} \mathrm{Cl}_{3} \mathrm{~L}_{1}\right]$ decrease from 0.31 to $0.11 \mathrm{~J} \mathrm{~cm}^{-2}(\mathrm{Yb})$ and from 0.79 to $0.26 \mathrm{~J} \mathrm{~cm}^{-2}(\mathrm{Lu}){ }^{109}$ Similarly, PBC thin films of $\left\{\mathrm{Ln}\left[\mathrm{Pc}(\mathrm{tbutOPh})_{4}\right]_{2}\right\}$ and their reduced forms $\left\{\mathrm{Ln}\left[\mathrm{Pc}(\text { tbutOPh })_{4}\right]_{2}\right\}^{-}$have much smaller $F_{\text {sat }}$ values and transmission reduction can be as high as $88 \% .^{323}$ A very low $F_{\text {sat }}$ value of $0.05 \mathrm{~J} \mathrm{~cm}^{-2}$ is reached for the PCB thin film incorporating $\left[\mathrm{Nd}\left(\mathrm{PcOPy}_{4}\right)_{2}\right]$ and transmission attenuation reaches $73 \%$ instead of $39 \%$ for the solution. ${ }^{322}$

In an effort to improve optical limiting properties, phthalocyaninates have been conjugated to various entities, e.g. quantum dots for the europium double and triple deckers with $\left(\mathrm{PcOBut}_{8}\right)$ and $\left(\mathrm{PcOBut}_{6} \mathrm{R}_{2}\right)$ leading to a decrease in $F_{\text {sat }}$ up to $50 \%,{ }^{324}$ or gold nanoparticles in the case of a completely chlorinated phthalocyanine, $\mathrm{PcCl}_{16}$. For the europium complex, the plasmonic effect of gold nanoparticles considerably increases reverse saturable absorption with the nonlinear absorption coefficient $\beta$ increasing from $3.2 \times 10^{-12} \mathrm{~cm} \mathrm{~W}^{-1}$ for the pure $\left[\mathrm{Eu}\left(\mathrm{PcCl}_{16}\right)_{2}\right]$ compound to 11 and $18 \times 10^{-12} \mathrm{~cm} \mathrm{~W}^{-1}$ for its conjugates with 20 and $30 \mathrm{~nm}$ gold nanoparticles, respectively. ${ }^{325}$ Finally, a bis(phthalocyaninate) di-neodymium complex has been conjugated with amino-functionalized multiwalled carbon nanotubes (MWCNT) with large decreases in $\beta$, from 3.78 to $0.70 \times 10^{-8} \mathrm{~m} \mathrm{~W}^{-1}$, and in $F_{\text {sat }}$, from 0.42 to $0.055 \mathrm{~J} \mathrm{~cm}^{-2}$, which is one of the lowest values reported in the literature. $^{326}$

\subsection{Upconversion through triplet-triplet annihilation (TTA)}

One mechanism of upconversion in organic compounds is triplet-triplet annihilation (TTA) which was first proposed in the 1960s to explain delayed fluorescence in anthracene. After initial excitation of the sensitizer molecules into their $S_{1}$ states and subsequent intersystem crossing to $\mathrm{T}_{1}\left(\phi_{\text {isc }}\right)$, these molecules transfer their triplet state energy to the emitter molecules (triplet-triplet transfer, $\phi_{\text {TтET }}$ ). Triplet-triplet transfer then occurs between two emitter molecules $\left(\phi_{\text {TTA }}\right)$, one returning 
Table 6 Optical limiting parameters recently reported for some lanthanide phthalocyaninates (excitation wavelength: $532 \mathrm{~nm}$; Z-scan technique)

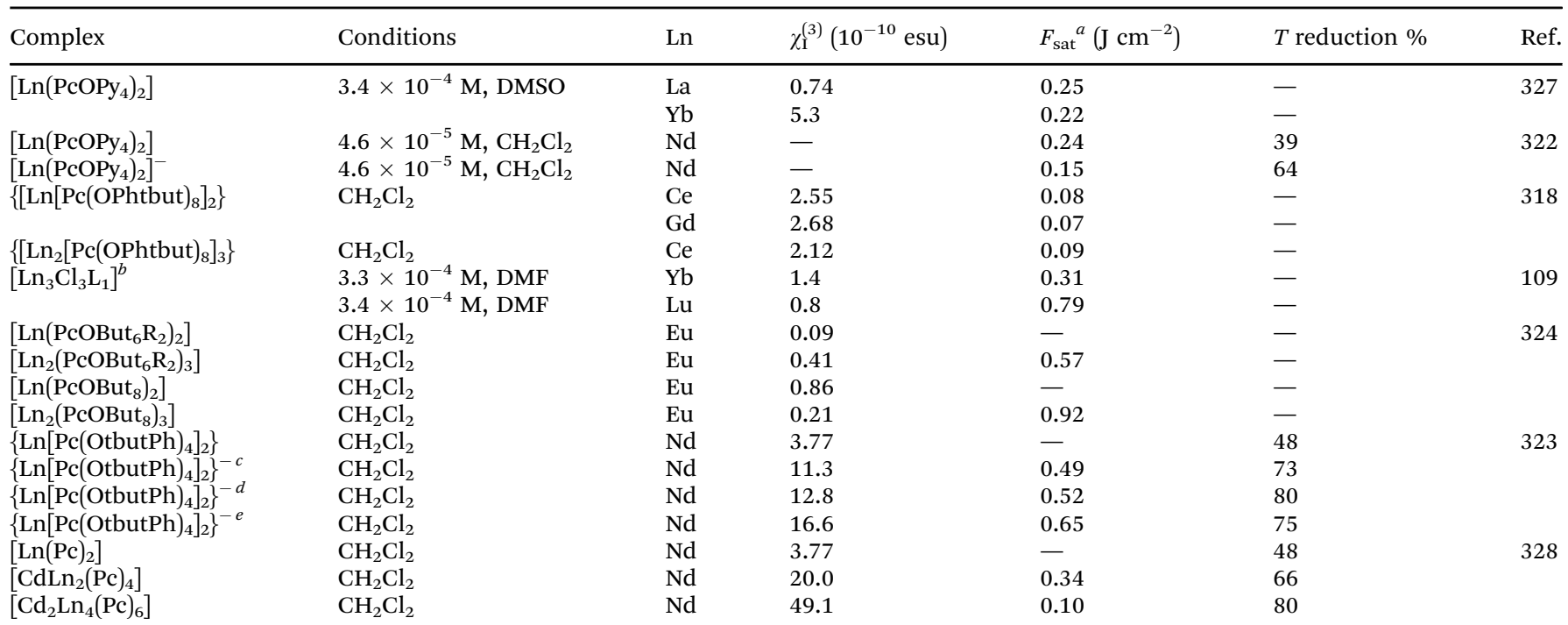

${ }^{a}$ Absence of data means that $50 \%$ attenuation of transmittance is not achieved. ${ }^{b} \mathrm{~L}_{1}=2,4,6$-tris $[3$-thio-9,10,16,17,23,24-hexa(4terbutylphenoxy)phthalocyaninato]-1,3,5-triazin. ${ }^{c}$ Counter-ion: $\mathrm{Me}_{3}\left(\mathrm{C}_{16} \mathrm{H}_{33}\right) \mathrm{N}^{+}$. ${ }^{d}$ Counter-ion: $\left[\mathrm{Nd}(\mathrm{Ac})_{2}\right]^{+} .{ }^{e}$ Counter-ion: $\left[\mathrm{Dy}(\mathrm{Ac})_{2}\right]^{+}$.

to its ground state and the other being promoted to a higher singlet state which finally de-excites by emitting delayed fluorescence $\left(\phi_{\mathrm{F}}\right)$. The upconversion yield is given by

$$
\phi_{\mathrm{UC}-\mathrm{TTA}}=\phi_{\text {isc }} \times \phi_{\text {TTET }} \times \phi_{\text {TTA }} \times \phi_{\mathrm{F}}
$$

While it can be quite efficient, the phenomenon suffers usually of a relatively small anti-Stokes shift. The advantage of organicbased TTA upconversion systems over inorganic lanthanidebased upconverting systems is that excitation and emission wavelengths can be easily tuned through the choice of the components and/or their chemical modification. Polyaromatic hydrocarbons and some organic dyes are among the best emitters, while tetrapyrrole complexes with heavy transition metals, e.g. [Pt(OEtPor)], are among the best sensitizers in view of a small $\mathrm{S}_{1}-\mathrm{T}_{1}$ energy gap, a large intersystem crossing rate, a slow phosphorescence decay rate, and a large absorption cross section.

Although lanthanide ions have smaller spin-orbit constants than platinum or palladium for instance, gadolinium and lutetium porphyrinates display strong ligand-centred phosphorescence with a long lifetime, which is favourable for acting as a sensitizer in oxygen sensing or photodynamic therapy of cancer. Therefore $\mathrm{Lu}$ and $\mathrm{Gd}$ complexes with tetrakis (pentafluorophenyl)porphyrin $\left(\mathrm{F}_{20} \mathrm{TPP}\right)$, porpholactone $\left(\mathrm{F}_{20} \mathrm{TPPL}\right)$ and porphodilactone $\left(\mathrm{F}_{20} \mathrm{TPPDL}\right.$, cis and trans) have been recently tested as photosensitizers for TTA. ${ }^{329}$ The chosen sensitizers were 9,10-bis(2-phenylethynyl)anthracene (BPEA) for [ $\left.\mathrm{M}\left(\mathrm{F}_{20} \mathrm{TPP}\right) \mathrm{CoP}^{\mathrm{Me}}\right]$ $(\mathrm{M}=\mathrm{Lu}, \mathrm{Gd}, \mathrm{Pd})$ and $\left[\mathrm{Lu}\left(\mathrm{F}_{20} \mathrm{TPPL}\right) \mathrm{CoP}^{\mathrm{Me}}\right]$, and rubrene for $\left[\mathrm{Lu}\left(\mathrm{F}_{20} \mathrm{TPPDL}\right) \mathrm{CoP}^{\mathrm{Me}}\right]$; measurements were conducted in degassed toluene. The Lu complexes with $\mathrm{F}_{20}$ TPPDL have sensitization ability for rubrene comparable to that of previously reported Pd and Pt analogues, namely $\phi_{\text {UC-TTA }}=0.9$ and $0.5 \%$ for the cis and trans isomers, respectively. Interestingly, $\left[\mathrm{Lu}\left(\mathrm{F}_{20} \mathrm{TPPL}\right) \mathrm{CoP}^{\mathrm{Me}}\right]$ has a much larger $\phi_{\mathrm{UC}-\mathrm{TTA}}, 7.8 \%$, while for complexes with $\mathrm{F}_{20} \mathrm{TPP}, \phi_{\mathrm{UC}-\mathrm{TTA}}$ reaches $6.3 \%$ for $\mathrm{Gd}$ and $12.4 \%$ for Lu. As a comparison the Pd complex with the same ligand has $\phi_{\text {UC-TTA }}=8.6 \%$. Although $\left[\mathrm{Lu}\left(\mathrm{F}_{20} \mathrm{TPPL}\right) \mathrm{CoP}^{\mathrm{Me}}\right]$ has a smaller upconversion yield compared with $\left[\mathrm{Lu}\left(\mathrm{F}_{20} \mathrm{TPP}\right) \mathrm{CoP}^{\mathrm{Me}}\right]$, the incident wavelength can be shifted from 560 to just over $600 \mathrm{~nm}$, which is an advantage for bioapplications. As a proof of concept, encapsulating BPEA and a Lu complex with $\mathrm{F}_{20}$ TPP or $\mathrm{F}_{20}$ TPPL into nanomicelles allows one to use the UC systems in aerated water and their imaging capability was tested successfully on HeLa cells. ${ }^{329}$

Triplet-triplet annihilation was recently invoked to explain anti-Stokes shifts in lanthanide double deckers "conjugated" with trifluoroacetic acid (TFA), $\left[\operatorname{LnPc}_{2}(\mathrm{TFA})_{8}\right]$, in which the protons of TFA interact with the meso $\mathrm{N}$ atoms of the phthalocyanine rings. Excitation in the Q band at $650 \mathrm{~nm}$ results in ligand fluorescence with modest anti-Stokes shifts of about 13$15 \mathrm{~nm}$ for some lanthanides (Nd, Sm, Eu, Gd) but not for the conjugates of $\mathrm{Yb}$ and $\mathrm{Lu}^{330}$

\subsection{Liquid crystals}

When tetrapyrroles are fitted with long aliphatic and/or branched peripheral substituents, nematic phases can be obtained. As a matter of fact, the first lanthanide-containing metallomesogens were lutetium double deckers with phthalocyanines fitted with alkoxy chains containing 8-18 carbon atoms. In view of the nature of the ligands, most liquid crystalline phases are aligned columnar phases, where the molten alkyl chains act as insulating layers; therefore, these arrangements are a kind of molecular electric wires. The double deckers have large electrical conductivity and some, such as $\left[\mathrm{Lu}(\mathrm{Pc})_{2}\right]$, behave like semiconductors. Lanthanidomesogens with tetrapyrrole ligands have been thoroughly reviewed, ${ }^{35,331}$ and most works in this field are devoted to characterizing the mesophases along with electrochemical properties. Therefore, 
we do not discuss these compounds further within the frame of this review.

\section{Sensing and biomedical applications}

The perfect match between lanthanide(III) ions and macrocyclic tetrapyrrole ligands gave rise to kaleidoscopes of advanced functional materials which have been chemically, electronically, photonically, magnetically and even catalytically endowed, as showcased in the previous sections and other relevant reviews. Countless lanthanide-tetrapyrrole complexes and conjugates of fascinating architectures have, over the past few decades, spanned the fields of electrochromic and optoelectronic devices, photovoltaic cells, single-molecule magnets, Lewis acid/photo-catalysts, and even molecular rotors. In stark contrast, when it comes to sensing and biomedical applications, there had been distinctly scarcer examples in the early days, given (i) their underexplored biochemistry, (ii) the problematic availability of high-purity lanthanide elements, (iii) inefficient traditional synthetic and functionalization methods, and (iv) the intrinsic hydrophobicity of tetrapyrrolic macrocycles. This situation has dramatically changed since the turn of the century and more particularly during the recent decades, in that there have been fiery developments of lanthanide-tetrapyrrole complexes and materials in sensing and biomedical domains, thanks to continual and decisive advances in synthesis and spectroscopy. Regarding the former, one can cite smart ligation strategies on tetrapyrroles for global water solubility enhancements and selective bio-targeting achievements by tailored lanthanide complexes, while two-photon excitation and improved NIR detection systems have paved the way for sensitive biosensing and bioimaging. We have named this decade as the second golden period of development of lanthanide-tetrapyrrole chemistry. In this section, we are going to discuss in detail the design strategies and the structure-property relationship of the recently designed lanthanide-tetrapyrrole complexes for biomedical applications, hopefully casting more insights for more breakthroughs in the years to come!

\subsection{Chemical, biological and physical sensing}

Lanthanide-tetrapyrrole systems have been widely and wisely employed in a diversity of chemical, biological and physical sensing-from various gases and metal ions, to chiral small molecules, biomolecules, and temperature. We have selected and categorized most of the related literature as follows.

6.1.1 Gases and volatile organic compounds. In 1997, Aroca et al. first investigated the interaction between $\mathrm{NO}_{2}$ and Langmuir-Blodgett (LB) films of $\mathrm{Eu}^{\mathrm{III}}$ bis(phthalocyanines) as gas sensors. ${ }^{332}$ Since then, films of lanthanide(III)-phthalocyanine sandwiches $\left(\mathrm{LnPc}_{2}\right)$ have become outstanding sensors for gases and volatile organic compounds (VOCs) due to their special electronic conductivity and spectroscopic properties. ${ }^{333,334}$

(a) $\mathrm{NO}_{2} \& \mathrm{NH}_{3}$. In 2009, Öztürk's et al. studied the $\mathrm{NO}_{2}$ and $\mathrm{O}_{3}$ sensing performances of a series of $\mathrm{Lu}^{\text {III }}$-phthalocyanine homoleptic double-decker complexes derivatized with various lengths of alkylthio chains in different concentration ranges $\left(\mathrm{NO}_{2}=1-10 \mathrm{ppm} ; \mathrm{O}_{3}=50 \mathrm{ppb}-1 \mathrm{ppm}\right)$ and in the temperature range of $25-150{ }^{\circ} \mathrm{C} .{ }^{335}$ The sandwich complexes exist in solid state at $25{ }^{\circ} \mathrm{C}$ and in the liquid crystalline phase at $150{ }^{\circ} \mathrm{C}$; the response time and the sensor response were found to be highly dependent on the alkyl chain lengths. In 2012, Bouvet and Chen et al. prepared, by the quasi-Langmuir-Schäfer (QLS) method, solution-processed thin films of heteroleptic (phthalocyaninato)(porphyrinato) Eu ${ }^{\text {III }}$ triple-decker complexes with different cis/trans-peripheral tert-butyl and hydroxyl groups to be used as $\mathrm{NH}_{3}$ sensors. ${ }^{336}$ Their supramolecular structures in nano-grains and nano-sheets were formed.

An ambipolar $\mathrm{NO}_{2}$ and $\mathrm{NH}_{3}$ sensor was developed by Chen et al. in 2007 based on QLS films of an amphiphilic and heteroleptic triple-decker $\left[\mathrm{Eu}_{2}(\mathrm{TPyP})(\mathrm{Pc})_{2}\right]$ complex; the sensor featured very good conductivity, crystallinity, and excellent linear sensitivity, $31.9 \% \mathrm{ppm}^{-1}$ for $\mathrm{NO}_{2}$ but only $0.04 \% \mathrm{ppm}^{-1}$ for $\mathrm{NH}_{3}{ }^{337}$ In 2018, Jiang and Chen et al. discovered polymorphism $(\chi, \beta$, and $\alpha$ phases) in the self-assembled nanostructures of new trifluoroethoxy-substituted homoleptic tris(phthalocyaninato) $\mathrm{Eu}^{\mathrm{III}}$ complexes of solvent-controlled nanomorphologies (nanobowls, nanobelts and nanoparticles) and confirmed the phase-dependent sensitivity towards $\mathrm{NO}_{2}$, phase $\chi>$ phase $\beta>$ phase $\alpha$; the largest response was recorded for phase $\chi$, with a lowest detection limit of $20 \mathrm{ppb}$ for room-temperature $\mathrm{NO}_{2}$ gas sensing. ${ }^{338}$

To further optimize the $\mathrm{NO}_{2}$ sensing behaviour of $\mathrm{Eu}^{\mathrm{III}}$ phthalocyaninato triple decker-based thin-film sensors, Jiang, Chen et al. proposed to extend the $\pi$-conjugation of the system by fusing two of them to form a quintuple-decker dimer sandwich (Fig. 59). ${ }^{339}$ Significant increases in the hole and
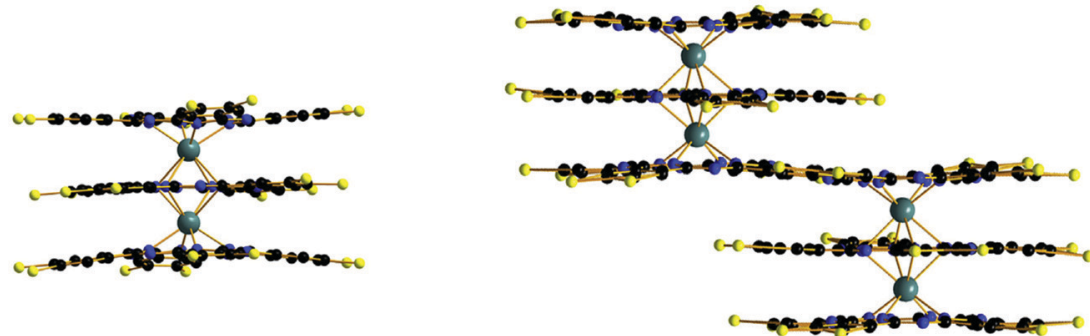

Fig. 59 Schematic molecular structures of $\left\{\mathrm{Eu}_{2}\left[\mathrm{Pc}\left(\mathrm{SC}_{6} \mathrm{H}_{13}\right)_{8}\right]_{3}\right\}$ (left) and $\left\{\left[\mathrm{Pc}\left(\mathrm{SC}_{6} \mathrm{H}_{13}\right)_{8}\right]_{2} \mathrm{Eu}_{2}\left[\mathrm{BiPc}\left(\mathrm{SC}_{6} \mathrm{H}_{13}\right)_{12}\right]_{\mathrm{Eu}}\left[\mathrm{Pc}\left(\mathrm{SC}_{6} \mathrm{H}_{13}\right)_{8}\right]_{2}\right\}(\mathrm{right})\left(\mathrm{Eu}^{\prime \prime \prime}=\mathrm{green}, \mathrm{C}=\right.$ black, $\mathrm{N}=$ blue, $\mathrm{S}=$ yellow) with all the hydrogen atoms and $n$-hexyl chains omitted for clarity. The computed adsorption energy of the left compound towards $\mathrm{NO}_{2}$ is $-34.3 \mathrm{kcal} \mathrm{mol}^{-1}$. Reproduced with permission from ref. 339, copyright (2019) Elsevier B.V. 
electron mobilities, up to 0.07 and $0.06 \mathrm{~cm}^{2} \mathrm{~V}^{-1} \mathrm{~s}^{-1}$, respectively, and a much higher sensitivity, from $23.4 \% \mathrm{ppm}^{-1}$ for the monomer to $46.7 \% \mathrm{ppm}^{-1}$ for the quintuple decker were recorded for this OFET-based sensor. On the other hand, the authors had also attempted to substitute one of the middle-layer $\mathrm{Eu}^{\mathrm{III}}$-layers with $\mathrm{Cd}^{\mathrm{II}}$ and synthesized a novel sandwich-type $\mathrm{Eu}^{\mathrm{III}}-\mathrm{Cd}^{\mathrm{II}}$ tetrakis(phthalocyaninato) quadruple-decker. ${ }^{340}$ New records of ambipolar OFET properties of such a thin film, i.e., hole and electron mobilities of $5.6 \times 10^{-3}$ and $1.2 \times 10^{-3} \mathrm{~cm}^{2} \mathrm{~V}^{-1} \mathrm{~s}^{-1}$, respectively, and effective response towards $\mathrm{NO}_{2}$ concentrations ranging from 0.25 to $2.5 \mathrm{ppm}$, were obtained.

(b) $\mathrm{O}_{3} \& \mathrm{O}_{2}$. Differing from Öztürk et al.'s work using homoleptic bis[tetrakis(alkylthio)phthalocyaninato] doubledecker $\mathrm{Lu}^{\mathrm{III}}$ complexes for sensing $\mathrm{O}_{3}$, Bouvet and Jiang et al. adopted the new QLS process in 2010 to fabricate amphiphilic heteroleptic tris(phthalocyaninato) $\mathrm{Eu}^{\mathrm{III}}$ triple-decker thin-film sensing transistors, in which two layers of the phthalocyanine sandwich were peripherally functionalized with crown ether moieties and the top layer with long alkyl chains. ${ }^{341}$ Outstanding sensitivity, and stable and reproducible responses towards $\mathrm{O}_{3}$ were reported. By loading monoporphyrinato $\mathrm{Lu}^{\mathrm{III}}$ and $\mathrm{Gd}^{\mathrm{III}}$ complexes into the thin films of copolymers of poly-tertbutylmethacrylate, polystyrene and methylcellulose, Ermolina et al. constructed an optical oxygen sensor by exploiting the $\mathrm{O}_{2}$ quenching effect on the room-temperature phosphorescence at $780 \mathrm{~nm}$ of the doped solid-state systems. ${ }^{216}$ The device response time and the detection limit of $\mathrm{O}_{2}$ were recorded as $1.0-1.2 \mathrm{~s}$ and $0.05 \%$, respectively.

(c) $\mathrm{SO}_{2}$. In 2015, a structurally novel "molecular ball" composed of a Lu ${ }^{\text {III }}$-bis(phthalocyanine) complex as the core and four salen-type arch pillars was designed and synthesized by Bekaroğlu et al., which, in the form of thin film, electrically and reversibly responded to $\mathrm{SO}_{2}$ within $40 \mathrm{~s}$ (Fig. 60). ${ }^{342}$

(d) Volatile organic compounds (VOCs). In 2001, RodrìguezMendez and Saja et al. documented that the nature of the central lanthanide ion, the presence of tert-butyl groups, and the thickness of the $\mathrm{LnPc}_{2}(\mathrm{Ln}=\mathrm{Pr}, \mathrm{Lu}) \mathrm{LB}$ films could help modulate the device response of their sensor array, which could even discriminate between different types of olive oil aromas upon principal component analysis of the signals. ${ }^{343}$ In 2001 , a

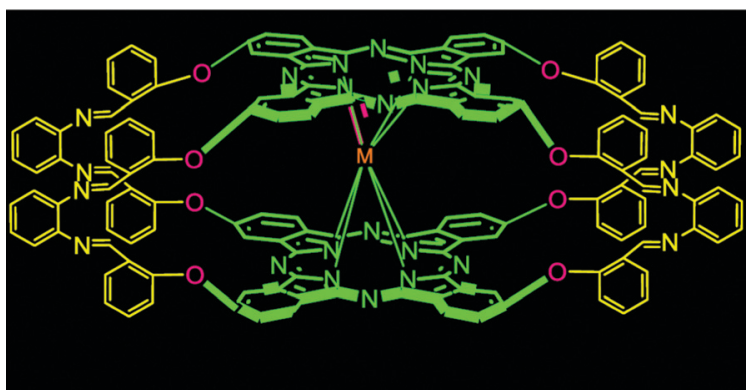

Fig. 60 "Molecular ball": Lu"'-bis(phthalocyanine) sandwich complex chelated by four salen-type ligands capable of sensing $\mathrm{SO}_{2}$. Reproduced with permission from ref. 342, copyright (2015) Elsevier B.V. wide range of VOCs, alcohols, aldehydes and esters, as well as gases, had been further examined by the authors, ${ }^{344}$ with the new possibility of NIR-emissive LB films of $\mathrm{LnPc}_{2}$ as gas/VOCsensing materials in fibre-optic sensors being showcased. By octa-substituting the phthalocyanine with imidazole moieties, Bekaroğlu et al., in 2018, prepared more sensitive and semiconducting $\mathrm{LB}$ films of $\mathrm{LnPc}_{2}\left(\mathrm{Ln}=\mathrm{Eu}^{\mathrm{III}}, \mathrm{Lu}^{\mathrm{III}}\right)$ for detecting organic vapours of toluene, ethanol, THF, $n$-hexane, chloroform, and xylene. ${ }^{345}$

6.1.2 Metal ions. The use of lanthanide-tetrapyrrole complexes for ion sensing is rather scarce and new, in contrast to gas sensing for which numerous reports are available. In 2010 only, Kandaza et al. synthesized new lanthanide(III) doubledecker films for spectrophotometrically sensing $\mathrm{Ag}^{+}$and $\mathrm{Pd}^{2+}$ based on soft-soft interaction upon functionalizing the long chain of terminated peripheral end-sites of phthalocyanines with ionophoric hydroxyhexylsulfanyl moieties. ${ }^{346}$ A few years later, Wong et al. developed a highly selective and responsive visible/NIR-luminescent probe for $\mathrm{Hg}^{2+}$ in buffered solutions: a capped $\mathrm{Yb}^{\mathrm{III}}$ monoporphyrinate complex was fitted with a reaction-based $\mathrm{Hg}^{2+}$-ring-openable rhodamine $\mathrm{B}$ derivative to trigger fluorescence resonance energy transfer (FRET); ${ }^{123}$ a detection limit of $10 \mathrm{mM}$ was achieved. In 2016, Boroujerdi described a one-step synthesis of nanorods of a $\mathrm{Ce}^{\mathrm{III}}$-porphyrin triple-decker, $\left[\mathrm{Ce}_{2}(\mathrm{TPP})_{3}\right]$, functioning as a spectrofluorometric naked-eye nanosensor for measuring trace amounts of $\mathrm{Hg}^{2+}$ and $\mathrm{Cu}^{2+}$; low detection limits of $16 \mathrm{nM}$ for $\mathrm{Hg}^{2+}$ and $2.34 \mu \mathrm{M}$ for $\mathrm{Cu}^{2+}$ were obtained. ${ }^{347}$ In 2019, a nanosized Gd ${ }^{\mathrm{III}}$-porphyrin-based coordination polymer having good water solubility was prepared and applied as a dual colorimetric ("turn-off") and fluorometric $\mathrm{Fe}^{3+}$ sensor reaching a detection limit of $98 \mathrm{nM}^{348}{ }^{34} \mathrm{Th}^{\mathrm{III}}$-tetrakis(4carboxyphenylporphyrin) nanosensor was used in assays for $\mathrm{Fe}^{3+}$ determination in fetal bovine serum samples.

6.1.3 Small molecules and biomolecules. In the late 1990s, Shinkai et al. reported a strong positive allosteric effect in the recognition of chiral dicarboxylic acids with a cerium(Iv) bis[tetrakis(4-pyridyl)-porphyrinate] double-decker, detected via circular dichroism (CD) and evidencing a Hill factor of 4 . Interestingly, a memory effect was observed in that the removal of the chiral carboxylate guest left the double-decker probe CD active for 3 days at $0{ }^{\circ} \mathrm{C}$ (Fig. 61). ${ }^{162,349}$ The authors attributed their promising findings to the smart design and application of this lanthanide sandwich with (i) the constrained rotation of the two porphyrin planes with respect to each other at room temperature and (ii) the extreme difficulty for them to tilt. To render the system workable for specific substrates in aqueous media, the authors attached boronic acid moieties onto the pyridines, thereby creating a new water-soluble $\mathrm{Ce}^{\mathrm{IV}}$ bis(porphyrinate) double-decker system with "off-on" CD signalling and positive allosterism upon binding with saccharide guests. $^{350}$ Mechanism-wise, after binding with the first sugar molecule by one boronic acid moiety from each porphyrin, the rotational freedom of the sandwich system would be decreased, which autocatalytically facilitated the second sugar binding and made the final sandwich CD-active (Hill coefficients: 1.6 for D-glucose and 2.0 for D-fructose). 

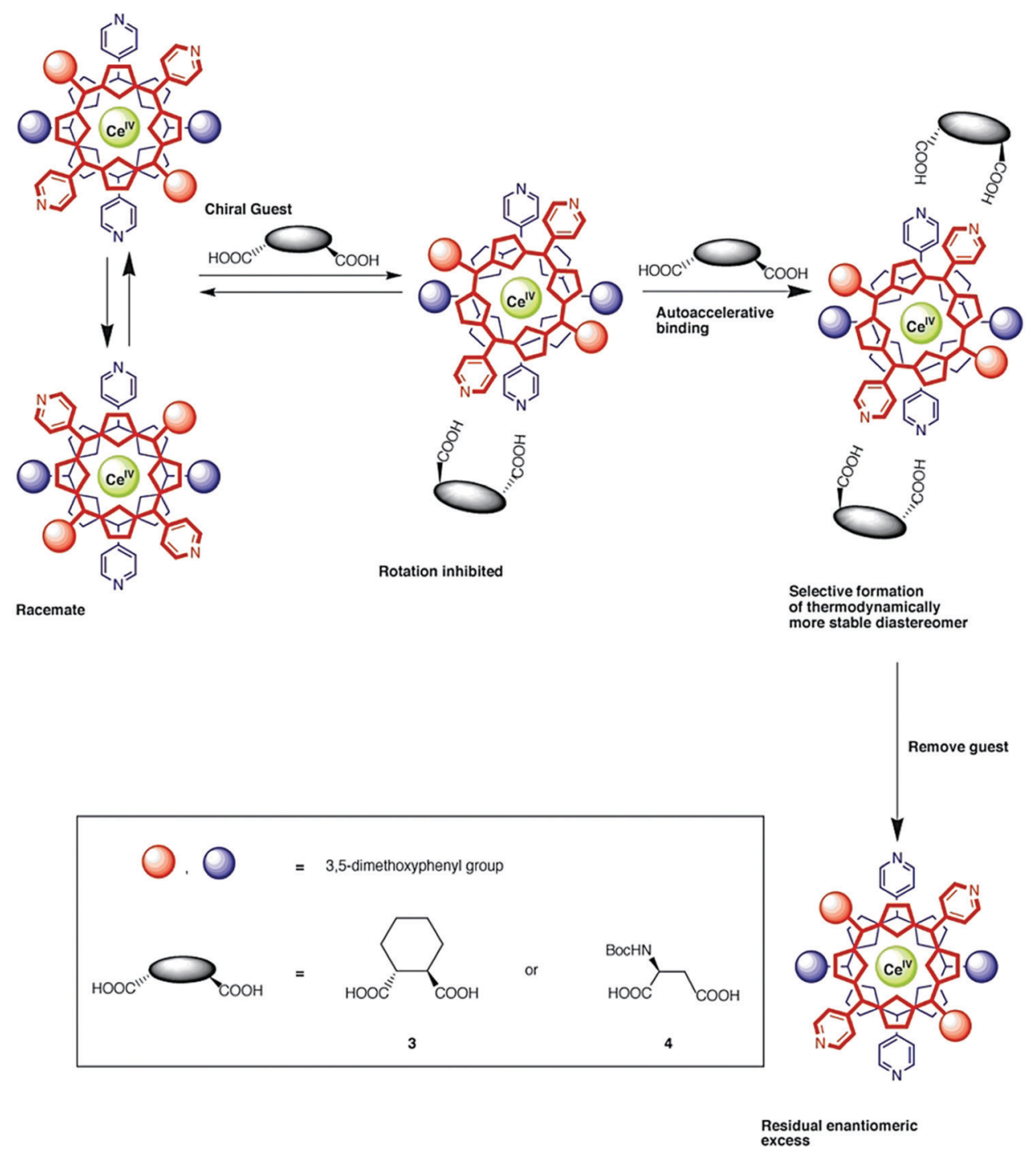

Fig. 61 Scheme for chiral dicarboxylic acid sensing by sandwich Ce $\mathrm{I}^{\mathrm{IV}}$-bisporphyrinates. Reproduced with permission from ref. 349, copyright (1999) The Royal Society of Chemistry.

In 2001, Tsukube et al. constructed an $\mathrm{Er}^{\mathrm{III}}$ porphyrinate/ benzo-18-crown-6 conjugate which can synergistically recognize zwitterionic chiral amino acids and biogenic amines, actualizing induced CD-based chirality sensing of the tested biomolecules; in fact, just mixing the separate $\mathrm{Er}^{\mathrm{III}}$ porphyrinate and the crown ether components failed to do so (Fig. 2).$^{50}$ More intriguingly, the authors asserted that only the $\mathrm{Er}^{\mathrm{III}}$, but not the $\mathrm{Gd}^{\mathrm{III}}$ or $\mathrm{Yb}^{\mathrm{III}}$, conjugates could afford such a CD-enhancement.

In 2003, Chudinova et al. developed a new donor-acceptor energy transfer and NIR-emissive marker pair based on (i) fluorescein isothiocyanate and (ii) $\mathrm{Yb}^{\mathrm{III}}$-porphyrin-benzoyl trifluoroacetone-isothiocyanate; they applied it in a luminescence immunoassay for the detection of protein antigens on the surface of Langmuir-Blodgett films of antibodies; to reduce non-specific binding, a non-polar substrate consisting of layers of stearic acid was used as the substrate for the LB film. ${ }^{351} \mathrm{~A}$ high sensitivity $\left(\sim 10^{-11} \mathrm{M}\right)$ and a short assay time (6-8 min) were reported for the overall system.
In 2008, Basova et al. investigated the electrochromic properties of a spin-coated film of bis[octakis(hexylthio) phthalocyaninato] Dy ${ }^{\text {III }}$ deposited on an indium tin oxide electrode. This film displays a single redox couple at $E_{1 / 2}=$ $0.78 \mathrm{~V}$ and was used to determine nicotinamide adenine dinucleotide hydride (NADH) in aqueous solutions. ${ }^{352}$ The authors hypothesized that the oxidized form of the Dy ${ }^{\text {III }}$ sandwich of the chemically and electrochemically modified film would be reduced to its neutral form, i.e., $\left(\left[\left(\mathrm{C}_{6} \mathrm{H}_{13} \mathrm{~S}\right)_{8} \mathrm{Pc}\right]_{2} \mathrm{Dy}\right)^{+} \rightarrow$ $\left[\left(\mathrm{C}_{6} \mathrm{H}_{13} \mathrm{~S}\right)_{8} \mathrm{Pc}\right]_{2} \mathrm{Dy}$, when interacting with the reducing NADH.

More recently, a new prototype of an albumin and nanosilica sensing system was proposed based on supramolecular films of polyvinyl pyrrolidone and polyvinyl alcohol comprising $\mathrm{Lu}^{\mathrm{III}} / \mathrm{Yb}^{\mathrm{III}}$ diphthalocyanine double-decker complexes, highlighting the biomedical sensing potential of lanthanide sandwich complexes protected in biocompatible multicomponent host systems. ${ }^{353}$

In 2019, Nyokong's group reported new electrochemical sensors for detecting 4-chlorophenol, a toxic organic contaminant, in 

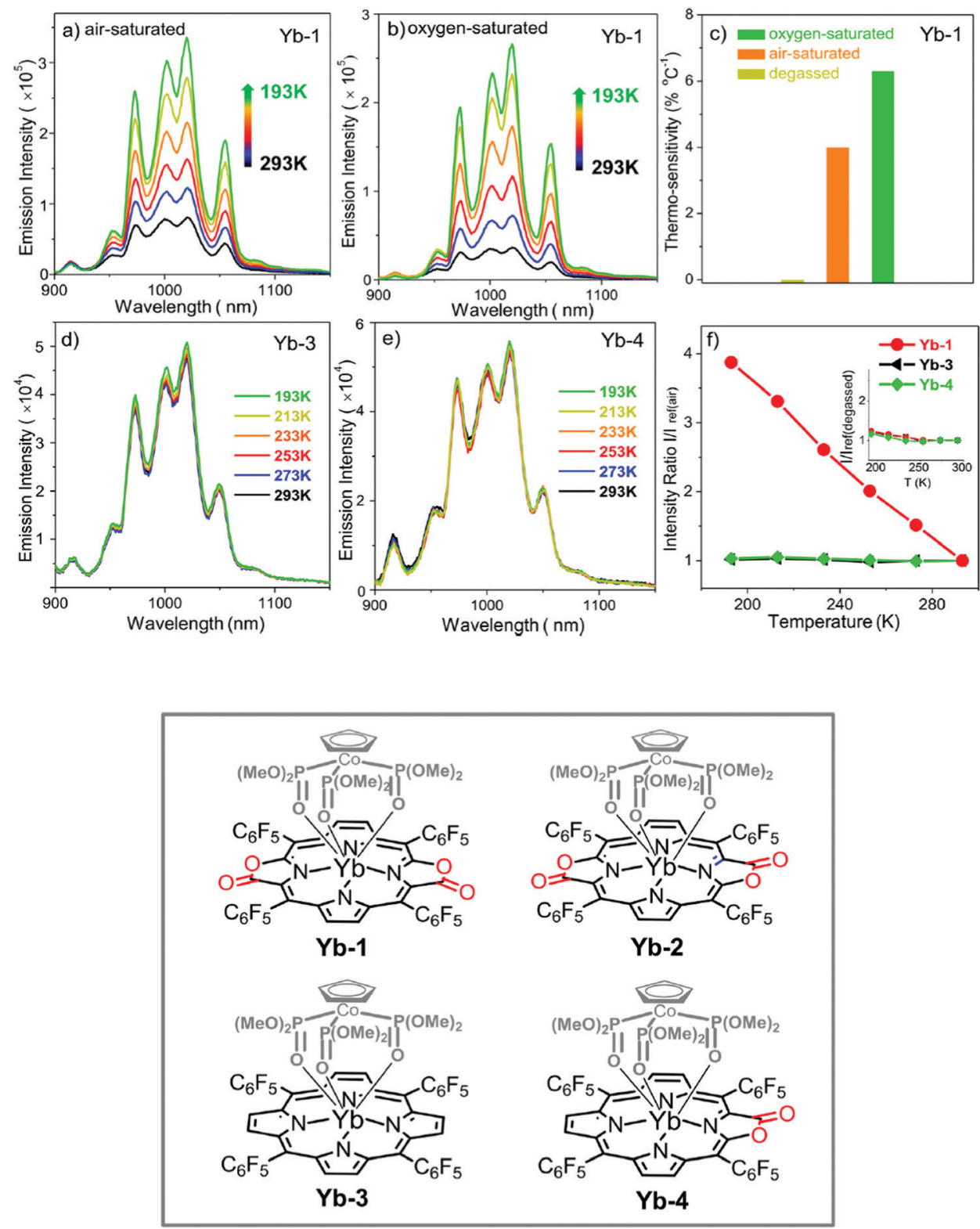

Fig. 62 Temperature-dependent emission of $\mathrm{Yb}-1$ in (a) air-saturated and (b) oxygen-saturated $\mathrm{CH}_{2} \mathrm{Cl}_{2}$ (293-193 K); (c) thermosensitivity of $\mathrm{Yb}-1$ in different gas atmospheres in $\mathrm{CH}_{2} \mathrm{Cl}_{2}$ (293-193 K); temperature-independent emission of (d) $\mathrm{Yb}$-3 and (e) $\mathrm{Yb}-4$ in $\mathrm{CH}_{2} \mathrm{Cl}_{2}$ (293-193 K); (f) emission intensity ratio normalized according to that at $293 \mathrm{~K}$ of $\mathrm{Yb}-1$ (red), $\mathrm{Yb}-3$ (black), and $\mathrm{Yb}-4$ (green) in air-saturated $\mathrm{CH}_{2} \mathrm{Cl}_{2}$ (Inset: Emission intensity ratio normalized according to that at $293 \mathrm{~K}$ in degassed $\mathrm{CH}_{2} \mathrm{Cl}_{2}$ ). Reproduced with permission from ref. 295, copyright (2017) The American Chemical Society.

aqueous media by modifying a glassy carbon electrode (GCE) with two forms of blue and green diethylaminophenoxy-bearing thulium double-decker phthalocyaninates, capitalizing on their respective electrocatalytic effect arising predominantly from the redox cycles of the Pc rings. The blue form stands for $\left[\left(\mathrm{Pc}^{2-}\right) \mathrm{Tm}^{\mathrm{III}}\left(\mathrm{Pc}^{2-}\right)\right]^{-}$(i.e., both the HOMO and LUMO are fully filled), with its overall charge compensated by a hexadecyltrimethylammonium cation, and responds better to oxidizing analytes, while the green form $\left[\left(\mathrm{Pc}^{-1 \bullet}\right) \mathrm{Tm}^{\mathrm{III}}\left(\mathrm{Pc}^{2-}\right)\right]$ with one electron hole prefers reducing analytes. The authors discovered that the blue-GCE demonstrated a lower peak potential of $0.88 \mathrm{~V}$ vs. $\mathrm{Ag} \mid \mathrm{AgCl}$, a higher catalytic current of $593 \mu \mathrm{A}$, and apparent sensitivity towards the presence of 4-chlorophenol with a lowest detection limit of $4.16 \times 10^{-8} \mathrm{M}^{354}$

6.1.4 Temperature. Temperature-dependent lanthanide luminescence is a well-known physical phenomenon that can be exploited for thermosensing. In 2017, Zhang et al. modified the porphyrin antenna for $\mathrm{Yb}(\mathrm{III})$ sensitization by $\beta$-cis/trans-dilactonization and found that the cis-orientation of such dilactone moieties on the porphyrin (i.e., Yb-1) exhibited "on/off" NIR emission with high oxygendependent thermosensitivity, $4.0 \%{ }^{\circ} \mathrm{C}^{-1}$ in solution and $4.9 \%{ }^{\circ} \mathrm{C}^{-1}$ in solid state (Fig. 62). ${ }^{294}$ This can be correlated with the apparent energy gap between the triplet state of 
the cis-/trans-porphodilactone and the excited state of $\mathrm{Yb}^{\mathrm{III}}$, thus modulating the back energy transfer efficiency: cis-isomer $\Delta E=1152 \mathrm{~cm}^{-1} ;$ trans-isomer $\Delta E=-25 \mathrm{~cm}^{-1}$ (Fig. 55).

\subsection{Time-resolved NIR imaging in vitro and in vivo}

In the early 1990s, Guidak et al. employed their home-made fibre-laser spectrofluorometer and disclosed the first proof-ofconcept of luminescence contrast-enhanced (i.e., autofluorescence-free) localization of tumours in vivo with NIRemissive $\mathrm{Yb}^{\mathrm{III}}$-porphyrin complexes. ${ }^{355}$ In parallel, Sessler et al. pioneered the use of gadolinium texaphyrin as a novel paramagnetic contrast agent in magnetic resonance imaging. ${ }^{356,357}$ These translational milestones laid the foundation of a new era for molecular lanthanide complexes in modern chemical biology and clinical radiology.

One of the critical problems of commercially available organic-based imaging agents, e.g., fluorescein, is high background noises during microscopic studies, which are caused by biological samples' autofluorescence and scattered light, as well as by the luminescence from the optical components and sample containers. Moreover, the poor photostability of most of them due to photobleaching is also a great concern. For this purpose, more attention has been focused on time-resolved luminescence techniques, with lanthanide complexes being new rising stars. The emission lifetimes of photostable lanthanide ions are in the micro- to milli-second scale, which is perfect for time-resolved detection. Moreover, some ions like $\mathrm{Nd}^{\mathrm{III}}$, $\mathrm{Er}^{\mathrm{III}}$, or $\mathrm{Yb}^{\mathrm{III}}$ exhibit emission in the near-infrared II/III biological windows (1000-1700 nm), which enables higher tissue penetration. Several critical benchmarks have to be met when designing practical lanthanide/tetrapyrrole-based molecular in vitro/in vivo imaging probes: (i) high water solubility and biostability, (ii) adequate biocompatibility, (iii) impressive photophysical properties (i.e., high brightness and long lifetime), and (iv) target selectivity and specificity.

In the literature, when it comes to mainstream applications of lanthanide-based bioimaging and bioanalysis, visibleemissive $\mathrm{Eu}^{\mathrm{III}}$ and $\mathrm{Tb}^{\mathrm{III}}$ have been ubiquitous since they usually present large values of quantum yield and brightness, and long lifetimes. In contrast, before 2010, the highest NIR emission quantum yield and lifetime of $\mathrm{Yb}^{\mathrm{III}}$ with non-macrocyclic ligands were $c a .0 .5 \%$ and $<5 \mu \mathrm{s}$ in water, respectively. ${ }^{358}$ In 2011, Wong et al. introduced the first water-soluble monoporphyrinato capped ytterbium(III) complex linked with rhodamine $\mathrm{B}(\mathrm{Yb}-\mathrm{RhB})$ which showed mitochondria-specific subcellular localization and, at that time, record-high NIR emission quantum yield from $\mathrm{Yb}^{\mathrm{III}}\left(1 \%\right.$ at $\lambda_{\mathrm{ex}}=340 \mathrm{~nm} ; 2.5 \%$ at $\lambda_{\mathrm{ex}}=430 \mathrm{~nm}$; both in water) (Fig. 23). ${ }^{70}$ By changing the vector from rhodamine $\mathrm{B}$ to ammonium salt, the same authors reported later another similar $\mathrm{Yb}^{\mathrm{III}}$ capped monoporphyrinate $(\mathrm{Yb}-\mathrm{N})$ which demonstrated strong binding to phosphatidylserine. The latter is an anionic phospholipid component appearing mainly in the interior of the cell membrane's lipid bilayer under normal conditions, but which is transported to the outer surface in the early and intermediate stages of apoptosis. Therefore,
$\mathrm{Yb}-\mathrm{N}$ differentiates the cancerous cells from the normal cells upon selective targeting of the more anionic phospholipid membrane of cancerous cells, as demonstrated by in vitro NIR imaging. ${ }^{122}$ Given that the extent and the rate of onset of induced targeted cancer apoptosis can serve as prognostic indicators of the treatment outcome, $\mathrm{Yb}-\mathrm{N}$ holds promise as an NIR prognostic bioprobe.

To further ameliorate the NIR photophysical properties, water solubility and biocompatibility of $\mathrm{Yb}^{\mathrm{III}}$ porphyrin complexes, Zhang et al. introduced (i) fluorination at the mesophenyl and $\beta$-peripheral positions of the porphyrin and (ii) deuteration of the Kläui ancillary ligand, to circumvent the quenching effect of the high-vibration $\mathrm{X}-\mathrm{H}$ bonds $(\mathrm{X}=\mathrm{C}, \mathrm{N}$ and $\mathrm{O})$; peripheral porphyrin $\beta$-cycloaddition and $\beta$-lactonization, and (iii) ligation with various hydrophilic side chains, were also attempted (Fig. 63). ${ }^{105}$ The resulting capped monoporphyrinato $\mathrm{Yb}^{\mathrm{III}}$ complexes gave rise to new records of NIR quantum yields (5-13\% in water) and decay lifetimes (56-173 $\mu$ s in water). Confocal live cell imaging and time-resolved fluorescence lifetime imaging (FLIM) in vitro verified the preferential localization of the NIR-emissive $\mathrm{Yb}^{\mathrm{III}}$ complex in the lysosome and high signal-to-noise ratios for effective autofluorescence discrimination. The authors subsequently employed the complexes in high-resolution non-invasive in vivo NIR-II imaging of small animals' whole body, vasculature, and lymph nodes, and confirmed their safe metabolic clearance pathway through the hepatobiliary and renal systems like most organic fluorophores. ${ }^{289}$

In 2010, Klapshina et al. adopted an encapsulation approach to prepare PEG-organized biocompatible silica-modified and disk-shaped nanoparticles doped with tricyanovinylbenzenebridged bis(ytterbium(III) cyanoporphyrazine) complexes for in vivo imaging. ${ }^{359}$ Modification of the PEG nanoparticles with a hydrophobic organosilicon component led to uniform nanoparticles. The adopted sol-gel strategy rather than the commonly used water-in-oil method appears to be ideal for biomedical work since it avoids centrifugation and washing. Host protection helped in enhancing the water nanosuspension, biostability (for several weeks), and biocompatibility of the overall system. Protecting the lanthanide emitter from undesired interactions and shielding of living organisms from potentially toxic heavy metal effects were also achieved, in parallel with a large enhancement of NIR emission upon binding to biomolecules in physiological liquids.

\subsection{Biomolecular interactions}

Although free tetrapyrrolic macrocycles and their transitionmetal complexes had been well-identified for their imaging and therapeutic potentials and for their interactions with biomolecules via intercalation, stacking, and binding, ${ }^{360,361}$ such information for their lanthanide counterparts had long been elusive. Liu and Wong et al. first spectroscopically investigated the thermodynamics of the binding between a lanthanide cationic porphyrin complex (YbTMPyP) and bovine serum albumin (BSA) in water, in 2007; they confirmed that such a process is enthalpy-driven and brings the reactants in close 
(A)

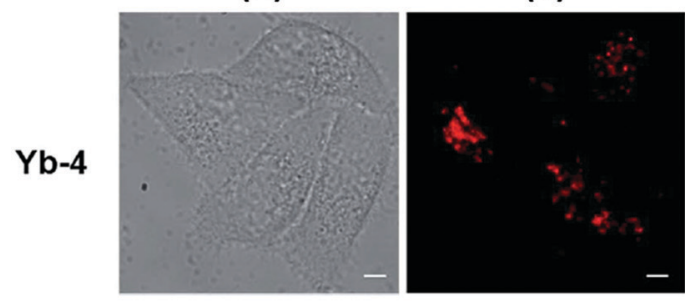

(C)

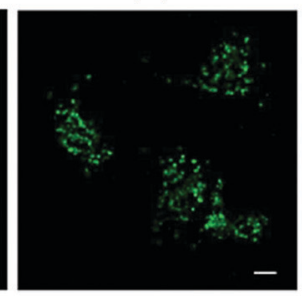

(D)

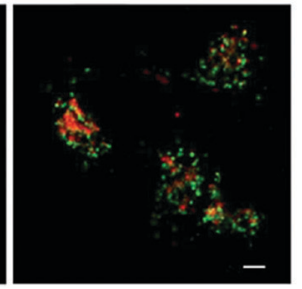

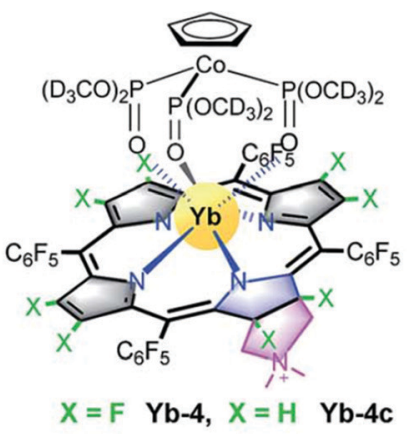

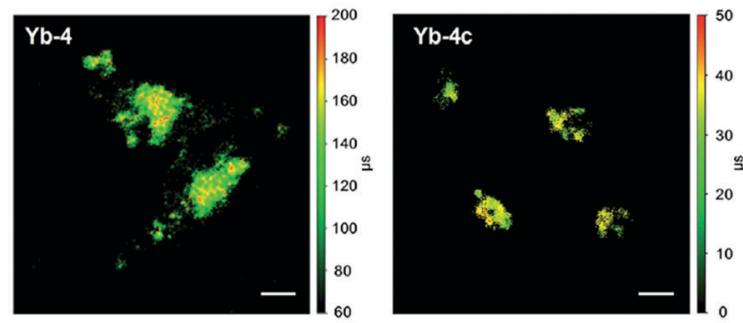

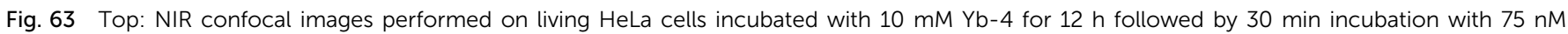
LysoTracker Green. (A) Bright field; (B) NIR signal arising from Yb ${ }^{I I I}$ in channel 1 ( $\lambda_{\mathrm{ex}}, 620 \mathrm{~nm}$; $\lambda_{\mathrm{em}}, 935,170 \mathrm{~nm}$ bandpass); (C) visible signal arising from LysoTracker Green in channel 2 ( $\lambda_{\mathrm{ex}}, 470 \mathrm{~nm} ; \lambda_{\mathrm{em}}, 530,43 \mathrm{~nm}$ bandpass); (D) merged b and c showing colocalization $(P=0.52)$. Scale bar: $10 \mu \mathrm{m}$. Bottom: NIR time-resolved images of living HeLa cells incubated with $10 \mathrm{mM} \mathrm{Yb-4}$ and Yb-4c ( $\lambda_{\text {ex }}, 408 \mathrm{~nm} ; \lambda_{\mathrm{em}}, 935,170 \mathrm{~nm}$ bandpass; dwell time, $\left.4 \mathrm{~ms}\right)$. Scale bar: $10 \mu \mathrm{m})$. Reproduced with permission from ref. 105, copyright (2018) The Royal Society of Chemistry.

proximity so that molecular resonance energy transfer with tryptophan and tyrosine residues of BSA occurs. ${ }^{362}$ In 2011, Wong et al. synthesized a series of water-soluble meso-pyridylsubstituted $\mathrm{Ln}^{\text {III }}$ porphyrinates with different substitution patterns and capped with a tripodal ligand, and examined their binding modes to and photocleavage of DNA. All the results of absorption and fluorescence titrations, induced circular dichroism measurements, plasmid DNA-unwinding assays and gel electrophoresis were complementary and supported the intercalative binding of the complex. ${ }^{104}$ For similar porphyrin systems, yet with a long protruding hydroxamic acid tail for external lanthanide coordination, Coutsolelos et al. observed different DNA-interaction modes depending on the nature of the DNA: intercalation for GC-rich DNAs, outside binding for AT-rich DNAs. They reported a positive correlation between the nuclease activity and the concentration and size of the lanthanide ion. Optimal conditions were found to correspond to a ratio of gadolinium/hydroxamic acid functionality of $2: 1 .^{363} \mathrm{~A}$ working model has been proposed (Fig. 64). In contrast, a negative correlation was found for interaction with RNAs, which was explained by the lanthanide interference with respect to the interaction between the porphyrin-hydroxamic acid derivatives and the open-chain RNAs. ${ }^{103}$ In 2017, Bağda et al. first studied the DNA-binding mechanism of a watersoluble $\mathrm{Lu}^{\mathrm{III}}$ double-decker phthalocyaninate, bearing bioactive quaternized 5-(3-pyridyl)-1,3,4-oxadiazole-2-thiol substituent groups, with calf thymus DNA; they found that the intercalative DNA binding process of such planar sandwich structure was highly favoured, being exoenergetic, and further favoured by an increase in viscosity. ${ }^{364}$

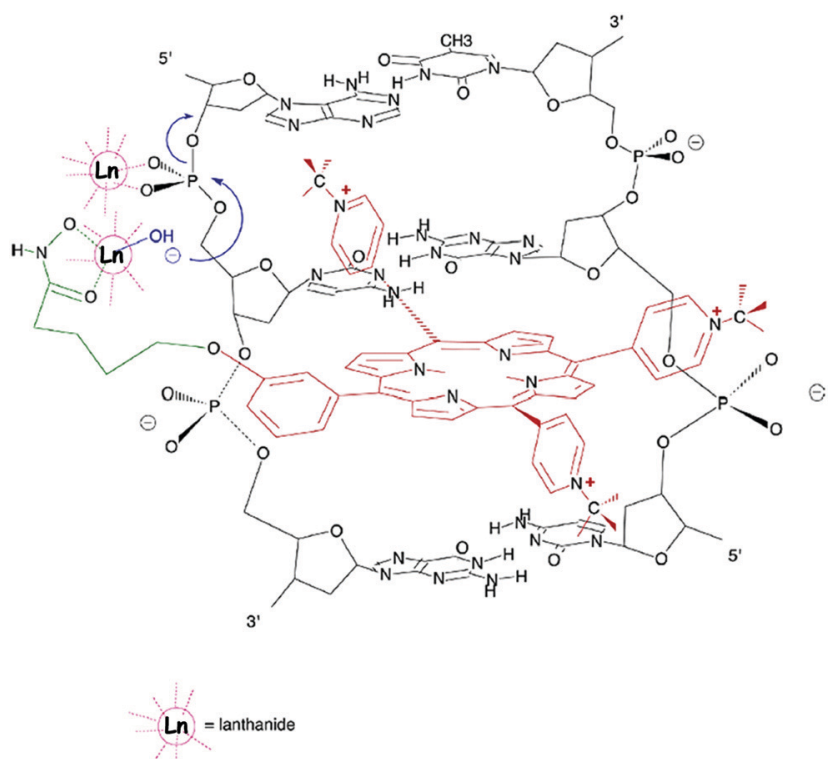

Fig. 64 Proposed model for the hydrolysis of a DNA ACG sequence by an intercalated porphyrin-hydroxamic acid-lanthanide ion adduct. Reproduced with permission from ref. 363, copyright (2001) World Scientific.

\subsection{Photosensitized singlet oxygen generation}

Cancer has been the leading cause of human deaths for more than a century and research focusing on its treatment has always attracted huge attention. Radiotherapy and chemotherapy are the traditional methods for killing cancer cells effectively; however, their side effects can have deleterious 
effects on the patients. Therefore considerable efforts have been invested in designing efficient targeted cancer therapy while minimizing harmful side effects. Photodynamic therapy (PDT) has progressively become an attractive cornerstone for targeted cancer therapy, with tetrapyrrole-based photosensitisers being in the limelight. ${ }^{365-367}$ Indeed, cancer cells can be killed selectively through in situ photogeneration of cytotoxic reactive oxygen species (ROS). At the same time, specific targeting avoids undesired damage to normal cells. PDT proceeds in two main sequences: first, the administration of a photosensitizer into the patient's body and, second, the activation of this photosensitizer by non-thermal light of a specific wavelength, resulting in the production of singlet oxygen, which is a powerful oxidant causing serious cellular damages. ${ }^{7}$

Laser is the frequently used light source for PDT as the light beam is coherent and monochromatic. It allows the light to be focused on a specific targeted area in order to bring less harm to the nearby tissue. Generally, lasers emitting in the nearinfrared range are applied for PDT as NIR light has deeper tissue penetration ability compared to visible light, around 3 to $8 \mathrm{~mm}$; in addition, shorter wavelength excitation may also result in strong light scattering and the strong absorption of light shorter than $580 \mathrm{~nm}$ by haemoglobin greatly interferes with in vivo treatments. ${ }^{6}$ There are two mechanisms for ROS generation (Fig. 65). In type I mechanism, radicals are produced through a series of electron-transfer processes. After activation of the photosensitizer by light, a mixture of oxygenated products is produced. Subsequent reactions between oxygen and the radicals produce ${ }^{\bullet} \mathrm{OH}$ radicals and superoxide ${ }^{\bullet} \mathrm{O}_{2}{ }^{-}$. In type II mechanism, singlet oxygen is produced from molecular oxygen $\left({ }^{3} \mathrm{O}_{2}\right)$ via a photochemical process. Since singlet oxygen has two valence electrons spinpaired in one $\pi^{*}$ orbital, it is more reactive than ground state molecular dioxygen.

The photosensitizer determines the efficiency of PDT and several strategies can be used to enhance its efficiency: (i) introduction of heavy atoms such as halogens and metals in the proximity of the photosensitizer avoids the generation of free radicals and prevents interactions with the triplet excited state. (ii) Incorporation of a central metal into the photosensitizer prevents its aggregation; the latter results in a shorter lifetime of the triplet state which, in turn, reduces the ${ }^{1} \mathrm{O}_{2}$ production. (iii) Expansion of the photosensitizer's conjugated system to increase its absorption efficiency at longer wavelengths for a better penetration depth in human tissue. (iv) Increasing the lipophilicity of the photosensitizer, by incorporating suitable functional groups, leads to better cellular uptake and improves its localization ability.

Since Sessler et al. reported that $\mathrm{Lu}^{\mathrm{III}}$ texaphyrin is an effective photosensitizer with an ${ }^{1} \mathrm{O}_{2}$ quantum yield $\Phi_{\Delta}$ in water equal to $11 \%$, and with high biostability and biocompatibility in photodynamic therapy, ${ }^{368-370}$ lanthanide-tetrapyrrole complexation systems have become attractive molecular platforms for singlet oxygen generation in vitro/in vivo. However, as discussed in Section 2, the intrinsic hydrophobicity renders water solubilization of most tetrapyrroles significantly challenging. In addition, there is still much room for improving the singlet oxygen generation efficiency, which is limited by their small molar absorption coefficients in the biological optical windows. New and smart molecular design strategies have recently emerged to overcome these bottlenecks.

The energies of the emissive ${ }^{2} \mathrm{~F}_{5 / 2}$ state of $\mathrm{Yb}^{\mathrm{III}}$ and of the $\mathrm{T}_{1}$ state of phthalocyanines are close so that $\mathrm{Yb}^{\mathrm{III}}$ emission is prevented due to back energy transfer, while ${ }^{1} \mathrm{O}_{2}$ production is favoured, as seen from its phosphorescence in the NIR region. Taking this fact into consideration, Wong et al. developed potential one/two-photon photodynamic therapeutic agents and extended the $\pi$-conjugation of the tetrapyrrolic antenna ligand by developing acetylene bridged porphyrin-monophthalocyaninato $\mathrm{Yb}^{\mathrm{III}}$ hybrids (Fig. 16). The underlying reasons for such bridging are to (i) enlarge the two-photon absorption cross-sections $\left(\sigma_{2}\right)$ of the complexes by increasing the intramolecular charge-transfer and coherent structure domain and (ii) enhance the simultaneous ${ }^{1} \mathrm{O}_{2}$ production with two conjugated photosensitizing moieties. ${ }^{108}$ The authors highlighted that the absorption spectra of the hybrids are not a superposition of the individual spectra of the porphyrin and the

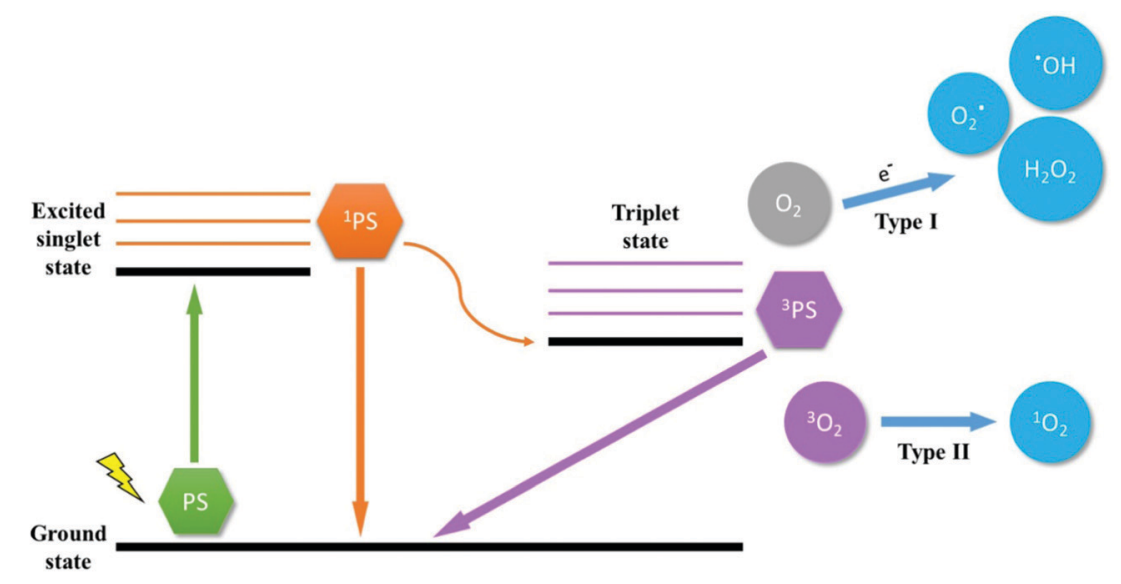

Fig. 65 Type I and type II mechanisms of ${ }^{1} \mathrm{O}_{2}$ generation. 
$\mathrm{Yb}^{\mathrm{III}}$-phthalocyanine components. Singlet oxygen is efficiently produced in toluene upon one- or two-photon excitation either in the porphyrin Soret band or in the Q-band of the phthalocyanine: $\Phi_{\Delta}=1.07-1.38, \lambda_{\mathrm{ex}}=416 \mathrm{~nm} ; \Phi_{\Delta}=0.73-0.79, \lambda_{\mathrm{ex}}=675 \mathrm{~nm}$. Hydrophilic modifications of the porphyrin chromophore to achieve better water solubility for the hybrids is highly feasible.

Apart from the $\pi$-conjugation extension strategy, Wong et al. continued to explore the impact of peripheral substitutions of their capped monophthalocyaninato $\mathrm{Yb}^{\mathrm{III}}$ complexes on the singlet oxygen quantum yields. ${ }^{371}$ In addition to the heavyatom effect exerted by the lanthanide boosting the intersystem crossing (isc) from the ligand-centred singlet state to triplet state, the introduction of iodine and bulky 3,5-di-t-butylphenoxy substituents at the periphery further triggers isc and provides shielding from solvent-induced nonradiative quenching, leading to higher ${ }^{1} \mathrm{O}_{2}$ yields ( $\Phi_{\Delta}=0.63-0.82$ in toluene).

Considering the limited light penetration depth and irradiation efficiency of gadolinium-porphyrin complexes in biological medium, namely the weak $Q$ band absorption at 500$600 \mathrm{~nm}$, Zhang et al. proposed another $\pi$-conjugation modulation strategy to introduce a new type of macrocyclic tetrapyrrole-like antenna ligands-porpholactone derivatives (Fig. 66). ${ }^{68}$ In nature, macrocyclic pigments such as chlorins, bacteriochlorins, iso-bacteriochlorins and pyrrocorphins have all been biosynthesized by minor structural modifications to address various problems, water solubility, oxidation resistance and deep-red to NIR absorption tunability. Inspired by this, Zhang et al. replaced the porphyrin's $\beta, \beta^{\prime}$-double bond with a lactone moiety, forming a series of porpholactones, cis- and trans-porphodilactones, and the corresponding capped $\mathrm{Gd}^{\mathrm{III}}$ complexes. Such replacement not only narrows the energy gap between the lowest triplet states of the ligand and the energy of the ${ }^{1} \mathrm{O}_{2}\left({ }^{1} \Delta_{\mathrm{g}} \rightarrow{ }^{3} \Sigma_{\mathrm{g}}\right.$ transition) of ${ }^{1} \mathrm{O}_{2}$, resulting in a higher yield of the reactive oxygen species, but also allows excitation in the visible to NIR spectral range. Quantum yields reach almost unity, $\Phi_{\Delta}=0.76-0.99$, in chloroform. To improve the water solubility of the new systems for further in vitro PDT studies, the authors glycosylated the four pentafluorophenyl rings at the methenyl bridges via nucleophilic aromatic substitution with 2,3,4,6-tetra-O-acetylglucosyl thioacetates, followed by removal of the acetyl protective group.

In 2017, Cai et al. reported a water-soluble molecular dyad comprising two non-capped $\mathrm{Gd}^{\mathrm{III}}$-sinoporphyrin sodium moieties, Gd-DVDMS; DVDMS is a porphyrin dimer combined with an ether bond isolated from Photofrin II and named sinoporphyrin by Fang. ${ }^{372}$ This system was proposed as a potential multifunctional theranostic agent, possibly accommodating two different metals. ${ }^{373}$ Gd-DVDMS exhibits large molar absorption coefficients because of the presence of two porphyrin rings and thus a reasonable ${ }^{1} \mathrm{O}_{2}$ quantum yield $\left(\Phi_{\Delta}=\right.$ 0.46 in methanol). The authors claimed another application of the dyad, namely phosphorescence-based oxygen sensing in PDT, by monitoring the intensity of the phosphorescence of the dyad at $712 \mathrm{~nm}$, which is oxygen-sensitive.

More recently, in 2019, Wong et al. synthesized the first water-soluble and stable $\mathrm{Ln}^{\mathrm{III}}$-porphyrin double-deckers, LnDD
(Fig. 67), which have been a long-standing synthetic challenge. These double deckers displayed impressive NIR brightness and long lifetimes; more importantly, ${ }^{1} \mathrm{O}_{2}$ generation was observed in aqueous solution, another long awaited property. ${ }^{374}$ At variance with their previous water-soluble polyethylene glycol (PEG) chain-conjugated, capped $\mathrm{Ln}^{\mathrm{III}}$ monoporphyrinates ( $\mathrm{YbN}$ \& GdN), the authors strategically fitted two optimally short hydrophilic methylated diethylene glycol chains to reach water solubility; moreover, the double-deckers sensitize efficiently the NIR luminescence of ytterbium by (i) having two antenna chromophores and (ii) minimizing the inner-sphere quenching effect by expelling bound water molecules from the inner sphere. These resulted in an NIR emission quantum yield of $2.8 \%$ for $\mathrm{YbDD}$ in water, slightly larger than that of $\mathrm{YbN}\left(\Phi_{\mathrm{NIR}}=\right.$ $2.7 \%$ ); the singlet oxygen quantum yield of $46 \%$ in water was also better than that of $\mathrm{YbN}\left(\Phi_{\Delta}=42 \%\right)$. Although the ${ }^{1} \mathrm{O}_{2}$ generation efficiency of GdDD is smaller than those of the FDAapproved commercially available photosensitizing agents Photofrin ${ }^{\circledR}(89 \%)$ and Levulan ${ }^{\circledR}$ (56\%) (Fig. 68), GdDD has a much higher molar absorption coefficient, $223872 \mathrm{M}^{-1} \mathrm{~cm}^{-1}$ at $412 \mathrm{~nm}$ and $52480 \mathrm{M}^{-1} \mathrm{~cm}^{-1}$ at $580 \mathrm{~nm}$ compared to $3000 \mathrm{M}^{-1} \mathrm{~cm}^{-1}$ at $632 \mathrm{~nm}$ for Photofrin ${ }^{\circledR}$ and $5000 \mathrm{M}^{-1} \mathrm{~cm}^{-1}$ at $632 \mathrm{~nm}$ for Levulan ${ }^{\circledR}$. More importantly, GdDD displayed a higher photodynamic therapeutic index against HeLa cells over the normal cells and performed similarly well under both normoxic and hypoxic conditions.

\subsection{Multimodal theranostics}

As mentioned earlier, the past decade, from 2010 to 2020, can be landmarked as the second golden period of lanthanidetetrapyrrole chemistry as many breakthroughs have been made, thanks to advances in synthetic chemistry: hydrophobic lanthanide-tetrapyrrole complexes have been strategically made water-soluble, biostable and biocompatible via novel tetrapyrrole ligand design such as peripherical perfluorination/lactonization, expanded/fused porphyrins, and PEGylation. Moreover, advanced synthesis allowed side-chain ligation and multipledecker assembly. Such fundamental achievements pave the ways for further translational biomedical applications for these macrocyclic complexes, for instance, upon integrating their imaging capability with photodynamic therapy functionality-as novel multifunctional theranostic molecular platforms.

In 2008, Liu and Wong et al. documented the first in vitro example of a combined agent for photodynamic therapy and NIR tumour-imaging based on an $\mathrm{Yb}^{\mathrm{III}}$ amphiphilic bis(porphyrin) complex. ${ }^{375}$ Porphyrin derivatives are likely to accumulate in tumours lacking lymphatic drainage due to their high hydrophobicity, vascular permeability and affinity towards proliferating endothelium/low-density lipoproteins. The authors took advantage of this passive bio-targeting/cellular uptake property by augmenting the molecular weight and hydrophobicity of the overall system, that is, connecting one more cationic porphyrin moiety to the $\mathrm{Yb}^{\mathrm{III}}$ monoporphyrinate complex, which resulted in a tumour-selective dual NIR-PDT functional probe. It should however be noted that the greater the hydrophobicity, the higher the cellular uptake efficiency, 

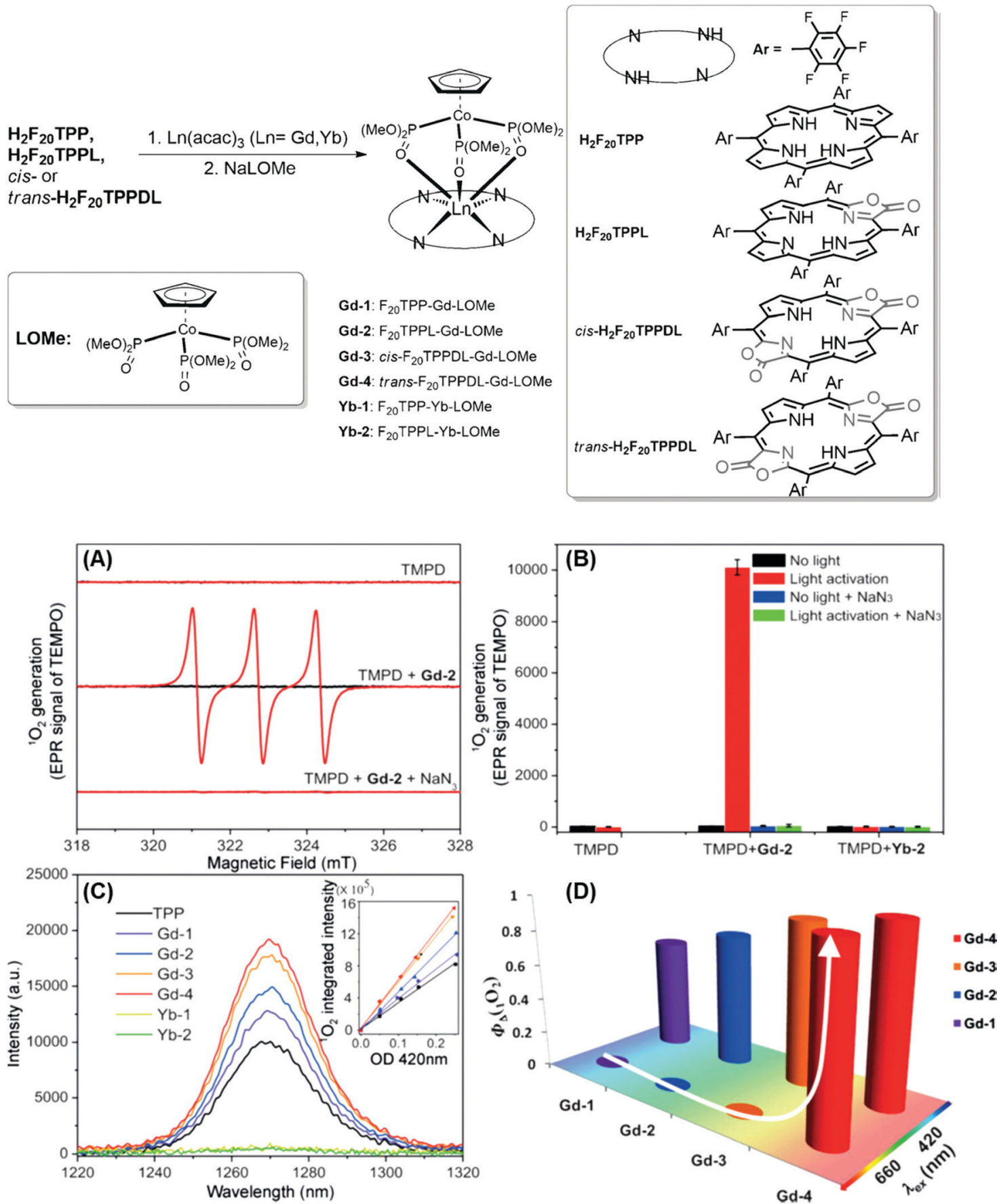

Fig. 66 Synthesis of $\mathrm{Ln}$ perfluorinated monoporphyrinates and porpholactone analogues for ${ }^{1} \mathrm{O}_{2}$ production. (A) Typical EPR spectra of nitroxide radicals detected in DMSO solution containing TMPD $(10 \mathrm{~mm})$ and Gd-2 $(0.01 \mathrm{~mm})$, and irradiated (red) or not (black) with a mercury lamp $(200 \mathrm{~W}, \lambda>400 \mathrm{~nm}$, $2 \mathrm{~min}$ ) in the presence (or not) of $\mathrm{NaN}_{3}\left(10 \mathrm{mM}\right.$ ). (B) Derived amount of ${ }^{1} \mathrm{O}_{2}$ produced under the indicated conditions. (C) NIR emission of ${ }^{1} \mathrm{O}_{2}$ at $1270 \mathrm{~nm}$ excited at $420 \mathrm{~nm}$ in $\mathrm{CHCl}_{3}$ (Inset: Relative intensity of ${ }^{1} \mathrm{O}_{2}$ production versus absorption for $\mathrm{Gd}-1-4$ and TPP at $420 \mathrm{~nm}$ ). (D) ${ }^{1} \mathrm{O}_{2}$ quantum yield measured upon excitation at 420 and $660 \mathrm{~nm}$ in $\mathrm{CHCl}_{3}$. Reproduced with permission from ref. 68, copyright (2016) Wiley-VCH Verlag GmbH \& Co.

but the lower the efficiency of singlet oxygen generation, due to self-aggregation, and vice versa.

Later, Che et al. described a series of monomeric $\mathrm{Yb}^{\mathrm{III}}$ porphyrin complexes exhibiting potential anti-cancer activity, with $\mathrm{IC}_{50}$ values in the sub-micromolar range in DMSO/ water. ${ }^{134}$ The best performing complex was an OEP complex which exists as a $\mu$-OH dimer in $\mathrm{CH}_{2} \mathrm{Cl}_{2},\left\{[\mathrm{Yb}(\mathrm{OEP})]_{2}(\mu-\mathrm{OH})_{2}\right\}$, and as a monomeric species in aqueous DMSO, $[\mathrm{Yb}(\mathrm{OEP})$ (DMSO) $\left.\left(\mathrm{H}_{2} \mathrm{O}\right)(\mathrm{OH})\right]$. The authors conducted comprehensive studies using transcriptomics, bioinformatics connectivity map analysis and biochemical experiments, and confirmed that the cancer-killing mechanism of this complex could be ascribed to the endoplasmic reticulum stress-induced apoptosis pathway. This is different from other anti-cancer 
(A)

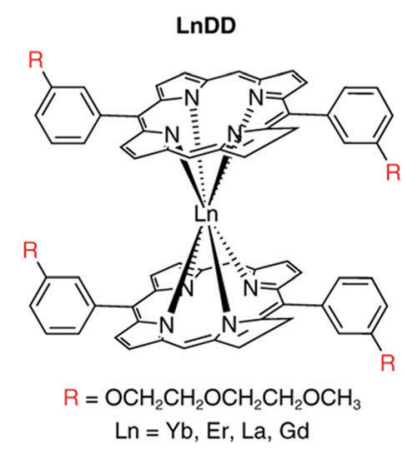

(C)

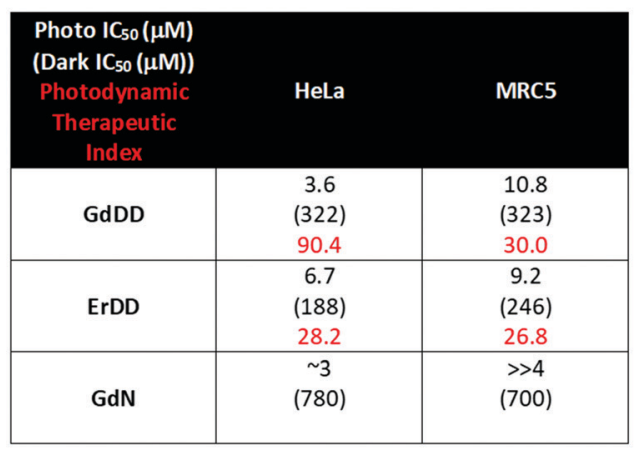

(B)

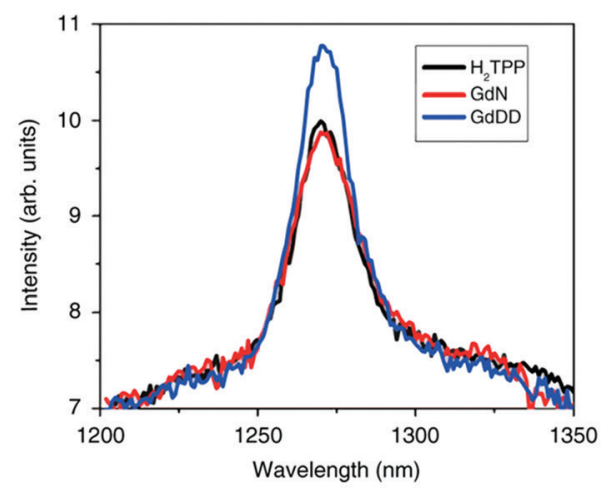

(D)

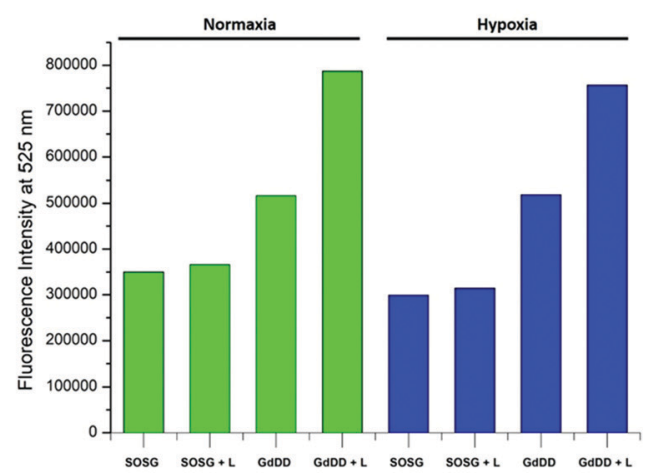

Fig. 67 (A) Structure of LnDD; (B) near-infrared ${ }^{1} \mathrm{O}_{2}$ phosphorescence spectrum sensitized by GdDD, GdN, and the standard tetraphenylporphyrin $\mathrm{H}_{2}$ TPP (in $\mathrm{CHCl}_{3}$. Absorbance $=0.05$ at the excitation wavelength of $425 \mathrm{~nm}$ ); (C) photo-/dark cytotoxicity of GdDD, ErDD and GdN towards HeLa cancer and normal MRC5 cells under $1 \mathrm{~J} \mathrm{~cm}^{-2}$ light irradiation $\left(\lambda_{\mathrm{ex}}=430 \mathrm{~nm}\right.$ ); MTT assays were carried out after incubation at $37{ }^{\circ} \mathrm{C}$ for $24 \mathrm{~h}$; (D) fluorescence intensity of emission at $525 \mathrm{~nm}$ of singlet oxygen sensor green of different samples in normoxic and hypoxic conditions (Exc.: NIR laser, $808 \mathrm{~nm} ; 2 \mathrm{~W} \mathrm{~cm}^{-2} ; 1 \mathrm{~min}$ ). Reproduced with permission from ref. 374, copyright (2019) Nature Publishing Group.

(A)

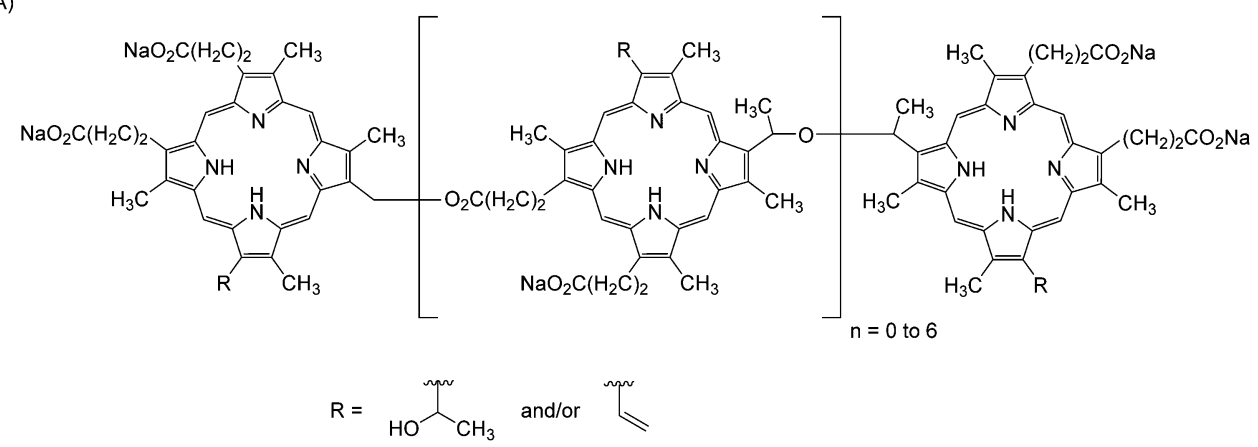

(B)

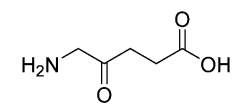

Fig. 68 Structures of (A) Photofrin ${ }^{\circledR}$ (Porfimer sodium, a mixture of porphyrin oligomers formed by ether and ester linkages) and (B) Levulan ${ }^{\circledR}$ (5aminolevulinic acid, a biosynthetic precursor to natural photosensitizer-protoporphyrin IX).

non-macrocyclic lanthanide complexes targeting and photocleaving cellular DNA.

The same year, in continuation of the previous work on $\mathrm{Yb}-$ $\mathrm{RhB}$ as a monofunctional NIR imaging agent, ${ }^{70}$ Wong et al. replaced $\mathrm{Yb}^{\mathrm{III}}$ with $\mathrm{Er}^{\mathrm{III}}$ and developed a new water-soluble, mitochondria-specific and one/two-photon-excitable porphyrin complex as a dual theranostic probe-NIR imaging and PDT (Fig. 23). ${ }^{120}$ Indeed, the energy difference between the porphyrin triplet state and the $\mathrm{Yb}^{\mathrm{III}}\left({ }^{2} \mathrm{~F}_{5 / 2}\right)$ state is small so that energy transfer is highly efficient, resulting in a poor singlet 
oxygen production ( $\Phi_{\Delta}=2 \%$ in chloroform). On the contrary, the larger energy gap between the porphyrin triplet state and the much lower $\operatorname{Er}^{\mathrm{III}}\left({ }^{4} \mathrm{I}_{13 / 2}\right)$ emissive level makes part of the excitation energy available for ${ }^{1} \mathrm{O}_{2}$ production $\left(\Phi_{\Delta}=10 \%\right.$ in chloroform). Such an autofluorescence-suppressed optically traceable mild ${ }^{1} \mathrm{O}_{2}$ generator selectively accumulated in the mitochondria of the cancer cells in vitro and enabled real-time longitudinal monitoring of the whole process for the first time.

A further improvement was disclosed by the same authors who presented a $\mathrm{Gd}^{\mathrm{III}}$ monoporphyrinate fitted with a short DEG ammonium chain (Gd-N) as the next-generation blueprint of selective in vivo cancer-tracking and a two-photon photodynamic therapeutic agent (Fig. 69). ${ }^{121}$ The complex recognises tumour cells by their anionic phosphatidylserine membrane. It also features a large ${ }^{1} \mathrm{O}_{2}$ production with $\Phi_{\Delta}=51 \%$ in chloroform upon excitation in the Soret band, i.e., comparable to the yield of $\mathrm{H}_{2} \mathrm{TPP}$, in view of its highly energetic ${ }^{6} \mathrm{P}_{7 / 2}$ emissive level, $32000 \mathrm{~cm}^{-1}$ compared with 23 200, 15300 (singlets), and 12500 (triplet) $\mathrm{cm}^{-1}$ for the porphyrin ligand. Importantly, the PDT effect can be generated by 2-photon excitation in the NIR region (860 $\mathrm{nm}$ ), which also results in exploitable NIR emission from the porphyrin for cell imaging. Gd-N-based photo-treatment at $860 \mathrm{~nm}$ not only efficaciously inhibits the growth of solid tumour but also reduces it by one half after $24 \mathrm{~h}$ in xenografted nude mice. A final advantage of this agent is its long residence time in the mice, around 8-9 h. The authors then continued to perform SILAC-based quantitative proteomics analysis and concluded that the newly developed Gd-N PDT led to (i) dysregulation of the expression of 485 proteins, phosphorylation of 106 proteins, and oxidation of 1050 proteins; (ii) the lysosome was discovered to be chiefly affected, along with the downregulation of most lysosomal acid hydrolases and the proton pump complex ATP6V/TCIRG1, where new insights into the cellular mechanism to oxidative stress and PDT effect were provided. ${ }^{124}$

In a search for ultimate precision multimodal PDT treatment not only selectively targeting cancer cells over the normal cells, but accurately one cancer type over the others, Wong et al. proposed specifically modified lanthanide porphyrin complexes as in vitro NIR-PDT and in vivo NIR-MRI-PDT theranostic agents, respectively, taking bladder cancer as an example (Fig. 70). ${ }^{125,126}$ Various bladder cancer-specific molecules were developed via a combinatorial chemistry approach by targeting the integrin $\alpha_{v} \beta_{3}$ isoform, which is overexpressed in the neovasculature of bladder cancers; the peptides were conjugated to the previously developed porphyrin platforms. In addition to
(A)
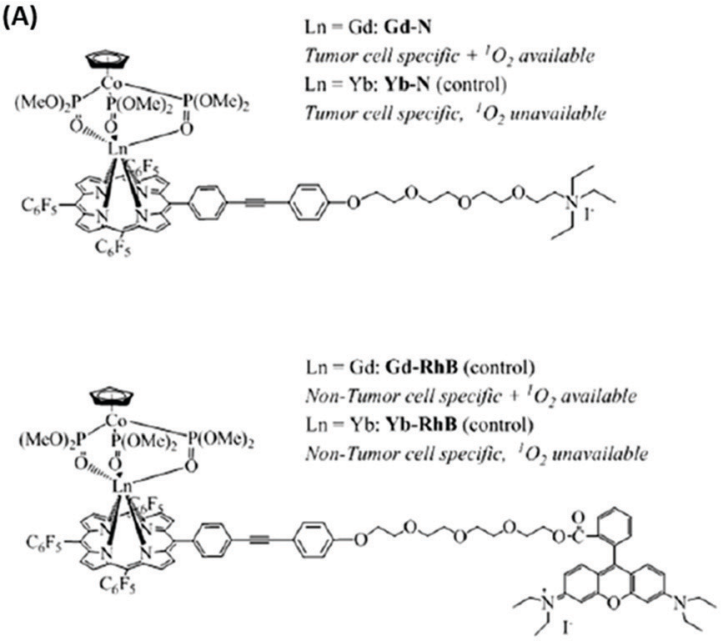

(B)
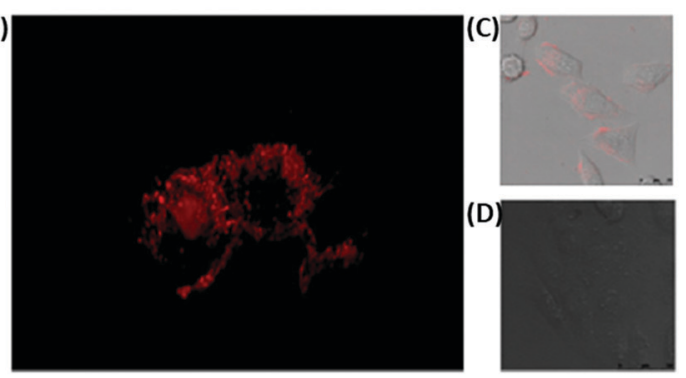

(E)

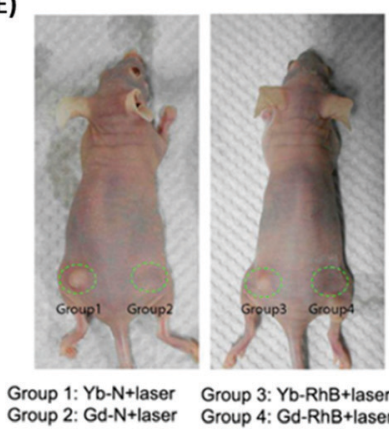

(G)
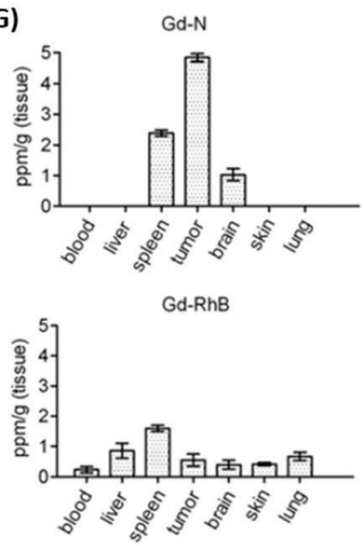

(F)
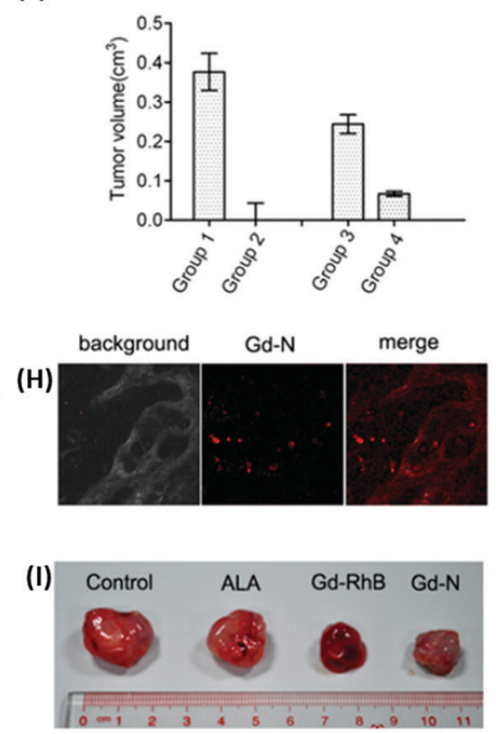

(J)

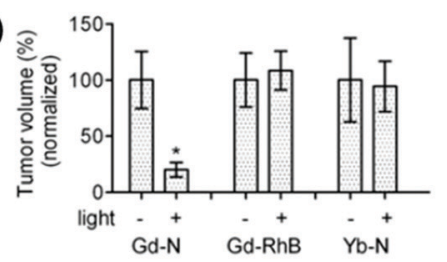

Fig. 69 Left: (A) The molecular structure of the smart cancer specific photodynamic therapy agent (Gd-N) and their control analogues $\mathrm{Yb}-\mathrm{N}$ and $\mathrm{Gd}-$ RhB. (B) The 3D in vitro imaging of Gd-N after $15 \mathrm{~h}$ incubation in HeLa cells. (C and D) The difference in subcellular localization of Gd-N in cancer cells (HeLa) and normal cells (WPMY-1). Right: In vivo studies of Gd-N as the cancer cell-specific PDT agent. (E) The representative gross images of tumours after PDT under $860 \mathrm{~nm}$ laser irradiation for four groups administered with different complexes: group 1: Yb-N; group 2: Gd-N; group 3: Yb-RhB; group 4: Gd-RhB. (F) Tumour volume in A. (G) In vivo biodistribution of Gd-N via ICP-MS studies. (H) Two-photon microscopic images of tumour samples in C. (I) In vivo tumour inhibition assays of $\mathrm{Gd}-\mathrm{N}$. (J) In vivo tumour inhibition via $\mathrm{Gd}-\mathrm{N}$ and $\mathrm{Gd}-\mathrm{RhB}$-induced ${ }^{1} \mathrm{O}_{2}$ through caudal vein injection. Reproduced with permission from ref. 121, copyright (2019) National Academy of Sciences of the United States of America. 
(A)

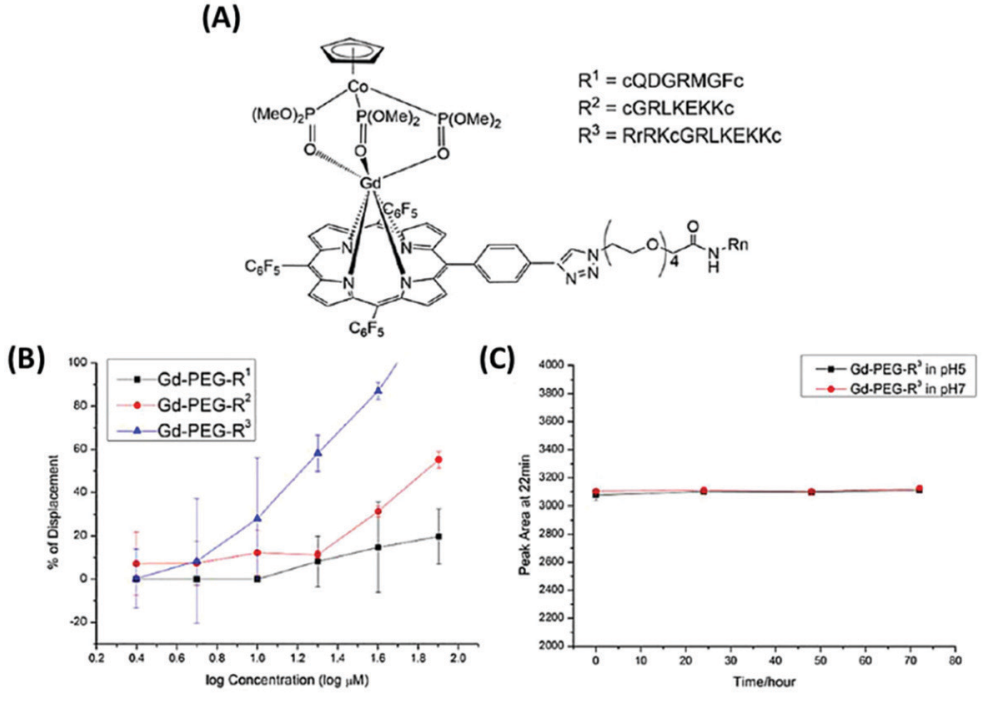

(D)
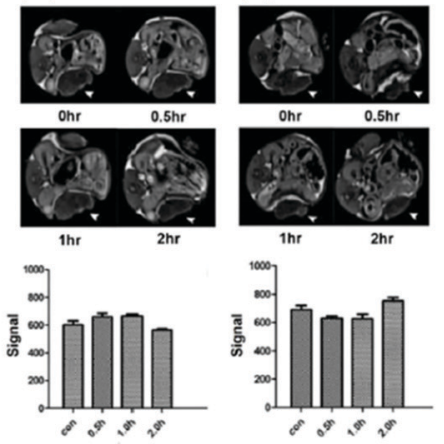

(G)

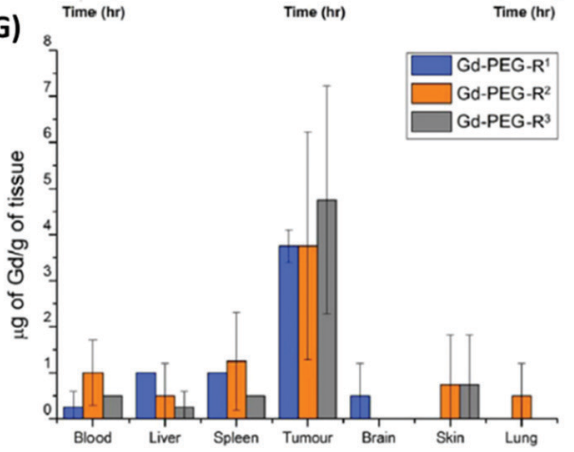

(E)

(F)

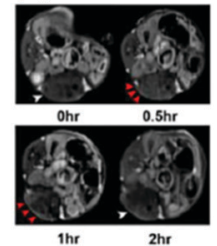

${ }^{1000}+\infty$

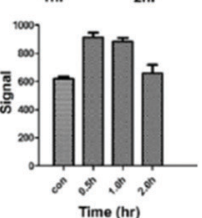

AEG-R

Fig. 70 Left: (A) molecular structures of Gd-PEG-R $(n=1-3)$. (B) Displacement percentages of the vitronectin $-\alpha_{v} \beta_{3}$ integrin net binding at different

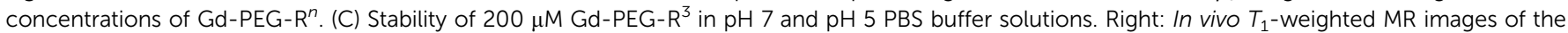
mouse T24 tumour model after injection of (D) GdDOTA, (E) Gd-PEG-COOH, and (F) Gd-PEG-R $\mathrm{R}^{3}$ at different time points. (G) In vivo biodistribution of Gd-PEG- $\mathrm{R}^{n}(n=1-3)$ via ICP-MS studies, 3 samples in each group. Reproduced with permission from ref. 126, copyright (2019) Wiley VCH Verlag GmbH.

specificity for bladder cancer, this ensured enough water solubility and cell membrane permeability. Finally, a small hydrophilic peptide RrRK sequence was also conjugated to the hydrophobic bladder cancer-specific peptide sequences to make them amphiphilic. As previously demonstrated, singlet oxygen production varied depending on the lanthanide ion: $\mathrm{Gd}^{\mathrm{III}}$ (for MRI-PDT) $\gg \mathrm{Er}^{\mathrm{III}}$ (for NIR-PDT) $\gg \mathrm{Yb}^{\mathrm{III}}$ (for NIR). Furthermore, for the in vivo $\mathrm{Gd}^{\mathrm{III}}$ agents, one complex, Gd-PEG$\mathrm{R}^{3}$, featured (i) high photo-cytotoxicity $\left(\mathrm{IC}_{50}=8.2 \mu \mathrm{M}\right)$ against T24 bladder cancer cells while remaining non-cytotoxic in the dark (PTI $=199.0,20$-fold higher than 5-aminolevulinic acid) and in normal and HeLa cells; (ii) "off-on" responsive $T_{1}$ relaxivity enhancement over 17 times upon $\alpha_{v} \beta_{3}$ binding; and (iii) a safe tumour-centred biodistribution profile without breaking the blood-brain barrier. This work substantiates the huge potential of lanthanide-tetrapyrrole systems for further clinical exploration.

\section{Conclusion and outlook}

The past decades have witnessed tremendous progress in the lanthanide-tetrapyrrole systems, and their unique properties and functionalities have been exploited in a range of applications from a wide spectrum of disciplines, from optical materials to biomedical agents ${ }^{277}$ and photocatalysis. ${ }^{376}$ Advanced synthetic and functionalization methodologies have been developed and exploited to realize various strategies for (1) conjugation extension in porphyrin/phthalocyanine rings for fine-tuning of their HOMO-LUMO energy gap, (2) modular lanthanide coordination and symmetry tailoring, (3) directed multiple-decker assembly with different twist angles, (4) better photosensitization for efficient Vis/NIR emission with high quantum yields and brightness, (5) improved solutionprocessability in organic solvents and water solubilization, and (6) enhanced biocompatibility, to impart lanthanide-tetrapyrrole complexes with novel biochemical properties, as well as for sensing, bio-targeting and multimodal theranostic applications. In this review, we briefly introduced the long and rich history of different lanthanide porphyrinates and phthalocyaninates, highlighting their syntheses and structure-property relationship, and surveying their applications in contemporary photonic, sensing and biomedical research. Despite the efforts and breakthroughs in this field in the past 20 years, there are still some challenges and opportunities lying ahead that we describe below.

\subsection{Hybrid organic-inorganic complexation to photosensitize} less-explored luminescent lanthanides

$\mathrm{Nd}^{\mathrm{III}}$ and $\mathrm{Sm}^{\mathrm{III}}$ are luminescent lanthanide ions that are seldom employed with tetrapyrrolic ligands because of intrinsically weak quantum yields partly due to energy mismatch between the ligand donor states and the lanthanide excited states. Recently, however, organic-inorganic hybrid acetatecoordinated $\mathrm{Sm}^{\text {III }}$-based polyoxometalates have been reported with 
excitation-dependent reversible colour-tuneable photoluminescence. ${ }^{377}$ This approach enables reversible colour switching in the same material without adjusting the doping concentration of $\mathrm{Ln}^{\mathrm{III}}$ ions. On the other hand, Kögerler et al. disclosed new thermodynamically highly stable phthalocyanine-polyoxotungstate lanthanide double deckers, in which the redox-active polyoxometalates serve as versatile polydentate ligands; ${ }^{378}$ multiple decker-like phthalocyaninato lanthanide-ligated polyoxovanadate cages $\left\{\left[\mathrm{V}_{12} \mathrm{O}_{32}(\mathrm{Cl})\right](\mathrm{YbPc})_{x}\right\}^{n-5}(x=1$ or 2$)$ have also been synthesized and characterized. $^{379}$ Given the cornucopias of polyoxometalate structures, we believe that developing various functional lanthanidetetrapyrrole-polyoxometalates with improved optical and redox properties and optimizing them for unparalleled photonic and biomedical applications will become an attractive research direction in this field.

\subsection{Photocatalytic transformations with lanthanide- tetrapyrrole complexes}

Lanthanide-tetrapyrrole complexes, in particular phthalocyaninato lanthanide sandwiches, have been sporadically employed in photocatalysis, e.g., (i) photocatalytic degradation of 4nitrophenol and 2-propanol upon impregnation onto $\mathrm{TiO}_{2},{ }^{380,381}$ (ii) oxidative desulfurization of thiophene upon bonding on the surface of $\mathrm{ZMS}-5,{ }^{382}$ and (iii) oxidative $\mathrm{C}-\mathrm{H}$ bond functionalization of secondary or tertiary amines and oxygenation of cholesterol. ${ }^{68}$ In organic asymmetric synthesis, the concept of photoredox catalysis, operating through singleelectron transfer, energy transfer and radical processes, has long become a research hotspot and gives rise to unprecedented reactivities and products. ${ }^{383}$ Given that eye-catching photocatalyst applications of lanthanides have recently come under the limelight, ${ }^{384,385}$ and that lanthanide-tetrapyrrole complexes possess unique photophysical and redox properties, we believe that new photocatalytic potentials of lanthanidetetrapyrrole systems will soon be unleashed. One aspect is asymmetric synthesis, which is currently and actively pursued in our laboratory; on the other hand, further real-life photocatalytic applications of lanthanide-tetrapyrroles for environmental organic waste treatment and biomass conversion are also foreseeable.

7.3 Towards peptide/aptamer-guided drug delivery and deeptissue photoactivation of lanthanide-tetrapyrrole theranostic probes

To address the long-standing translational challenges of (i) poor water solubility, (ii) nonspecific toxicity, and (iii) lack of cancer selectivity of most lanthanide-tetrapyrrole-based PDT agents, different in vivo targeted delivery strategies have to be explored. For instance, both specific peptides and aptamers, which have been extensively surface-functionalized in nanomedicine for cancer targeting, can be conjugated similarly to the Ln-tetrapyrrole systems by optimization of their biostabilities and bioactivities. The systems can also be loaded onto proteins ${ }^{386}$ and attached to polymer carriers functionalized with specific vectors, ${ }^{387}$ or inserted into nanomaterials sensitive to tumour microenvironments (e.g., pH, presence of glutathione, etc.) and stimuli-activatable (e.g., through photoirradiation, ultrasound, etc.). ${ }^{388,389}$ This enables achieving safer and more specific targeting for multimodal imaging. Furthermore, X-ray and two-photon excitation can promisingly allow deep-tissue photodynamic therapy upon coupling to nanoscintillators, ${ }^{390}$ and this direction is under-explored with lanthanide-tetrapyrrole complexes. Hence, new multifunctional bioapplications of smart and biocompatible lanthanide-tetrapyrrole systems are conceivable.

As a final remark, we would like to point out that developments in the field will need to be built on precise knowledge of all the crucial parameters relevant to each application. For instance, reports demonstrating the usefulness of lanthanidetetrapyrrole complexes for bio-applications should not only describe their synthesis, structure, and imaging properties but also, and most crucially for biosafety, report their stability constants in vitro/in vivo. This has often been ignored, but is now being better acknowledged by the bioinorganic community. All photophysical parameters should also be quantitatively reported, interpreted and modelled. Providing such data in future work will give a more holistic view of the translational bioapplications of tetrapyrrole complexes.

\section{Conflicts of interest}

There are no conflicts to declare.

\section{Acknowledgements}

KLW acknowledges the support from Dr Mok Man Hung Endowed Professorship in Chemistry; this project was funded through grants RC-ICRS-18-19-01A from HKBU, RGC HKBU 12300318 and CAS-Croucher Funding Scheme for Joint Laboratories (CAS 18204) from Croucher Foundation. J.-C. G. B. thanks HKBU for a Dr Kennedy Wong Distinguished Visiting Professorship (2017-2019).

\section{References}

1 F. Hoppe-Seyler, Physiologische Chemie, A. Hirschwald Verlag, Berlin, 1877.

2 P. R. Ortiz de Montellano, Wiley Encycl. Chem. Biol., 2008, 1-10, DOI: 10.1002/9780470048672.wecb221.

3 S. Nardis, F. Mandoj, M. Stefanelli and R. Paolesse, Coord. Chem. Rev., 2019, 388, 360.

4 J. F. Longevial, S. Clément, J. A. Wytko, R. Ruppert, J. Weiss and S. Richeter, Chem. - Eur. J., 2018, 24, 15442.

5 X. D. Ren, X. Y. Hao, H. C. Li, M. R. Ke, B. Y. Zheng and J. D. Huang, Drug Discovery Today, 2018, 23, 1791.

6 S. B. Park, H. H. Jang, H. L. Lee, J. Kim, J. W. Nah, D. H. Kim, Y. I. Jeong and D. H. Kang, Bull. Korean Chem. Soc., 2019, 40, 439.

7 K. Yang, T. Niu, M. Luo, L. Tang and L. Kang, Photodiagn. Photodyn. Ther., 2018, 24, 332. 
8 E. Campazzi, E. Solari, R. Scopelliti and C. Floriani, Chem. Commun., 1999, 1617.

9 P. A. Gale, J. Anzenbacher and J. L. Sessler, Coord. Chem. Rev., 2001, 222, 57.

10 G. P. Moss, Eur. J. Biochem., 1988, 178, 277.

11 A. Braun and J. Tcherniac, Ber. Deutch. Chem. Ges., 1907, 40, 2709.

12 T. Posner, Ber. Deutch. Chem. Ges., 1897, 30, 1693.

13 J. K. F. van Staden, Talanta, 2015, 139, 75.

14 F. Mohn, L. Gross, N. Moll and G. Meyer, Nat. Nanotechnol., 2012, 7, 227.

15 C.-P. Wong, R. F. Venteicher and W. W. de Horrocks Jr., J. Am. Chem. Soc., 1974, 96, 7149.

16 T. F. Kachura, A. N. Sevchenko, K. N. Solov'ev and M. P. Tsvirko, Dokl. Acad. Nauk. SSSR, 1974, 217, 1121.

17 J. W. Buchler, H. G. Kapellmann, M. Knoff, K. L. Lay and S. Pfeifer, Z. Naturforsch., B: Anorg. Chem., Org. Chem., 1983, 38, 1339.

18 J. W. Buchler, A. De Cian, J. Fischer, M. Kihn-Botulinski, H. Paulus and R. Weiss, J. Am. Chem. Soc., 1986, 108, 3652.

19 I. S. Kirin, P. N. Moskalev and Y. A. Makashev, Russ. J. Inorg. Chem., 1965, 10, 1065.

20 A. T. Chang and J.-C. Marchon, Inorg. Chim. Acta, 1981, 53, L241.

21 R. Weiss and J. Fischer, in The Porphyrin Handbook, ed. K. M. Kadish, K. M. Smith and R. Guilard, Academic Press, Amsterdam, 2003, vol. 16, p. 171.

22 W. K. Wong, L. Zhang, F. Xue and T. C. W. Mak, J. Chem. Soc., Dalton Trans., 1999, 3053.

23 W. K. Wong, L. L. Zhang, F. Xue and T. C. W. Mak, J. Chem. Soc., Dalton Trans., 2000, 2245.

24 X. Zhu, W.-K. Wong, J. P. Guo, W.-Y. Wong and J.-P. Zhang, Eur. J. Inorg. Chem., 2008, 3515.

25 Y. S. Korostei, V. G. Tarasova, V. E. Pushkarev, N. E. Borisova, A. K. Vorobiev and L. G. Tomilova, Dyes Pigm., 2018, 159, 573.

26 A. Y. Tolbin, V. E. Pushkarev, L. G. Tomilova and N. S. Zefirov, Mendeleev Commun., 2009, 19, 78.

27 Y. Horii, K. Katoh, N. Yasuda, B. K. Breedlove and M. Yamashita, Inorg. Chem., 2015, 54, 3297.

28 F. T. Edelmann, New J. Chem., 2011, 35, 517.

29 M. R. Sambrook and S. Notman, Chem. Soc. Rev., 2013, 42, 9251.

30 C. Bazzicalupi, A. Bianchi, E. García-España and E. Delgado-Pinar, Inorg. Chim. Acta, 2014, 417, 3.

31 S. Comby and J.-C. G. Bünzli, in Handbook on the Physics and Chemistry of Rare Earths, ed. K. A. Gschneidner Jr., J.-C. G. Bünzli and V. K. Pecharsky, Elsevier Science B.V., Amsterdam, 2007, ch. 235, vol. 37, p. 217.

32 V. Bulach, F. Sguerra and M. W. Hosseini, Coord. Chem. Rev., 2012, 256, 1468.

33 H. He, Coord. Chem. Rev., 2014, 273, 87.

34 X. Jing, C. He, L. Zhao and C. Duan, Acc. Chem. Res., 2019, 52, 100.

35 K. Binnemans, in Handbook on the Physics and Chemistry of Rare Earths, ed. J.-C. G. Bünzli and V. K. Pecharsky, Elsevier Science, B.V., Amsterdam, 2013, ch. 254, vol. 43, p. 1.
36 S. Shinoda and H. Tsukube, Bunseki Kagaku, 2012, 61, 169. 37 O. J. Stacey and S. J. A. Pope, RSC Adv., 2013, 3, 25550.

38 M. O. Senge, M. Fazekas, E. G. A. Notaras, W. J. Blau, M. Zawadzka, O. B. Locos and E. M. Ni Mhuircheartaigh, Adv. Mater., 2007, 19, 2737.

39 D. N. Woodruff, R. E. P. Winpenny and R. A. Layfield, Chem. Rev., 2013, 113, 5110.

40 K. M. Kadish, K. M. Smith and R. Guilard, in The Porphyrin Handbook, ed. K. M. Kadish, K. M. Smith and R. Guilard, Academic Press (Elsevier B.V.), Amsterdam, 1999.

41 W.-K. Wong, X. Zhu and W.-Y. Wong, Coord. Chem. Rev., 2007, 251, 2386.

42 D. K. P. Ng, in Handbook on the Physics and Chemistry of Rare Earths, ed. K. A. Gschneidner Jr., L. Eyring and G. H. Lander, Elsevier Science B.V., Amsterdam, 2001, ch. 210, vol. 32, p. 611.

43 J. Jiang and D. K. P. Ng, Acc. Chem. Res., 2008, 42, 79. 44 P. Rothemund, J. Am. Chem. Soc., 1935, 57(10), 2010.

45 A. D. Adler, F. R. Longo, J. D. Finarelli, J. Goldmacher, J. Assour and L. Korsakoff, J. Org. Chem., 1967, 32, 476.

46 J. S. Lindsey, I. C. Schreiman, H. C. Hsu, P. C. Kearney and A. M. Marguerettaz, J. Org. Chem., 1987, 52, 827.

47 W.-K. Wong, L. Zhang, W.-T. Wong, F. Xue and T. C. W. Mak, J. Chem. Soc., Dalton Trans., 1999, 615.

48 X.-B. Zhang, C.-C. Guo, J.-B. Xu, G.-L. Shen and R.-Q. Yu, Analyst, 2000, 125, 867.

49 M. Asano-Someda and Y. Kaizu, J. Photochem. Photobiol., A, 2001, 139, 161.

50 H. Tsukube, M. Wada, S. Shinoda and H. Tamiaki, J. Alloys Compd., 2001, 323-324, 133.

51 W.-K. Wong, A. Hou, J. Guo, H. He, L. Zhang, W.-Y. Wong, K.-F. Li, K.-W. Cheah, F. Xue and T. C. W. Mak, J. Chem. Soc., Dalton Trans., 2001, 3092.

52 X.-J. Zhu, T. Zhang, S. Zhao, W.-K. Wong and W.-Y. Wong, Eur. J. Inorg. Chem., 2011, 3314.

53 H. He, W.-K. Wong, K.-F. Li and K.-W. Cheah, Synth. Met., 2004, 143, 81.

54 H. He, W.-K. Wong, J. Guo, K.-F. Li, W.-Y. Wong, W.-K. Lo and K.-W. Cheah, Inorg. Chim. Acta, 2004, 357, 4379.

55 H. He, J. Guo, Z. Zhao, W.-K. Wong, W.-Y. Wong, W.-K. Lo, K.-F. Li, L. Luo and K.-W. Cheah, Eur. J. Inorg. Chem., 2004, 837.

56 H. He, M. Dubey, A. G. Sykes and P. S. May, Dalton Trans., 2010, 39, 6466.

57 J.-F. Zhang, H. Wong, A.-X. Hou, C.-F. Wang and H.-S. Zhang, J. Sep. Sci., 2004, 27, 1037.

58 J. S. Lindsey and R. W. Wagner, J. Org. Chem., 1989, 54, 828.

59 S. Fu, G. Zhou, X. Zhu, C. Ye, W.-K. Wong and Z. Li, Chem. Lett., 2006, 35, 802.

60 C.-W. Huang, K. Y. Chiu and S.-H. Cheng, Dalton Trans., 2005, 2417.

61 J. S. Lindsey, Acc. Chem. Res., 2010, 43, 300.

62 S. Hiroto, Y. Miyake and H. Shinokubo, Chem. Rev., 2017, 117, 2910.

63 A. K. Burrell, D. L. Officer, P. G. Plieger and D. C. W. Reid, Chem. Rev., 2001, 101, 2751. 
64 R. P. Linstead, J. Chem. Soc., 1934, 1016.

65 J. Mack and N. Kobayashi, Chem. Rev., 2011, 111, 281.

66 C.-P. Wong, R. F. Venteicher and W. D. Horrocks Jr., J. Am. Chem. Soc., 1974, 96, 7149.

67 X.-S. Ke, B.-Y. Yang, X. Cheng, S. L.-F. Chan and J.-L. Zhang, Chem. - Eur. J., 2014, 20, 4324.

68 X.-S. Ke, Y. Ning, J. Tang, J.-Y. Hu, H.-Y. Yin, G.-X. Wang, Z.-S. Yang, J. Jie, K. Liu, Z.-S. Meng, Z. Zhang, H. Su, C. Shu and J.-L. Zhang, Chem. - Eur. J., 2016, 22, 9676.

69 J. X. Meng, K. F. Li, J. Yuan, L. L. Zhang, W. K. Wong and K. W. Cheah, Chem. Phys. Lett., 2000, 332, 313.

70 T. Zhang, X. Zhu, C. C. W. Cheng, W.-M. Kwok, H.-L. Tam, J. Hao, D. W. J. Kwong, W.-K. Wong and K.-L. Wong, J. Am. Chem. Soc., 2011, 133, 20120.

71 T. J. Foley, K. A. Abboud and J. M. Boncella, Inorg. Chem., 2002, 41, 1704.

72 T. J. Foley, B. S. Harrison, A. S. Knefely, K. A. Abboud, J. R. Reynolds, K. S. Schanze and J. M. Boncella, Inorg. Chem., 2003, 42, 5023.

73 A. Santria, A. Fuyuhiro, T. Fukuda and N. Ishikawa, Inorg. Chem., 2017, 56, 10625.

74 A. Santria, A. Fuyuhiro, T. Fukuda and N. Ishikawa, Dalton Trans., 2019, 48, 7685.

75 H. He and A. G. Sykes, Inorg. Chem. Commun., 2008, 11, 1304.

76 M. G. Gurevich and K. N. Solov'ev, Dokl. Acad. Nauk. SSSR, 1961, 5, 291-294 (Chem. Abstr., 1962, 57, 15948).

77 H. Sugimoto, T. Higashi, A. Maeda, M. Mori, H. Masuda and T. Taga, J. Chem. Soc., Chem. Commun., 1983, 1234.

78 A. De Cian, M. Moussavi, J. Fischer and R. Weiss, Inorg. Chem., 1985, 24, 3162.

79 H. Ke, W.-K. Wong, W.-Y. Wong, H.-L. Tam, C.-T. Poon and F. Jiang, Eur. J. Inorg. Chem., 2009, 1243.

80 S. A. Znoiko, O. N. Zubkova, A. V. Borisov, V. E. Maizlish and G. P. Shaposhnikov, Russ. J. Gen. Chem., 2015, 85, 2642.

81 A. D. Kosov, T. V. Dubinina, N. E. Borisova, A. V. Ivanov, K. A. Drozdov, S. A. Trashin, K. De Wael, M. S. Kotova and L. G. Tomilova, New J. Chem., 2019, 43, 3153.

82 Q. Fan, J.-N. Luy, M. Liebold, K. Greulich, M. Zugermeier, J. Sundermeyer, R. Tonner and J. M. Gottfried, Nat. Commun., 2019, 10, 5049.

83 R. Marin, G. Brunet and M. Murugesu, Angew. Chem., Int. Ed., 2021, 60, 1728.

84 Z. X. Zhao, W. Liu, M. Jin and G. F. Liu, Synth. React. Inorg. Met.-Org. Chem., 2000, 30, 1747.

85 Z.-X. Zhao, Q.-H. Xu, D.-M. Li, G.-F. Liu, L.-S. Li and R.-R. Xu, Solid State Sci., 2001, 3, 339.

86 Z. X. Zhao, T. F. Xie, D. M. Li, D. J. Wang and G. F. Liu, Synth. Met., 2001, 123, 33.

87 Z. X. Zhao and G. F. Liu, Synth. React. Inorg. Met.-Org. Chem., 2002, 32, 465.

88 M. Yu, G. Liu, Y. Cheng and W. Xu, Liq. Cryst., 2005, 32, 771.

89 J. S. Lindsey, K. A. MacCrum, J. S. Tyhonas and Y. Y. Chuang, J. Org. Chem., 1994, 59, 579.
90 K. Wada, T. Mizutani and S. Kitagawa, J. Org. Chem., 2003, 68, 5123.

91 T. P. Wijesekera, J. B. Paine III and D. Dolphin, J. Org. Chem., 1985, 50, 3832.

92 C.-H. Lee and L. S. Lindsey, Tetrahedron, 1994, 50, 11427.

93 E.-J. Kim, P. Kim, C.-H. Lee, J. Sung, H. Yoon, D. Kim and W.-D. Jang, Chem. Commun., 2012, 48, 5611.

94 C.-H. Lee, S. Lee, H. Yoon and W.-D. Jang, Chem. - Eur. J., 2011, 17, 13898.

95 Y. J. Zhang, J. Shi, W. Liu and M. Yu, Synth. React. Inorg. Met.-Org. Chem., 2013, 43, 640.

96 C. Piechocki, J. Simon, J.-J. André, D. Guillon, P. Petit, A. Skoulios and P. Weber, Chem. Phys. Lett., 1985, 122, 124.

97 Z. Zhao and G. Liu, Liq. Cryst., 2002, 29, 1335.

98 T. Wijesekera, A. Matsumoto, D. Dolphin and D. Lexa, Angew. Chem., Int. Ed. Engl., 1990, 29, 1028.

99 G. A. Spyroulias, A. P. Despotopoulos, C. P. Raptopoulou, A. Terzis, D. de Montauzon, R. Poilblanc and A. G. Coutsolelos, Inorg. Chem., 2002, 41, 2648.

100 J.-Y. Hu, Y. Ning, Y.-S. Meng, J. Zhang, Z.-Y. Wu, S. Gao and J.-L. Zhang, Chem. Sci., 2017, 8, 2702.

101 J. Itoh, J. Liu and M. Komata, Talanta, 2006, 69, 61.

102 M.-C. Chalbot, L. Gryllos, K. Kefokeris, N. Manoussakis, C. Verchère-Béaur, M. Perrée-Fauvet and A. G. Coutsolelos, J. Porphyrins Phthalocyanines, 2011, 15, 704.

103 M. Marketaki, E. Touloupakis, G. Charalambidis, M.-C. Chalbot, D. F. Ghanotakis and A. G. Coutsolelos, J. Porphyrins Phthalocyanines, 2012, 16, 997.

104 X.-J. Zhu, P. Wang, H. W. C. Leung, W.-K. Wong, W.-Y. Wong and D. W. J. Kwong, Chem. - Eur. J., 2011, 17, 7041.

105 Y. Ning, J. Tang, Y.-W. Liu, J. Jing, Y. Sun and J.-L. Zhang, Chem. Sci., 2018, 9, 3742.

106 Y. Ning, S. Cheng, J.-X. Wang, Y.-W. Liu, W. Feng, F. Li and J.-L. Zhang, Chem. Sci., 2019, 10, 4227.

107 F.-L. Jiang, W.-K. Wong, X.-J. Zhu, G.-J. Zhou, W.-Y. Wong, P.-L. Wu, H.-L. Tam, K.-W. Cheah, C. Ye and Y. Liu, Eur. J. Inorg. Chem., 2007, 3365.

108 H. Ke, W. Li, T. Zhang, X. Zhu, H.-L. Tam, A. Hou, D. W. J. Kwong and W.-K. Wong, Dalton Trans., 2012, 41, 4536.

109 K. E. Sekhosana, E. Amuhaya and T. Nyokong, Polyhedron, $2015,85,347$.

110 Y. Korovin, Z. Zhilina, N. Rusakova, V. Kuz'min, S. Vodzinsky and Y. Ishkov, J. Porphyrins Phthalocyanines, 2001, 5, 481.

111 V. Thanabal and V. Krishnan, J. Am. Chem. Soc., 1982, 104, 3643.

112 N. N. Semenishyn, N. V. Rusakova, A. V. Mazepa and Y. V. Korovin, Macroheterocycles, 2009, 2, 57.

113 N. Rusakova, N. Semenishyn and Y. Korovin, J. Porphyrins Phthalocyanines, 2010, 14, 166.

114 N. N. Semenishyn, S. S. Smola, N. P. Efryushina and N. V. Rusakova, Theor. Exp. Chem., 2015, 51, 224.

115 N. N. Semenishyn and N. V. Rusakova, Macroheterocycles, 2016, 9, 163. 
116 H.-S. He, Z.-X. Zhao, W.-K. Wong, K.-F. Lai, J.-X. Meng and K.-W. Cheah, Dalton Trans., 2003, 980.

117 F. Eckes, V. Bulach, A. Guenet, C. A. Strassert, L. De Cola and M. W. Hosseini, Chem. Commun., 2010, 46, 619.

118 A. Guenet, F. Eckes, V. Bulach, C. A. Strassert, L. De Cola and M. W. Hosseini, ChemPhysChem, 2012, 13, 3163.

119 J. Lindsey, J. Org. Chem., 1980, 45, 5215.

120 T. Zhang, C.-F. Chan, J. Hao, G.-L. Law, W.-K. Wong and K.-L. Wong, RSC Adv., 2013, 3, 382.

121 T. Zhang, R. Lan, C.-F. Chan, G.-L. Law, W.-K. Wong and K.-L. Wong, Proc. Natl. Acad. Sci. U. S. A., 2014, 111, E5492.

122 T. Zhang, C.-F. Chan, R. Lan, H. Li, N.-K. Mak, W.-K. Wong and K.-L. Wong, Chem. Commun., 2013, 49, 7252.

123 T. Zhang, C.-F. Chan, R. Lan, W.-K. Wong and K.-L. Wong, Chem. - Eur. J., 2014, 20, 970.

124 D. Qi, Q. Wang, H. Li, T. Zhang, R. Lan, D. W. J. Kwong, W.-K. Wong, K.-L. Wong, S. Li and F. Lu, Mol. BioSyst., 2015, 11, 3059.

125 Y. Zhou, C.-F. Chan, D. W. J. Kwong, G.-L. Law, S. Cobb, W.-K. Wong and K.-L. Wong, Chem. Commun., 2017, 53, 557.

126 C. Xie, H.-F. Chau, J.-X. Zhang, S. Tong, L. Jiang, W.-Y. Fok, H.-L. Lung, S. Zha, R. Zou, J. Jiao, C.-F. Ng, P. Ma, J. Zhang, J. Lin, K. K. Shiu, J.-C. G. Bünzli, W.-K. Wong, N. J. Long, G.-L. Law and K.-L. Wong, Adv. Ther., 2019, 1900068.

127 G. Liu, T. Shi and X. Liu, Polyhedron, 1994, 13, 2255.

128 D.-M. Li, Z.-X. Zhao, S.-Q. Liu, G.-F. Liu, T.-S. Shi and X.-X. Liu, Synth. Commun., 2000, 30, 4017.

129 E. Hasegawa, J.-I. Nemoto, T. Kanayama and E. Tsuchida, Eur. Polym. J., 1978, 14, 123.

130 X. L. Cui, M. Yu and G. F. Liu, Synth. React. Inorg. Met.-Org. Chem., 2005, 35, 785.

131 X. L. Cui, G. F. Liu and M. Yu, J. Coord. Chem., 2006, 59, 1361.

132 X. Cui, X. Shi and S. Li, Adv. Mater. Res., 2011, 308310, 643.

133 T. S. Srivastava, Bioinorg. Chem., 1978, 8, 61.

134 W.-L. Kwong, R. W.-Y. Sun, C.-N. Lok, F.-M. Siu, S.-Y. Wong, K.-H. Low and C.-M. Che, Chem. Sci., 2013, 4, 747.

135 J. P. Collman, R. R. Gagne, C. A. Reed, T. R. Halbert, G. Lang and W. T. Robinson, J. Am. Chem. Soc., 1975, 87, 1427.

136 P. J. Chmielewski, L. Latos-Grażyński, K. Rachlewicz and T. Glowiak, Angew. Chem., Int. Ed. Engl., 1994, 33, 779.

137 H. Furuta, T. Asano and T. Ogawa, J. Am. Chem. Soc., 1994, 116, 767.

138 K.-H. Schumacher and B. Franck, Angew. Chem., Int. Ed. Engl., 1989, 28, 1243.

139 P. J. Chmielewski, M. Siczek and L. Szterenberg, Inorg. Chem., 2011, 50, 6719.

140 J. M. Fisher, V. K. Kensy and G. R. Geier, III, J. Org. Chem., 2017, 82, 4429.

141 R. Li, A. D. Lammer, G. M. Ferrence and T. D. Lash, J. Org. Chem., 2014, 79, 4078.

142 Q. Li, C. Li, J. Kim, M. Ishida, X. Li, T. Gu, X. Liang, W. Zhu, H. Agren, D. Kim, H. Furuta and Y. Xie, J. Am. Chem. Soc., 2019, 141, 5294.
143 T. D. Lash, A. D. Lammer and G. M. Ferrence, Angew. Chem., Int. Ed., 2011, 50, 9718.

144 G. R. Geier, Y. Ciringh, F. Li, D. M. Haynes and J. S. Lindsey, Org. Lett., 2000, 2, 1745.

145 J. L. Shaw, S. A. Garrison, E. A. Alemán, C. J. Ziegler and D. A. Modarelli, J. Org. Chem., 2004, 69, 7423.

146 X. Zhu, W.-K. Wong, W.-K. Lo and W.-Y. Wong, Chem. Commun., 2005, 1022.

147 T. Tanaka and A. Osuka, Chem. Rev., 2017, 117, 2584.

148 V. J. Bauer, D. L. J. Clive, D. Dolphin, J. B. Paine III, F. L. Harris, M. M. King, J. Loder, S. W. Chien Wang and R. B. Woodward, J. Am. Chem. Soc., 1983, 105, 6429.

149 J. L. Sessler, M. R. Johnson and V. Lynch, J. Org. Chem., 1987, 52, 4394.

150 J. L. Sessler, T. D. Mody, G. W. Hemmi and V. Lynch, Inorg. Chem., 1993, 32, 3175.

151 J. L. Sessler, T. Murai and G. Hemmi, Inorg. Chem., 1989, 28, 3390.

152 J. Lisowski, J. L. Sessler, V. Lynch and T. D. Mody, J. Am. Chem. Soc., 1995, 117, 2273.

153 J. T. Brewster II, H. Zafar, H. D. Root, G. D. Thiabaud and J. L. Sessler, Inorg. Chem., 2020, 59, 32.

154 S. M. Meyer, M. C. Hoehner, V. Lynch and J. L. Sessler, J. Porphyrins Phthalocyanines, 1999, 3, 148.

155 J. L. Sessler, P. J. Melfi, E. Tomat, W. Callaway, M. T. Huggins, P. L. Gordon, D. Webster Keogh, R. W. Date, D. W. Bruce and B. Donnio, J. Alloys Compd., 2006, 418, 171.

156 J. Jiang, K. Machida and G. Adachi, Bull. Chem. Soc. Jpn., 1992, 65, 1990.

157 J. W. Buchler, A. De Cian, J. Fischer, M. Kihn-Botulinski and R. Weiss, Inorg. Chem., 1988, 27, 339.

158 J. W. Buchler, A. De Cian, J. Fischer, P. Hammerschmitt, J. Löffler, B. Scharbert and R. Weiss, Chem. Ber., 1989, $122,2219$.

159 D. Chabach, M. Tahiri, A. De Cian, J. Fischer, R. Weiss and M. El Malouli Bibout, J. Am. Chem. Soc., 1995, 117, 8548.

160 D. Chabach, A. De Cian, J. Fischer, R. Weiss and M. El Malouli Bibout, Angew. Chem., Int. Ed. Engl., 1996, 35, 898.

161 J. Jiang, R. L. C. Lau, T. W. D. Chan, T. C. W. Mak and D. K. P. Ng, Inorg. Chim. Acta, 1997, 255, 59.

162 M. Takeuchi, T. Imada and S. Shinkai, Angew. Chem., Int. Ed., 1998, 37, 2096.

163 H. Miwa, N. Kobayashi, K. Ban and K. Ohta, Bull. Chem. Soc. Jpn., 1999, 72, 2719.

164 J. Li, D. Gryko, R. B. Dabke, J. R. Diers, D. F. Bocian, W. G. Kuhr and J. S. Lindsey, J. Org. Chem., 2000, 65, 7379.

165 J. Jiang, R. C. W. Liu, T. C. W. Mak, T. W. D. Chan and D. K. P. Ng, Polyhedron, 1997, 16, 515.

166 J. Jiang, W. Liu, K. L. Cheng, K. W. Poon and D. K. P. Ng, Eur. J. Inorg. Chem., 2001, 413.

167 J. Jiang, Y. Z. Bian, F. Furuya, W. Liu, M. T. M. Choi, N. Kobayashi, H. W. Li, Q. C. Yang, T. C. W. Mak and D. K. P. Ng, Chem. - Eur. J., 2001, 7, 5059.

168 J. W. Buchler, P. Hammerschmitt, I. Kaufeld and J. Löffler, Chem. Ber., 1991, 124, 2151. 
169 W. Buchler, J. Huttermann and J. Löffler, Bull. Chem. Soc. Jpn., 1988, 61, 71.

170 M. O. Liu and A. T. Hu, J. Organomet. Chem., 2004, 689, 2450.

171 H. G. Jin, X. Jiang, I. A. Kuhne, S. Clair, V. Monnier, C. Chendo, G. Novitchi, A. K. Powell, K. M. Kadish and T. S. Balaban, Inorg. Chem., 2017, 56, 4864.

172 S. Alpugan, Ü. İşci, F. Albrieux, C. Hirel, A. Gül Gürek, Y. Bretonnière, V. Ahsen and F. Dumoulin, Chem. Commun., 2014, 50, 7466.

173 Y. Zhou, Y. Zhang, H. Wang, J. Jiang, Y. Bian, A. Muranaka and N. Kobayashi, Inorg. Chem., 2009, 48, 8925.

174 X. Wu, W. Lv, Q. Wang, H. Wang, X. Zhang and J. Jiang, Dalton Trans., 2011, 40, 107.

175 Z. Valicsek, G. Eller and O. Horvath, Dalton Trans., 2012, 41, 13120.

176 J. Kan, H. Wang, W. Sun, W. Cao, J. Tao and J. Jiang, Inorg. Chem., 2013, 52, 8505.

177 T. Nakai, K. Ban, K. Ohta and M. Kimura, J. Mater. Chem., 2002, $12,844$.

178 K.-H. Schweikart, V. L. Malinovskii, J. R. Diers, A. A. Yasseri, D. F. Bocian, W. G. Kuhr and J. S. Lindsey, J. Mater. Chem., 2002, 12, 808.

179 K. Padmaja, W. J. Youngblood, L. Wei, D. F. Bocian and J. S. Lindsey, Inorg. Chem., 2006, 45, 5479.

180 J. Otsuki, Y. Komatsu, D. Kobayashi, M. Asakawa and K. Miyake, J. Am. Chem. Soc., 2010, 132, 6870.

181 X. Zhang, Y. Li, D. Qi, J. Jiang, X. Yan and Y. Bian, J. Phys. Chem. B, 2010, 114, 13143.

182 N. Sheng, P. Zhu, C. Ma and J. Jiang, Dyes Pigm., 2009, 81, 91.

183 J. Lu, Y. Deng, X. Zhang, N. Kobayashi and J. Jiang, Inorg. Chem., 2011, 50, 2562.

184 K. P. Birin, Y. G. Gorbunova and A. Y. Tsivadze, Magn. Reson. Chem., 2010, 48, 505.

185 K. P. Birin, Y. G. Gorbunova and A. Y. Tsivadze, Dalton Trans., 2012, 41, 9672.

186 P. Zhu, X. Zhang, H. Wang, Y. Zhang, Y. Bian and J. Jiang, Inorg. Chem., 2012, 51, 5651.

187 N. Pan, Y. Bian, T. Fukuda, M. Yokoyama, R. Li, S. Neya, J. Jiang and N. Kobayashi, Inorg. Chem., 2004, 43, 8242.

188 V. E. Pushkarev, V. V. Kalashnikov, A. Y. Tolbin, S. A. Trashin, N. E. Borisova, S. V. Simonov, V. B. Rybakov, L. G. Tomilova and N. S. Zefirov, Dalton Trans., 2015, 44, 16553.

189 W. Cao, H. Wang, X. Wang, H. K. Lee, D. K. Ng and J. Jiang, Inorg. Chem., 2012, 51, 9265.

190 K. P. Birin, I. A. Abdulaeva, A. I. Poddubnaya, Y. G. Gorbunova and A. Y. Tsivadze, Dyes Pigm., 2020, 181, 108550.

191 Y. Gorbunova, L. A. Lapkina, A. G. Martynov, I. V. Biryukova and A. Y. Tsivadze, Russ. J. Coord. Chem., 2004, 30, 245.

192 A. A. Sinelshchikova, Y. G. Gorbunova, L. A. Lapkina, N. Y. Konstantinov and A. Y. Tsivadze, Russ. J. Inorg. Chem., 2011, 56, 1370.
193 A. G. Martynov, M. A. Polovkova, G. S. Berezhnoy, A. A. Sinelshchikova, F. M. Dolgushin, K. P. Birin, G. A. Kirakosyan, Y. G. Gorbunova and A. Y. Tsivadze, Inorg. Chem., 2020, 59, 9424.

194 D. González-Lucas, S. C. Soobrattee, D. L. Hughes, G. J. Tizzard, S. J. Coles and A. N. Cammidge, Chem. Eur. J., 2020, 26, 10724.

195 J. Jubb and S. Gambarotta, J. Am. Chem. Soc., 1994, 116, 4477.

196 E. Campazzi, E. Solari, C. Floriani and R. Scopelliti, Chem. Commun., 1998, 2603.

197 E. Campazzi, E. Solari, R. Scopelliti and C. Floriani, Chem. Commun., 1999, 1617.

198 H. He, X. Zhu, A. Hou, J. Guo, W.-K. Wong, W.-Y. Wong, K.-F. Li and K.-W. Cheah, Dalton Trans., 2004, 4064.

199 J. J. Le Roy, J. Cremers, I. A. Thomlinson, M. Slota, W. K. Myers, P. H. Horton, S. J. Coles, H. L. Anderson and L. Bogani, Chem. Sci., 2018, 9, 8474.

200 S. R. Batten, N. R. Champness, X.-M. Chen, J. GarciaMartinez, S. Kitagawa, L. Öhrström, M. O'Keeffe, M. P. Suh and J. Reedijk, CrystEngComm, 2012, 14, 3001.

201 S. George, S. Lipstman and I. Goldberg, Cryst. Growth Des., 2006, 6, 2651.

202 S. Muniappan, S. Lipstman, S. George and I. Goldberg, Inorg. Chem., 2007, 46, 5544.

203 S. Lipstman and I. Goldberg, Cryst. Growth Des., 2010, 10, 1823.

204 G. Nandi and I. Goldberg, Chem. Commun., 2014, 50, 13612.

205 J. Demel, P. Kubat, F. Millange, J. Marrot, I. Cisarova and K. Lang, Inorg. Chem., 2013, 52, 2779.

206 Y.-P. Pei, J.-G. Huang, R.-H. Hu, Y.-X. Yang, J. Zhou and W.-T. Chen, J. Porphyrins Phthalocyanines, 2015, 19, 811.

207 X.-G. Yi, J.-G. Huang, R.-H. Hu, Z.-G. Luo, Y.-P. Pei and W.-T. Chen, J. Porphyrins Phthalocyanines, 2015, 19, 1072.

208 C. F. Pereira, F. Figueira, R. F. Mendes, J. Rocha, J. T. Hupp, O. K. Farha, M. M. Q. Simoes, J. P. C. Tome and F. A. A. Paz, Inorg. Chem., 2018, 57, 3855.

209 S. Lipstman and I. Goldberg, J. Mol. Struct., 2008, 890, 101. 210 L. Zhang, S. Yuan, L. Feng, B. Guo, J. S. Qin, B. Xu, C. Lollar, D. Sun and H. C. Zhou, Angew. Chem., Int. Ed., 2018, 57, 5095.

211 J. B. Oh, K. L. Paik, J.-W. Ka, S.-G. Roh, M.-K. Nah and H. K. Kim, Mater. Sci. Eng., C, 2004, 24, 257.

212 J. B. Oh, Y. H. Kim, M. K. Nah and H. K. Kim, J. Lumin., 2005, 111, 255.

213 R. Xiong, D. Mara, J. Liu, R. Van Deun and K. E. Borbas, J. Am. Chem. Soc., 2018, 140, 10975.

214 B. S. Harrison, T. J. Foley, A. S. Knefely, J. K. Mwaura, G. B. Cunningham, T.-S. Kang, M. Bouguettaya, J. M. Boncella, J. R. Reynolds and K. S. Schanze, Chem. Mater., 2004, 16, 2938.

215 R. Pizzoferrato, L. Lagonigro, T. Ziller, A. Di Carlo, R. Paolesse, F. Mandoj, A. Ricci and C. Lo Sterzo, Chem. Phys., 2004, 300, 217.

216 E. G. Ermolina, R. T. Kuznetsova, T. A. Solodova, E. N. Tel'minov, T. N. Kopylova, G. V. Mayer, 
N. N. Semenishyn, N. V. Rusakova and Y. V. Korovin, Dyes Pigm., 2013, 97, 209.

217 G. A. Corker, B. Grant and N. J. Clecak, J. Electrochem. Soc., 1979, 126, 1339.

218 A. T. Chang and J.-C. Marchon, Inorg. Chim. Acta, 1981, 53, L241.

219 R. B. Daniels, G. L. Payne and J. Peterson, J. Coord. Chem., 1993, 28, 23.

220 P. M. S. Monk, R. J. Mortimer and D. A. Rosseinsky, Electrochromism and electrochromic devices, Cambridge University Press, Cambridge, 2007.

221 G. Guillaud, M. Al Sadoun, M. Maitrot, J. Simon and M. Bouvet, Chem. Phys. Lett., 1990, 167, 503.

222 A. Iwase and K. Tanaka, Electrochim. Acta, 1990, 35, 1707.

223 N. Nemykin, Y. Chernii and V. Volkov, J. Chem. Soc., Dalton Trans., 1998, 2995.

224 M. M'Sadak, J. Roncali and F. Garnier, J. Electroanal. Chem. Interfacial Electrochem., 1985, 189, 99.

225 R. B. Daniels, J. Peterson, W. C. Porter and Q. D. Wilson, J. Coord. Chem., 1993, 30, 357.

226 H. Konami, M. Hatano, N. Kobayashi and T. Osa, Chem. Phys. Lett., 1990, 165, 397.

227 I. P. Kalashnikova, I. V. Zhukov, L. G. Tomilova and N. S. Zefirov, Russ. Chem. Bull., 2005, 54, 2094.

228 M. L. Rodrìguez-Mendez, R. Aroca and J. A. Desaja, Chem. Mater., 1992, 4, 1017.

229 Y. Liu, K. Shigehara, M. Hara and A. Yamada, J. Am. Chem. Soc., 1991, 113, 440.

230 I. V. Zhukov, V. E. Pushkarev, L. G. Tomilova and N. S. Zefirov, Russ. Chem. Bull., 2005, 54, 189.

231 V. E. Pushkarev, A. Y. Tolbin, N. E. Borisova, S. A. Trashin and L. G. Tomilova, Eur. J. Inorg. Chem., 2010, 5254.

232 I. V. Zhukov, L. A. Lapkina, Y. G. Gorbunova, V. E. Larchenko and A. Y. Tsivadze, J. Porphyrins Phthalocyanines, 2005, 9, 1.

233 N. Sheng, R. Li, C.-F. Choi, W. Su, D. K. P. Ng, X. Cui, K. Yoshida, N. Kobayashi and J. Jiang, Inorg. Chem., 2006, 45, 3794.

234 M. N. Yarasir, M. Kandaz, A. Koca and B. Salih, J. Porphyrins Phthalocyanines, 2006, 10, 1022.

235 P. Zhu, F. Lu, N. Pan, D. Arnold, S. Zhang and J. Jiang, Eur. J. Inorg. Chem., 2004, 510.

236 R. Li, X. Zhang, P. Zhu, D. K. P. Ng, N. Kobayashi and J. Jiang, Inorg. Chem., 2006, 45, 2327.

237 X. Li, D. Qi, C. Chen, L. Yang, J. Sun, H. Wang, X. Li and Y. Bian, Dyes Pigm., 2014, 101, 179.

238 E. B. Orman, A. Koca, A. R. Özkaya, İ. Gürol, M. Durmus and V. Ahsen, J. Electrochem. Soc., 2014, 161, H422.

239 T. V. Dubinina, K. V. Paramonova, S. A. Trashin, N. E. Borisova, L. G. Tomilova and N. S. Zefirov, Dalton Trans., 2014, 43, 2799.

240 R. Li, X. Zhang, N. Pan, P. Zhu, N. Kobayashi and J. Jiang, J. Porphyrins Phthalocyanines, 2005, 9, 40.

241 J. Jiang, W. Liu, K. W. Poon, D. Du, D. P. Arnold and D. K. P. Ng, Eur. J. Inorg. Chem., 2000, 205.

242 Y. Bian, J. Jiang, Y. Tao, M. T. M. Choi, R. Li, A. C. H. Ng, P. Zhu, N. Pan, X. Sun, D. P. Arnold, Z. Y. Zhou, H. W. Li,
T. C. W. Mak and D. K. P. Ng, J. Am. Chem. Soc., 2003, 125, 12257.

243 S. L. Selector, V. V. Arslanov, Y. G. Gorbunova, O. A. Raitman, L. S. Sheinina, K. P. Birin and A. Y. Tsivadze, J. Porphyrins Phthalocyanines, 2008, 12, 1154.

244 N. Ishikawa, J. Porphyrins Phthalocyanines, 2001, 5, 87.

245 T. H. Tran-Thi, T. A. Mattioli, D. Chabach, A. De Cian and R. Weiss, J. Phys. Chem., 1994, 98, 8279.

246 M. Tahiri, D. Chabach, M. Elmalouli-bibout, A. De Cian, J. Fischer and R. Weiss, Ann. Chim.-Sci. Mater., 1995, 20, 81.

247 V. E. Pushkarev, V. V. Kalashnikov, S. A. Trashin, N. E. Borisova, L. G. Tomilova and N. S. Zefirov, Dalton Trans., 2013, 42, 12083.

248 H. Pan, L. Gong, W. Liu, C. Lin, Q. Ma, G. Lu, D. Qi, K. Wang and J. Jiang, Dyes Pigm., 2018, 156, 167.

249 H. L. Buckley, M. R. Anstey, D. T. Gryko and J. Arnold, Chem. Commun., 2013, 49, 3104.

250 G. Lu, J. Li, S. Yan, W. Zhu, Z. Ou and K. M. Kadish, Inorg. Chem., 2015, 54, 5795.

251 G. Lu, J. Li, X. Jiang, Z. Ou and K. M. Kadish, Inorg. Chem., 2015, 54, 9211.

252 G. Lu, C. He, K. Wang, J. Sun, D. Qi, L. Gong, C. Wang, Z. Ou, S. Yan, S. Zeng and W. Zhu, Inorg. Chem., 2017, 56, 11503.

253 R. Wang, Y. Li, R. Li, D. Y. Y. Cheng, P. Zhu, D. K. P. Ng, M. Bao, X. Cui, N. Kobayashi and J. Jiang, Inorg. Chem., 2005, 44, 2114.

254 K. Yamashita, T. Yamanaka, N. Sakata and T. Ogawa, Chem. - Asian J., 2018, 13, 1692.

255 J.-C. G. Bünzli, in Handbook on the Physics and Chemistry of Rare Earths, ed. J.-C. G. Bünzli and V. K. Pecharsky, Elsevier Science, B.V., Amsterdam, 2016, ch. 287, vol. 50, p. 141.

256 S. Comby and J.-C. G. Bünzli, in Handbook on the Physics and Chemistry of Rare Earths, ed. K. A. Gschneidner Jr., J.-C. G. Bünzli and V. K. Pecharsky, Elsevier Science B.V., Amsterdam, 2007, ch. 235, vol. 37, p. 217.

257 R. Wiglusz, J. Legendziewicz, A. Graczyk, S. Radzki, P. Gawryszewska and J. Sokolnicki, J. Alloys Compd., 2004, 380, 396.

258 G. E. Khalil, E. K. Thompson, M. Gouterman, J. B. Callis, L. R. Dalton, N. J. Turro and S. Jockusch, Chem. Phys. Lett., 2007, 435, 45.

259 W. Zheng, B.-B. Wang, J.-C. Lai, C.-Z. Wan, X.-R. Lu, C.-H. Li and X.-Z. You, J. Mater. Chem. C, 2015, 3, 3072.

260 N. Kobayashi, Coord. Chem. Rev., 2002, 227, 129.

261 P. Zhu, N. Pan, R. Li, J. Dou, Y. Zhang, D. Y. Y. Cheng, D. Wang, D. K. P. Ng and J. Jiang, Chem. - Eur. J., 2005, 11, 1425.

262 D. V. Konarev, S. S. Khasanov, M. S. Batov, A. G. Martynov, I. V. Nefedova, Y. G. Gorbunova, A. Otsuka, H. Yamochi, H. Kitagawa and R. N. Lyubovskaya, Inorg. Chem., 2019, 58, 5058.

263 M. M. Ayhan, A. Singh, E. Jeanneau, V. Ahsen, J. Zyss, I. Ledoux-Rak, A. G. Gürek, C. Hirel, Y. Bretonnière and C. Andraud, Inorg. Chem., 2014, 53, 4359.

264 F. Guyon, A. Pondaven, J. M. Kerbaol and M. L’Her, Inorg. Chem., 1998, 37, 569. 
265 A. N. Carneiro Neto, E. E. S. Teotonio, G. F. de Sá, H. F. Brito, J. Legendziewicz, L. D. Carlos, M. C. Felinto, P. Gawryszewska, R. T. Moura, R. L. Longo, W. M. Faustino and O. L. Malta, in Handbook on the Physics and Chemistry of Rare Earths, Including Actinides, ed. J.-C. G. Bünzli and V. K. Pecharsky, Elsevier B.V., Amsterdam, 2019, ch. 310, vol. 56, p. 55.

266 K.-L. Wong, J.-C. G. Bünzli and P. A. Tanner, J. Lumin., 2020, 224, 117256.

267 H. Ishida, J.-C. G. Bünzli and A. Beeby, Pure Appl. Chem., 2016, 88, 701.

268 A. Aebischer, F. Gumy and J.-C. G. Bünzli, Phys. Chem. Chem. Phys., 2009, 11, 1346.

269 C. Doffek, N. Alzakhem, C. Bischof, J. Wahsner, T. GüdenSilber, J. Lügger, C. Platas-Iglesias and M. Seitz, J. Am. Chem. Soc., 2012, 134, 16413.

270 Y. V. Korovin and N. V. Rusakova, Rev. Inorg. Chem., 2001, 21, 299.

271 W.-K. Wong, X. Zhu and W.-Y. Wong, Coord. Chem. Rev., 2007, 251, 2386.

272 X. Zhu, W. K. Wong, W. Y. Wong and X. Yang, Eur. J. Inorg. Chem., 2011, 4651.

273 O. V. Snurnikova, A. P. Lukyanenko, E. A. Alekseeva, Y. V. Korovin and N. V. Rusakova, Macroheterocycles, 2011, 4, 93.

274 H. He, Coord. Chem. Rev., 2014, 273, 87.

275 X. H. Chang, J. Zhang, L. H. Wu, Y. K. Peng, X. Y. Yang, X. L. Li, A. J. Ma, J. C. Ma and G. Q. Chen, Micromachines, 2019, 10, 422.

276 X. X. Peng, X. F. Zhu and J.-L. Zhang, J. Inorg. Biochem., 2020, 209, 111118.

277 G. Q. Jin, Y. Ning, J.-X. Geng, Z.-F. Jiang, Y. Wang and J.-L. Zhang, Inorg. Chem. Front., 2020, 7, 289.

278 Y. Ning, M. Zhu and J. L. Zhang, Coord. Chem. Rev., 2019, 399, 213028.

279 J. Y. Liew, J. J. Brown, E. G. Moore and M. Schwalbe, Chem. - Eur. J., 2016, 22, 16178.

280 H. He, P. S. May and D. Galipeau, Dalton Trans., 2009, 4766.

281 H. He, W.-K. Wong, J. Guo, K.-F. Li, W.-Y. Wong, W.-K. Lo and K.-W. Cheah, Aust. J. Chem., 2004, 57, 803.

282 H. He, A. G. Sykes, P. S. May and G. He, Dalton Trans., 2009, 7454.

283 N. V. Rusakova, Y. V. Korovin, Z. I. Zhilina, S. V. Vodzinskii and Y. V. Ishkov, J. Appl. Spectrosc., 2004, 506.

284 N. M. Shavaleev, R. Scopelliti, F. Gumy and J.-C. G. Bünzli, Inorg. Chem., 2009, 48, 7937.

285 S. Zhuravlyov, N. Rusakova and Y. Korovin, J. Alloys Compd., 2008, 451, 334.

286 N. N. Semenishyn, N. V. Rusakova, A. V. Mazepa and Y. V. Korovin, Macroheterocycles, 2009, 2, 57.

287 T. Zhang, X. Zhu, W.-K. Wong, H.-L. Tam and W.-Y. Wong, Chem. - Eur. J., 2013, 19, 739.

288 H. He, J. D. Bosonetta, K. A. Wheeler and S. P. May, Chem. Commun., 2017, 53, 10120.

289 Y. Ning, S. Chen, H. Chen, J. X. Wang, S. He, Y. W. Liu, Z. Cheng and J.-L. Zhang, Inorg. Chem. Front., 2019, 6, 1962.
290 X.-J. Zhu, F.-L. Jiang, C.-T. Poon, W.-K. Wong and W.-Y. Wong, Eur. J. Inorg. Chem., 2008, 3151.

291 R. Pizzoferrato, R. Francini, S. Pietrantoni, R. Paolesse, F. Mandoj, A. Monguzzi and F. Meinardi, J. Phys. Chem. A, 2010, 114, 4163.

292 Y. Ning, G. Q. Jin and J. L. Zhang, Acc. Chem. Res., 2019, $52,2620$.

293 J.-Y. Hu, Z.-Y. Wu, K. Chai, Z.-S. Yang, Y.-S. Meng, Y. Ning, J. Zhang and J.-L. Zhang, Inorg. Chem. Front., 2017, 4, 1539.

294 Y. Ning, Y.-W. Liu, Y.-S. Meng and J.-L. Zhang, Inorg. Chem., 2018, 57, 1332.

295 Y. Ning, X.-S. Ke, J.-Y. Hu, Y.-W. Liu, F. Ma, H.-L. Sun and J.-L. Zhang, Inorg. Chem., 2017, 56, 1897.

296 S. Bo, J. Hu, Q. Wang, X. Liu and Z. Zhen, Photochem. Photobiol. Sci., 2008, 7, 474.

297 J. Hanuza, P. Godlewska, R. Lisiecki, W. RybaRomanowski, P. Kadlubanski, J. Lorenc, A. Lukowiak, L. Macalik, Y. Gerasymchuk and J. Legendziewicz, Spectrochim. Acta, Part A, 2018, 196, 202.

298 R. Zugle, C. Litwinski and T. Nyokong, Polyhedron, 2011, 30, 1612.

299 K. E. Sekhosana, E. Amuhaya, S. Khene and T. Nyokong, Inorg. Chim. Acta, 2015, 426, 221.

300 Y. Gerasymchuk, M. Guzik, R. Lisiecki, M. Sobczyk, J. Janski, A. Koll, G. Boulon and J. Legendziewicz, J. Lumin., 2018, 193, 84.

301 G. de la Torre, P. Vázquez, F. Aguillo-Lopez and T. Torres, Chem. Rev., 2004, 104, 3723.

302 R. L. Sutherland, D. G. McLean and S. Kirkpatrick, Handbook of Nonlinear Optics, Marcel Dekker, New York \& Basel, 2003.

303 K. P. Unnikrishnan, J. Thomas, V. P. N. Nampoori and C. P. G. Vallabhan, Chem. Phys., 2002, 279, 209.

304 R. del Coso and J. Solis, J. Opt. Soc. Am. B, 2004, 21, 640.

305 R. A. Ganeev, A. I. Ryasnyansky, A. L. Stepanov and T. Usmanov, Phys. Status Solidi B, 2004, 241, 935.

306 N. Sheng, Z. Yuan, J. Wang, W. Chen, J. Sun and Y. Bian, Dyes Pigm., 2012, 95, 627.

307 K. P. Unnikrishnan, J. A. Y. A. Thomas, B. I. N. O. Paul, A. C. H. A. Kurian, P. R. A. M. Gopinath, V. P. N. Nampoori and C. P. G. Vallabhan, J. Nonlinear Opt. Phys. Mater., 2001, 10, 113.

308 K. E. Sekhosana, E. Amuhaya, J. Mack and T. Nyokong, J. Mater. Chem. C, 2014, 2, 5431.

309 K. E. Sekhosana and T. Nyokong, Opt. Mater., 2014, 37, 139.

310 N. Sheng, D. Liu, B. Gu, J. He and Y. Cui, Dyes Pigm., 2015, $122,346$.

311 Z. Li, F. Gao, Z. Xiao, G. Ao, X. Wu, Y. Fang, Z. Nie, T. H. Wei, J. Yang, Y. Wang, X. Zhang, J. Zuo and Y. Song, Dyes Pigm., 2015, 119, 70.

312 K. E. Sekhosana and T. Nyokong, Inorg. Chim. Acta, 2016, 450, 87.

313 B. Ren, N. Sheng, B. Gu, Y. Wan, G. Rui, C. Lv and Y. Cui, Dyes Pigm., 2017, 139, 788.

314 A. I. Plekhanov, T. V. Basova, R. G. Parkhomenko and A. G. Gürek, Opt. Mater., 2017, 64, 13. 
315 Z. Li, F. Gao, Z. Xiao, X. Wu, J. Zuo and Y. Song, Opt. Laser Technol., 2018, 103, 42.

316 W. Huang, H. Xiang, Q. Gong, Y. Huang, C. Huang and J. Jiang, Chem. Phys. Lett., 2003, 374, 639.

317 A. Y. Tsivadze, G. V. Ionova and V. K. Mikhalko, Prot. Met. Phys. Chem. Surf., 2010, 46, 149.

318 K. E. Sekhosana, M. H. Manyeruke and T. Nyokong, J. Mol. Struct., 2016, 1121, 111.

319 N. Sheng, B. Gu, B. Ren, Y. Wang, L. Han, J. Wang, H. Cao, M. Guan, X. Zhai and J. Sha, Dyes Pigm., 2017, 136, 553.

320 S. M. O'Flaherty, S. V. Hold, M. J. Cook, T. Torres, Y. Chen, M. Hanack and W. J. Blau, Adv. Mater., 2003, 15, 19.

321 A. B. Karpo, V. E. Pushkarev, V. I. Krasovskii and L. G. Tomilova, Chem. Phys. Lett., 2012, 554, 155.

322 K. E. Sekhosana, M. Shumba and T. Nyokong, Polyhedron, 2017, 138, 154.

323 K. E. Sekhosana, R. Nkhahle and T. Nyokong, ChemistrySelect, 2018, 3, 6671.

324 D. O. Oluwole, A. V. Yagodin, N. C. Mkhize, K. E. Sekhosana, A. G. Martynov, Y. G. Gorbunova, A. Y. Tsivadze and T. Nyokong, Chem. - Eur. J., 2017, 23, 2820.

325 E. A. Kuzmina, T. V. Dubinina, A. V. Zasedatelev, A. V. Baranikov, M. I. Makedonskaya, T. B. Egorova and L. G. Tomilova, Polyhedron, 2017, 135, 41.

326 K. E. Sekhosana and T. Nyokong, J. Mol. Struct., 2016, 1117, 140.

327 K. E. Sekhosana and T. Nyokong, Opt. Mater., 2015, 47, 211.

328 K. E. Sekhosana and T. Nyokong, RSC Adv., 2019, 934, 16223.

329 Z.-S. Yang, Y. Ning, H.-Y. Yin and J.-L. Zhang, Inorg. Chem. Front., 2018, 5, 2291.

330 G. Dyrda, M. Zakrzyk, M. A. Broda, T. Pedzinski, G. Mele and R. Slota, Molecules, 2020, 25, 3638.

331 K. Binnemans, Chem. Rev., 2002, 102, 2303.

332 B. Berno, A. Nazri and R. Aroca, Appl. Spectrosc., 1997, 51, 1525.

333 M. L. Rodriguez-Mendez, Comments Inorg. Chem., 2000, 22, 227.

334 X. Tang, Q. Liu, C. Wei, X. Lv, Z. Jin, Y. Chen and J. Jiang, J. Rare Earths, 2021, 39, 113.

335 N. Kılınç, D. Atilla, A. G. Gürek, Z. Z. Öztürk and V. Ahsen, Sens. Actuators, B, 2009, 142, 73.

336 J. Gao, G. Lu, J. Kan, Y. Chen and M. Bouvet, Sens. Actuators, B, 2012, 166-167, 500.

337 K. Abdullah, Y. Wu, S. Zhao, X. Kong, X. Li and Y. Chen, Inorg. Chem. Commun., 2017, 86, 1.

338 Z. Dong, X. Kong, D. Qi, S. Zhao, X. Li, Y. Chen and J. Jiang, Org. Electron., 2018, 53, 127.

339 G. Lu, X. Kong, C. Wang, L. Zhao, D. Qi, Y. Jiang, S. Zhao, Y. Chen and J. Jiang, Dyes Pigm., 2019, 161, 240.

340 G. Lu, X. Kong, H. Wang, Y. Chen, C. Wei, Y. Chen and J. Jiang, New J. Chem., 2019, 43, 15763.

341 Y. Chen, M. Bouvet, T. Sizun, Y. Gao, C. Plassard, E. Lesniewska and J. Jiang, Phys. Chem. Chem. Phys., 2010, 12, 12851.
342 A. Yazıcıa, B. Sarıçiçek, A. Altındal, B. Salih and Ö. Bekaroğlu, Inorg. Chim. Acta, 2015, 428, 83.

343 N. Gutierrez, M. L. Rodriguez-Mendez and J. A. de Saja, Sens. Actuators, B, 2001, 77, 431.

344 M. L. Rodriguez-Mendez, Y. Gorbunova and J. A. de Saja, Langmuir, 2002, 18, 9560.

345 E. Yabaş, M. Sülü, F. Dumludağ, B. Salih and Ö. Bekaroğlu, Polyhedron, 2018, 153, 51.

346 M. Kandaza, A. T. Bilgicli and A. Altındal, Synth. Met., 2010, 160, 52.

347 R. Boroujerdi, J. Fluoresc., 2016, 26, 781.

348 X. Chen, Y. Wang, X. Zhao, B. Liu, Y. Xu and Y. Wang, Microchim. Acta, 2019, 186, 63.

349 A. Sugasaki, M. Ikeda, M. Takeuchi, A. Robertson and S. Shinkai, J. Chem. Soc., Perkin Trans. 1, 1999, 3259.

350 A. Sugasaki, M. Ikeda, M. Takeuchi, K. Koumoto and S. Shinkai, Tetrahedron, 2000, 56, 4717.

351 G. K. Chudinova, I. A. Nagovitsyn, R. E. Karpov and V. V. Savranskii, Quantum Electron., 2003, 33, 765.

352 T. Basova, I. Jushina, A. G. Gürek, V. Ahsen and A. K. Ray, J. R. Soc., Interface, 2008, 5, 801.

353 A. V. Lobanov, G. A. Gromova, Y. G. Gorbunova and A. Y. Tsivadze, Prot. Met. Phys. Chem. Surf., 2014, 50, 570 .

354 K. E. Sekhosana, M. Shumba and T. Nyokong, ChemistrySelect, 2019, 4, 8434.

355 M. I. Guidak and V. V. Grigoryants, J. Photochem. Photobiol., B, 1990, 7, 15.

356 J. L. Sessler, T. D. Mody, G. W. Hemmi, V. Lynch, S. W. Young and R. A. Miller, J. Am. Chem. Soc., 1993, 115, 10368.

357 S. W. Young, Q. Fan, A. Harriman, J. L. Sessler, W. C. Dow, T. D. Mody, G. Hemmi, Y. Hao and R. A. Miller, Proc. Natl. Acad. Sci. U. S. A., 1996, 93, 6610.

358 Y. V. Korovin, N. V. Rusakova, Y. A. Popkov and V. P. Dotsenko, J. Appl. Spectrosc., 2002, 69, 841.

359 L. G. Klapshina, W. E. Douglas, I. S. Grigoryev, E. Y. Ladilina, M. V. Shirmanova, S. A. Mysyagin, I. V. Balalaeva and E. V. Zagaynova, Chem. Commun., 2010, 46, 8398.

360 W. T. Morgan, A. Smith and P. Koskelo, Biochim. Biophys. Acta, 1980, 624, 271.

361 R. J. Fiel, J. Biomol. Struct. Dyn., 1989, 6, 1259.

362 P. Liu, Y. Liu, X. Li and W.-G. Huang, Chin. J. Chem., 2007, 25, 917.

363 M.-C. Chalbot, L. Gryllos, K. Kefokeris, N. Manoussakis, C. Verchère-Béaur, M. Perrée-Fauvet and A. G. Coutsolelos, J. Porphyrins Phthalocyanines, 2011, 15, 704.

364 E. Bağda, E. Yabaş and E. Bağda, Spectrochim. Acta, Part A, 2017, 172, 199.

365 M. Ethirajan, Y. Chen, P. Joshi and R. K. Pandey, Chem. Soc. Rev., 2011, 40, 340.

366 P.-C. Lo, M. S. Rodríguez-Morgade, R. K. Pandey, D. K. P. Ng, T. Torres and F. Dumoulin, Chem. Soc. Rev., 2020, 49, 1041.

367 X. Zhao, J. Liu, J. Fan, H. Chao and X. Peng, Chem. Soc. Rev., 2021, 50, 4185. 
368 S. W. Young, K. W. Woodburn, M. Wright, T. D. Mody, Q. Fan, J. L. Sessler, W. C. Dow and R. A. Miller, Photochem. Photobiol., 1996, 63, 892.

369 J. L. Sessler, W. C. Dow, D. O’Connor, A. Harriman, G. Hemmi, T. D. Mody, R. A. Miller, F. Qing, S. Springs, K. Woodburn and S. T. Young, J. Alloys Compd., 1997, 249, 146.

370 L. I. Grossweiner, M. D. Bilgin, P. Berdusis and T. D. Mody, Photochem. Photobiol., 1999, 70, 138.

371 Q. Zhang, G. Cheng, H. Ke, X. Zhu, N. Zhu, W.-Y. Wong and W.-K. Wong, RSC Adv., 2015, 5, 22294.

372 Q. C. Fang, Chin. J. New Drugs, 2014, 23, 1540.

373 L. Zang, H. Zhao, J. Hua, F. Qin, Y. Zheng, Z. Zhang and W. Cao, Dyes Pigm., 2017, 142, 465.

374 J.-X. Zhang, W.-L. Chan, C. Xie, Y. Zhou, H.-F. Chau, P. Maity, G. T. Harrison, A. Amassian, O. F. Mohammed, P. A. Tanner, W.-K. Wong and K.-L. Wong, Light Sci. Appl., 2019, 8, 46.

375 F.-L. Jiang, C.-T. Poon, W.-K. Wong, H.-K. Koon, N.-K. Mak, C. Y. Choi, D. W. J. Kwong and Y. Liu, ChemBioChem, 2008, 9, 1034.

376 Z. W. Jiang, Y. C. Zou, T. T. Zhao, S. J. Zhen, Y. F. Li and C. Z. Huang, Angew. Chem., Int. Ed., 2020, 59, 3300.

377 M. Zapata-Lizama, P. Hermosilla-Ibáñez, D. Venegas-Yazigi, G. Minguez Espallargas, L. J. Q. Maia, G. Gasparotto, R. C. D. Santana and W. Cañón-Mancisidor, Inorg. Chem. Front., 2020, 7, 3049.
378 S. Sarwar, S. Sanz, J. van Leusen, G. S. Nichol, E. K. Brechin and P. Kögerler, Dalton Trans., 2020, 49, 16638.

379 R. Pütt, X. Qiu, P. Kozłowski, H. Gildenast, O. Linnenberg, S. Zahn, R. C. Chiechi and K. Y. Monakhov, Chem. Commun., 2019, 55, 13554.

380 G. Mele, E. Garcia-Lòpez, L. Palmisano, G. Dyrda and R. Słota, J. Phys. Chem. C, 2007, 111, 6581.

381 G. Marcì, E. Garcì-Lòpez, G. Mele, L. Palmisano, G. Dyrda and R. Słota, Catal. Today, 2009, 143, 203.

382 Y. Zhang, D. Wang, R. Zhang, J. Zhao and Y. Zheng, Catal. Commun., 2012, 29, 21.

383 C. K. Prier, D. A. Rankic and D. W. C. MacMillan, Chem. Rev., 2013, 113, 5322.

384 A. Hu, J.-J. Guo, H. Pan and Z. Zuo, Science, 2018, 361, 668.

385 J. Ma, F. Schäfers, C. Daniliuc, K. Bergander, C. A. Strassert and F. Glorius, Angew. Chem., Int. Ed., 2020, 59, 9639.

386 L. Zhou, T. Yang, J. Wang, Q. Wang, X. Lv, H. Ke, Z. Guo, J. Shen, Y. Wang, C. Xing and H. Chen, Theranostics, 2017, 7, 764.

387 B. Xiang, Y. Xue, Z. Liu, J. Tian, H. Frey, Y. Gao and W. Zhang, Polym. Chem., 2020, 11, 3913.

388 C.-F. Chan, Y. Zhou, H. Guo, J. Zhang, L. Jiang, W. Chen, K.-K. Shiu, W.-K. Wong and K.-L. Wong, ChemPlusChem, 2016, 81, 535.

389 X.-F. Qiao, J.-C. Zhou, J.-W. Xiao, Y.-F. Wang, L.-D. Sun and C.-H. Yan, Nanoscale, 2012, 4, 4611.

390 W. Sun, Z. Zhou, G. Pratx, X. Chen and H. Chen, Theranostics, 2020, 10, 1296. 